\title{
REPLICAÇÃO DE ESTUdOS EMPÍRICOS EM ENGENHARIA DE SOFTWARE
}

\author{
Emerson Silas Dória \\ Orientador: Prof. Dr. José Carlos Maldonado \\ Dissertação apresentada ao Instituto de Ciências \\ Matemáticas e de Computação - ICMC-USP, \\ como parte dos requisitos para a obtenção do \\ título de Mestre em Ciências: Área: Ciências de \\ Computação e Matemática Computacional.
}

São Carlos

Maio / 2001 
"Quem semeia entre lágrimas, entre sorrisos colherá". 


\section{Agradecimentos}

A Deus por te me dado força, serenidade, sabedoria e paciência para superar todos esses dias em que estive entre as salas de aulas, os laboratórios e as estradas da vida em busca desta conquista profissional e pessoal.

A minha eterna companheira e esposa Claudia por estar sempre ao meu lado nesses últimos 10 anos. Você sabe, só você sabe como foi chegar até aqui. Obrigado.

Ao meu PAI e a minha MÃE que nunca mediram esforços para que eu e meu irmão pudéssemos estudar. Só estou aqui hoje porque vocês me ajudaram. Quantas não foram as noites acordadas esperando o Emão chegar ou partir!

Ao Prof. Dr. José Carlos Maldonado por ter acreditado em uma simples folha de papel e ter me chamado para o Mestrado. Lembro como se fosse hoje a primeira conversa com o Chefe: "Você tem que trazer na próxima semana um ofício da sua Universidade dizendo que após as disciplinas você ficará aqui tempo integral". Obrigado pela confiança e, principalmente, pela paciência nos momentos mais delicados.

Ao Prof. Dr. Sergio Minoru Oikawa da Unesp de Presidente Prudente pelas orientações e sugestões que foram muito importantes para a análise estatística dos resultados do trabalho.

Aos meus grandes amigos e amigas: Adriano, Marcelo, Wagner, Cristiane, Fabiana e Viviane.

Aos meus grandes companheiros de viagens: Osvandre e Dauton.

Ao Fema, Luis Begosso e Marisa. Um dia o Fema me disse: "Quando uma porta se fecha outras se abrem”. Lembra? No dia da prova da Federal. Pois é, aproveitei e passei por uma delas.

Aos colegas do LABES e outros laboratórios que sempre me trataram com muito respeito e sempre que precisei estavam a disposição. Quero não esquecer de ninguém: Ellen, Aline, Tati, Andrea, Mayb, Auri (espetáculo), Adenilso, Vangrei, Maluquinho, Cabeção, Reginaldo, Ana Cláudia, Kleber, Paulo Sá e Evandro.

Em especial a Luciana e a Prof. Dra. Sandra Fabbri pela ajuda imprescindível durante a realização dos experimentos. Sem vocês nada disso teria acontecido.

Aos companheiros, professores e funcionários da Faculdade de Informática de Presidente Prudente, em especial ao Prof. Moacir Del Trejo por ter me incentivado e apoiado desde o início.

A Reitoria da Universidade do Oeste Paulista pelo apoio Financeiro.

Ao Leandro Luiz de Almeida pela paciência com que me substituiu e me ajudou em todas as aulas de ATP durante os dois últimos anos. Valeu TIO! Nós conseguimos, viu!

A todos os alunos e professores que direta ou indiretamente participaram dos experimentos. 


\section{Sumário}

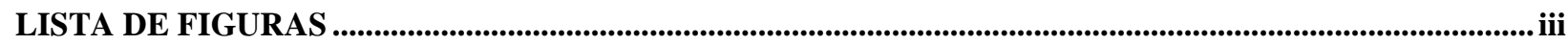

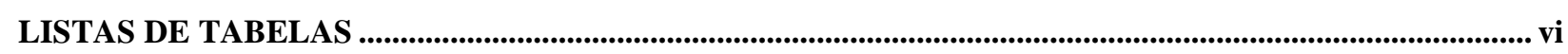

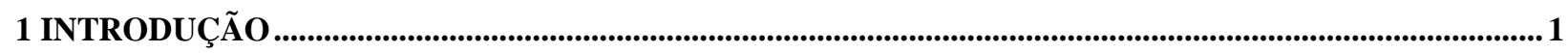

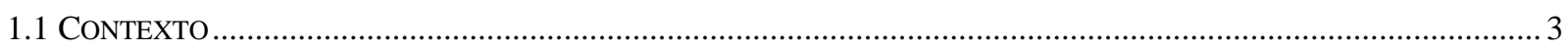

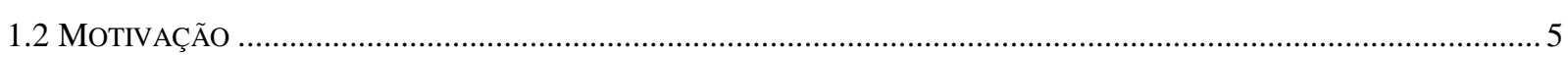

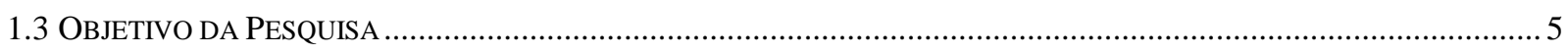

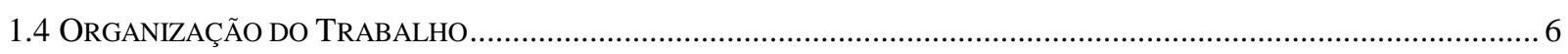

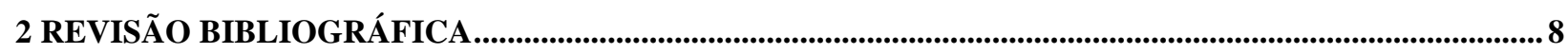

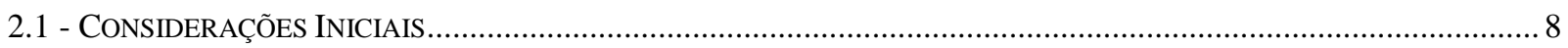

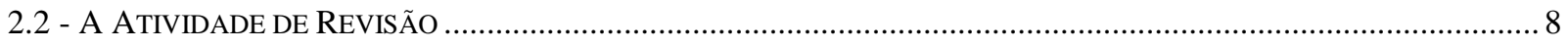

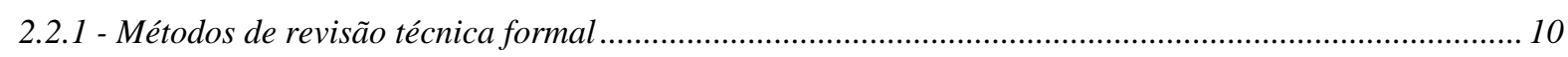

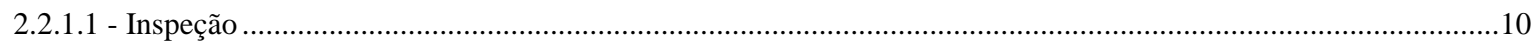

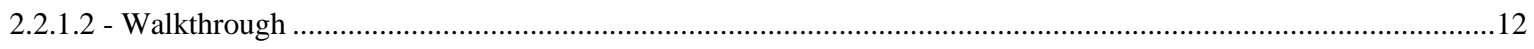

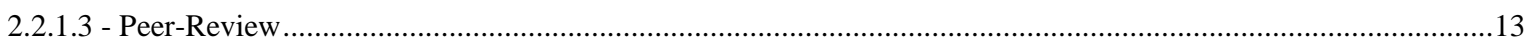

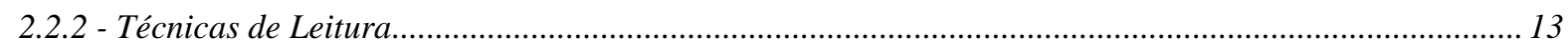

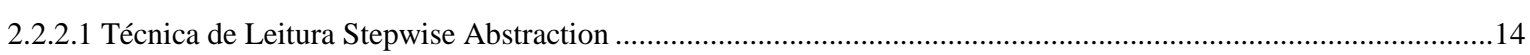

2.2.2.2 Técnica de Leitura Perspective Based Reading ......................................................................................15

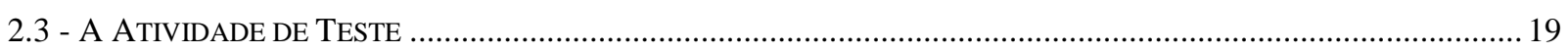

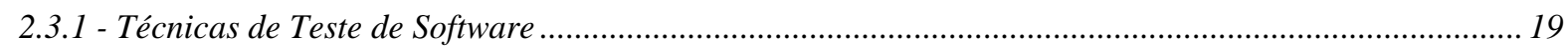

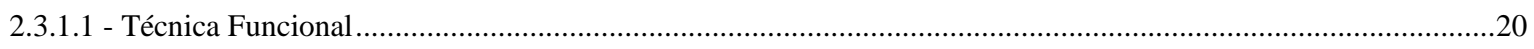

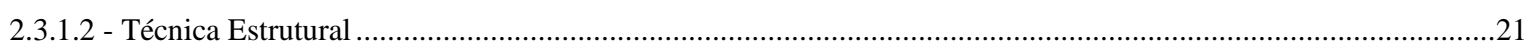

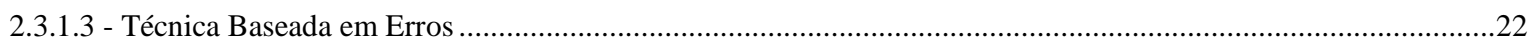

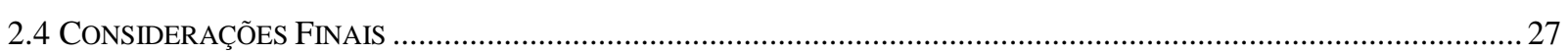

3 ESTUDOS EMPÍRICOS EM ENGENHARIA DE SOFTWARE: VV\&T ..................................................... 28

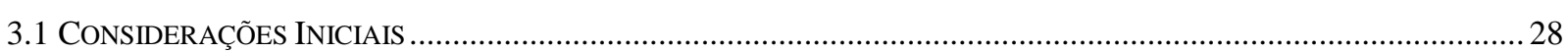

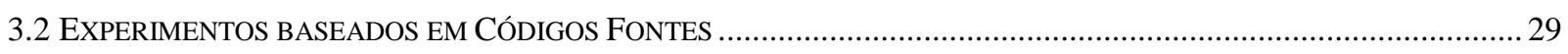

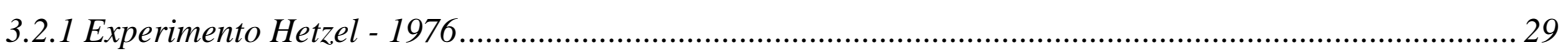

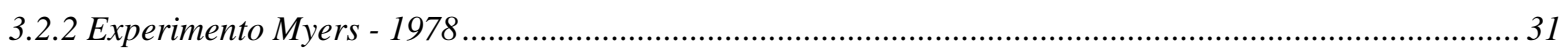

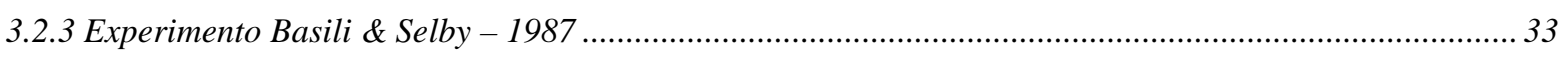

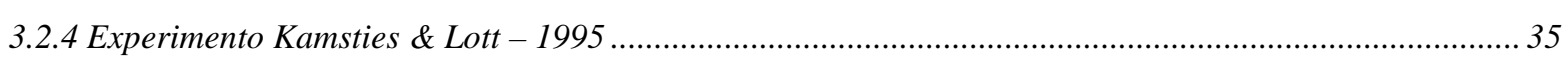

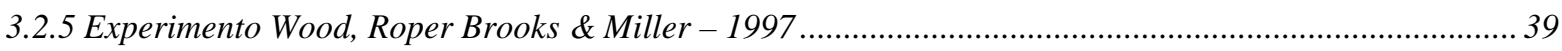

3.3 EXPERIMENTOS BASEADOS EM DOCUMENTOS DE ESPECIFICAÇÃO DE REQUISITOS ...........................................40

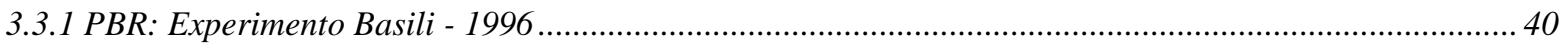

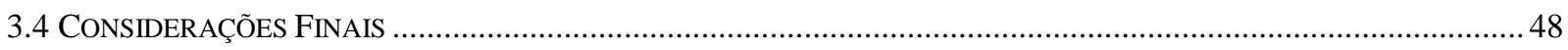




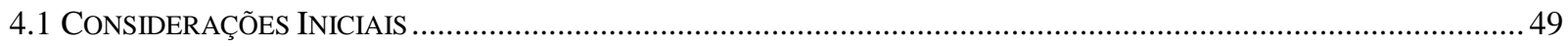

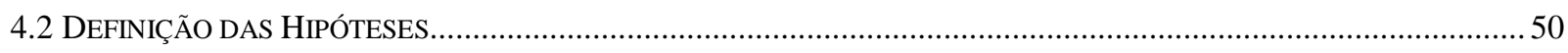

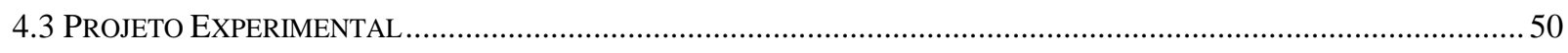

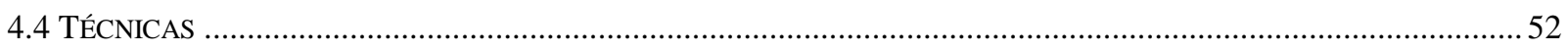

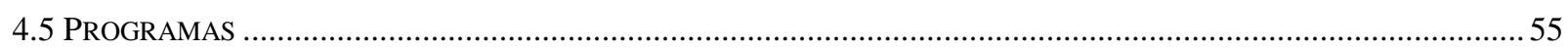

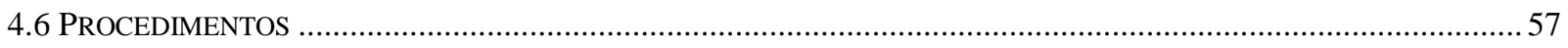

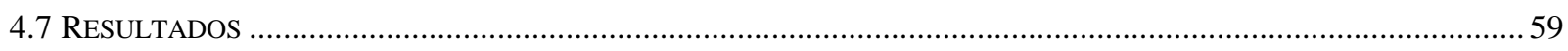

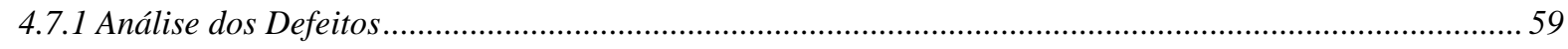

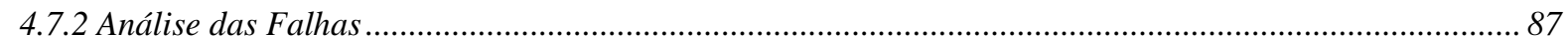

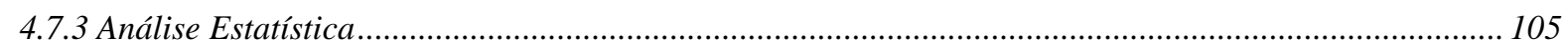

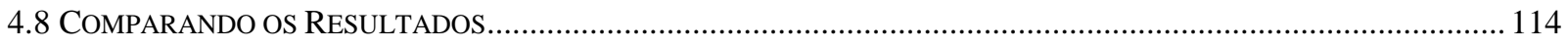

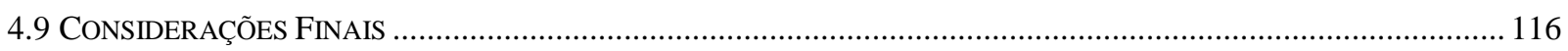

5 DOCUMENTOS DE ESPECIFICAÇÃO DE REQUISITOS: REPLICAÇÃO DE EXPERIMENTO......... 117

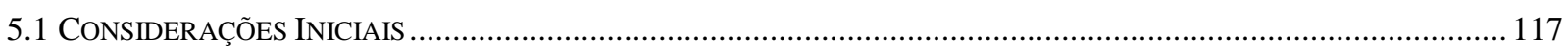

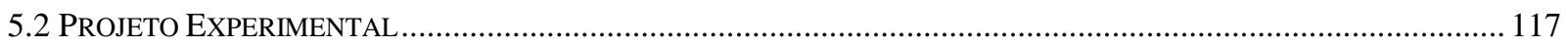

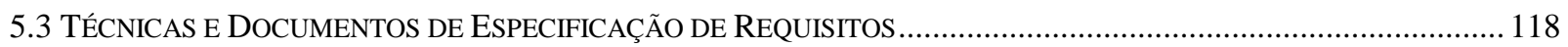

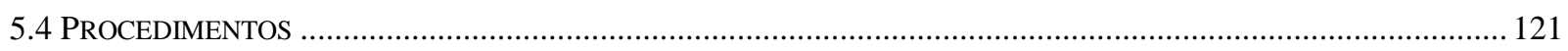

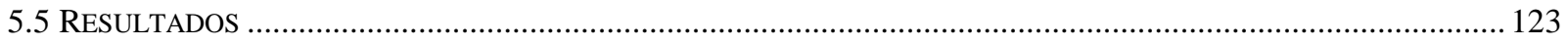

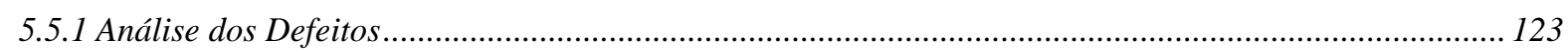

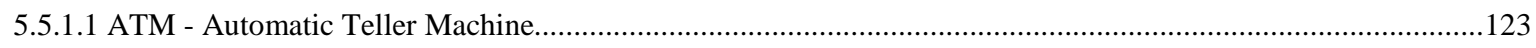

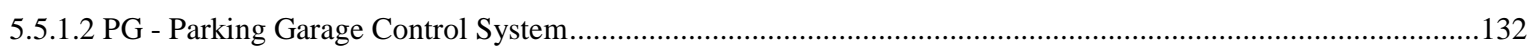

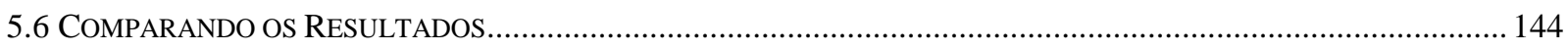

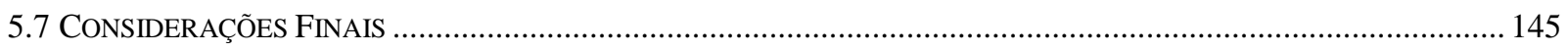

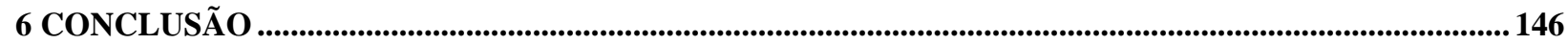




\section{Lista de Figuras}

FIGURA 2.1 - EXEMPLO DA APLICAÇÃO DA TÉCNICA STEPWISE ABSTRACTION....................................................... 14

FIGURA 2.2 - ESQUEMA PARA GERAÇÃO DO CENÁRIO DA PERSPECTIVA DO TESTADOR [BAS98]............................... 16

FIGURA 2.3 - (A) EXEMPLO DE UM CÓDIGO FONTE DE UM PROGRAMA; (B) EXEMPLO DE UM CÓDIGO FONTE COM UMA

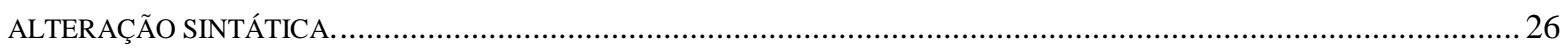

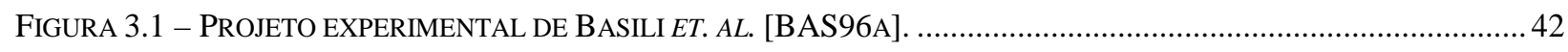

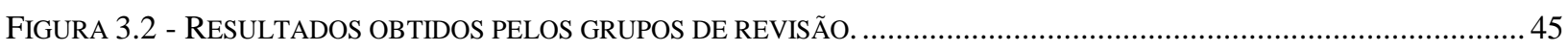

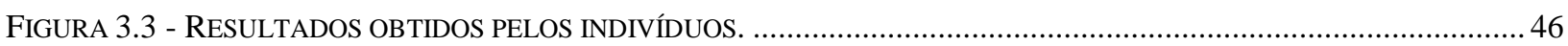

FIGURA 3.4 - COBERTURA OBTIDA PELAS PERSPECTIVAS NOS DOCUMENTOS GENÉRICOS.........................................47

FIGURA 3.5 - COBERTURA OBTIDA PELAS PERSPECTIVAS EM DOCUMENTOS ESPECÍFICOS.........................................47

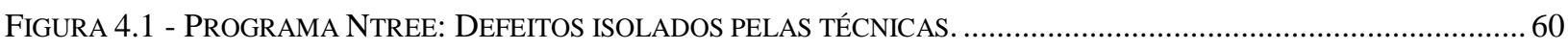

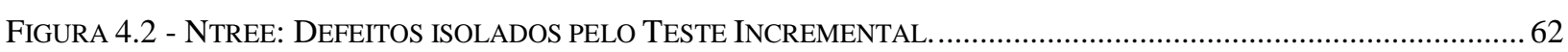

FIGURA 4.3 - NTREE: COBERTURAS OBTIDAS PELOS INDIVÍDUOS APLICANDO O TESTE INCREMENTAL. .....................62

FigURA 4.4 - NTREE: (A) QUANTIDADE E PERCENTUAL DE DEFEITOS ISOLADOS PELAS TÉCNICAS; (B) IDENTIFICAÇÃO

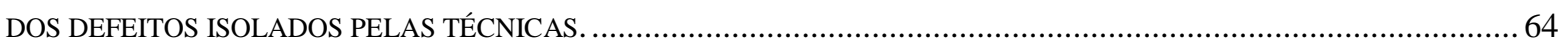

FIGURA 4.5 - NTREE: (A) NÚMERO DE OCORRÊNCIAS DE DEFEITOS ISOLADOS PELAS TÉCNICAS; (B) IDENTIFICAÇÃO DOS DEFEITOS ISOLADOS PELAS TÉCNICAS.

FiguRA 4.6 - NTREE: (A) IDENTIFICAÇÃO DOS DEFEITOS ONDE A TÉCNICA OBTEVE MELHOR OU IGUAL DESEMPENHO QUE ÀS OUTRAS TÉCNICAS; (B) IDENTIFICAÇÃO DOS DEFEITOS ISOLADOS PELAS TÉCNICAS. ..............................65

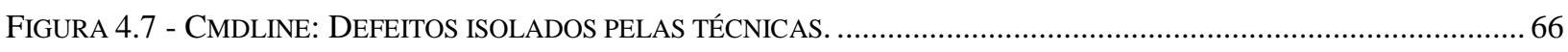

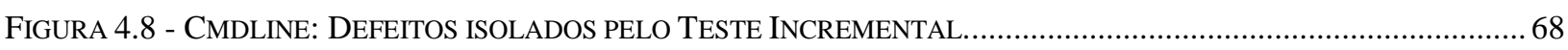

FIGURA 4.9 - CMDLINE: COBERTURAS OBTIDAS PELOS INDIVÍDUOS APLICANDO O TESTE INCREMENTAL. ..................68

FIGURA 4.10 - CMDLINE: (A) QUANTIDADE E PERCENTUAL DE DEFEITOS ISOLADOS PELAS TÉCNICAS; (B) IDENTIFICAÇÃO DOS DEFEITOS ISOLADOS PELAS TÉCNICAS. 70

Figura 4.11 - CMDLINE: (A) NÚMERO DE OCORRÊNCIAS DE DEFEITOS ISOLADOS PELAS TÉCNICAS; (B) IDENTIFICAÇÃO

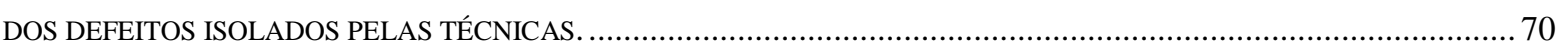

FIGURA 4.12 - CMDLINE: (A) IDENTIFICAÇÃO DOS DEFEITOS ONDE A TÉCNICA OBTEVE MELHOR OU IGUAL

DESEMPENHO QUE ÀS OUTRAS TÉCNICAS; (B) IDENTIFICAÇÃO DOS DEFEITOS ISOLADOS PELAS TÉCNICAS. ......... 71

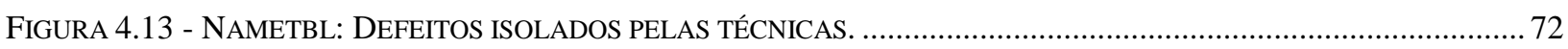

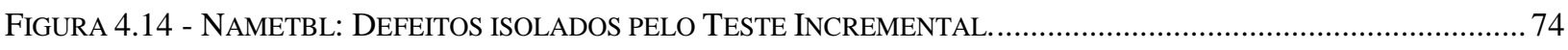

FIGURA 4.15 - NAMETBL: COBERTURAS OBTIDAS PELOS INDIVÍDUOS APLICANDO O TESTE INCREMENTAL.................74

FIGURA 4.16 - NAMETBL: (A) QUANTIDADE E PERCENTUAL DE DEFEITOS ISOLADOS PELAS TÉCNICAS; (B)

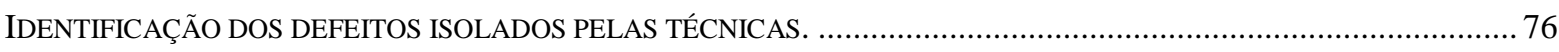

FIGURA 4.17 - NAMETBL: (A) NÚMERO DE OCORRÊNCIAS DE DEFEITOS ISOLADOS PELAS TÉCNICAS; (B)

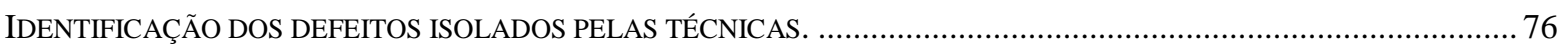

FIGURA 4.18 - NAMETBL: (A) IDENTIFICAÇÃO DOS DEFEITOS ONDE A TÉCNICA OBTEVE MELHOR OU IGUAL DESEMPENHO QUE ÀS OUTRAS TÉCNICAS; (B) IDENTIFICAÇÃO DOS DEFEITOS ISOLADOS PELAS TÉCNICAS. ..........77

FIGURA 4.19 - PERCENTUAL MÉDIO GERAL DOS INDIVÍDUOS NO EXPERIMENTO. .......................................................80 
FiguRA 4.20 - PERCENTUAL (DO TOTAL POSSÍVEL) DE DEFEITOS ISOLADOS PELOS INDIVÍDUOS COM LEITURA DE CÓDIGO.

FiguRA 4.21 - PERCENTUAL (DO TOTAL POSSÍVEL) DE DEFEITOS ISOLADOS PELOS INDIVÍDUOS COM TESTE

FUNCIONAL

Figura 4.22 - PERCENTUAL (DO TOTAL POSSÍvel) DE DEFEITOS ISOLADOS PELOS INDIVÍDUOS COM TESTE

INCREMENTAL.

FIGURA 4.23 - TÉCNICA QUE OBTEVE MELHOR/PIOR PERFORMANCE EM CADA PROGRAMA E TÉCNICAS QUE OBTIVERAM

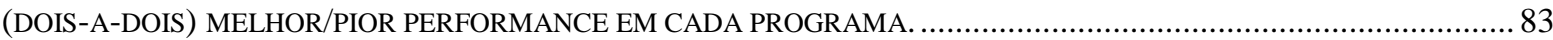

FIGURA 4.24 - TAXA MÉDIA DE COBERTURA OBTIDA PELO TESTE INCREMENTAL. .................................................8 84

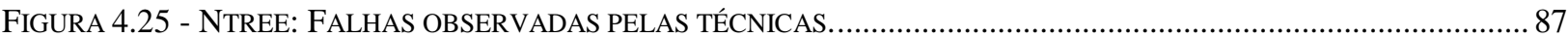

FIGURA 4.26 - NTREE: FALHAS OBSERVADAS PELO TESTE INCREMENTAL. ......................................................... 88

FIGURA 4.27 - NTREE: (A) QUANTIDADE E PERCENTUAL DE FALHAS OBSERVADAS PELAS TÉCNICAS; (B)

IDENTIFICAÇÃO DAS FALHAS OBSERVADAS PELAS TÉCNICAS

FIGURA 4.28 - NTREE: (A) NÚMERO DE OCORRÊNCIAS DE FALHAS OBSERVADAS PELAS TÉCNICAS; (B) IDENTIFICAÇÃO

DAS FALHAS OBSERVADAS PELAS TÉCNICAS.

FIGURA 4.29 - NTREE: (A) IDENTIFICAÇÃO DAS FALHAS ONDE A TÉCNICA OBTEVE MELHOR OU IGUAL DESEMPENHO

QUE AS OUTRAS TÉCNICAS; (B) IDENTIFICAÇÃO DAS FALHAS OBSERVADAS PELAS TÉCNICAS............................90

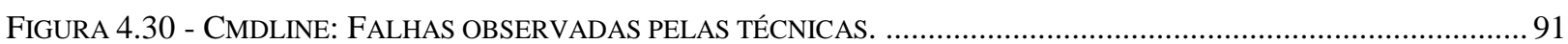

FIGURA 4.31 - CMDLINE: FALHAS OBSERVADAS PELO TESTE INCREMENTAL.....................................................92

FiguRA 4.32 - CMDLINE: (A) QUANTIDADE E PERCENTUAL DE FALHAS OBSERVADAS PELAS TÉCNICAS; (B)

IDENTIFICAÇÃO DAS FALHAS OBSERVADAS PELAS TÉCNICAS 93

FigURA 4.33 - CMDLINE: (A) NÚMERO DE OCORRÊNCIAS DE FALHAS OBSERVADAS PELAS TÉCNICAS; (B)

IDENTIFICAÇÃO DAS FALHAS OBSERVADAS PELAS TÉCNICAS

FIGURA 4.34 - CMDLINE: (A) IDENTIFICAÇÃO DAS FALHAS ONDE A TÉCNICA OBTEVE MELHOR OU IGUAL DESEMPENHO QUE AS OUTRAS TÉCNICAS; (B) IDENTIFICAÇÃO DAS FALHAS OBSERVADAS PELAS TÉCNICAS............................94

FIGURA 4.35 - NAMETBL: FALHAS OBSERVADAS PELAS TÉCNICAS. ....................................................................95

FIGURA 4.36 - NAMETBL: FALHAS OBSERVADAS PELO TESTE INCREMENTAL. ................................................... 96

FIGURA 4.37 - NAMETBL: (A) QUANTIDADE E PERCENTUAL DE FALHAS OBSERVADAS PELAS TÉCNICAS; (B)

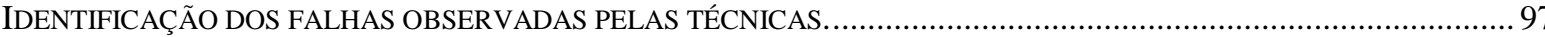

FIGURA 4.38 - NAMETBL: (A) NÚMERO DE OCORRÊNCIAS DE FALHAS OBSERVADAS PELAS TÉCNICAS; (B)

IDENTIFICAÇÃO DAS FALHAS OBSERVADAS PELAS TÉCNICAS 97

FIGURA 4.39 - NAMETBL: (A) IDENTIFICAÇÃO DAS FALHAS ONDE A TÉCNICA OBTEVE MELHOR OU IGUAL DESEMPENHO QUE ÀS OUTRAS TÉCNICAS; (B) IDENTIFICAÇÃO DAS FALHAS OBSERVADAS PELAS TÉCNICAS.............................98

FIGURA 4.40 - PERCENTUAL MÉDIO DOS INDIVÍDUOS NO EXPERIMENTO 101

FIGURA 4.41 - PERCENTUAL (DO TOTAL POSSÍVEL) DE DEFEITOS ISOLADOS PELOS INDIVÍDUOS COM LEITURA DE CÓDIGO 101

FiguRA 4.42 - PERCENTUAL (DO TOTAL POSSÍVEL) DE DEFEITOS ISOLADOS PELOS INDIVÍDUOS COM TESTE FUNCIONAL 
Figura 4.43 - PeRCENTUAL (DO TOTAL POSSÍVEL) DE DEFEITOS ISOLADOS PELOS INDivíduOS COM TESTE INCREMENTAL.

FIGURA 4.44: TÉCNICA QUE OBTEVE MELHOR/PIOR PERFORMANCE EM CADA PROGRAMA E TÉCNICAS QUE OBTIVERAM (DOIS-A-DOIS) MELHOR/PIOR PERFORMANCE EM CADA PROGRAMA. 104

FIGURA 4.45 - ORGANIZAÇÃO DO DADOS EM UMA PLANILHA DO SOFTWARE MINITAB....................................... 106

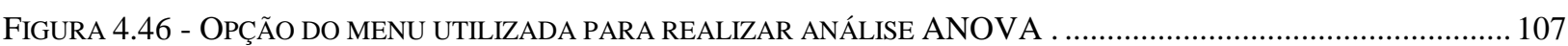

FIGURA 4.47 - TELA DE SELEÇÃO DA VARIÁVEL INDEPENDENTE E DA VARIÁVEL RESPOSTA. ..................................108

FIGURA 4.48 - RELATÓRIO CONTENDO INFORMAÇÕES SOBRE A INFLUÊNCIA DAS VARIÁVEIS INDEPENDENTES. ......... 109

FIGURA 5.1 - AD HoC/CHECKLIST: DEFEITOS ENCONTRADOS PELA TÉCNICA. .................................................... 123

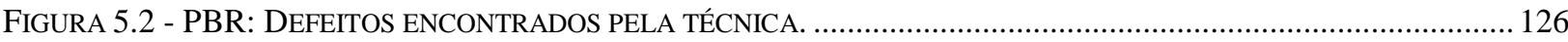

FIGURA 5.3 - (A) QUANTIDADE E PERCENTUAL DE DEFEITOS OBSERVADOS PELAS PERSPECTIVAS; (B) IDENTIFICAÇÃO DOS DEFEITOS OBSERVADOS PELAS PERSPECTIVAS.

FIGURA 5.4 - (A) NÚMERO DE OCORRÊNCIAS DE DEFEITOS OBSERVADOS PELAS PERSPECTIVAS; (B) IDENTIFICAÇÃO DOS DEFEITOS OBSERVADOS PELAS PERSPECTIVAS.

FIGURA 5.5 - (A) IDENTIFICAÇÃO DOS DEFEITOS ONDE AS PERSPECTIVAS OBTIVERAM PERFORMANCE MELHOR OU IGUAL COM RELAÇÃO AS OUTRAS PERSPECTIVAS; (B) IDENTIFICAÇÃO DOS DEFEITOS OBSERVADOS PELAS PERSPECTIVAS

FIGURA 5.6 - RESUMO DOS RESULTADOS COM O DOCUMENTO ATM

FIGURA 5.7 - AD HoC/CHECKLIST: DEFEITOS ENCONTRADOS PELA TÉCNICAS. 133

FIGURA 5.8 - PBR: DEFEITOS ENCONTRADOS PELA TÉCNICA. 135

FIGURA 5.9 - (A) QUANTIDADE E PERCENTUAL DE DEFEITOS OBSERVADOS PELAS PERSPECTIVAS; (B) IDENTIFICAÇÃO DOS DEFEITOS OBSERVADOS PELAS PERSPECTIVAS.

FIGURA 5.10 - (A) NÚMERO DE OCORRÊNCIAS DE DEFEITOS OBSERVADOS PELAS PERSPECTIVAS; (B) IDENTIFICAÇÃO DOS DEFEITOS OBSERVADOS PELAS PERSPECTIVAS.

FIGURA 5.11 - (A) IDENTIFICAÇÃO DOS DEFEITOS ONDE AS PERSPECTIVAS OBTIVERAM UM MELHOR OU IGUAL PERFORMANCE COM RELAÇÃO AS OUTRAS PERSPECTIVAS; (B) IDENTIFICAÇÃO DOS DEFEITOS OBSERVADOS PELAS PERSPECTIVAS

FigURA 5.12 - RESUMO DOS RESULTADOS COM O DOCUMENTO PG.

FiguRA 5.13 - PERCENTUAL (DO TOTAL POSSÍVEL) DE DEFEITOS OBSERVADOS PELOS INDIVÍDUOS COM AD HOC / CHECKLIST NO DOCUMENTO ATM.

FIGURA 5.14 - PERCENTUAL (DO TOTAL POSSÍVEL) DE DEFEITOS OBSERVADOS PELOS INDIVÍDUOS COM PBR NO DOCUMENTO ATM

FiguRA 5.15 - PERCENTUAL (DO TOTAL POSSÍvel) DE DEFEITOS OBSERVADOS PELOS INDIVÍDUOS COM AD HOC / CHECKLIST NO DOCUMENTO PG

FiguRA 5.16 - PERCENTUAL (DO TOTAL POSSÍVEL) DE DEFEITOS OBSERVADOS PELOS INDIVÍDUOS COM PBR NO DOCUMENTO PG.

FIGURA 5.17 - PERFORMANCE OBTIDA POR CADA TÉCNICA E PELOS PARES COMBINADOS DE TÉCNICAS 


\section{Lista de Tabelas}

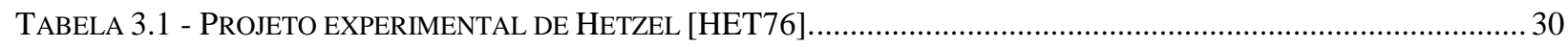

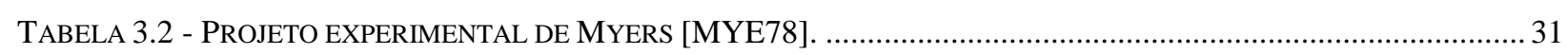

TABELA 3.3 - PROJETO EXPERIMENTAL DE BASILI E SELBY [BAS87] ............................................................33

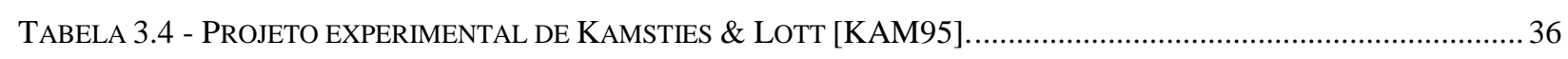

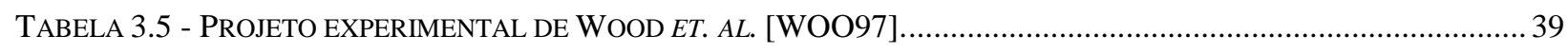

TABELA 3.6 - QUANTIDADE DE DEFEITOS EXISTENTES NOS DOCUMENTOS UTILIZADO NO EXPERIMENTO....................43

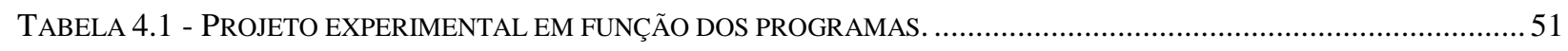

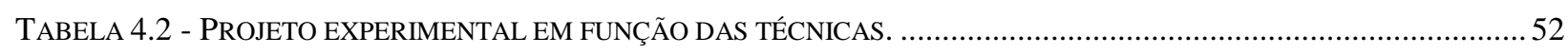

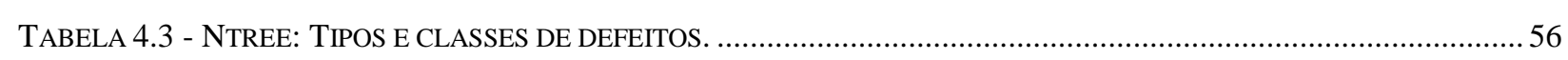

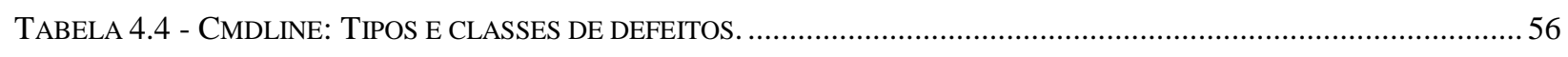

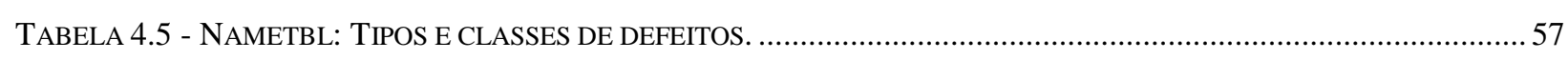

TABELA 4.6 - PERFIL DOS INDIVÍDUOS COM RELAÇÃO A EXPERIÊNCIA EM PROGRAMAÇÃO E PROFICIÊNCIA EM INGLÊS.

TABELA 4.7 - ESQUEMA DE CLASSIFICAÇÃO DA EXPERIÊNCIA NA LINGUAGEM C.....................................................58

TABELA 4.8 - NTREE: MÉDIA DE EXPERIÊNCIA DOS INDIVÍDUOS COM PROGRAMAÇÃO EM CADA TÉCNICA...................60

TABELA 4.9 - NTREE: POSSIBILIDADES DE ISOLAMENTO E QUANTIDADES ISOLADAS DE DEFEITOS POR TÉCNICA.........60

TABELA 4.10 - NTREE: QUANTIDADE E PERCENTUAL (DO TOTAL POSSÍVEL) DE DEFEITOS ISOLADOS POR TIPOS E

CLASSES

TABELA 4.11 - CUSTO E EFICIÊNCIA DOS CONJUNTOS DE CASOS DE TESTE OBTIDOS COM CADA CRITÉRIO DO TESTE

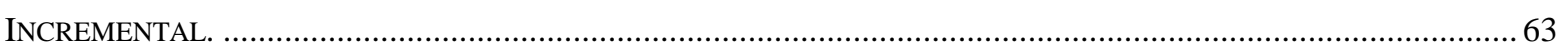

TABELA 4.12 - CMDLINE: MÉDIA DE EXPERIÊNCIA DOS INDIVÍDUOS COM PROGRAMAÇÃo EM CADA TÉCNICA. ........... 66

TABELA 4.13 - CMDLINE: POSSIBILIDADES DE ISOLAMENTO E QUANTIDADES ISOLADAS DE DEFEITOS POR TÉCNICA. . 66

TABELA 4.14 - CMDLINE: QUANTIDADE E PERCENTUAL (DO TOTAL POSSÍVEL) DE DEFEITOS ISOLADOS POR TIPOS E

CLASSES.

TABELA 4.15 - CUSTO E EFICIÊNCIA DOS CONJUNTOS DE CASOS DE TESTE OBTIDOS COM CADA CRITÉRIO DO TESTE INCREMENTAL 69

TABELA 4.16 - NAMETBL: MÉDIA DE EXPERIÊNCIA DOS INDIVÍDUOS COM PROGRAMAÇÃO EM CADA TÉCNICA............ 72

TABELA 4.17 - NAMETBL: POSSIBILIDADES DE ISOLAMENTO E QUANTIDADES ISOLADAS DE DEFEITOS POR TÉCNICA. 72 TABELA 4.18 - NAMETBL: QUANTIDADE E PERCENTUAL (DO TOTAL POSSÍVEL) DE DEFEITOS ISOLADOS POR TIPOS E CLASSES

TABELA 4.19 - CUSTO E EFICIÊNCIA DOS CONJUNTOS DE CASOS DE TESTE OBTIDOS COM CADA CRITÉRIO DO TESTE

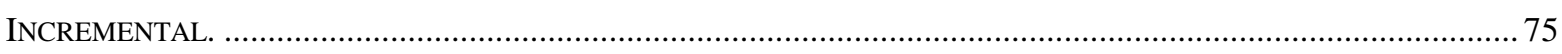

TABELA 4.20 - QUANTIDADE DE DEFEITOS ISOLADOS E TEMPO GASTO (EM MINUTOS) PELOS INDIVÍDUOS. ................. 78

TABELA 4.21 - MÉDIA DE DEFEITOS ISOLADOS PELOS INDIVÍDUOS UTILIZANDO CADA TÉCNICA. ...............................78

TABELA 4.22 - PERCENTUAL MÉdio DE DEFEITOS ISOLADOS (DO TOTAL POSSÍVEL) E TAXA DE ISOLAMENTO DE

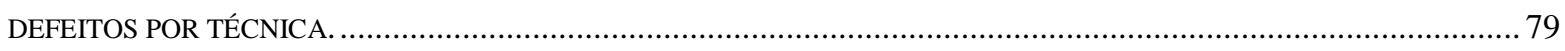

TABELA 4.23 - PERCENTUAL MÉdio DE DEFEITOS ISOLADOS (DO TOTAL POSSÍVEL) POR TIPOS E CLASSES.................. 79 
TABELA 4.24 - INDIVÍDUOS QUE OBTIVERAM A MELHOR PERFORMANCE COM CADA TÉCNICA.

TABELA 4.25 - OUTROS RESULTADOS OBTIDOS PELOS INDIVÍDUOS QUE OBTIVERAM AS MELHORES PERFORMANCE COM

CADA TÉCNICA.

TABELA 4.26 - TÉCNICA QUE OBTEVE MELHOR/PIOR PERFORMANCE EM CADA PROGRAMA E TÉCNICAS QUE

OBTIVERAM (DOIS-A-DOIS) MELHOR/PIOR PERFORMANCE EM CADA PROGRAMA. ..............................................8 84

TABELA 4.27 - COBERTURAS MÉDIAS OBTIDA PELOS INDIVÍDUOS APLICANDO O TESTE INCREMENTAL. .................... 85

TABELA 4.28 - NTREE: POSSIBILIDADES DE OBSERVAÇÃO E QUANTIDADES OBSERVADAS DE FALHAS POR TÉCNICA. . 88

TABELA 4.29 - CMDLINE: POSSIBILIDADES DE OBSERVAÇÃO E QUANTIDADES OBSERVADAS DE FALHAS POR TÉCNICA.

TABELA 4.30 - NAMETBL: POSSIBILIDADES DE OBSERVAÇÃO E QUANTIDADES OBSERVADAS DE FALHAS POR TÉCNICA.

TABELA 4.31 - QUANTIDADE DE FALHAS OBSERVADAS E TEMPO GASTO (EM MINUTOS) PELOS INDIVÍDUOS. ..............99

TABELA 4.32 - MÉDIA DE FALHAS OBSERVADAS PELOS INDIVÍDUOS UTILIZANDO CADA TÉCNICA...............................99

TABELA 4.33 - PERCENTUAL MÉDIO DE FALHAS OBSERVADAS (DO TOTAL POSSÍVEL) E TAXA DE OBSERVAÇÃO DE

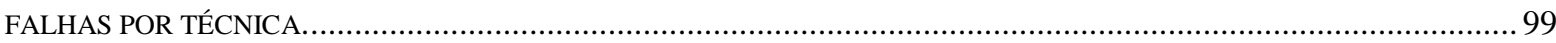

TABEla 4.34 - PERCENTUAL MÉdio DE FALHAS OBSERVADAS (DO TOTAL POSSÍVEL) POR TIPOS E CLASSES. ............. 100

TABELA 4.35 - INDIVÍDUOS QUE OBTIVERAM A MELHOR PERFORMANCE COM CADA TÉCNICA. ................................ 103

TABELA 4.36 - OUTROS RESULTADOS OBTIDOS PELOS INDIVÍDUOS QUE OBTIVERAM AS MELHORES PERFORMANCE COM

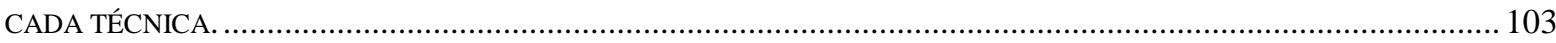

TABELA 4.37 - TÉCNICA QUE OBTEVE MELHOR/PIOR PERFORMANCE EM CADA PROGRAMA E TÉCNICAS QUE

OBTIVERAM (DOIS-A-DOIS) MELHOR/PIOR PERFORMANCE EM CADA PROGRAMA. .......................................... 104

TABELA 4.38 - ANÁLISE ONE-WAY DO PERCENTUAL MÉDIO (DO TOTAL POSSÍVEL) DE DEFEITOS ISOLADOS. ........... 109

TABELA 4.39 - ANÁLISE ONE-WAY DO PERCENTUAL MÉDIO (DO TOTAL POSSÍVEL) DE FALHAS OBSERVADAS. ......... 109

TABELA 4.40 - ANÁLISE DE COVARIÂNCIA UTILIZANDO A EXPERIÊNCIA EM PROGRAMAÇÃO....................................110

TABELA 4.41 - ANÁLISE DE COVARIÂNCIA UTILIZANDO NÍVEL DE PROFICIÊNCIA EM INGLÊS (LEITURA)...................111

TABELA 4.42 - ANÁLISE ONE-WAY DO TEMPO DE ISOLAMENTO DE DEFEITOS. ..................................................... 111

TABELA 4.43 - ANÁLISE ONE-WAY DO TEMPO DE OBSERVAÇÃO DE FALHAS. ..................................................... 112

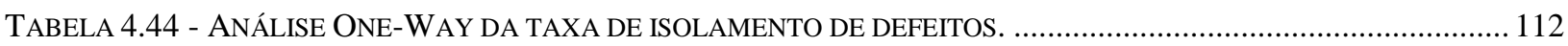

TABELA 4.45 - ANÁLISE ONE-WAY DA TAXA DE OBSERVAÇÃO DE FALHAS .......................................................... 113

TABELA 4.46 - ANÁLISE ONE-WAY DO PERCENTUAL MÉDIO (DO TOTAL POSSÍVEL) DE DEFEITOS ISOLADOS POR TIPOS E

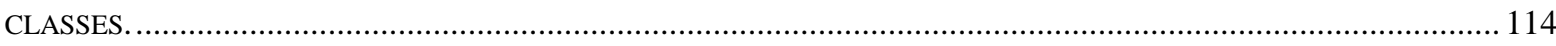

TABELA 4.47 - ANÁLISE ONE-WAY DO PERCENTUAL MÉDIO (DO TOTAL POSSÍVEL) DE FALHAS OBSERVADAS POR TIPOS

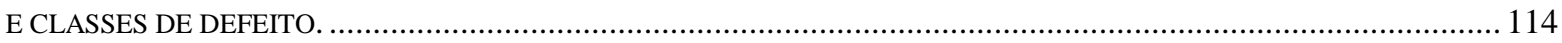

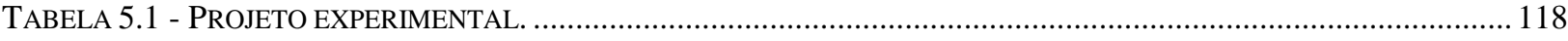

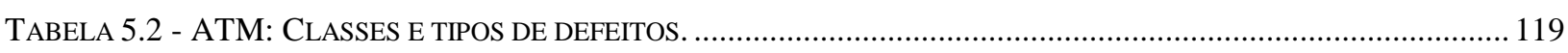

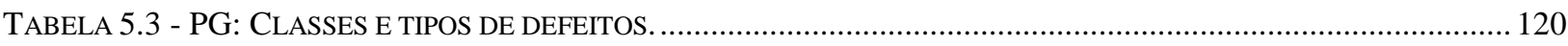

TABELA 5.4: PERFIL DOS INDIVÍDUOS QUE PARTICIPARAM DO EXPERIMENTO......................................................... 122

TABELA 5.5 - PERFIL dOS INDIVÍdUOS QUE APLICARAM A TÉCNICA Ad HoC/CHECKLIST NO DOCUMENTO ATM..... 123 
TABELA 5.6 - NÚMERO MÁXIMO DE POSSIBILIDADES DE OBSERVAÇÃO DE DEFEITOS E NÚMERO DE DEFEITOS OBSERVADOS PELA TÉCNICA.

TABELA 5.7 - QUANTIDADE E PERCENTUAL (DO TOTAL POSSÍVEL) DE DEFEITOS OBSERVADOS POR CLASSE E TIPO UTILIZANDO A TÉCNICA AD HOC/CHECKLIST.

TABELA 5.8 - MÉDIA DE DEFEITOS OBSERVADOS POR CADA INDIVÍDUO.

TABELA 5.9 - PERCENTUAL MÉDIO de DEFEITOS OBSERVADOS (DO TOTAL POSSÍVEL) E TAXA DE OBSERVAÇÃo DE DEFEITOS.

TABELA 5.10 - PERFIL DOS INDIVÍDUOS QUE APLICARAM A TÉCNICA PBR (PERSPECTIVA DO PROJETO) NO DOCUMENTO ATM.

TABELA 5.11 - PeRfil DOS INDIVÍdUOS QUe APLICARAM A TÉCNICA PBR (PERSPECTIVA DO TESTE) NO DOCUMENTO ATM......

TABELA 5.12 - PERFIL dOS INDIVÍdUOS QUE APLICARAM A TÉCNICA PBR (PERSPECTIVA DO USO) NO DOCUMENTO ATM

TABELA 5.13 - NÚMERO MÁXIMO DE POSSIBILIDADES DE OBSERVAÇÃO DE DEFEITOS E NÚMERO DE DEFEITOS OBSERVADOS PELA TÉCNICA.

TABELA 5.14 - QUANTIDADE E PERCENTUAL (DO TOTAL POSSÍVEL) DE DEFEITOS OBSERVADOS POR TIPOS E CLASSES UTILIZANDO A TÉCNICA PBR.

TABELA 5.15 - MÉDIA DE DEFEITOS OBSERVADOS POR CADA INDIVÍDUO.

TABELA 5.16 - PeRCENTUAL MÉdio de DEFEITOS OBSERVADOS (DO TOTAL POSSÍVEL) E TAXA DE OBSERVAÇão DE DEFEITOS.

TABELA 5.17 - PeRfil dos INDIVÍdUOS QUE APLICARAM A TÉCNICA AD HOC/CHECKLIST NO DOCUMENTO PG. 133

TABELA 5.18 - NÚMERO MÁXIMO DE POSSIBILIDADES DE OBSERVAÇÃO DE DEFEITOS E NÚMERO DE DEFEITOS OBSERVADOS PELA TÉCNICA.

TABELA 5.19 - QUANTIDADE E PERCENTUAL (DO TOTAL POSSÍVEL) DE DEFEITOS OBSERVADOS POR CLASSE E TIPO UTILIZANDO AS TÉCNICAS AD HOC / CHECKLIST.

TABELA 5.20 - MÉDIA DE DEFEITOS OBSERVADOS POR CADA INDIVÍDUO.

TABELA 5.21 - PERCENTUAL MÉdio de DEFEITOS OBSERVADOS (DO TOTAL POSSÍVEL) E TAXA DE OBSERVAÇão DE DEFEITOS.

TABELA 5.22 - PERFIL dOS INDIVÍDUOS QUE APLICARAM A TÉCNICA PBR (PERSPECTIVA DO PROJETO) NO DOCUMENTO PG.

TABELA 5.23 - PERFIL DOS INDIVÍDUOS QUE APLICARAM A TÉCNICA PBR (PERSPECTIVA DO TESTE) NO DOCUMENTO PG.

TABElA 5.24 - PERFIL dOS INDIVÍdUOS QUE APLICARAM A TÉCNICA PBR (PERSPECTIVA DO USO) NO DOCUMENTO PG.

TABELA 5.25 - NÚMERO MÁXIMO DE POSSIBILIDADES DE OBSERVAÇÃO DE DEFEITOS E NÚMERO DE DEFEITOS OBSERVADOS PELA TÉCNICA.

TABELA 5.26 - QUANTIDADE E PERCENTUAL (DO TOTAL POSSÍVEL) DE DEFEITOS OBSERVADOS POR TIPOS E CLASSES UTILIZANDO A TÉCNICA PBR.

TABELA 5.27 - MÉDIA DE DEFEITOS ENCONTRADOS POR CADA INDIVÍDUO. 140 
TABELA 5.28 - PeRCENTUAL MÉdio DE DEFEITOS ENCONTRADOS (DO TOTAL POSSÍVEL) E TAXA DE OBSERVAÇÃo DE DEFEITOS. 140

TABELA 5.29 - PERFORMANCE OBTIDA POR CADA TÉCNICA E PELOS PARES COMBINADOS DE TÉCNICAS. . 144 


\section{Resumo}

A crescente utilização de sistemas baseados em computação em praticamente todas as áreas da atividade humana provoca uma crescente demanda por qualidade e produtividade, tanto do ponto de vista do processo de produção como do ponto de vista dos produtos de software gerados. Nessa perspectiva, atividades agregadas sob o nome de Garantia de Qualidade de Software têm sido introduzidas ao longo de todo o processo de desenvolvimento de software. Dentre essas atividades destacam-se as atividades de Teste e Revisão, ambas com o objetivo principal de minimizar a introdução de erros durante o processo de desenvolvimento nos produtos de software gerados. A atividade de Teste constitui um dos elementos para fornecer evidências da confiabilidade do software em complemento a outras atividades, como por exemplo, o uso de revisões e de técnicas formais e rigorosas de especificação e de verificação. A atividade de Revisão, por sua vez, é um "filtro" eficiente para o processo de engenharia de software, pois favorece a identificação e a eliminação de erros antes do passo seguinte do processo de desenvolvimento. Atualmente, pesquisas estão sendo realizadas com objetivo de determinar qual técnica, Revisão ou Teste, é mais adequada e efetiva, em determinadas circunstâncias, para descobrir determinadas classes de erros; e de forma mais ampla, como as técnicas podem ser aplicadas de forma complementar para melhoria da qualidade de software. Ainda que a atividade de teste seja indispensável no processo de desenvolvimento, investigar o aspecto complementar dessas técnicas é de grande interesse, pois em muitas situações tem-se observado que as revisões são tão ou mais efetivas quanto os testes. Nessa perspectiva, este trabalho tem como objetivo realizar um estudo comparativo, por meio da replicação de experimentos, entre Técnicas de Teste e Técnicas de Revisão no que se refere à detecção de erros em produtos de software (código fonte e documento de especificação de requisitos). Para realizar esse estudo são utilizados critérios de teste das técnicas funcional (particionamento em classes de equivalência e análise do valor limite), estrutural (todos-nós, todos-arcos, todos-usos, todos-potenciais-usos), baseada em erros (análise de mutantes), bem como, técnicas de leitura (stepwise abstraction e perspective based reading) e técnicas de inspeção (ad hoc e checklist). Além de comparar a efetividade e a eficiência das técnicas em detectar erros em produtos de software, este trabalho objetivo ainda utilizar os conhecimentos específicos relacionados a critérios de teste para reavaliar as técnicas utilizadas nos experimentos de Basili \& Selby, Kamsties \& Lott e Basili. 


\begin{abstract}
The increasing use of computer based systems in practically all human activity areas provokes higher demand for quality and productivity, from the point of view of software process as well as from the point of view of software products. In this perspective, activities aggregated under the name of Software Quality Assurance have been introduced throughout the software development process. Amongst these activities, the test and review activities are distinguished, both of them aiming at minimizing the introduction of errors during the development process. The test activity constitutes one of the elements to supply evidences of software reliability as a complement to other activities, for example, the use of review and formal, rigorous techniques for specification and verification. The review activity, in turn, is an efficient "filter" for the process of software engineering, therefore it favors the identification of errors before the next step of the development process. Currently, researches have been carried out with the objective of determining which technique, review or test, is more appropriate and effective, in certain circumstances, to discover some classes of errors, and mostly, how the techniques can be applied in complement to each other for improvement of software quality. Even if the test activity is indispensable in the development process, investigating the complementary aspect of these techniques is of great interest, for in many situations it has been observed that reviews are as or more effective as test. In this perspective, this work aims at accomplishing a comparative study, through the replication of experiments, between Testing Techniques and Reviews concerning error detection in software products at the source code and requirement specification level. To carry out this study are used testing criteria of the techniques: functional (equivalence partitioning and boundary value analysis); structural (all-nodes, all-edges, all-uses, all-potentialuses); error based (mutation testing), as well as reading techniques (stepwise abstraction and perspective based reading) and inspection techniques (ad hoc e checklist). Besides comparing the effectiveness and efficiency of the techniques in detecting errors in software products, this work also aims at reevaluating and eventually at improving the techniques used in experiment of Basili \& Selby, Kamsties \& Lott and Basili.
\end{abstract}




\section{CAPÍTULO 1}

\section{Introdução}

A Engenharia de Software emergiu na década de 70 e vem evoluindo significativamente nas últimas décadas procurando estabelecer técnicas, critérios, métodos e ferramentas para a produção de software, em consequiência da crescente utilização de sistemas baseados em computação em praticamente todas as áreas da atividade humana, o que provoca uma crescente demanda por qualidade e produtividade, tanto do ponto de vista do processo de produção como do ponto de vista dos produtos gerados.

Porém, uma vez desenvolvidas as novas abordagens, existem poucos dados experimentais (base de dados histórica) que demonstrem a sua utilidade [BAS98]. Os estudos empíricos colocam-se nessa perspectiva uma vez que fornecem subsídios para a avaliação e constituição de uma base histórica. Assim, a avaliação e a análise de dados experimentais são a base de muitos campos científicos.

A Engenharia de Software é praticamente um campo novo que tende a mudar de simples acertos sobre os efeitos de uma técnica para uma disciplina científica baseada em observações, formulação de teoria e experimentos. Uma vez que o componente empírico da Engenharia de Software está em um estágio muito primitivo de seu desenvolvimento, é raramente óbvio qual o tipo de experimento é mais apropriado para avaliar uma particular tecnologia, por isso, múltiplos estudos de diferentes tipos são freqüentemente necessários para executar uma avaliação adequada de uma nova tecnologia.

Um aspecto relevante em experimentação é a necessidade de replicar ou complementar um estudo experimental. Replicação em diferentes contextos é uma característica importante para qualquer tipo de estudo em Engenharia de Software. A replicação também é importante para obter-se credibilidade e aprendizagem. Também são importantes os estudos complementares que permitam aos pesquisadores combinar conhecimentos diretamente ou via alguma forma de meta- 
análise. A replicação e os estudos complementares são encorajados pela disponibilidade de pacotes de laboratório (lab packages) que documentam um experimento. Um pacote de laboratório descreve um experimento em termos específicos permitindo replicação, oportunidades de variação e um contexto para combinação de resultados em diferentes tipos de tratamentos experimentais. Os pacotes de laboratório apóiam replicações futuras com uma variedade de metas: confirmando/negando resultados originais, completando a experiência original, organizando o objeto do estudo para um contexto experimental específico.

Várias iniciativas de estudos empíricos nas mais diversas áreas da computação são identificadas. Na área de VV\&T - Verificação, Validação e Teste, mais especificamente, existe um significativo esforço no desenvolvimento de estudos empíricos objetivando investigar quais técnicas são mais adequadas e efetivas, em determinadas circunstâncias, para descobrir erros e como essas técnicas podem ser utilizadas de maneira complementar.

Dentre as técnicas de Verificação e Validação, a atividade de teste é uma das mais utilizadas, constituindo-se em um dos elementos para fornecer evidências da confiabilidade do software em complemento a outras atividades, como por exemplo, o uso de revisões e de técnicas formais e rigorosas de especificação e de verificação [MAL97]. Segundo Myers [MYE79], o principal objetivo do teste de software é revelar a presença de defeitos no produto.

A atividade de Teste é de extrema importância para a garantia de qualidade de software, porque erros ainda persistem nos produtos gerados e analisados durante o ciclo de vida, e pode ser vista como a última revisão da especificação, projeto e codificação. Por meio de técnicas de teste, produtos são analisados, com intuito de descobrir erros, contribuindo assim para melhoria do processo de desenvolvimento. No entanto, é uma das atividades mais onerosas de desenvolvimento de software [PRE00].

As atividades de Verificação e Validação também são fundamentais para garantia de qualidade de software. A atividade de Verificação garante que o produto está sendo construído corretamente, com base nos padrões pré-determinados pela organização. A atividade de Validação, por sua vez, garante que o software correto está sendo desenvolvido, confrontando-o com a especificação de requisitos. Verificação e Validação abrangem um conjunto amplo de atividades de Garantia da Qualidade de Software que incluem: aplicações de métodos técnicos e ferramentas; realização de revisões técnicas formais; atividades de testes de software; aplicação de padrões; controle de mudanças; medição; manutenção de registros e relatos [PRE00].

As revisões e os testes são considerados duas atividades distintas de validação. O teste de software realiza o que se chama de análise dinâmica de um produto de software. A análise dinâmica requer que o produto, por exemplo, um programa ou uma especificação, seja 
executado, e conseqüentemente siga o padrão tradicional de teste, no qual o produto é executado com alguns casos de teste e os resultados gerados são examinados para verificar se foram produzidos os resultados esperados. A análise estática, por sua vez, não envolve a execução dos produtos de software, detecta possíveis erros por meio da análise de determinadas características, como por exemplo, o fluxo de dados de um programa.

As revisões de software são técnicas de validação que podem realizar tanto uma análise dinâmica quanto uma análise estática de um determinado produto de software. As revisões de software do tipo inspeção, por exemplo, realizam uma análise estática do produto (durante uma reunião de inspeção pode-se utilizar um checklist de erros historicamente comuns de programação para descobrir problemas de qualidade no produto). As revisões de software do tipo walkthrough, por exemplo, realizam uma análise dinâmica, pois, simulam a execução de um programa com um conjunto de casos de teste [ADR82]. As revisões de software são uma das técnicas de validação disponíveis nas fases inicias de desenvolvimento.

Em resumo, as técnicas de VV\&T objetivam identificar a presença de erros logo que eles são introduzidos no processo de desenvolvimento e de certa forma aprender com esta atividade e evoluir tanto o processo de desenvolvimento como as próprias técnicas.

\subsection{Contexto}

Atualmente, pesquisas têm sido realizadas com objetivo de determinar qual técnica, Revisão ou Teste, é mais adequada e efetiva, em determinadas circunstâncias, para descobrir determinadas classes de erros, e de forma mais ampla, como as técnicas podem ser aplicadas de forma complementar para melhoria da qualidade do software. Ainda que a atividade de teste seja indispensável no processo de desenvolvimento, investigar o aspecto complementar dessas técnicas é de grande interesse, pois em muitas situações tem-se observado que as revisões são tão efetivas quanto os testes [BAR98a, BAR98b, BAS81, BAS86, BAS87, BAS96a, BAS96b, BAS96c, BAS98, BOC94, COW88, FUS97, HET72, HET76, KAM95, MEY78, POR95, SEL87, SOU96, SOV96, VIN98, WOO97, ZEL97].

Entre os estudos empíricos que visam a comparar a efetividade das Técnicas de Revisão com as Técnicas de Teste em termos de detectar defeitos em produtos de software pode-se destacar o trabalho de Basili \& Selby [BAS87] e Basili et. al. [BAS96a]. Em linhas gerais, Basili e Selby realizaram um experimento controlado objetivando comparar três técnicas de detecção de defeitos no que diz respeito à efetividade e eficiência em revelar falhas. Esse experimento foi conduzido por três vezes, as duas primeiras execuções foram realizadas com 42 estudantes avançados e a terceira execução utilizou desenvolvedores profissionais [BAS87]. 
Mesmo a atividade de teste sendo uma das mais importante atividade de garantia de qualidade de software, avaliar a qualidade dos produtos de software gerados durante o processo de desenvolvimento deve ser uma atividade contínua. Assim, as revisões de software são de grande importância nas fases iniciais do desenvolvimento. Basili et. al. [BAS96a] definiram a técnica de leitura chamada Perspective Based Reading (PBR) que objetiva descobrir defeitos em especificações de requisitos, ou seja, logo no inicio do processo de desenvolvimento.

Nessa perspectiva, Basili também executou um experimento controlado objetivando avaliar a efetividade da técnica de leitura PBR na detecção de defeitos, quando aplicada em documentos de especificação de requisitos, comparando-a com técnicas convencionais de inspeção. O experimento foi conduzido com desenvolvedores profissionais de software da National Aeronautics and Space Administration / Goddard Space Flight Center (NASA/GSFC) Software Engineering Laboratory (SEL) [BAS96a].

O Grupo de Engenharia de Software do Instituto de Ciências Matemáticas e de Computação (ICMC-USP), em colaboração com o Grupo de Teste - DCA/FEE/UNICAMP, tem desenvolvido pesquisas na área de teste, com ênfase no estudo de princípios, estratégias, métodos e critérios de teste e validação, bem como no desenvolvimento de ferramentas de teste que apóiem a realização das atividades de teste e viabilizem a avaliação do aspecto complementar das técnicas de VV\&T.

Atualmente, o Grupo de Engenharia de Software do ICMC-USP, em colaboração com UMD - University of Maryland, propôs o projeto "NSF-CNPq Collaborative Research to Develop, Validate and Package Reading Techniques for Software Defect Detection" (NSFCNPq Readers) que objetiva realizar pesquisas em leitura de software, teste e estudos empíricos para avaliar e desenvolver técnicas para analisar produtos de software com objetivo de detectar erros. Em linhas gerais, essas técnicas de análise deverão ser organizadas para realizarem uma tarefa específica relacionada a software, por exemplo, detectar defeitos, utilizando tipos específicos de produtos de software (especificações de requisitos e/ou código) em ambientes ou contextos culturais diferentes, e ainda deverão ser empiricamente validadas por meio de experimentos controlados.

Nessa perspectiva, o presente trabalho de mestrado está em consonância com os objetivos gerais do projeto NSF-CNPq Readers, pois objetiva realizar um estudo empírico que compara Técnicas de Revisão com Técnicas de Teste na detecção de problemas de qualidade nos produtos de software gerados durante o ciclo de vida de desenvolvimento. 


\subsection{Motivação}

Este trabalho de mestrado está em consonância com a proposta de pesquisa apresentada no projeto de colaboração entre a Universidade de São Paulo e a Universidade de Maryland. Neste contexto, as motivações para realização da presente pesquisa são:

- Atualmente, a indústria de software tem um conhecimento limitado sobre como o software é estruturado, construído e desenvolvido no tempo; fazem-se necessários modelos adequados para discutir sobre processos e produtos de software, entender e analisar os limites da tecnologia em determinados contextos, pois nos falta habilidade de análise e experimentação;

- Tecnologias que surgem para resolver um problema em um contexto específico podem não ser aplicáveis ao mesmo problema em diferentes contextos. Freqüentemente essas limitações são amplamente desconhecidas pelos engenheiros de software;

- Tecnologias de software são fortemente influenciadas pelo ambiente e pelo contexto cultural nos quais elas são usadas. Por esta razão, necessita-se munir os engenheiros de software com habilidade para controlá-las e manipulá-las, baseado no contexto cultural, ambiente e conjunto de metas de um projeto. Esta habilidade deve ser baseada em evidências empíricas e experimentais do que funciona e do que não funciona sobre certas circunstâncias; e

- Novas tecnologias devem ser agrupadas com o que é conhecido sobre sua aplicação em diferentes contextos, bem como os detalhes de avaliação a que elas são submetidas.

\subsection{Objetivo da Pesquisa}

O objetivo deste trabalho é realizar um estudo comparativo, por meio da replicação de experimentos, entre Técnicas de Teste e Técnicas de Revisão no que se refere à detecção de erros em produtos de software (código fonte e documento de especificação de requisitos). Para realizar esses estudos são utilizados critérios de teste das técnicas funcional (particionamento em classes de equivalência e análise do valor limite), estrutural (todos-nós, todos-arcos, todos-usos, todospotenciais-usos), baseada em erros (análise de mutantes), bem como, técnicas de leitura (stepwise abstraction e perspective based reading) e técnicas de inspeção (ad hoc e checklist). Além de comparar a efetividade e a eficiência das técnicas em detectar erros em produtos de software, este trabalho objetivo ainda utilizar os conhecimentos específicos relacionados a critérios de teste para reavaliar as técnicas utilizadas nos experimentos de Basili \& Selby, Kamsties \& Lott e Basili. A avaliação da efetividade da técnica de leitura PBR, aplicável ao nível de especificação, também é de interesse de nossos estudos. 
Os experimentos a serem realizados durante o presente trabalho de mestrado se classificam em: experimentos baseados código fonte, ou seja, que utilizam como produto de software códigos fontes de programas, e; experimentos baseados em documentos de especificação de requisitos, ou seja, que utilizam como produto de software documentos textuais de especificação de requisitos. O experimento baseado em código fonte é uma replicação dos experimentos de Basili \& Selby [BAS87] e Kamsties \& Lott [KAM95]. O experimento baseado em documentos de especificação de requisitos é uma replicação do experimento de Basili et. al. [BAS96a]. Esses experimentos estão descritos detalhadamente no Capítulo 3.

Os objetivos específicos deste trabalho são:

- Criar/Aplicar tecnologias de análise de software que possam ser usadas eficientemente para detectar erros em especificações de software e código; e desenvolver métodos para melhorar continuamente essas técnicas em diferentes ambientes e contextos culturais.

- Expandir a base de tecnologia de análise de software, criando novos pacotes de laboratórios, que possam ser adaptados e reutilizados por outros pesquisadores de engenharia de software baseado em suas próprias necessidades culturais e ambientais.

\subsection{Organização do Trabalho}

Neste capítulo foram apresentados: o contexto no qual este trabalho está inserido, a motivação para realizá-lo e os objetivos a serem atingidos.

No Capítulo 2 apresenta-se uma revisão bibliográfica sobre as técnicas de revisão de software e sobre as técnicas de teste de software, enfatizando os critérios e técnicas utilizadas durante este trabalho.

No Capítulo 3, apresentam-se detalhadamente os principais estudos comparativos entre técnicas de revisão e teste já realizados e os principais resultados alcançados.

No Capítulo 4 é apresentada a replicação do experimento baseado em códigos fontes, bem como, os principais objetivos, projeto experimental, caracterização dos indivíduos, técnicas de detecção de defeitos utilizadas, artefatos de software utilizados, procedimentos experimentais, técnicas estatísticas utilizadas e os resultados obtidos.

No Capítulo 5 é apresentada a replicação do experimento baseado em documentos de especificação de requisitos, bem como, os principais objetivos, projeto experimental, 
caracterização dos indivíduos, técnicas de detecção de defeitos utilizadas, artefatos de software utilizados, procedimentos experimentais e os resultados obtidos.

No Capítulo 6, apresentam-se as conclusões e as principais contribuições deste trabalho. Também são apresentadas algumas propostas de trabalhos futuros. 


\section{CAPÍTULO 2}

\section{Revisão Bibliográfica}

\section{1 - Considerações Iniciais}

Como mencionado anteriormente, este trabalho aborda estudos comparativos entre técnicas de revisão e técnicas de teste de software por meio da replicação de experimentos. Fazse então, neste capítulo, uma revisão bibliográfica das principais técnicas de revisão e de teste. Na Seção 2.2 é apresentada uma visão geral da atividade de revisão, bem como os principais métodos de revisão: inspeção, walkthrough e peer-review. Na Seção 2.2.3 são apresentadas as técnicas de leitura stepwise abstraction e perspective based reading, devido a importância no contexto deste trabalho. Na Seção 2.3, é apresentada uma visão geral da atividade de teste, bem como as técnicas e critérios de teste a ela relacionada, enfatizando os critérios que são utilizados durante este trabalho.

\section{2 - A Atividade de Revisão}

A atividade de revisão é parte integrante de um conjunto de atividades agregadas sob o nome de Garantia de Qualidade de Software. Essas atividades constituem um padrão sistemático e planejado de ações que são exigidas para garantir a qualidade do software e que devem ser aplicadas ao longo de todo processo de engenharia de software. A Garantia de Qualidade de Software abrange: (1) aplicação de métodos técnicos e ferramentas; (2) realização de revisões técnicas formais; (3) atividades de testes de software; (4) aplicação de padrões; (5) controle de mudanças; (6) medição; (7) manutenção de registros e relatos [PRE00].

Nesse contexto, a revisão de software é um filtro para o processo de engenharia de software. As revisões de software são aplicadas em vários pontos durante o ciclo de vida do desenvolvimento de software e servem para descobrir defeitos que possam ser eliminados, sendo esse seu principal objetivo [PRE00]. 
As revisões de software são necessárias, pois erros humanos acontecem; e embora as pessoas sejam capazes de identificar, com certa facilidade, seus próprios erros, existem categorias de erros que escapam ao seu autor mais facilmente do que a qualquer outra pessoa [FRE93].

Segundo Pressman [PRE00], qualquer revisão, seja de software ou não, é uma forma de utilizar a diversidade e o poder de um grupo de pessoas para:

- Apontar as melhorias a serem feitas num produto criado por um único indivíduo ou equipe;

- Confirmar as partes de um produto nas quais as melhorias não são necessárias ou desejadas;

- Obter trabalho técnico de qualidade mais uniforme ou, pelo menos, mais previsível do que aquele conseguido sem as revisões, visando torná-lo mais gerencial.

As revisões podem ser classificadas em: revisão informal e revisão técnica formal.

A revisão informal caracteriza-se pela informalidade que as revisões dos produtos de software se realizam em todo o processo de engenharia de software. Esse tipo de revisão é realizado freqüentemente pelos grupos de desenvolvimento. Qualquer tipo de reunião informal, na qual se discutam problemas técnicos do software ou qualquer revisão de um produto de software por um membro do grupo é considerada uma revisão informal.

A revisão técnica formal é um "filtro" eficiente do ponto de vista de garantia da qualidade de software. Quando realizada efetivamente torna-se um meio real para melhorar a qualidade do software. Isso é possível, pois através da revisão técnica formal, defeitos de software são precocemente identificados e eliminados antes do passo seguinte do processo de engenharia de software [PRE00].

Em projetos de desenvolvimento de software complexos, por exemplo, o trabalho de muitas pessoas deve ser coordenado durante todo o processo de engenharia de software. Essa coordenação requer gerenciamento, e tal gerenciamento requer informações confiáveis sobre as atividades que estão sendo realizadas. A revisão técnica formal caracteriza-se pelo fornecimento de informações confiáveis sobre assuntos técnicos [FRE93]. O que torna uma revisão técnica formal é a combinação de:

- Relatórios escritos sobre o status do produto revisado - um relatório que seja disponível para cada envolvido no projeto, incluindo a gerência; 
- Participação ativa e aberta de todos no grupo de revisão, seguindo algumas tradições, costumes e regras instituídos sobre como tal revisão deve ser conduzida;

- Plena responsabilidade de todos os participantes quanto à qualidade da revisão.

Segundo Pressman [PRE00], os objetivos das revisões técnicas formais são:

(1) Descobrir erros de função, lógica ou implementação em qualquer produto de software;

(2) Verificar se o software que se encontra sob revisão atende a seus requisitos;

(3) Garantir que o software tenha sido representado de acordo com padrões predefinidos;

(4) Obter um software que seja desenvolvido uniformemente;

(5) Tornar os projetos mais administráveis.

A seguir dá-se uma visão geral dos principais métodos de revisão técnica formal: inspeção, walkthrough e peer-review.

\subsection{1 - Métodos de revisão técnica formal}

Inicialmente, faz-se necessário no contexto deste trabalho a introdução da terminologia proposta por Porter, Votta e Basili [POR95]. Uma técnica é uma série de passos que requerem aplicação especializada produzindo algum efeito desejado. Um método é um procedimento de gerenciamento para aplicação das técnicas de software, especificando quais técnicas aplicar e em que condições. Uma tecnologia é um conjunto de técnicas e métodos, que é embutida em um modelo de ciclo de vida. Essa terminologia é importante para o entendimento dos diferentes termos utilizados ao longo deste texto.

\subsubsection{1 - Inspeção}

A inspeção é um método de revisão que realiza uma análise estática para avaliar, objetivamente, um produto de software, através da concentração da atenção para alguns aspectos selecionados, um de cada vez [FRE93]. As revisões técnicas formais desse tipo podem inspecionar tanto produtos de software (por exemplo: códigos e especificações de requisitos) como também podem ser utilizadas para inspecionar projetos de software. O diferencial para essas tarefas está na seleção dos aspectos a serem considerados durante a revisão.

A inspeção envolve a leitura, passo a passo, de um produto de software, cada passo sendo confrontado a uma lista de itens (checklist). Os itens incluem erros historicamente comuns, conformidade aos padrões de programação, e consistência com a especificação do programa [FRE93]. 
A inspeção de especificações de requisitos, por exemplo, tenta garantir em um plano mais geral, a completitude, consistência e precisão da especificação de requisitos e em um plano mais detalhado tenta descobrir problemas que possam estar ocultos no conteúdo da especificação de requisitos.

Uma equipe de inspeção consiste normalmente de 4 pessoas, sendo que uma delas deve atuar no papel de moderador. Espera-se que o moderador seja um projetista/programador competente, contudo, ele não pode ser o autor e não precisa estar familiarizado com os detalhes do produto que está sendo inspecionado. As funções do moderador durante a inspeção são: distribuir e organizar os materiais, conduzir a sessão, registrar todos os erros encontrados, e assegurar que os erros sejam subseqüentemente corrigidos. O moderador pode ser comparado a um engenheiro de controle de qualidade. Além do moderador a equipe de inspeção deve contar ainda com: programadores, projetistas, especialistas em testes e usuários.

Para se conduzir uma inspeção os seguintes passos devem ser seguidos: Primeiramente o moderador da equipe de revisão deve distribuir, no caso de um código, a listagem dos programas e a especificação do projeto para os outros participantes da revisão. É importante ressaltar que a distribuição dos documentos deve ocorrer dias antes da sessão de revisão, pois, somente assim, os revisores terão a possibilidade de se familiarizarem com os mesmos. Durante a inspeção ocorrem as seguintes atividades: (1) É solicitado ao programador que narre, declaração por declaração, a lógica do programa. Durante a narração, perguntas são levantadas e questionamentos realizados para determinar se existem erros. Experiências têm mostrado que muitos erros descobertos são realmente encontrados pelo programador durante a narração. $\mathrm{O}$ simples fato de ler em voz alta para uma platéia mostra que a leitura pode ser uma técnica efetiva de detecção de erros; (2) O programa é analisado com base em um checklist de erros de programação historicamente comuns. É função do moderador garantir que os participantes concentrem-se em encontrar erros e não em corrigi-los [MYE79].

Após o término da sessão de revisão, as correções necessárias devem ser realizadas e se necessário for o moderador deve, em casos especiais, inspecionar novamente o programa após os problemas terem sido corrigidos. A lista dos erros encontrados é analisada, categorizada, e usada para refinar o checklist de erros de programação historicamente comuns, melhorando a efetividade de futuras inspeções [PRE00].

Para que o processo de inspeção seja efetivo é necessário que atitudes apropriadas sejam estabelecidas, como por exemplo, se o programador encarar a inspeção como um ataque pessoal ao seu trabalho e adotar uma postura defensiva, o processo de inspeção não será efetivo. $\mathrm{O}$ programador deve entender o processo como positivo e altamente construtivo, uma vez que o objetivo da inspeção é encontrar erros no programa e não nos componentes da equipe [MYE79]. 


\subsubsection{2 - Walkthrough}

O termo walkthrough tem sido utilizado na literatura como sinônimo para qualquer tipo de revisão técnica formal e principalmente, para aquelas caracterizadas pela presença de um produtor do material revisado e sua orientação durante a condução da revisão. Basicamente, o processo de walkthrough é realizado com base numa execução, passo a passo, de um procedimento, como quando percorremos um código, linha a linha, com um conjunto fíctício de dados de entrada. Pode-se utilizar walkthrough para revisar código fonte e especificação de requisitos [FRE93].

Walkthrough é um método de revisão formal baseada na leitura de um produto de software (ex., especificação de requisitos ou código) em um ambiente de reunião formal com regras específicas de avaliação [FRE93].

O procedimento inicial para condução de um walkthrough é similar ao procedimento para condução de uma inspeção. A diferença principal está na maneira com que a sessão é conduzida. Em vez de simplesmente ler o programa ou checar erros por meio de um checklist os participantes simulam a execução do programa. A pessoa designada como testador vem para a sessão de revisão munida com um pequeno conjunto de casos de teste escritos em papel, representando um conjunto de entradas (e saídas esperadas) para o programa ou módulos. Durante a sessão, os casos de teste são utilizados para simular uma execução do programa, os valores das variáveis do programa são monitorados e vão sendo anotados em papel. Os casos de testes servem para questionar o programador sobre sua lógica de programação e suas suposições. Na maioria dos walkthroughs, mais erros são encontrados durante o processo de questionamento do programador do que os encontrados diretamente pelos casos de testes [MYE79].

Uma sessão de revisão do tipo walkthrough não deve ser interrompida e deve ter duração de 1 a 2 horas. Essas restrições também são aplicadas às revisões do tipo inspeção. A equipe de walkthrough consiste de 3 a 5 pessoas. Uma das pessoas da equipe deve assumir o papel do moderador que é similar ao moderador do processo de inspeção e outra pessoa deve assumir o papel de secretário da sessão de revisão, nesse caso, a função do secretário e registrar todos os erros que forem encontrados durante a revisão. Uma terceira pessoa deve assumir o papel de testador. Entre os outros participantes de um walkthrough é importante destacar a presença de: um programador com grande experiência; um programador expert na linguagem de programação; um programador iniciante; uma pessoa que eventualmente irá dar manutenção no software; desenvolvedores de outros projetos; alguém da equipe de programadores.

O processo pós walkthrough é similar ao da inspeção e as considerações feitas com relação à efetividade também são válidas. 


\subsubsection{3 - Peer-Review}

Peer-Review é mais uma técnica de revisão formal de um produto de software (código) conduzida pelos pares de programadores. A finalidade de um Peer-Review é conseguir uma exposição do produto de software e obter os benefícios provenientes de pontos de vista divergentes. Este tipo de revisão pelos pares, entretanto, não é uma crítica ao trabalho alheio, em outras palavras, o propósito do Peer-Review é ajudar o programador, que no caso está com seu material sendo revisado, a marcar/levantar os problemas. Não se deve incluir a participação de líderes de projeto e gerenciamento na condução da revisão. Um Peer-Review deve ser um tipo não ameaçador de revisão, mesmo que seja conduzido com algum formalismo [BEI84].

Os grupos de Peer-Review devem ser formados por programadores de diferentes projetos e organizados em pares, é importante que os revisores tenham o mesmo nível de conhecimento. Um líder é essencial para manter uma linha de conduta durante o processo de revisão; prevenir disputas pessoais; evitar desperdícios de tempo em detalhes desnecessários; julgar diferenças honestas de opiniões e estilos; e manter o objetivo principal da revisão que é encontrar problemas de qualidade. Os resultados obtidos durante as reuniões são publicados em um relatório informal, esse relatório é para benefício dos revisores e não deve fazer parte da documentação oficial do projeto [BEI84].

Após a realização da revisão, o grupo de revisores confirma por meio de um checklist que todos os problemas levantados durante as reuniões anteriores tenham sido corrigidos ou então propriamente eliminados. Normalmente os programas podem ser revisados num prazo de 1 a 2 horas. Em cada sessão de revisão, somente um programa ou parte dele (rotinas) deve ser revisado [BEI84].

\subsection{2 - Técnicas de Leitura}

As técnicas de leituras são definidas como um conjunto concreto de instruções que são dadas ao leitor de como ler e o que olhar em um produto de software. Leitura de software é uma análise individual de um produto textual de software (ex., especificação de requisitos, projeto, código, plano de testes) para se alcançar o entendimento necessário para realizar uma particular tarefa, como, por exemplo, detectar defeitos [BAS96a].

A leitura é considerada uma atividade técnica chave para verificação e validação dos produtos de software gerados durante o processo de engenharia de software [BAS96a]. As técnicas de leitura estão embutidas em métodos de revisão de software como, por exemplo, Inspeção. 


\subsubsection{Técnica de Leitura Stepwise Abstraction}

A técnica stepwise abstraction é uma técnica de leitura utilizada para detectar defeitos em código fonte. Segundo Linger [LIN79], a técnica consiste em desenvolver abstrações funcionais, a partir do código fonte, para determinar a funcionalidade do programa. Revisores são instruídos a lerem o código fonte e escreverem suas próprias especificações para o programa. Os revisores identificam subprogramas no código fonte e escrevem suas próprias especificações para esses subprogramas, ou seja, realizam abstrações de funcionalidade. As abstrações construídas para os subprogramas devem ser combinadas, repetidamente, em uma abstração mais geral, até que se tenha capturado a função completa do programa. Inconsistências são detectadas por meio da comparação da especificação original com a especificação construída por meio das abstrações. A Figura 2.1 apresenta um exemplo da aplicação da técnica stepwise abstraction em um código fonte.

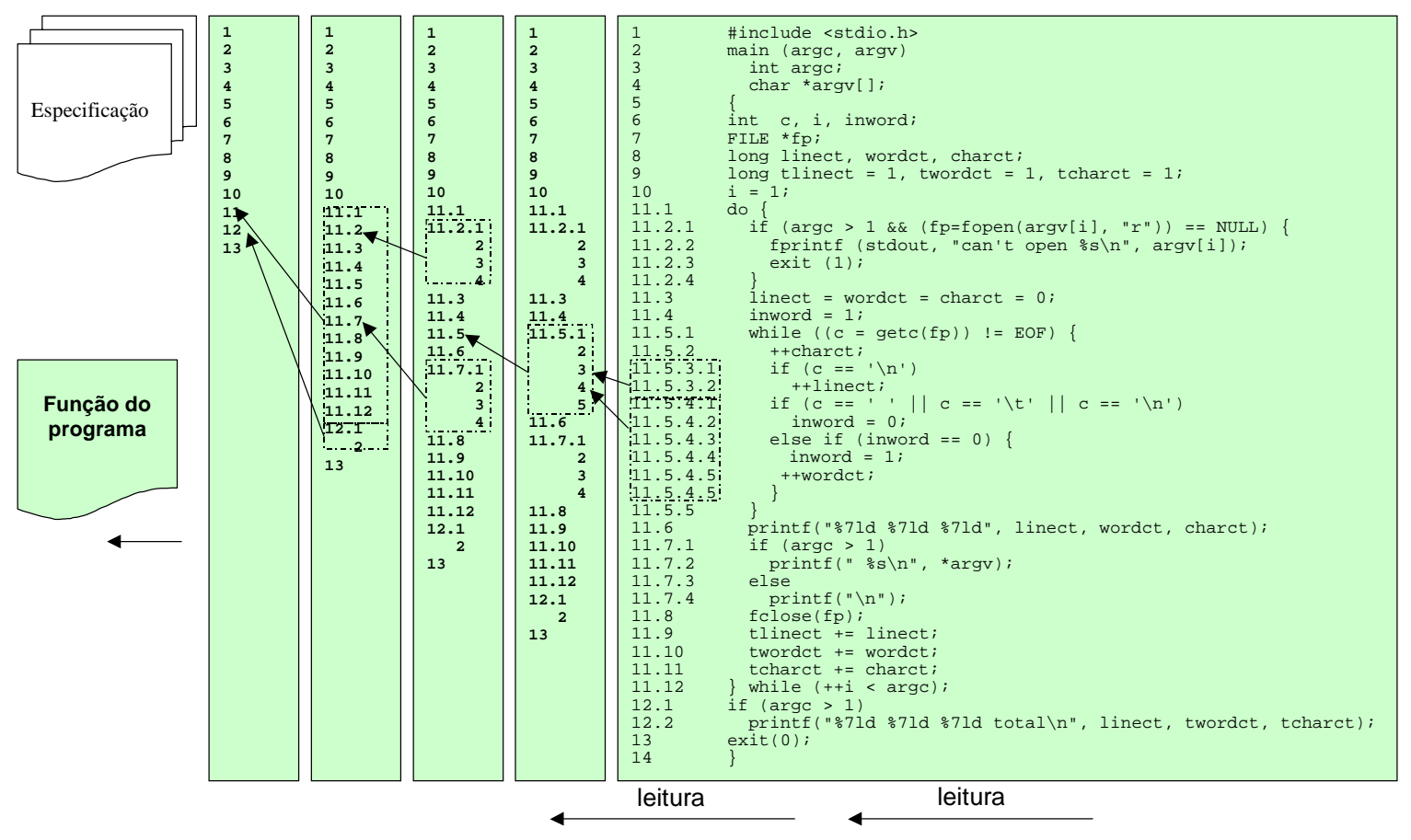

Figura 2.1 - Exemplo da aplicação da técnica stepwise abstraction. 


\subsubsection{Técnica de Leitura Perspective Based Reading}

A Perspective Based Reading (PBR) é uma técnica de leitura proposta por Basili [BAS96a] com a finalidade de detectar defeitos em especificações de requisitos. A motivação para introdução dessa técnica está relacionada diretamente com as responsabilidades de revisão atribuídas aos indivíduos, ou seja, as técnicas de leitura normalmente não definem responsabilidades específicas para cada revisores. Na tentativa de encontrar uma solução para o problema de responsabilidade Basili [BAS96a] apresenta a técnica PBR. A técnica requer um indivíduo para em um primeiro momento criar uma abstração de um produto de software e então responder questões baseadas na análise da abstração a partir de uma regra específica (a regra representa perspectivas diferentes, em outras palavras, pontos de vista diferentes) que o indivíduo assume. Um indivíduo pode revisar um documento de software da perspectiva do desenvolvedor, do testador e do usuário final do sistema. Para cada uma das perspectivas existe um cenário que é um conjunto de questões e atividades que dizem ao indivíduo o que ele deve fazer e como ele deve ler um documento. As questões e atividades habilitam o indivíduo a descobrir defeitos em um determinado produto de software.

A eficiência da técnica de leitura PBR é determinada pelos cenários. Um cenário descreve quais atividades que devem ser executadas pelo indivíduo enquanto ele estiver lendo um produto de software. Além das atividades, um cenário contém questões relacionadas às atividades que ajudam os indivíduos a descobrirem defeitos. Em resumo, um cenário é uma coleção de procedimentos que permitem operacionalizar estratégias para detectar defeitos [BAS98].

Uma questão fundamental é como gerar bons cenários? Segundo Basili [BAS98], existem várias razões que dificultam a geração dos cenários, são elas:

- Existem vários níveis de abstração em um documento de especificação;

- Não existe um padrão para documentos de especificação. Um documento de especificação de requisitos pode conter: breve esboço, definições de I/O, requisitos funcionais, funções dos algoritmos e outros aspectos que são importantes para o sistema;

- Vários diferentes métodos e técnicas podem ser utilizados dentro de cada perspectiva

O ponto inicial para criação dos cenários utilizados no experimento de Basili et. al. [BAS96a] foi um modelo abstrato do processo de desenvolvimento de software. Cada perspectiva dentro desse processo foi caracterizada por um conjunto de atividades de alto nível, como por exemplo, "Gerar Casos de Teste" para os testadores. Para assegurar a possibilidade de 
encontrar todos os defeitos foi utilizado um esquema de classificação de defeitos que fornece questões para cada classe de defeito. O passo seguinte foi associar as questões para cada atividade de uma perspectiva a respeito dos resultados da atividade ou da própria atividade. Os cenários incluem questões que não são detalhadas em excesso, conseqüentemente, elas não descrevem como executar a atividade. A Figura 2.2 representa o esquema para geração do cenário da perspectiva do testador.

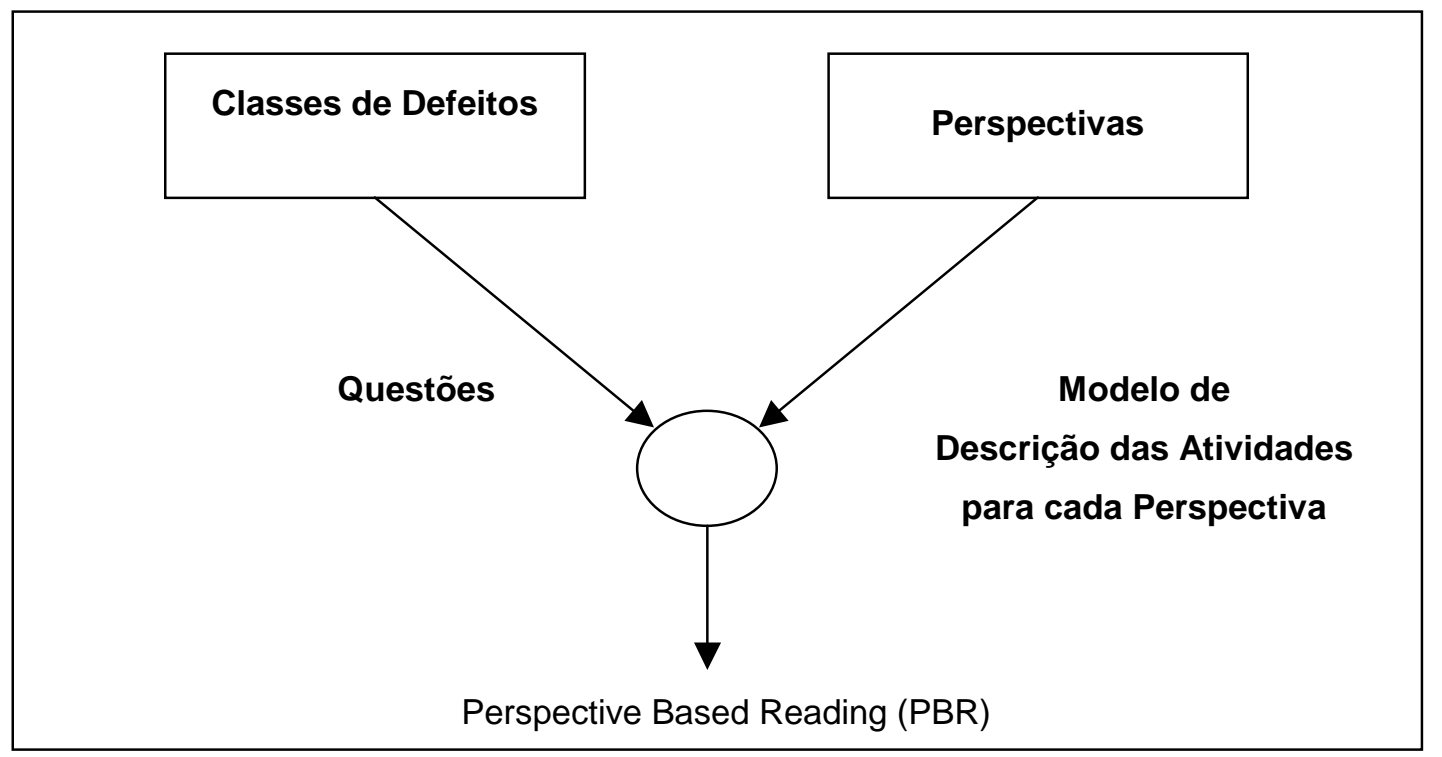

Figura 2.2 - Esquema para geração do cenário da perspectiva do testador [BAS98].

Tendo como base a perspectiva do testador, por exemplo, um indivíduo pode projetar um conjunto de testes para um plano de teste potencial, conduzindo-o a descobrir defeitos em uma determinada especificação de requisitos que poderiam ser encontrados no futuro pelo teste do produto final. De forma similar, tendo como base as perspectivas do desenvolvedor e do usuário, podem-se também gerar modelos físicos para análise baseada na perspectiva, como por exemplo: manual do usuário para a perspectiva baseada no usuário final e projeto de alto nível para perspectiva baseada no desenvolvedor.

A suposição é que a união das perspectivas oferece uma extensa cobertura do produto de software em análise, ainda mais que cada indivíduo é responsável por uma visão delimitada e focalizada do documento, o que deveria levar a uma análise mais profunda dos defeitos potenciais no produto de software em revisão [BAS96a].

A seguir, apresentam-se as perspectivas do desenvolvedor, testador e usuário, definidas e utilizadas no experimento de Basili et. al. [BAS96a]: 


\section{Perspectiva Baseada no Projeto}

Gerar um projeto do sistema a partir do qual o sistema possa ser implementado. Utilize sua abordagem e técnica padrão de projeto, e incorpore todos os objetos de dados, estruturas de dados e funções necessárias. Enquanto o projeto está sendo gerado faça a si mesmo as seguintes perguntas:

1. Todos os objetos necessários (dados, estruturas de dados, e funções) estão definidos?

2. Todas as interfaces estão especificadas e consistentes?

3. Todos os tipos de dados podem ser definidos (exemplo: precisão e unidade requerida estão especificadas)?

4. Toda informação necessária para fazer o projeto está disponível? Todas as condições envolvendo todos os objetos estão especificadas (exemplo: alguma especificação de requisitos/funcional está faltando)?

5. Existe algum ponto que não está claro para você sobre o que você deveria fazer porque a especificação de requisitos/funcional não está clara ou não está consistente?

6. A especificação de requisitos/funcional faz sentido a partir do que você conhece sobre a aplicação ou do que está especificado na descrição geral/introdução?

\section{Perspectiva Baseada no Teste}

Para cada especificação de requisitos/funcional, gerar um teste ou um conjunto de testes que permita a você assegurar que uma implementação do sistema satisfaz a especificação de requisitos/funcional. Utilize sua abordagem e técnica padrão de teste, e incorpore critério de teste no acompanhamento do teste. Enquanto os casos de testes estão sendo gerados faça a si mesmo as seguintes perguntas:

1. Você tem toda informação necessária para identificar o item que está sendo testado de acordo com o critério de teste? Você pode gerar um caso de teste razoável para cada item baseado no critério?

2. Você pode assegurar que os testes gerados produzirão os valores corretos nas unidades corretas? 
3. Existem outras interpretações desta especificação de requisitos/funcional que o implementador pode fazer, baseado na forma que a especificação está definida?

4. Há outro requisito funcional para o qual você deveria gerar um caso de teste similar, mas que obteria um resultado contraditório?

5. A especificação de requisitos/funcional faz sentido a partir do que você conhece sobre a aplicação ou do que está especificado na descrição geral/introdução?

\section{Perspectiva Baseada no Uso}

Defina o conjunto de funções que um usuário do sistema deveria estar apto a executar. Defina um conjunto de objetos de entrada necessários para executar cada função, e o conjunto de objetos de saída que são gerados por cada função. Isto pode ser visto como escrever todos os cenários operacionais ou subconjuntos de cenários operacionais que o sistema deveria executar. Inicie com os cenários mais convencionais e prossiga para os cenários menos comuns ou condições especiais. Enquanto os cenários estão sendo gerados faça a si mesmo as seguintes perguntas:

1. Todas as funções necessárias para escrever o cenário operacional estão especificadas na especificação de requisitos/funcional (exemplo: todas as capacidades listadas na descrição geral estão especificadas)?

2. Todas as condições iniciais para começar um cenário operacional estão claras e corretas?

3. As interfaces entre as funções estão bem definidas e compatíveis (exemplo: fazer as entradas de uma função link para as saídas da função anterior)?

4. Você pode entrar em um estado do sistema que deve ser evitado (exemplo: por razões de cuidado e segurança)?

5. Alguma porção de um cenário operacional pode dar uma resposta diferente dependendo de como uma especificação de requisitos/funcional é interpretada?

6. A especificação de requisitos/funcional faz sentido a partir do que você conhece sobre a aplicação ou do que está especificado na descrição geral/introdução?

Essas questões formam a base para a abordagem que o indivíduo irá utilizar para fazer a revisão dos produtos de software. 


\section{3 - A Atividade de Teste}

O processo de desenvolvimento de software envolve uma série de atividades nas quais, apesar das técnicas, métodos e ferramentas empregadas, erros no produto ainda podem ocorrer. Assim, a atividade de teste é de fundamental importância para a identificação e eliminação de erros que persistem, representando a última revisão da especificação, projeto e codificação [MAL91a].

A realização dos testes é composta basicamente das seguintes etapas: projeto e construção dos casos de teste, execução do programa $\mathrm{P}$ com os casos de teste e análise do comportamento de $\mathrm{P}$ a fim de determinar se o mesmo está correto ou não. Esse procedimento é repetido até que o testador tenha confiança de que $\mathrm{P}$ comporta-se conforme o esperado com o mínimo de erros possível.

Os testes podem ser conduzidos em três níveis [PRE00]:

Teste de unidade: concentra esforços na menor unidade do projeto de software (módulo), ou seja, procura identificar erros de lógica e de implementação em cada módulo do software separadamente;

Teste de integração: é uma técnica sistemática para a construção da estrutura de programa, realizando-se, ao mesmo tempo, teste para descobrir erros associados às interfaces. $\mathrm{O}$ objetivo é, a partir dos módulos testados no nível de unidade, construir a estrutura de programa, que foi determinada pelo projeto;

Teste de sistema: é na verdade uma série de diferentes testes cujo objetivo é verificar se todos os elementos do sistema foram adequadamente integrados e realizam as funções atribuídas.

Em geral, não se consegue, por meio de testes, provar que um programa está correto; portanto, testar contribui no sentido de aumentar a confiança de que o software executa corretamente as funções especificadas. Apesar das limitações próprias da atividade de teste, sua aplicação de maneira sistemática e bem planejada pode garantir ao software algumas características mínimas que são importantes tanto para o estabelecimento da qualidade do produto quanto para o seu processo de evolução [DEL93].

\subsection{1 - Técnicas de Teste de Software}

Entre as várias técnicas propostas para conduzir e avaliar a qualidade da atividade de teste encontram-se as técnicas de teste funcional, estrutural e baseada em erros. Tais técnicas se 
diferenciam pela origem da informação utilizada na avaliação e construção dos conjuntos de casos de teste [MAL91a].

Na técnica funcional utiliza-se a especificação para derivar os requisitos de teste; na técnica estrutural os requisitos são derivados a partir dos aspectos de implementação do software; e na técnica baseada em erros os elementos requeridos para caracterizar a atividade de teste são baseados nos erros mais comuns que o programador pode cometer durante o desenvolvimento do software.

Deve-se notar que nenhuma das técnicas de teste é completa, visto que, em geral, nenhuma delas é suficiente para garantir a qualidade da atividade de teste. Na realidade, essas diferentes técnicas complementam-se e devem ser aplicadas em conjunto a fim de assegurar um teste de boa qualidade [PRE00].

A seguir dá-se uma visão geral das principais técnicas de teste: Funcional, Estrutural e Baseada em Erros. Os aspectos teóricos das próximas seções foram extraídos e sintetizados de Maldonado [MAL98].

\subsubsection{1 - Técnica Funcional}

O teste funcional também é conhecido como teste caixa preta pelo fato de tratar o software como uma caixa cujo conteúdo é desconhecido e da qual só é possível visualizar o lado externo, ou seja, os dados de entrada fornecidos e as respostas produzidas como saída. Na técnica de teste funcional são verificadas as funções do sistema sem se preocupar com os detalhes de implementação.

O teste funcional envolve dois passos principais: $1^{\circ}$ ) identificar as funções que o software deve realizar e; $2^{\circ}$ ) criar casos de teste capazes de checar se essas funções estão sendo realizadas pelo software. As funções que o software possui são identificadas a partir de sua especificação. Assim, uma especificação correta e de acordo com os requisitos do usuário é essencial para esse tipo de teste.

Alguns exemplos de critérios de teste funcional são:

- Particionamento em Classes de Equivalência: divide o domínio de entrada de um programa em classes de dados que provavelmente exercitarão uma função de software específica. O objetivo é minimizar o número de casos de teste, obtendo-se somente aqueles considerados essenciais, ou seja, que possuam alta probabilidade de revelar a presença de erros existentes no programa; 
- Análise do Valor Limite: é um complemento ao critério Particionamento em Classes de Equivalência, no qual procura testar os limites de cada classe. Ao invés de selecionar qualquer elemento de uma classe, os casos de teste são escolhidos nas fronteiras das classes, pois nesses pontos se concentra um grande número de erros. Além disso, o espaço de saída do programa também é particionado e são exigidos casos de teste que produzam resultados nos limites dessas classes de saída;

- Grafo de Causa-Efeito: possibilita que o testador valide conjuntos complexos de condições e ações. Primeiramente, são levantadas as possíveis condições de entrada (causas) e as possíveis ações (efeitos) do programa. A seguir é construído um grafo relacionando as causas e efeitos levantados. Esse grafo é convertido em uma tabela de decisão a partir da qual são derivados os casos de teste.

Um problema relacionado aos critérios de teste funcional é a dificuldade de quantificar a atividade de teste, visto que não se pode garantir que partes essenciais ou críticas do programa sejam executadas. Outro problema é o que o teste caixa preta está sujeito às inconsistências decorrentes da especificação, pois é ela a base a partir da qual são derivados os casos de teste.

\subsubsection{2 - Técnica Estrutural}

O teste estrutural também é conhecido como teste caixa branca (em oposição ao nome caixa preta), no qual os aspectos de implementação são fundamentais na escolha dos casos de teste. $\mathrm{O}$ teste estrutural baseia-se no conhecimento da estrutura interna da implementação. Em geral, a maioria dos critérios dessa técnica utiliza uma representação de programa conhecida como grafo de fluxo de controle ou grafo de programa. Um grafo de fluxo de controle é um grafo orientado, com um único nó de entrada e um único nó de saída, no qual cada vértice representa um bloco de comandos que são sempre executados seqüencialmente, e cada aresta representa uma transferência de controle entre esses blocos. Por meio do grafo de programa podem ser escolhidos os componentes que devem ser executados, caracterizando assim o teste estrutural.

Os critérios de teste estrutural baseiam-se em diferentes tipos de estruturas para determinar quais partes do programa têm sua execução requerida.

Alguns exemplos de critérios de teste estrutural são:

- Critérios Baseados em Fluxo de Dados: utilizam informações de fluxo de dados do programa para determinar os requisitos de teste. Esses critérios exploram as interações que envolvem definições de variáveis e referências a tais definições. Exemplos dessa classe de 
critérios são os Critérios de Rapps e Weyuker [RAP82, RAP85] e os Critérios PotenciaisUsos [MAL91].

- Critérios Baseados em Fluxo de Controle: utilizam apenas características de controle da execução do programa, como comandos ou desvios, para determinar quais estruturas são necessárias. Os critérios mais conhecidos dessa classe são Todos-Nós (exige que a execução do programa passe, ao menos uma vez, em cada vértice do grafo de fluxo, ou seja, que cada comando do programa seja executado pelo menos uma vez), Todos-Arcos (requer que cada aresta do grafo, ou seja, cada desvio do programa, seja exercitado pelo menos uma vez) e Todos-Caminhos (requer que todos os caminhos possíveis do programa sejam executados).

- Critérios Baseados na Complexidade: utilizam informações sobre a complexidade do programa para derivar os requisitos de teste. Um critério bastante conhecido dessa classe é o Critério de McCabe, que utiliza a complexidade ciclomática para derivar os requisitos de teste. Essencialmente, esse critério requer que um conjunto linearmente independente de caminhos do grafo de programa seja executado.

Os casos de testes obtidos durante a aplicação dos critérios funcionais podem corresponder ao conjunto inicial dos testes estruturais. Como, em geral, esse conjunto não é suficiente para satisfazer totalmente um critério estrutural, novos casos de teste são gerados a adicionados ao conjunto até que se atinja o grau de satisfação desejado, explorando-se, desse modo, os aspectos complementares das duas técnicas [SOU96].

Um problema relacionado ao teste estrutural é a impossibilidade de determinar automaticamente se um caminho é ou não executável, ou seja, não existe algoritmo que dado um caminho completo qualquer, forneça o conjunto de valores que causam a execução desse caminho. Assim, é preciso intervenção do testador para determinar quais são os caminhos não executáveis para o programa que está sendo testado.

A ferramenta Poke-Tool (Potential Uses Criteria Tool for Program Testing), desenvolvida na Faculdade de Engenharia Elétrica da Universidade Estadual de Campinas UNICAMP, apóia a aplicação dos critérios Potenciais-Usos e também de outros critérios estruturais como Todos-Nós e Todos-Arcos [MAL98, CHA91]. Essa ferramenta foi utilizada durante a replicação do experimento baseado em códigos fontes.

\subsubsection{3 - Técnica Baseada em Erros}

A técnica de teste baseada em erros utiliza informações sobre os tipos de erros mais freqüentes no processo de desenvolvimento de software para derivar os requisitos de teste. A 
ênfase da técnica está nos erros que o programador pode cometer durante o desenvolvimento e nas abordagens que podem ser usadas para detectar a sua ocorrência. Semeadura de Erros (Error Seeding) e Análise de Mutantes (Mutation Analysis) são critérios típicos técnica baseada em erros [MAL98].

A Análise de Mutantes utiliza um conjunto de programas ligeiramente modificados (mutantes) obtidos a partir de determinado programa $\mathrm{P}$ para avaliar o quanto um conjunto de casos de teste T é adequado para o teste de P. O objetivo é encontrar um conjunto de casos de teste que consiga revelar, por meio da execução de $\mathrm{P}$, as diferenças de comportamento existentes entre P e seus mutantes [MAL98].

Duas variantes do critério Análise de Mutantes são a Mutação Fraca (WeakMutation) e a Mutação Forte (Firm Mutation)]. A idéia básica da Mutação Fraca e da Mutação Forte é a mesma: é feita uma pequena mudança no programa e os resultados da versão original são comparados com os da versão modificada. A diferença é que na Mutação Fraca um mutante é criado imediatamente antes da execução de um componente (um componente corresponde a estruturas computacionais elementares tais como: referência a uma variável, expressão aritmética, expressão booleana ou relação entre expressões aritméticas) e os resultados são comparados logo após sua execução, enquanto que na Mutação Forte os mutantes são gerados antes do início da execução do programa e a comparação dos resultados acontece depois que a execução se completa. Nesse caso, pode-se pensar no programa como sendo um "componente de tamanho maior". Uma solução intermediária entre esses dois extremos - a Mutação Firme realiza uma modificação no programa e compara os estados do programa original e do programa mutante em mais de um ponto, antes do final da execução [MAL98].

Uma visão geral do critério Análise de Mutantes, com seus principais conceitos, vantagens e limitações, é dada seguir.

\section{O Critério Análise de Mutantes}

O critério Análise de Mutantes surgiu na década de 70 na YALE University e Georgia Institute of Technology, possuindo um forte relacionamento com um método clássico para detecção de erros lógicos em circuitos digitais - o modelo de teste de falha única.

Um dos primeiros artigos que descrevem a idéia de teste de mutantes foi publicado em 1978 [DEM78]. A idéia básica da técnica apresentada por DeMillo, conhecida como hipótese do programador competente, assume que programadores experientes escrevem programas muito próximos do correto. Assumindo a validade dessa hipótese, pode-se afirmar que erros são introduzidos nos programas por meio de pequenos desvios sintáticos que, embora não causem 
erros sintáticos, alteram a semântica do programa e, conseqüentemente, conduzem o programa a um comportamento incorreto. Para revelar tais erros, a Análise de Mutantes identifica os desvios sintáticos mais comuns e, através da aplicação de pequenas transformações sobre o programa em teste, encoraja o testador a construir casos de teste que mostrem que tais transformações levam a um programa incorreto [MAL98].

Uma outra hipótese explorada na aplicação do critério Análise de Mutantes é o efeito de acoplamento (coupling effect), a qual assume que erros complexos estão relacionados a erros simples. Assim sendo, espera-se, e alguns estudos empíricos já confirmaram essa hipótese [ACR79, BUD80], que conjuntos de casos de teste capazes de revelar erros simples são também capazes de revelar erros complexos. Nesse sentido, aplica-se uma mutação de cada vez no programa $\mathrm{P}$ em teste, ou seja, cada mutante contém apenas uma transformação sintática [MAL98].

Partindo-se da hipótese do programador competente e do efeito de acoplamento, a Análise de Mutantes pode ser descrita da seguinte maneira:

A princípio, o testador deve fornecer um programa $\mathrm{P}$ a ser testado e um conjunto de casos de teste $\mathrm{T}$ cuja adequação se deseja avaliar. O programa é executado sobre $\mathrm{T}$ e, se apresentar resultados incorretos, então um erro foi encontrado e o teste termina. Caso contrário, o programa ainda pode conter erros que o conjunto $\mathrm{T}$ não conseguiu revelar. $\mathrm{O}$ programa $\mathrm{P}$ sofre então pequenas alterações, dando origem aos programas $\mathrm{P}_{1}, \mathrm{P}_{2} \ldots \mathrm{P}_{\mathrm{n}}$, que são mutantes de $\mathrm{P}$, diferindo deste apenas ocorrência de erros simples, ou seja, cada mutante contém apenas uma mutação.

Posteriormente, os mutantes são executados com o mesmo conjunto de casos de teste T. Conseguindo-se obter casos de teste que resultem apenas em mutantes mortos e equivalentes, tem-se um conjunto de casos de teste $\mathrm{T}$ adequado ao programa $\mathrm{P}$ em teste, no sentido de que, ou P está correto, ou possui erros pouco prováveis de ocorrerem.

A Análise de Mutantes fornece uma medida objetiva do nível de confiança da adequação dos casos de teste analisados através da definição de um escore de mutação, que relaciona o número de mutantes gerados com o número de mutantes mortos [MAL98].

O escore de mutação é calculado da seguinte forma:

$$
m s(P, T)=\frac{D M(P, T)}{M(P)-E M(P)}
$$


Onde:

$\mathrm{DM}(\mathrm{P}, \mathrm{T})$ : Total de mutantes mortos pelo conjunto de casos de teste $\mathrm{T}$;

$\mathrm{M}(\mathrm{P})$ : Total de mutantes gerados a partir do programa $\mathrm{P}$;

$\mathrm{EM}(\mathrm{P})$ : Total de mutantes equivalentes ao programa $\mathrm{P}$;

O escore de mutação varia no intervalo [0,1] na qual, quanto maior o escore mais adequado é o conjunto de casos de teste para o programa que está sendo testado. Percebe-se com essa fórmula que apenas DM (P,T) depende do conjunto de teste utilizado e que, EM(P) é obtido à medida que o testador decide que determinado mutante vivo é equivalente [SOU96].

\section{Passos da Análise de Mutantes}

Basicamente, dados um programa $\mathrm{P}$ e um conjunto de casos de teste $\mathrm{T}$ cuja qualidade deseja-se avaliar, pode-se aplicar o critério Análise de Mutantes por meio dos seguintes passos [VIN98]:

\section{ExecuÇão do Programa}

Nesse passo deve-se executar o programa original $\mathrm{P}$ para os casos de teste selecionados e verificar se o resultado é o esperado. Caso o programa apresente um comportamento diferente para algum caso de teste, então um erro foi descoberto e o processo termina. Caso nenhum dos testes revele erro, o teste continua no passo seguinte. Decidir se o resultado está correto ou não, isto é realizar a tarefa do oráculo, é geralmente desempenhada pelo testador [VIN98].

\section{GERAÇÃo DE MUTANTES}

Os mutantes são gerados por meio da aplicação de operadores de mutação no programa $P$ que está sendo testado. Os operadores de mutação são as regras que definem as alterações que devem ser aplicadas no programa original P. A aplicação de um operador de mutação gera, na maioria das vezes, mais que um mutante, pois como $\mathrm{P}$ pode conter várias entidades que estão no domínio de um operador, então esse operador é aplicado a cada uma dessas entidades, uma de cada vez.

O critério para escolha do conjunto de operadores de mutação depende dos erros que se quer revelar, da cobertura que se quer garantir, da linguagem de programação na qual os programas a serem testados foram escritos e do sistema de mutação. 
A Figura 2.3 (a) apresenta um programa que calcula o fatorial de um número inteiro positivo e Figura 2.3 (b) ilustra um mutante desse programa obtido por meio da aplicação de um operador de mutação.

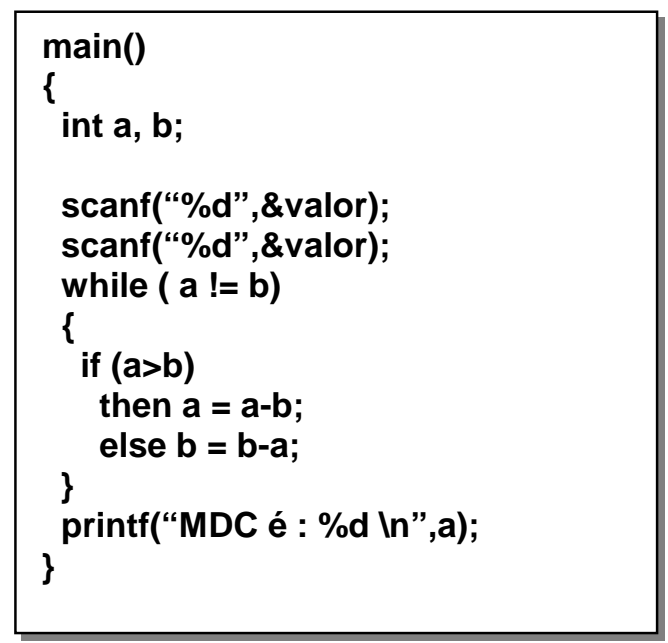

(a)

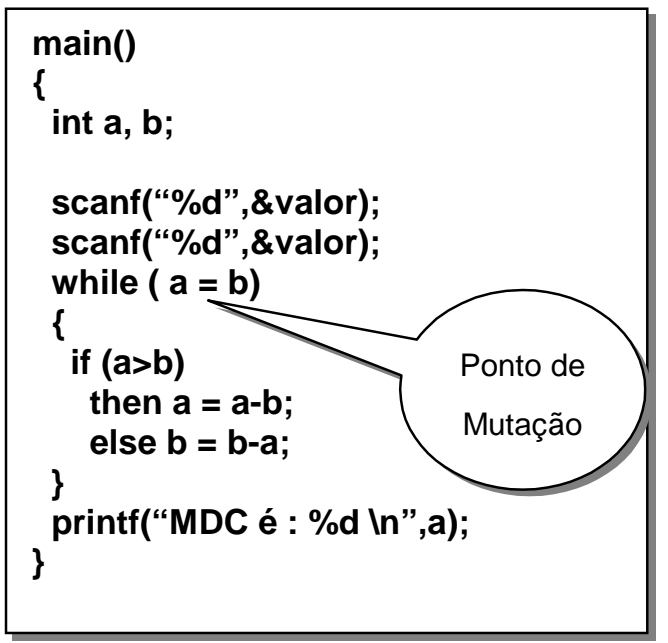

(b)

Figura 2.3 - (a) Exemplo de um código fonte de um programa; (b) Exemplo de um código fonte com uma alteração sintática.

\section{EXECUÇÃo DOS MUTANTES}

Esse passo pode ser totalmente automatizado, não requerendo intervenção humana. $\mathrm{O}$ conjunto de casos de teste $\mathrm{T}$ é aplicado a cada mutante $\mathrm{P}_{\mathrm{i}} \mathrm{e}$ os resultados obtidos são comparados com o resultado de $\mathrm{P}$. Se os resultados forem iguais, $\mathrm{P}_{\mathrm{i}}$ continua vivo. Isso pode ocorrer ou porque $\mathrm{P}$ e $\mathrm{P}_{\mathrm{i}}$ são equivalentes; ou porque o conjunto de casos de teste utilizado não é adequado o suficiente para distinguir o comportamento de $\mathrm{P}$ e $\mathrm{P}_{\mathrm{i}}$. Caso contrário, se os resultados forem diferentes, $P_{i}$ é dito estar morto e pode ser descartado [VIN98]. Finalizada a execução dos mutantes pode-se calcular o escore de mutação, o qual servirá como um indicativo da qualidade do conjunto de casos de teste utilizado.

\section{ANÁlise dos Mutantes Vivos}

Esta é a fase da Análise de Mutantes que requer mais intervenção humana. Primeiramente, é necessário analisar os mutantes que sobreviveram à execução com os casos de teste disponíveis e decidir se tais mutantes são equivalentes ou não ao programa original. Se o mutante for equivalente ao programa original, ele deve ser descartado. Caso contrário, o conjunto de casos de teste não foi capaz de diferenciá-lo do programa original, faz-se necessário então a inclusão de novos casos de teste ao conjunto. Desse modo, o processo deve retornar ao segundo passo do critério, executar $\mathrm{P}$ com os novos casos de teste, executar os mutantes, 
recalcular o escore de mutação e assim por diante, até que se consiga um conjunto $\mathrm{T}$ adequado [VIN98].

Vale ressaltar que, em geral, a equivalência entre programas é uma questão indecidível. Deve-se salientar que o procedimento descrito acima exige, além da execução do programa sendo testado, que algumas tarefas sejam realizadas automaticamente. Tarefas como geração e execução de mutantes e comparação dos resultados obtidos demandam grande esforço de processamento, sendo praticamente impossível executá-las de modo eficiente e preciso sem o auxilio do computador. Assim, faz-se necessária à utilização de ferramentas que automatizem a aplicação do critério [VIN98].

A ferramenta Proteum [DEL93], desenvolvida no ICMC-USP, é a única ferramenta que apóia o teste de mutação para programas escritos na linguagem C. Essa ferramenta foi utilizada durante a replicação do experimento baseado em códigos fontes.

\subsection{Considerações Finais}

Neste capítulo foi apresentada uma visão geral da atividade de teste e da atividade de revisão. A Seção 2.2 apresentou os conceitos básicos relacionados à atividade de revisão, bem como, seus principais métodos e técnicas. A atividade de revisão é de extrema importância durante o processo de software, uma vez que, erros humanos são inseridos e embora as pessoas sejam capazes de identificar seus próprios erros, existem classes de erros que não são identificadas. Revisão é uma das atividades de garantia de qualidade de software disponível logo nas fases iniciais do processo de software.

Em seguida, na Seção 2.3, foram apresentados os conceitos básicos relacionados à atividade de teste, bem como, as fases necessárias para sua condução e as técnicas e critérios de teste mais utilizados. Dentre as atividades de garantia de qualidade de software a atividade de teste é uma das mais utilizadas porque erros ainda persistem nos produtos gerados durante o processo de software, e pode ser vista como a última revisão da especificação, projeto e codificação. No entanto, a atividade de teste é considerada uma das mais onerosas para garantia de qualidade de software.

Em determinadas circunstâncias tem-se observado que as atividades de revisão têm um custo benefício melhor que as atividades de teste. Desta forma, o Capítulo 3 apresenta os principais estudos comparativos conduzidos durante as últimas décadas com objetivo de avaliar a efetividade e eficiência das técnicas de teste e revisão. 


\section{CAPÍTULO 3}

\section{Estudos Empíricos em Engenharia de}

\section{Software: VV\&T}

\subsection{Considerações Iniciais}

Estudos empíricos são motivados pela premente necessidade de se saber avaliar as tecnologias que surgem a cada momento, para construir uma base sólida de informações a fim de contribuir para evolução dessas tecnologias e da área de computação como um todo. Avaliar o custo/benefício das técnicas de VV\&T tem sido uma preocupação constante dos pesquisadores. Isso se deve ao fato do custo associado a cada atividade. Assim este trabalho está direcionado a estudos empíricos na área de VV\&T.

Durante as últimas décadas, várias pesquisas vêm sendo realizadas com o objetivo de avaliar isoladamente o custo/benefício das técnicas de teste e revisão, bem como investigar os aspectos complementares das técnicas [BAR98a, BAR98b, BAS81, BAS86, BAS87, BAS96a, BAS96b, BAS96c, BAS98, BOC94, COW88, FUS97, HET72, HET76, KAM95, MEY78, POR95, SEL87, SOU96, SOV96, VIN98, WOO97, ZEL97].

Como mencionado anteriormente, este trabalho aborda a replicação de experimentos controlados que objetivam comparar técnicas de detecção de defeitos com relação à efetividade e eficiência em observar inconsistências/falhas e isolar defeitos, bem como, analisar os aspectos complementares das técnicas. O termo efetividade é definido como o percentual do total possível de inconsistências/falhas observadas ou defeitos isolados, enquanto que o termo eficiência é definido como o percentual do total possível de inconsistências/falhas observadas ou defeitos isolados dividido pelo tempo gasto na observação e no isolamento. 
Neste capítulo, são apresentados os principais experimentos já realizados nessa perspectiva. Para cada experimento apresentam-se as seguintes informações: principais objetivos, projeto experimental, caracterização dos indivíduos, técnicas de detecção de defeitos utilizadas, artefatos de software utilizados, procedimentos experimentais, técnicas estatísticas utilizadas na análise dos dados e os principais resultados. Dessa forma, torna-se possível realizar comparações entre os resultados. Na Seção 3.2 são apresentados os experimentos baseados em códigos fontes e na Seção 3.3 um experimento baseado em documentos de especificação de requisitos. Na Seção 3.4 são apresentadas as considerações finais.

\subsection{Experimentos baseados em Códigos Fontes}

\subsubsection{Experimento Hetzel - 1976}

Hetzel executou um experimento controlado, ou seja, planejado, objetivando comparar três técnicas de detecção de defeitos, no que diz respeito à efetividade em revelar falhas. Indivíduos foram randômicamente divididos em três grupos: A, B e C, para então realizar a combinação das técnicas com os programas. Dessa forma, a ordem em que os indivíduos viram os programas e aplicaram as técnicas de detecção de defeitos foram randomizadas.

As técnicas utilizadas durante o experimento foram: Leitura de Código Disciplinada; Teste de Especificação e Teste Misto. Uma breve descrição das técnicas é apresentada a seguir:

- Leitura de Código Disciplinada: A partir do código fonte, uma especificação é desenvolvida caracterizando as estruturas de código de mais baixo nível (parágrafos), posteriormente, calcula-se o efeito do programa completo por meio da combinação das especificações desenvolvidas para cada parágrafo. A especificação desenvolvida é comparada com a especificação original com a intenção de revelar inconsistências.

- Teste de Especificação: Essa técnica utiliza somente a especificação para derivar os casos de teste, nenhum critério foi especificado. Defeitos são detectados comparando as saídas produzidas pelos casos de teste com a especificação original.

- Teste Misto: Essa técnica combina Teste de Especificação e Teste Estrutural. Indivíduos utilizam a especificação para derivar os casos de teste e são instruídos a alcançarem $100 \%$ de cobertura de todas as declarações do programa, ou seja, de todos comandos do programa. Defeitos são detectados comparando as saídas produzidas pelos casos de teste com a especificação original. 
Conforme pode ser observado na Tabela 3.1, o $1^{\circ}$ indivíduo, do grupo A, aplicou a técnica Leitura de Código Disciplinada (Disciplined Code Reading - DR) no programa 1 durante a $1^{\mathrm{a}}$ sessão, aplicou a técnica Teste Misto (Mixed Testing - MT) no programa 3 durante a $2^{\mathrm{a}}$ sessão, e aplicou a técnica Teste de Especificação (Specification Testing - ST) no programa 2 durante a $3^{\mathrm{a}}$ sessão.

Durante o experimento, foram utilizados três programas estruturados, escritos em PL/I, de 64, 164 e 170 declarações. Os programas continham defeitos que causavam 9, 15 e 25 diferentes tipos de falhas, respectivamente.

\begin{tabular}{|c|c|c|c|c|c|c|c|c|c|}
\hline \multirow{2}{*}{ Indivíduo } & \multicolumn{3}{|c|}{ Grupo A } & \multicolumn{3}{c|}{ Grupo B } & \multicolumn{3}{c|}{ Grupo C } \\
\cline { 2 - 11 } & $1^{\mathrm{a}}$ sessão & $2^{\mathrm{a}}$ sessão & $3^{\mathrm{a}}$ sessão & $1^{\mathrm{a}}$ sessão & $2^{\mathrm{a}}$ sessão & $3^{\mathrm{a}}$ sessão & $1^{\mathrm{a}}$ sessão & $2^{\mathrm{a}}$ sessão & $3^{\mathrm{a}}$ sessão \\
\hline 1 & DR 1 & MT 3 & ST 2 & DR 2 & MT 1 & ST 3 & ST 1 & MT 2 & DR 3 \\
\hline 2 & DR 1 & MT 3 & ST 2 & DR 2 & MT 1 & ST 3 & MT 2 & DR 3 & ST 1 \\
\hline$\cdot$ &. &. &. &. &. &. &. &. &. \\
\hline$\cdot$ &. &. &. &. &. &. &. &. &. \\
\hline 13 & ST 2 & DR 1 & MT 3 & MT 1 & ST 3 & DR 2 & DR 3 & ST 1 & MT 2 \\
\hline
\end{tabular}

Tabela 3.1 - Projeto experimental de Hetzel [HET76].

Os 39 indivíduos que participaram do experimento foram selecionados de acordo com a experiência com programação em PL/I. Em média, cada indivíduo tinha mais de 3 anos de experiência com programação em PL/I. O grupo foi formado por alunos de graduação e programadores inexperientes. Um importante prêmio monetário que variou de acordo com a performance de cada indivíduo (mínimo de U\$ 75 e no máximo U\$200) foi utilizado como fator de seleção e motivação.

A sessão de treinamento e as sessões experimentais foram executadas durante um período de seis dias. A sessão de treinamento foi constituída, basicamente, de uma introdução teórica às técnicas, uma apresentação das especificações, e uma visão geral das estruturas dos três programas utilizados no experimento. Um tempo limite (máximo 3h:30min ou 4h:30min dependendo do programa) foi estipulado para aplicação de cada técnica em cada programa.

Antes e durante a execução do experimento foram utilizados formulários específicos para coletar dados, tais como: experiência dos indivíduos; atitudes em relação às técnicas; falhas e defeitos encontrados durante a aplicação das técnicas, e; tempo gasto para encontrar as falhas e defeitos. 
Para analisar os dados foi utilizada estatística paramétrica (ANOVA). Os principais resultados obtidos pelo experimento de Hetzel estão sintetizados a seguir:

a) Nenhuma diferença significativa com relação à efetividade foi detectada entre as duas técnicas de teste. De qualquer forma, os dados mostraram que os indivíduos que aplicaram a Leitura de Código Disciplinada tiveram uma efetividade menor do que aqueles que aplicaram as técnicas de teste (nível de significância estatística < 0.01);

b) As diferenças atribuídas aos programas foram até maiores que as diferenças atribuídas às técnicas, sugerindo um forte efeito de seleção de produtos;

c) As medidas de efetividade obtidas pelos indivíduos correlacionaram-se bem (algumas com níveis de significância estatística < 0.01) com o número de cursos realizados pelos indivíduos na área de ciências da computação;

d) Os indivíduos observaram somente $50 \%$ das falhas possíveis.

\subsubsection{Experimento Myers - 1978}

Myers executou um experimento controlado, ou seja, planejado, objetivando comparar três técnicas de detecção de defeitos no que diz respeito à efetividade e eficiência em revelar falhas. Cada indivíduo foi observado somente uma vez. Foram definidos 3 grupos de indivíduos, levando em conta a experiência com programação em PL/I e o conhecimento das técnicas de walkthrough/inspection, conforme pode ser observado na Tabela 3.2.

\begin{tabular}{|c|c|c|}
\hline Grupo A & Grupo B & Grupo C \\
\hline Teste Funcional & Teste Estrutural & Walkthrough/Inspection \\
\hline \hline PL/I rating: 1,5 & PL/I rating: 2,1 & PL/I rating: 2,4 \\
\hline W/I rating: 0,2 & W/I rating: 0,3 & W/I rating: 0,6 \\
\hline
\end{tabular}

Tabela 3.2 - Projeto experimental de Myers [MYE78].

A experiência com programação em PL/I (PL/I rating) foi calculada usando uma escala ordinal (1 - nenhum conhecimento, 2 - conhecimento rudimentar, 3 - conhecimento avançado na linguagem) e o conhecimento das técnicas de walkthrough/inspection (W/I rating) foi calculado usando outra escala ordinal ( 0 - sem experiência, 1 - alguma experiência com as técnicas). Os valores apresentados na Tabela 3.2 são as médias de experiência dos grupos. 
Os indivíduos que participaram do experimento foram 59 programadores profissionais que participaram de um curso promovido para os funcionários da IBM. Porém, um número insuficiente de indivíduos com experiência com PL/I e walkthrough/inspection para permitir equilibrar os grupos com base nas taxas de experiência e conhecimento. $\mathrm{O}$ resultado foi que indivíduos aplicaram as técnicas com as quais eles tinham mais experiência. $\mathrm{O}$ grupo A e $\mathrm{B}$ contou com 16 indivíduos cada, já o grupo $\mathrm{C}$ foi dividido em 9 subgrupos de 3 indivíduos cada, totalizando 27 indivíduos.

As técnicas utilizadas durante o experimento foram: Teste Funcional (Functional Testing), Teste Estrutural (Structural Testing) e Walkthrough/Inspection Method. Uma breve descrição das técnicas é apresentada a seguir:

- Teste Funcional: Os indivíduos (Grupo A) têm acesso somente à especificação do programa e a uma versão executável para derivar os casos de teste e observar possíveis problemas. Nenhum critério para derivar os casos de teste foi especificado.

- Teste Estrutural: Os indivíduos (Grupo B) têm acesso à especificação e ao código fonte do programa para derivar os casos de teste e observar possíveis problemas. Nenhum critério para derivar e avaliar os casos de teste foi especificado.

- Walkthrough/Inspection Method: Os indivíduos (Grupo C) têm acesso ao programa e utilizando sua própria experiência $(A d H o c)$ observam possíveis inconsistências.

Um único programa escrito em PL/I de 63 declarações foi utilizado. O programa continha um total 15 defeitos.

Durante o experimento não houve uma fase específica de treinamento, embora, tenham acontecido sessões teóricas sobre teste de programa durante o curso. Os indivíduos que utilizaram as técnicas de teste foram instruídos a testar até acreditarem ter encontrado todas as falhas, sem restrição de tempo. Os indivíduos que executaram métodos de walkthrough/inspection levaram os documentos com eles, preparam seus próprios documentos e retornaram os tempos gastos. Da mesma forma que o experimento de Hetzel [HET76], antes e durante a execução do experimento foram utilizados formulários específicos para coletar dados.

Myers utilizou métodos estatísticos não paramétricos e teste de correlação (KruskalWallis) para analisar os resultados. Os principais resultados obtidos pelo experimento estão sintetizados a seguir: 
a) Os dados não mostram diferença significativa na efetividade das três técnicas. Porém, diferenças no tempo gasto por defeito foram julgadas com sendo altamente significativas. Métodos de walkthrough/inspection gastaram o maior tempo, Teste Funcional gastou um pouco menos, e teste estrutural a menor quantia de tempo;

b) Baseado na grande variabilidade observada entre os indivíduos foi verificado correlação dos resultados com as variáveis independentes, tal como, a experiência do indivíduo, mas não foram correlações significativas do ponto de vista estatístico;

c) Mesmo ignorando alguns resultados significativos, Myers relata que os resultados foram em grande parte decepcionantes. Os indivíduos ignorando casos de teste de entrada nãoconvencionais em favor de um convencional, negligenciaram muitas falhas, e isolaram na média 1/3 dos defeitos conhecidos;

d) Com relação aos aspectos complementares das técnicas, Myers investigou combinações teóricas das técnicas. Na média $33 \%$ dos defeitos foram detectados utilizando uma técnica e 50\% utilizando combinações teóricas (dois-a-dois).

\subsubsection{Experimento Basili \& Selby -1987}

Basili e Selby executaram um experimento controlado objetivando comparar três técnicas de detecção de defeitos no que diz respeito à efetividade e eficiência em revelar falhas. Esse experimento foi repetido por três vezes, as duas primeiras execuções foram realizadas com 42 estudantes (com nível de conhecimento avançado) e a terceira execução utilizou desenvolvedores profissionais. A seguir, apresentam-se os resultados e os procedimentos experimentais da última execução.

\begin{tabular}{|c|c|c|c|c|}
\hline \multicolumn{2}{|c|}{ Indivíduos } & Leitura de Código & Teste Funcional & Teste Estrutural \\
\hline \multirow{4}{*}{ Avançado } & S1 & $\mathrm{P} 4$ & P3 & $\mathrm{P} 1$ \\
\hline & $\mathrm{S} 2$ & $\mathrm{P} 3$ & $\mathrm{P} 1$ & $\mathrm{P} 4$ \\
\hline & $\ldots$ & & & \\
\hline & S8 & P1 & $\mathrm{P} 4$ & $\mathrm{P} 3$ \\
\hline \multirow{4}{*}{ Intermediário } & S9 & $\mathrm{P} 3$ & $\mathrm{P} 1$ & $\mathrm{P} 4$ \\
\hline & $\mathrm{S} 10$ & $\mathrm{P} 4$ & $\mathrm{P} 3$ & $\mathrm{P} 1$ \\
\hline & $\ldots$ & & & \\
\hline & S19 & $\mathrm{P} 1$ & $\mathrm{P} 4$ & $\mathrm{P} 3$ \\
\hline \multirow{4}{*}{ Júnior } & $\mathrm{S} 20$ & $\mathrm{P} 3$ & $\mathrm{P} 1$ & $\mathrm{P} 4$ \\
\hline & $\mathrm{S} 21$ & $\mathrm{P} 1$ & $\mathrm{P} 4$ & P3 \\
\hline & $\ldots$ & & & \\
\hline & S32 & $\mathrm{P} 4$ & $\mathrm{P} 3$ & $\mathrm{P} 1$ \\
\hline
\end{tabular}

Tabela 3.3 - Projeto experimental de Basili e Selby [BAS87]. 
A Tabela 3.3 apresenta o projeto experimental de Basili e Selby. Participaram da terceira execução 32 programadores com experiência profissional entre 1,5 e 20 anos. A experiência dos indivíduos foi considerada um variável independente e foi caracterizada em termos de anos de experiência profissional e conhecimento acadêmico. Foi realizado uma divisão randômica de indivíduos, técnicas, programas e nível de experiência. Os indivíduos trabalharam com os programas em uma ordem fixada, isto é, todos trabalharam com o programa $\mathrm{P} 1$ no $1^{\circ}$ dia, com o programa P3 no $2^{\circ}$ dia, e finalmente, com o programa $\mathrm{P} 4$ no $3^{\circ}$ dia. Em função dessa ordem, a Tabela 3.3 apresenta a randomização da ordem de aplicação das técnicas. Por exemplo, o indivíduo S2 aplicou a técnica 2 Teste Funcional (Functional Testing) no programa 1 (P1) no $1^{\circ}$ dia, aplicou a técnica 1 Leitura de Código (Code Reading) no programa 3 (P3) no $2^{\circ}$ dia, e por fim, aplicou a técnica 3 Teste Estrutural (Structural Testing) no programa P4 no $3^{\circ}$ dia.

As técnicas utilizadas durante o experimento foram: Leitura de Código, Teste Funcional e Teste Estrutural. Uma breve descrição das técnicas é apresentada a seguir:

- Leitura de Código: Indivíduos utilizam o código fonte do programa e a técnica de leitura Stepwise Abstraction [LIN79] para escreverem suas próprias especificações do programa. Utilizando essa técnica os indivíduos identificam subprogramas (blocos base) no código fonte, escrevem uma especificação para esses subprogramas, e combinam essas especificações, repetidamente, em uma especificação macro até capturarem o comportamento completo do programa. Os indivíduos comparam sua especificação com a especificação original para detectar inconsistências.

- Teste Funcional: Indivíduos analisam a especificação com o objetivo de identificar classes de equivalência (critério particionamento em classes de equivalência) nos dados de entrada, isto é, nas restrições de entrada. Os indivíduos derivam os casos de teste a partir dessa análise focalizando especialmente os valores limites (critério análise do valor limite), executam os casos de teste, e por fim, comparam a saída obtida com a saída esperada em busca de falhas.

- Teste Estrutural: Indivíduos utilizam o código fonte do programa para derivar casos de teste que conduzam a uma cobertura de $100 \%$ das declarações do programa. Após alcançar a cobertura especificada, os casos de teste são executados e as saídas obtidas são comparadas com as saídas esperadas em busca de falhas.

Foram utilizados três programas, escritos em Fortran, de 169, 147 e 365 linhas de código. Esses programas têm 9, 6 e 12 falhas, respectivamente. Um dos programas (P4) foi rescrito em Fortran e reutilizado do estudo de Hetzel [HET76]. Outro programa (P1) foi rescrito em Fortran e reutilizado do estudo de Myers [MYE78]. Defeitos foram classificados em diferentes tipos e 
classes objetivando permitir comparar se as técnicas diferem no que diz respeito à detecção de falhas causadas por diferentes tipos e classes de defeitos.

Um tutorial de 4 horas sobre as técnicas foi realizado na fase de treinamento. Os indivíduos já haviam previamente utilizado a técnica 2 Teste Funcional. Durante a execução do experimento os indivíduos aplicaram as técnicas em 3 sessões separadas. Da mesma forma que o experimento de Myers [MYE78], antes e durante a execução do experimento foram utilizados formulários específicos para coletar dados.

Basili \& Selby utilizaram estatística paramétrica (ANOVA) para analisar os resultados. Os principais resultados obtidos pelo experimento estão sintetizados a seguir:

a) A análise dos dados mostrou que a técnica Leitura de Código detectou um percentual maior de inconsistências (nível de significância < 0.01). O Teste Funcional detectou mais falhas (nível de significância < 0.01) que o Teste Estrutural. Com Leitura de Código, falhas não são reveladas, ao contrário, inconsistências entre a especificação construída pelo indivíduo e a especificação original são identificadas. O termo inconsistência é análogo a falhas em técnicas de validação.

b) Os indivíduos gastaram uma quantia similar de tempo aplicando as técnicas (nenhuma diferença significativa foi encontrada), mesmo assim, a técnica Leitura de Código foi mais eficiente na observação de falhas (nível de significância < 0.01).

c) Como no estudo de Hetzel [HET76], Basili e Selby relatam um resultado desapontador. Na média, somente $50 \%$ das falhas possíveis foram reveladas e registradas.

\subsubsection{Experimento Kamsties \& Lott -1995}

Kamsties \& Lott estenderam o projeto e as técnicas originalmente utilizadas por Basili \& Selby [BAS87]. Basicamente, um passo para isolar defeitos foi inserido após o passo de observação de falhas. Basili \& Selby [BAS87] observaram que os indivíduos que aplicaram a técnica Leitura de Código revelaram inconsistências e ao mesmo tempo realizaram um trabalho considerável em direção ao isolamento dos defeitos que causaram as inconsistências. Isolar defeitos significa localizar no código fonte o local exato que causou a(s) falha(s) observada(s) na execução. Esse experimento foi executado por 2 vezes. Na primeira execução foram utilizados 27 estudantes universitários e na segunda foram utilizados 23. A seguir, apresentam-se os procedimentos e os resultados da segunda execução. O objetivo foi comparar 3 técnicas de 
detecção de defeitos com relação à efetividade e eficiência em observar inconsistências/falhas e isolar defeitos.

A Tabela 3.4 apresenta o projeto experimental de Kamsties \& Lott. As variáveis independentes são as técnicas, os programas, os indivíduos e a ordem de aplicação das técnicas. Foi realizada uma divisão randômica das técnicas, programas, indivíduos e ordem de aplicação das técnicas. Os indivíduos foram divididos em seis grupos a fim de manipular a ordem de aplicação das técnicas, por cada indivíduo. Contudo, a ordem em que os indivíduos viram os três programas foi fixada, ou seja, não foi randomizadas. Isso previne que os indivíduos troquem informações entre si sobre os programas e, desse modo, influenciem os resultados. Indivíduos do grupo 1 aplicaram a técnica 1 Leitura de Código no programa 1 (P1) no primeiro dia, aplicaram a técnica 2 Teste Funcional no programa 2 (P2) no segundo dia, e por fim aplicaram a técnica 3 Teste Estrutural no programa 3 no terceiro dia.

\begin{tabular}{|c|c|c|c|}
\hline $\begin{array}{c}\text { Programa } \\
\text { Dia }\end{array}$ & $\begin{array}{c}\text { Leitura de } \\
\text { Código }\end{array}$ & $\begin{array}{c}\text { Functional } \\
\text { Testing }\end{array}$ & $\begin{array}{c}\text { Structural } \\
\text { Testing }\end{array}$ \\
\hline Programa 1 (dia 1) & Grupo 1, 2 & Grupo 3, 4 & Grupo 5, 6 \\
\hline Programa 2 $($ dia 2$)$ & Grupo 3, 5 & Grupo 1, 6 & Grupo 2, 4 \\
\hline Programa 3 (dia 3) & Grupo 4, 6 & Grupo 2, 5 & Grupo 1, 3 \\
\hline
\end{tabular}

Tabela 3.4 - Projeto experimental de Kamsties \& Lott [KAM95].

As técnicas utilizadas durante o experimento foram: Leitura de Código, Teste Funcional e Teste Estrutural. Uma breve descrição das técnicas é apresentada a seguir:

- Leitura de Código: Inicialmente, os indivíduos recebem o código fonte impresso, mas não têm acesso à especificação do programa. Eles são instruídos a lerem o código fonte e escreverem suas próprias especificações para o programa, baseados na técnica de leitura stepwise abstraction [LIN79]. Os indivíduos identificam subprogramas no código fonte, escrevem uma especificação para esses subprogramas e combinam essas especificações, repetidamente, em uma especificação macro até capturarem o comportamento completo do programa. Após escreverem suas próprias especificações, os indivíduos deixam os responsáveis pelo experimento realizarem uma cópia da especificação construída e em troca recebem a especificação original. Posteriormente, os indivíduos comparam a especificação original com sua própria especificação em busca de inconsistências, observando o comportamento esperado e especificado. A etapa final consiste em isolar os defeitos que produziram as inconsistências observadas. Nenhuma técnica para isolar defeitos foi especificada. 
- Teste Funcional: Inicialmente, os indivíduos recebem a especificação, mas não têm acesso ao código fonte do programa. Eles identificam classes de equivalência nas restrições de entrada (critério particionamento em classes de equivalência) e derivam os casos de teste utilizando as classes de equivalência, com atenção especial aos valores limites (critério análise do valor limite). Posteriormente, os indivíduos recebem uma versão executável do programa e executam seus casos de teste no computador. Eles foram instruídos a não gerarem casos de teste adicionais durante essa etapa. Ao terminar a execução dos casos de teste os indivíduos imprimem seus resultados e encerram a seção de teste no computador. Com a especificação em mãos e os resultados da seção de teste os indivíduos verificam a existência de falhas. Após registrar as eventuais falhas, os indivíduos entregam uma cópia de seus resultados e recebem o código fonte impresso. Finalmente, os indivíduos utilizam o código fonte para isolar defeitos que causaram as falhas observadas. Nenhuma técnica especial para isolar defeitos foi especificada.

- Teste Estrutural: Inicialmente, os indivíduos recebem o código fonte impresso, mas não têm acesso à especificação. Eles são instruídos a construírem casos de teste que alcancem $100 \%$ de cobertura de todos os arcos, todas as condições múltiplas, todos os loops e todos operadores relacionais. Nessa etapa, a ferramenta Generic Coverage foi utilizada. Por exemplo, $100 \%$ de cobertura de uma condição múltipla utilizando um único operador lógico "E" significa que todas as 4 combinações de verdadeiro e falso devem ser testadas, e $100 \%$ de cobertura de um loop significa que ele deve ser executado nenhuma vez, uma vez e muitas vezes. Posteriormente, os indivíduos por meio de uma versão instrumentada do programa executam seus casos de teste e verificam os valores de cobertura obtidos. Os indivíduos constroem casos de teste adicionais até alcançarem 100\% de cobertura para os critérios descritos acima, ou até acreditarem que não é possível alcançar cobertura melhor devido aos caminhos não executáveis. Ao terminar a execução dos casos de teste, os indivíduos imprimem seus resultados e encerram a seção de teste no computador. Com a especificação em mãos e os resultados da seção de teste os indivíduos verificam a existência de falhas. Após registrar as eventuais falhas, os indivíduos entregam uma cópia de seus resultados e, finalmente, utilizam o código fonte para isolar defeitos que causaram as falhas observadas. Nenhuma técnica especial para isolar defeitos foi especificada.

Foram utilizados três programas de 260, 279, 282 linhas escritos na linguagem C. Os programas têm um total de 11,14 e 11 defeitos, respectivamente.

O treinamento consistiu de uma parte teórica e outra prática. Primeiramente, os indivíduos receberam explanações teóricas sobre as técnicas. A fase de treinamento foi executada durante uma única semana, utilizando três pequenos programas escritos na linguagem C, com 44, 89 e 127 linhas de código. Cada indivíduo ganhou experiência com cada uma das três 
técnicas de detecção de defeitos, uma vez que, aplicou uma técnica em um dos programas de treinamento. Os indivíduos trabalharam independentemente e escolheram seus próprios horários para executar a sessão prática. O período de treinamento também permitiu aos indivíduos um contato inicial com os formulários e procedimentos operacionais. $\mathrm{O}$ experimento foi executado utilizando três dias da semana. Os indivíduos que utilizaram a técnica 1 Leitura de Código utilizaram uma sala de aula e os indivíduos que utilizaram as técnicas de teste utilizaram laboratórios. Todas as salas contavam com a presença de monitores. Foi definido um prêmio para os indivíduos que fossem mais efetivos e eficientes com uma determinada técnica. Da mesma forma que o experimento de Myers [MYE78], antes e durante a execução do experimento foram utilizados formulários específicos para coletar dados.

Kamsties \& Lott utilizaram estatística paramétrica (ANOVA) para testar as hipóteses, uma vez que, o projeto inclui randomização, satisfazendo assim um fundamental requisito, e um teste não paramétrico para analisar a correlação, por exemplo, da experiência dos indivíduos com os resultados. Os principais resultados obtidos pelo experimento estão sintetizados a seguir:

a) Diferenças significativas não foram observadas entre as técnicas com relação ao percentual de falhas observadas. Os indivíduos que aplicaram a técnica Leitura de Código e a técnica Teste Funcional isolaram aproximadamente o mesmo percentual de defeitos, e os indivíduos que aplicaram a técnica Teste Estrutural obtiveram uma performance bem menor;

b) A técnica Teste Funcional necessitou da menor quantia de tempo (do total possível) para revelar as falhas e isolar os defeitos. Nenhuma diferença significativa foi observada entre a técnica Leitura de Código e a técnica Teste Estrutural. Combinando esses resultados, a técnica Teste Funcional observou falhas mais eficientemente e isolou defeitos mais eficientemente que as outras técnicas;

c) Nenhuma diferença significativa entre os programas foi observada;

d) Nenhuma correlação significativa entre a experiência dos indivíduos e os resultados obtidos foram observados;

e) Similar aos estudos anteriores, amplas diferenças individuais foram observadas, e somente $50 \%$ dos defeitos, do total possível, foram detectados na média. 


\subsubsection{Experimento Wood, Roper Brooks \& Miller - 1997}

Wood et. al. [WOO97] replicaram o experimento de Kamsties \& Lott [KAM95]. O projeto experimental combinou três técnicas de detecção de defeitos e três programas. Conforme pode ser visto na Tabela 3.5 foram organizados 6 grupos, onde Px refere-se ao programa utilizado por cada indivíduo e $\mathbf{X}$ indica qual combinação de técnica e programa cada grupo aplicou. Cada fase do experimento foi realizada em uma semana diferente. Desta forma, a ordem que os indivíduos viram os programas foi fixada: O programa P1 foi utilizado na primeira semana, o programa P2 na segunda semana e o programa P3 na terceira semana.

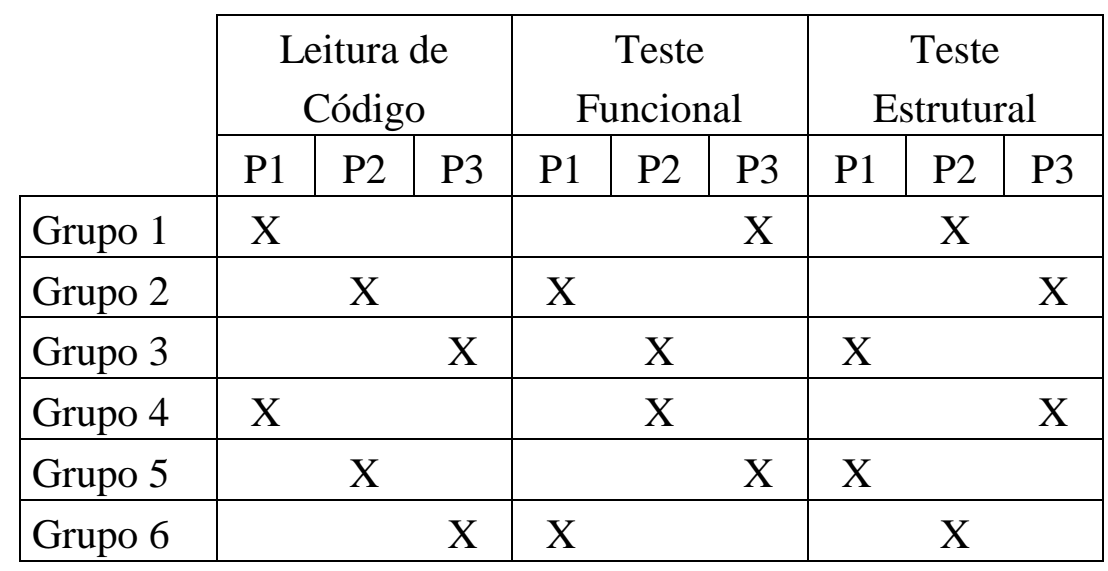

Tabela 3.5 - Projeto experimental de Wood et. al. [WOO97].

As técnicas de detecção de defeito utilizadas no experimento foram, basicamente, as mesmas usadas por Kamsties \& Lott [KAM95] e Basili \& Selby [BAS87]. A única diferença está com relação à técnica 3 Teste Estrutural. Nesse experimento foi utilizado somente o critério que cobre $100 \%$ das declarações do programa, ou seja, que cobre todos os comando do programa. Os outros critérios utilizados por Kamsties \& Lott não foram aplicados, pois, foram considerados não realistas em aplicações práticas.

Os programas utilizados tanto na fase de treinamento quanto na fase de execução foram obtidos do pacote de replicação disponibilizado por Kamsties \& Lott [KAM95]. O primeiro programa (P1), chamado NTREE.C, implementa um tipo de dado abstrato, mais especificamente, implementa uma árvore com ramificações ilimitadas. O segundo programa (P2), chamado CMDLINE.C, basicamente mostra o resultado de um "parsing" de uma linha de comando na tela. O terceiro programa (P3), chamado NAMETBL.C, implementa outro tipo de dado abstrato, nesse caso, uma tabela de símbolos. Os programas têm 8, 9, 8 defeitos, respectivamente. 
Os indivíduos que participaram do experimento foram 47 estudantes matriculados em uma turma de Engenharia de Software Prática da Universidade de Strathclyde. Todos os indivíduos já haviam completado dois anos de programação, incluindo linguagem C, no curso de graduação. Os experimentos foram organizados como parte de um curso obrigatório para todos os estudantes. Eles foram comunicados que seus trabalhos seriam utilizados para fins experimentais. Os indivíduos foram divididos em seis grupos, sendo que cada grupo foi balanceado em função das habilidades de cada estudante. As medidas de habilidades dos estudantes foram obtidas por meio da performance deles nos cursos de programação que haviam realizado anteriormente.

Antes do experimento os indivíduos receberam treinamento teórico em cada uma das técnicas de detecção de defeitos e na seqüência realizaram 3 sessões ( 2 horas cada) de treinamento prático. A execução do experimento foi organizada em 3 sessões (3 horas cada) durante 3 semanas consecutivas. A execução foi organizada em condição de avaliação, proibindo cooperação entre os indivíduos. Os indivíduos poderiam sair mais cedo caso completassem a tarefa. Da mesma forma que o experimento de Myers [MYE78], antes e durante a execução do experimento foram utilizados formulários específicos para coletar dados.

Wood et. al. utilizaram estatísticas paramétricas (ANOVA) para testar as hipóteses. Os principais resultados obtidos pelo experimento estão sintetizados a seguir:

a) As técnicas individualmente, de um modo geral, são efetivamente similares em termos de observação de falhas e isolamento de defeitos;

b) A efetividade relativa das técnicas depende da natureza do programa e dos seus defeitos;

c) As técnicas são muito mais efetivas quando usadas em combinação com as outras técnicas. Na média as piores combinações de técnicas foram $13 \%$ mais efetivas que a média das técnicas individualmente. Na média todas as técnicas combinadas foram $25 \%$ mais efetivas que a média das técnicas individualmente.

\subsection{Experimentos baseados em documentos de especificação de requisitos}

\subsubsection{PBR: Experimento Basili - 1996}

Basili et. al. [BAS96a] executou um experimento controlado objetivando avaliar a efetividade da técnica de leitura Perspective Based Reading (PBR) na detecção de defeitos, quando aplicada em documentos de especificação de requisitos, comparando-a com técnicas 
convencionais de revisão. O experimento foi conduzido com desenvolvedores profissionais de software da National Aeronautics and Space Administration / Goddard Space Flight Center (NASA/GSFC) Software Engineering Laboratory (SEL). Para a realização do experimento foi desenvolvido um conjunto de documentos de especificação de requisitos e neles foram introduzidos defeitos comuns ao seu ambiente, são eles:

- Dois documentos de domínio específico: Esses documentos foram concebidos para serem utilizados especificamente no contexto da NASA. Eles foram derivados de um conjunto de documentos de especificação de requisitos já existentes, especificamente aplicações de dinâmicas de vôo, e foram identificados como: NASA_A e NASA_B;

- Dois documentos de domínio genérico: Esses documentos foram concebidos para serem utilizados em contextos diferentes pois, são mais representativos em outros domínios de aplicação. Eles foram identificados como: Parking Garage Control System (PG) e Automatic Teller Machine (ATM)

Em linhas gerais, o experimento foi conduzido em duas etapas. Na primeira etapa foram entregues aos desenvolvedores dois documentos de especificação de requisitos (um de domínio específico e um de domínio genérico) e solicitado a eles que descobrissem defeitos utilizando suas técnicas convencionais de teste. Na segunda etapa, os mesmos desenvolvedores receberam treinamento na técnica PBR e mais outros dois documentos de especificação de requisitos (um de domínio genérico e outro de domínio específico) para descobrirem defeitos. O objetivo foi verificar se o desempenho melhorou após terem utilizado a técnica PBR.

A Figura 3.1 apresenta o projeto experimental de Basili et. al. [BAS96a]. Inicialmente, os indivíduos foram divididos em dois grupos, identificados como: Grupo 1 e Grupo 2. Cada grupo foi dividido em 3 subgrupos. Cada subgrupo contém 2 indivíduos e está relacionado a uma das perspectivas (Projeto, Teste e Uso). Foram necessários 2 dias para executar o experimento. No primeiro dia os indivíduos dos Grupos 1 e 2 utilizaram as suas técnicas convencionais para revisarem os documentos de domínio específico NASA_A e NASA_B e os de domínio genérico ATM e PG. No segundo dia, cada indivíduo foi treinado em uma das perspectivas (Projeto, Teste e Uso) da técnica PBR para então iniciar o processo de revisão dos documentos de domínio genérico PG e ATM e dos de domínio específico NASA_B e NASA_A. Antes de iniciar cada seção de revisão, os indivíduos eram instruídos em como procederem durante a seção utilizando determinada técnica. 


\begin{tabular}{|c|c|c|c|c|c|c|c|}
\hline & \multicolumn{3}{|c|}{ Grupo 1} & \multicolumn{3}{|c|}{ Grupo 2} & \multirow{6}{*}{$\begin{array}{c}\text { Primeiro } \\
\text { Dia }\end{array}$} \\
\hline \multirow{5}{*}{$\begin{array}{c}\text { Técnica } \\
\text { Convecional }\end{array}$} & Designer & Tester & User & Designer & Tester & User & \\
\hline & \multicolumn{3}{|c|}{ Treinamento } & \multicolumn{3}{|c|}{ Treinamento } & \\
\hline & \multicolumn{3}{|c|}{ NASA_A } & \multicolumn{3}{|c|}{ NASA_B } & \\
\hline & \multicolumn{3}{|c|}{ Treinamento } & \multicolumn{3}{|c|}{ Treinamento } & \\
\hline & \multicolumn{3}{|c|}{ ATM } & \multicolumn{3}{|c|}{$\mathrm{PG}$} & \\
\hline \multirow{5}{*}{$\begin{array}{l}\text { Técnica } \\
\text { PBR }\end{array}$} & \multicolumn{6}{|c|}{ Teoria sobre a técnica PBR } & \multirow{5}{*}{$\begin{array}{c}\text { Segundo } \\
\text { Dia }\end{array}$} \\
\hline & \multicolumn{3}{|c|}{ Treinamento } & \multicolumn{3}{|c|}{ Treinamento } & \\
\hline & \multicolumn{3}{|c|}{$\mathrm{PG}$} & \multicolumn{3}{|c|}{ ATM } & \\
\hline & \multicolumn{3}{|c|}{ Treinamento } & \multicolumn{3}{|c|}{ Treinamento } & \\
\hline & \multicolumn{3}{|c|}{ NASA_B } & \multicolumn{3}{|c|}{ NASA_A } & \\
\hline
\end{tabular}

Figura 3.1 - Projeto experimental de Basili et. al. [BAS96a].

O experimento destinou-se a responder às seguintes questões:

1. Se aos grupos de revisão fossem dados unicamente as regras PBR (tal como durante uma sessão de inspeção) um número maior de defeitos seria detectado do que aqueles detectados caso os grupos de revisão utilizassem técnicas convencionais?

2. Se os indivíduos revisassem um documento utilizando PBR, um número diferente de defeitos seria detectado do que aqueles detectados caso os indivíduos utilizassem técnicas convencionais?

3. A experiência do indivíduo em uma das perspectivas (projeto, teste, uso) teve influência na performance individual?

Durante o projeto do experimento foram considerados quais os fatores eram mais prováveis de ter um impacto nos resultados. O projeto experimental levou em conta esses fatores (chamados de variáveis independentes) e permitiu que eles fossem separados um dos outros, possibilitando assim, uma relação casual entre o teste e a taxa de detecção de defeitos (chamada de variável dependente). As variáveis que puderam ser manipuladas separadamente foram: técnicas de leitura, perspectivas e documentos de requisitos.

As restrições que limitaram a forma com que se poderia manipular as variáveis independentes foram determinadas basicamente por dois fatores: 
Tempo: Uma vez que os desenvolvedores foram emprestados das organizações, não foi possível contar com eles por um tempo indefinido. Exigiu-se que o experimento fosse realizado num tempo tão eficiente quanto possível, sem comprometer a integridade do experimento; e

Custo: Pela mesma razão descrita acima, não foi possível obter uma grande quantidade de indivíduos quanto se gostaria. O custo por indivíduo é significante e por essa razão, a maior restrição do projeto experimental foi alcançar resultados significativos com um número mínimo de indivíduos e um número mínimo de replicações.

Confiada a tarefa aos desenvolvedores, mesmo sendo eles voluntários, foi necessário oferecer algum benefício potencial aos indivíduos e a organização que os cederam. Isso foi obtido por meio do treinamento que eles receberam em uma nova técnica (PBR).

Basicamente, as tarefas realizadas pelos indivíduos consistiram em ler e revisar um documento de especificação de requisitos e registrar os defeitos detectados em formulários especiais. Os documentos revisados foram diferentes para cada indivíduo, devido ao fato de que se um documento fosse revisado mais que uma vez pelo mesmo indivíduo os resultados seriam influenciados pelo conhecimento já adquirido em leituras prévias. Baseado nas restrições descritas acima, cada indivíduo teve tempo de ler e revisar não mais do que quatro documentos: 2 de domínio genérico e 2 de domínio específico.

A Tabela 3.6 apresenta a quantidade de defeitos associados a cada um dos documentos utilizados durante o experimento.

\begin{tabular}{|l|c|c|}
\hline \multicolumn{1}{|c|}{ Documentos } & Quantidade de Páginas & Quantidade de Defeitos \\
\hline ATM & 17 & 29 \\
\hline PG & 16 & 27 \\
\hline NASA_A & 27 & 15 \\
\hline NASA_B & 27 & 15 \\
\hline
\end{tabular}

Tabela 3.6 - Quantidade de defeitos existentes nos documentos utilizado no experimento.

A primeira execução do experimento de Basili foi conduzida em Novembro de 1994 e foi denominado de Estudo Piloto. Durante a condução do experimento foram identificados alguns problemas potenciais, são eles:

- Tentou-se indicar indivíduos para cada perspectiva de acordo com suas experiências. Porém, a maioria dos participantes era desenvolvedor de software e não foi possível uma 
divisão adequada. Decidiu-se então que as atribuições seriam randomizadas em qualquer futura replicação do experimento;

- Os documentos de domínio específico da NASA foram considerados longos demais para uma análise apropriada em uma única sessão. Decidiu-se revisar os documentos e tornálos menor para qualquer futura replicação do experimento;

- Cada indivíduo teve um tempo de até 3 horas para revisar cada documento (isso significa um documento de manhã e outro à tarde). Somente um indivíduo levou mais de 2 horas, portanto, concordou-se que um limite de 2 horas por documento seria efetivo em qualquer futura replicação do experimento;

- Foi permitido que os indivíduos trabalhassem em suas próprias salas, dessa forma eles estavam sujeitos a interrupções, chamadas telefônicas e outras eventualidades do dia-adia. Acredita-se que haveria maior validade interna dos resultados se fosse utilizados ambientes uniformes em qualquer futura replicação do experimento.

- Algumas inconsistências foram descobertas nas especificações de requisitos. Algumas sentenças foram mudadas para tornar o documento menos ambíguo As especificações consistem de uma descrição geral do problema e depois de uma série de especificações precisas, algumas das quais estavam intencionalmente incorretas. Decidiu-se que para qualquer futura replicação do experimento a descrição geral da especificação deve estar correta, ou seja, não deve ser semeada com defeitos para que os indivíduos possam ter alguma base para tomar decisões.

Devido aos problemas relacionados acima, uma nova execução do experimento foi realizada em Junho de 1995 com 14 indivíduos. Um dos 14 indivíduos não estava familiarizado com aplicações de dinâmicas de vôo, portanto, foram utilizados somente 13 indivíduos nesse caso.

A seguir, apresentam-se os principais resultados obtidos durante a primeira e segunda replicação do experimento.

\section{Efeitos da técnica PBR em grupos de inspeção}

As técnicas PBR, ou seja, as perspectivas, são consideradas específicas. A suposição é que a união das perspectivas ofereça uma maior cobertura do documento em análise, portanto, é necessário combinar as perspectivas dentro de um mesmo grupo de revisão. Como o principal interesse do experimento está nos resultados obtidos pelos grupos de revisão, e devido às 
restrições de custo e tempo, a análise da cobertura obtida pelos grupos foi realizada pela simulação de grupos compostos de um indivíduo para cada uma das três perspectivas.

Conforme apresentado na Figura 3.1, os indivíduos foram organizados em dois grupos, os indivíduos do Grupo 1 aplicaram suas técnicas convencionais no conjunto de documentos $\mathbf{A}$ (NASA_A e ATM) e a técnica PBR no conjunto de documentos B (PG e NASA_B), onde A e B representam dois documentos, 1 genérico e 1 específico. Da mesma forma, os indivíduos do Grupo 2 aplicaram suas técnicas convencionais no conjunto de documentos B (NASA_B e PG) e a técnica PBR conjunto de documentos A (ATM e NASA_A). A análise da cobertura obtida por cada uma das técnicas foi realizada por meio da observação da taxa média de detecção de defeitos em cada conjunto de documentos.

Conforme mostra a Figura 3.2, na primeira execução do experimento (Estudo Piloto) foram obtidos resultados significativos com grupos PBR, apenas nos documentos de domínio genérico. Os valores no gráfico representam as taxas médias de detecção de defeitos obtida pelas técnicas em cada conjunto de documentos. Na segunda execução do experimento, os grupos que utilizaram PBR conseguiram melhora em ambas classes de documentos. A razão para essa melhora observada entre a primeira e a segunda execução do experimento pode ser atribuída aos documentos de domínio específico que foram reformulados e às sessões de treinamento antes de cada sessão de revisão dos documentos.

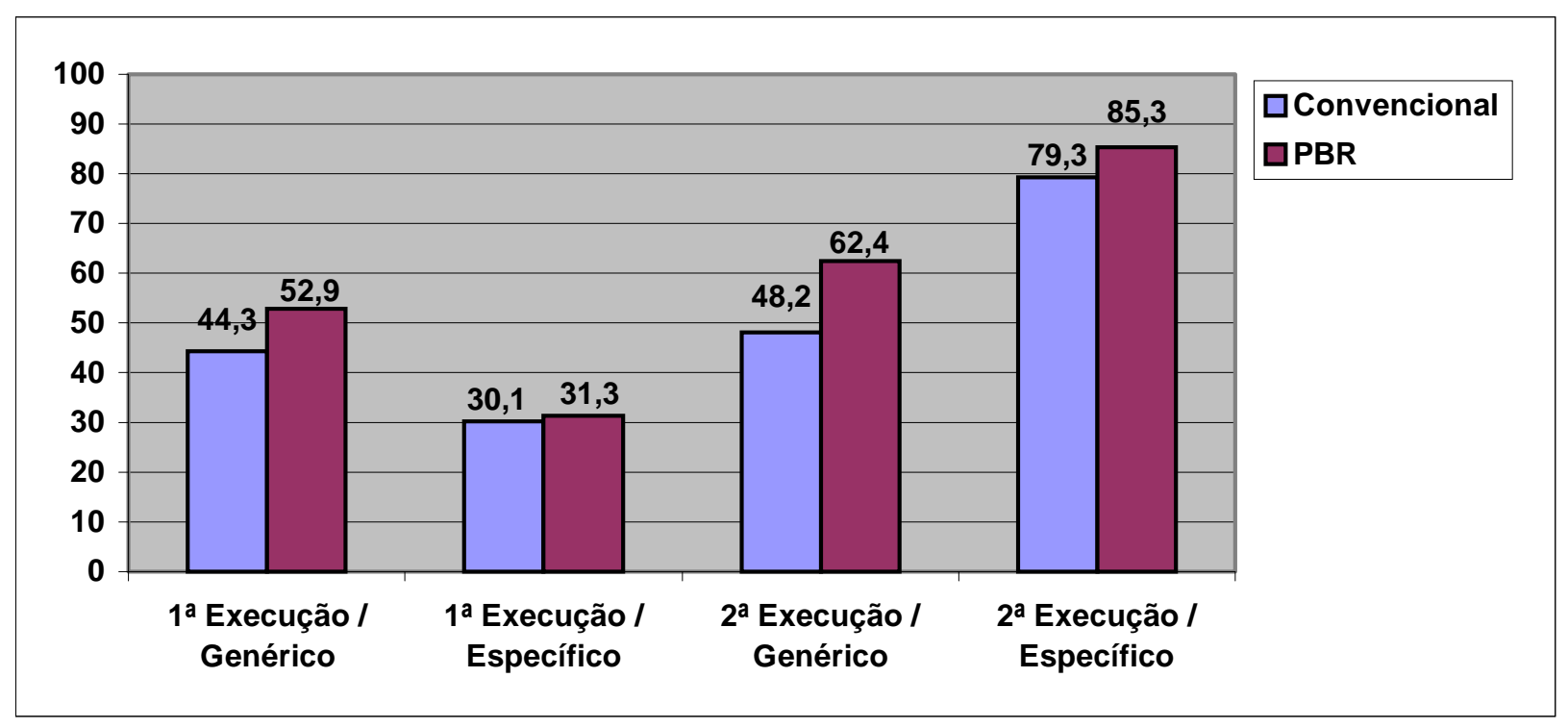

Figura 3.2 - Resultados obtidos pelos grupos de revisão. 


\section{Efeitos da técnica PBR em indivíduos}

O objetivo principal do experimento foi investigar os efeitos da técnica PBR em grupos de revisão, porém, comparou-se também a técnica PBR com as técnicas convencionais no que se refere à performance individual. A análise foi realizada por meio da observação do percentual de defeitos detectados por cada indivíduo em relação ao número total de defeitos existente no documento inspecionado.

Embora em muitos casos, indivíduos utilizando PBR descobriram o mesmo número de defeitos que indivíduos utilizando técnicas convencionais de teste, os indivíduos que aplicaram PBR tiveram realmente um desempenho significativamente melhor nos documentos de domínio genérico na segunda execução do experimento, conforme pode ser observado na Figura 3.3. Um resultado de certa forma inesperado, uma vez que os benefícios reais da técnica PBR são esperados em termos de grupos de revisão, pelo fato de combinarem as perspectivas. Os resultados obtidos pelos indivíduos mostram que sob certas circunstâncias a utilização de técnicas sistemáticas, ou seja, técnicas com responsabilidades específicas, pode melhorar também em termos de percentuais individuais a cobertura do documento.

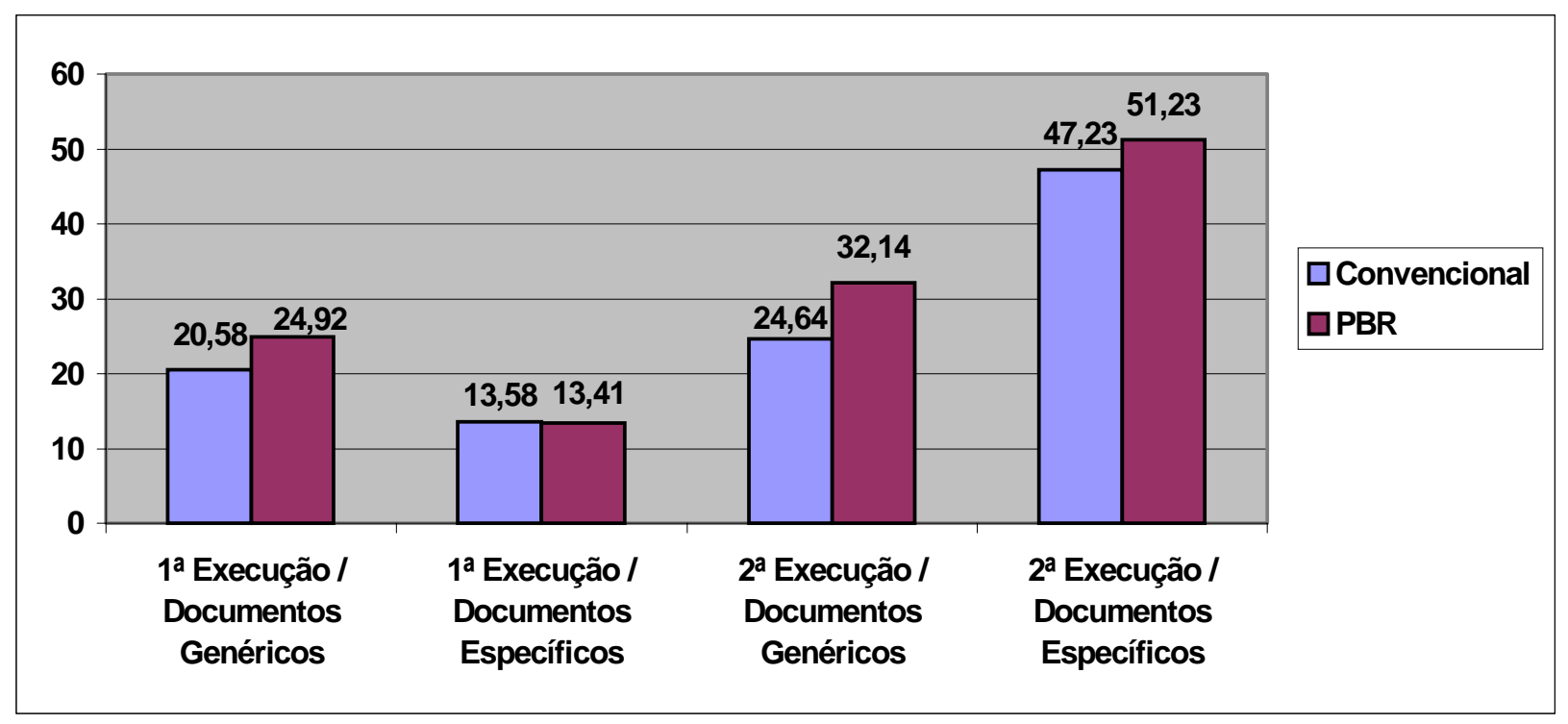

Figura 3.3 - Resultados obtidos pelos indivíduos.

\section{Análise das perspectivas e da experiência dos indivíduos}

Outro interesse particular do experimento foi determinar se indivíduos utilizando PBR descobriram classes mais amplas de defeitos e se os defeitos detectados eram ortogonais (isto é, as perspectivas não realizaram sobreposição em relação ao conjunto de defeitos que elas ajudaram a descobrir). Em documentos de domínio genérico foi possível observar que houve um 
número de defeitos que foram descobertos apenas por uma das perspectivas, conforme mostra a Figura 3.4, enquanto que nos documentos específicos foram observados graus maiores de sobreposição entre as perspectivas, conforme mostra a Figura 3.5.

A seguir, apresentam-se os resultados obtidos em um documento de domínio genérico (ATM) e em um documento de domínio específico (NASA_A). Como pode ser visto na Figura 3.4, indivíduos utilizando a perspectiva do projeto da técnica PBR, por exemplo, encontraram 11 defeitos no total durante a segunda execução do experimento, são eles: 2 que não foram detectados por nenhuma outra perspectiva; 3 que também foram detectados pela perspectiva do Teste; 1 que também foi detectado pela perspectiva do usuário; e 5 que foram detectados pelas perspectivas do Testador e do Usuário.

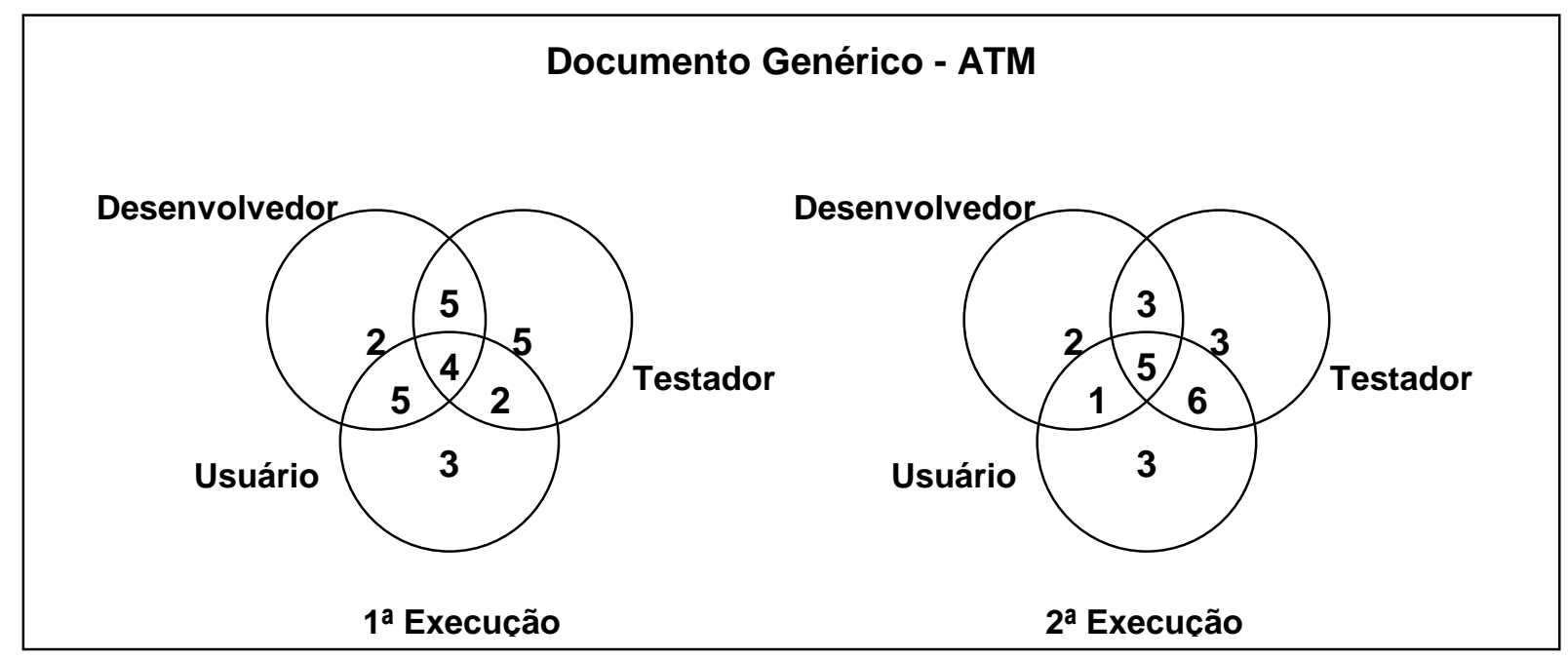

Figura 3.4 - Cobertura obtida pelas perspectivas nos documentos genéricos.

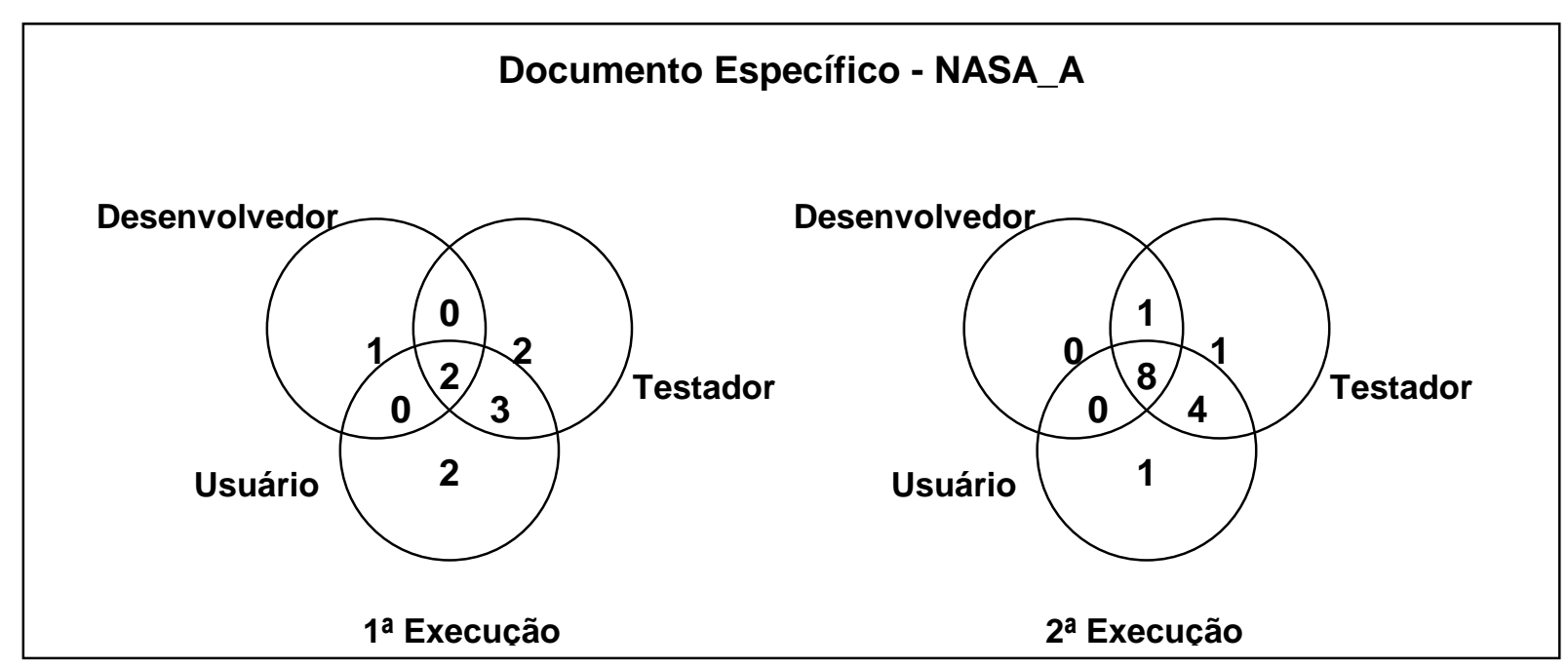

Figura 3.5 - Cobertura obtida pelas perspectivas em documentos específicos. 
Finalmente pode-se observar que a relação entre a taxa de detecção de defeitos obtida pelos indivíduos que aplicaram PBR e a experiência dos indivíduos é fraca. Indivíduos com mais experiência não executam melhor a revisão do que indivíduos com menos experiência. Em alguns casos indivíduos com experiência menor têm aprendido aplicar melhor a técnica PBR.

\subsection{Considerações Finais}

Neste capítulo foram apresentados os principais experimentos relacionados a este trabalho realizados durante as últimas três décadas destinados a comparar técnicas de teste e revisão. Foram abordados alguns pontos específicos de cada experimento devido sua relevância na realização das replicações. As informações referentes aos resultados obtidos em cada experimento são de extrema importância, pois elas servirão de base para as conclusões deste trabalho.

É fundamental ressaltar que as técnicas de teste e validação estão em constate evolução e os experimentos apresentados aqui foram realizados em paralelo a essa evolução. É necessário que as novas replicações de experimentos, similares aos apresentados neste capítulo, incluam novos elementos para maior validade dos resultados.

Nos próximos dois capítulos são descritos detalhadamente as replicações dos experimentos baseados em códigos fontes e em documentos de especificação de requisitos. No Capítulo 4 é descrita a replicação do experimento baseado em códigos fontes. No Capítulo 5 é descrita a replicação do experimento baseado em especificação de requisitos. 


\section{CAPÍTULO 4}

\section{Códigos Fontes: Replicação de}

Experimento

\subsection{Considerações Iniciais}

Um aspecto relevante em experimentação é a necessidade de replicar ou complementar um estudo experimental para ampliar a base de dados e a validade estatística dos resultados. Replicação em diferentes contextos é uma característica importante para qualquer tipo de estudo em Engenharia de Software. A replicação também é importante para se obter credibilidade e aprendizagem. A replicação e os estudos complementares são encorajados pela disponibilidade dos pacotes de laboratório que documentam um experimento. Os pacotes de laboratório descrevem um experimento em termos específicos permitindo replicação, oportunidades de variação e um contexto para combinação de resultados em diferentes tipos de tratamentos experimentais. Assim, este trabalho pretende realizar replicações de experimentos que vêm sendo realizados nos últimos anos com o objetivo de comparar técnicas de teste e revisão. Um dos experimentos a ser replicado neste trabalho de mestrado está baseado nos experimentos de Basili \& Selby [BAS87] e Kamsties \& Lott [KAM95], apresentado neste capítulo.

Considerando o interesse nos critérios de teste baseados em fluxo de dados e em mutação, considerou-se adicionar esses critérios ao experimento de Basili \& Selby [BAS87] e Kamsties \& Lott [KAM95], com a proposição do Teste Incremental. A técnica denominada Teste Incremental (Incremental Testing) é uma estratégia de teste que pretende combinar os pontos positivos da técnica estrutural com os da técnica baseada em erros em um processo evolutivo de teste. O Teste Incremental combina os critérios baseados em fluxo de controle (Todos-Nós e Todos-Arcos) e os critérios baseados em fluxo de dados (Todos-Usos, Todos-Potenciais-Usos) da técnica estrutural com o critério Análise de Mutantes da técnica baseada em erros. 
Na Seção 4.2 são apresentadas a hipóteses pertinentes ao experimento. Na Seção 4.3 é apresentado o projeto experimental, ou seja, a organização do experimento em função dos participantes, técnicas e programas utilizados. Na Seção 4.4 são apresentadas as técnicas utilizadas durante o experimento. Na Seção 4.5 são apresentados os programas utilizados durante a replicação do experimento, bem como, as classes e os tipos de defeitos associados a cada programa. Na Seção 4.6 são apresentados o perfil dos participantes, a organização das sessões de treinamento e a organização das execuções do experimento. Na Seção 4.7 são apresentados os principais resultados obtidos durante a replicação.

\subsection{Definição das Hipóteses}

As hipóteses para esta replicação do experimento de Basili \& Selby [BAS87] e Kamsties \& Lott [KAM95] apresentam-se a seguir:

Hipótese 1 - As técnicas (Leitura de Código pelo Stepwise Abstraction, Teste Funcional e Teste Incremental) diferem em termos da efetividade, isto é, do percentual (do total possível) de defeitos isolados e falhas observadas.

Hipótese 2 - As técnicas (Leitura de Código pelo Stepwise Abstraction, Teste Funcional e Teste Incremental) diferem em termos da eficiência, isto é, do percentual (do total possível) de defeitos isolados e de falhas observadas dividido pelo tempo gasto no isolamento e observação.

Hipótese 3 - As técnicas (Leitura de Código pelo Stepwise Abstraction, Teste Funcional e Teste Incremental) diferem em termos da efetividade no isolamento e na observação de diferentes tipos e classes de defeitos.

Hipótese 4 - As técnicas (Leitura de Código pelo Stepwise Abstraction, Teste Funcional e Teste Incremental) obtêm resultados mais significativos quando combinadas.

\subsection{Projeto Experimental}

Foi utilizado um projeto fatorial-fracional, randomizado, que combina três programas e três técnicas de detecção de defeitos, similar aos projetos de Basili \& Selby [BAS87] e Kamsties \& Lott [KAM95]. O projeto inclui os passos para observação de falhas e isolamento de defeitos. O projeto é chamado fatorial-fracional porque um único indivíduo não aplica todas as técnicas em todos os programas. Uma permutação de programas e técnicas entre os indivíduos garante que cada indivíduo aplica cada técnica somente uma vez, que todas as combinações de programa e técnicas ocorram e que todas as possíveis ordens de aplicação das técnicas nos programas sejam executadas [WIN71]. 
A Tabela 4.1 apresenta o projeto experimental em função dos programas. O indivíduo identificado com o número 5, por exemplo, aplicou no programa 1 a técnica T2, aplicou no programa 2 a técnica T3 e aplicou no programa 3 a técnica T1. A Tabela 4.2 apresenta o projeto experimental em função das técnicas.

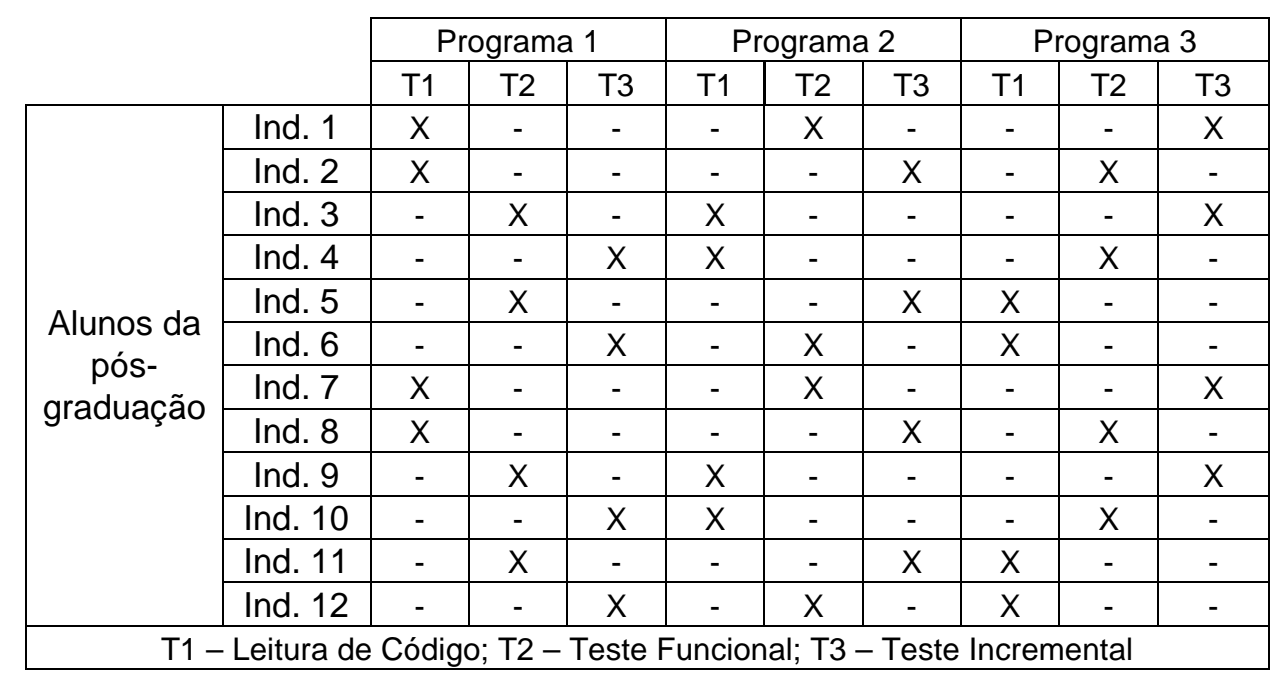

Tabela 4.1 - Projeto experimental em função dos programas.

Uma restrição prática adicional para este projeto experimental é que somente um programa foi utilizado em cada fase do experimento. Essa restrição previne que os indivíduos troquem informações entre si sobre os programas e, desse modo, influenciem os resultados. A ordem em que os indivíduos viram os 3 programas foi fixada, ou seja, não houve randomização. $\mathrm{Na}$ primeira fase do experimento 4 indivíduos aplicaram a técnica 1 no programa 1 (P1), 4 indivíduos aplicaram a técnica 2 no programa 1 (P1), e 4 indivíduos aplicaram a técnica 3 no programa 1 (P1). Na segunda e terceira fase foi utilizado o mesmo critério, respectivamente, para os programas 2 e 3 .

O projeto experimental tem duas variáveis independentes: as técnicas de detecção de defeitos e os programas. As variáveis dependentes são a quantidade de falhas observadas; a quantidade de defeitos isolados e o tempo gasto na observação de falhas e no isolamento de defeitos. 


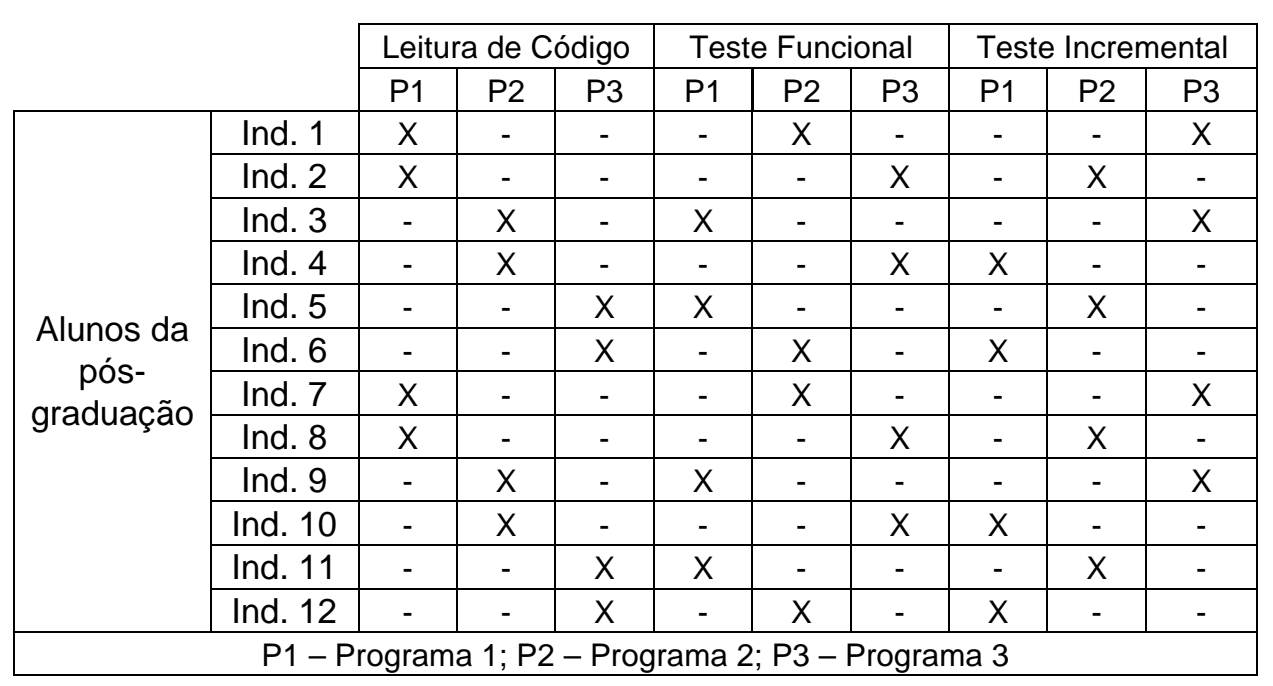

Tabela 4.2 - Projeto experimental em função das técnicas.

\subsection{Técnicas}

As técnicas de detecção de defeitos foram basicamente as mesmas do experimento de Basili \& Selby [BAS87] e Kamsties \& Lott [KAM95], exceção feita à técnica Teste Incremental, conforme mencionado na Seção 4.1. A seguir, apresentam-se as técnicas utilizadas nesta replicação do experimento:

- Leitura de Código: No $1^{\circ}$ passo, indivíduos recebem o código fonte impresso, mas não têm acesso à especificação do programa. Eles são instruídos a lerem o código fonte e escreverem suas próprias especificações para o programa, baseados na técnica de leitura Stepwise Abstraction [LIN79], descrita detalhadamente no Capítulo 2. Os indivíduos identificam subprogramas no código fonte e escrevem uma especificação para esses subprogramas e combinam essas especificações, repetidamente, em uma especificação macro até capturarem o comportamento completo do programa. Após escreverem suas próprias especificações, os indivíduos recebem a especificação original. Para efeitos de comparação Leitura de Código não tem o $2^{\circ}$ passo, que é o passo de execução dos casos de teste. No $3^{\circ}$ passo, indivíduos comparam a especificação original com sua própria especificação em busca de inconsistências, observando o comportamento esperado e especificado. $\mathrm{O} 4^{\circ}$ passo consiste em isolar os defeitos que produziram as inconsistências observadas. Nenhuma técnica especial para isolar defeitos foi especificada.

- Teste Funcional: No $1^{\circ}$ passo, indivíduos recebem a especificação, mas não têm acesso ao código fonte do programa. Eles derivam os casos de teste utilizando os critérios particionamento em classes de equivalência e análise do valor limite da técnica funcional. Os 
critérios estão descritos detalhadamente no Capítulo 2. No $2^{\circ}$ passo, os indivíduos recebem uma versão executável do programa e executam seus casos de teste no computador. Ao terminar a execução dos casos de teste os indivíduos imprimem seus resultados e encerram a seção de teste no computador. Com a especificação em mãos e os resultados da seção de teste os indivíduos verificam a existência de falhas, caracterizando assim o $3^{\circ}$ passo. Após registrar as eventuais falhas, os indivíduos recebem o código fonte impresso. No $4^{\circ}$ passo, os indivíduos utilizam o código fonte para isolar os defeitos que causaram as falhas observadas. Nenhuma técnica especial para isolar defeitos foi especificada.

- Teste Incremental: Envolve a aplicação dos critérios: Todos-Nós e Todos-Arcos que são critérios baseados em fluxo de controle, Todos-Usos e Todos-Potenciais-Usos que são baseados em fluxo de dados, e o critério Análise de Mutantes. A cada aplicação de um determinado critério de teste um conjunto adequado de casos de teste é definido. Esse conjunto adequado de casos de teste é utilizado para descobrir possíveis falhas, e posteriormente é utilizado pelo critério seguinte da estratégia incremental como um conjunto inicial de casos de teste. O conjunto de casos de teste vai sendo melhorado por meio de um processo evolutivo que vai do critério todos-nós até o critério análise de mutantes.

$1^{0}$ passo: Os indivíduos recebem o código fonte e são instruídos a construírem casos de teste até alcançarem 100\% de cobertura do critério Todos-Nós da técnica estrutural. Posteriormente, os indivíduos por meio de uma versão instrumentada do programa executam seus casos de teste e verificam os valores de cobertura obtidos. Os indivíduos constroem casos de teste adicionais até alcançarem 100\% de cobertura para o critério ou até acreditarem que não é possível alcançar cobertura melhor devido aos elementos não executáveis, ou seja, aqueles elementos cujo não existe um dado de entrada que o execute. Ao terminar a execução dos casos de teste, os indivíduos com a especificação em mãos e os resultados da seção de teste verificam a existência de falhas. Após registrar as eventuais falhas, os indivíduos utilizam o código fonte para isolar defeitos que causaram as falhas observadas. Nenhuma técnica especial para isolar defeitos foi especificada. Os indivíduos analisam a cobertura do conjunto de casos de teste TodosNos adequado com relação aos critérios Todos-Arcos, Todos-Usos e Todos-PotenciaisUsos.

$\mathbf{2}^{\mathbf{0}}$ passo: Os indivíduos são instruídos a construírem casos de teste até alcançarem $100 \%$ de cobertura do critério Todos-Arcos. A sequiência desse passo é a mesma do $1^{\circ}$ passo, exceção feita à fase de analisar a cobertura do conjunto de casos de teste Todos-Arcos adequado. Neste caso a análise é realizada com relação aos critérios Todos-Usos e TodosPotenciais-Usos; 
$3^{\circ}$ passo: Os indivíduos são instruídos a construírem casos de teste até alcançarem $100 \%$ de cobertura do critério Todos-Usos. A seqüência desse passo é similar ao $1^{\circ}$ passo, exceção feita: ao processo de marcação das associações não executáveis, ou seja, aquelas associações cujo não existe um dado de entrada que as execute; e a fase de analisar a cobertura do conjunto de casos de teste Todos-Usos adequado. Neste caso a análise é realizada com relação ao critério Todos-Potenciais-Usos;

$4^{\mathbf{0}}$ passo: Os indivíduos são instruídos a construírem casos de teste até alcançarem $100 \%$ de cobertura do critério Todos-Potenciais-Usos. A sequiência desse passo é a mesma do $3^{\circ}$ passo, exceção feita à fase de analisar a cobertura do conjunto de casos de teste TodosPotenciais-Usos adequado. Neste caso a análise é realizada com relação ao critério Análise de Mutantes;

Os 4 passos acima devem ser realizados em no máximo 6 horas. Quando os indivíduos completarem 04h30min receberão os elementos e associações não executáveis.

$5^{\circ}$ passo: Os indivíduos são instruídos a iniciarem o $5^{\circ}$ passo utilizando o conjunto de casos de teste gerado durante os 4 passo anteriores e construírem casos de teste até alcançarem $100 \%$ de cobertura do critério Análise de Mutantes. Posteriormente, os indivíduos por meio de uma versão instrumentada do programa executam seus casos de teste e verificam os valores de cobertura obtidos. Os indivíduos devem construir casos de teste adicionais até alcançarem $100 \%$ de cobertura, que significa ter que determinar os mutantes equivalentes, ou seja, aqueles programas cuja alteração sintática não altera o resultado se comparado ao programa original. Ao terminar a execução dos casos de teste, os indivíduos com a especificação em mãos e os resultados da seção de teste verificam a existência de falhas. Após registrar as eventuais falhas, os indivíduos utilizam o código fonte para isolar defeitos que causaram as falhas observadas. Nenhuma técnica especial para isolar defeitos foi especificada. O $5^{\circ}$ passo deve ser realizados em no máximo 6 horas. Quando os indivíduos completarem 04h30min receberão os mutantes equivalentes.

Nos 4 primeiros passos a ferramenta Poke-Tool (Potential Uses Criteria Tool for Program Testing) foi utilizada [CHA91]. No $5^{\circ}$ passo, a ferramenta Proteum foi utilizada [DEL93]. 


\subsection{Programas}

Os programas utilizados durante as fases de treinamento e execução do experimento são os disponibilizados no pacote de replicação de Kamsties \& Lott [KAM95]. Seis programas foram utilizados, 3 com propósito de treinamento e outros 3 com propósito de execução. Os 3 programas utilizados no treinamento foram: "count.c", "series.c" e "tokens.c". Os programas utilizados durante a execução do experimento foram: "ntree.c", "cmdline.c" e "nametbl.c".

O programa "count.c" conta palavras fornecidas via entrada de dados, "series.c" gera uma série de números e "tokens.c" sorteia tokens alfanuméricos. Os programas utilizados na execução são formados por pequenos conjuntos de funções escritas na linguagem $C$ (entre 10 e 30 linhas cada). O programa "ntree.c" implementa um tipo abstrato de dado, isto é, uma árvore de ramificações ilimitadas, "cmdline.c" avalia um número de opções que são fornecidas em uma linha de comando e "nametbl.c" implementa outro tipo abstrato de dado, isto é, uma simples tabela de símbolos.

O programa "ntree.c" contém 8 defeitos, o programa "cmdline.c" contém 9 defeitos e o programa "nametbl.c" contém 8 defeitos. Embora os programas contenham alguns defeitos cometidos originalmente pelos seus desenvolvedores, novos defeitos foram semeados no código fonte desses programas. Todos os defeitos causam falhas observáveis, nenhum defeito esconde outro. Os defeitos foram classificados de acordo com os esquemas de classificação do experimento de Basili \& Selby [BAS87], são eles:

\section{(1) Classe de Defeito}

- Omission - São defeitos causados por falta de segmento de código fonte;

- Commission - São defeitos causados por um segmento de código fonte incorreto.

\section{(2) Tipo de Defeito}

- Initialization - São defeitos causados por uma inicialização incorreta de uma variável ou estrutura de dados;

- Computation - São defeitos causados pela falta de uma expressão ou pela presença de uma expressão incorreta, tal como, um sinal de incremento no lugar de um sinal de decremento; 
- Control - São defeitos causados pela execução de um caminho (fluxo de controle) errado, isto é, pelo uso incorreto de um predicado em uma declaração do tipo IFTHEN-ELSE;

- Interface - São defeitos causados quando um módulo usa ou faz suposições sobre outros módulos;

- Data - São defeitos causados por um uso incorreto de uma estrutura de dados, tal como, determinar incorretamente o índice para o último elemento de um vetor;

- Cosmetic - Um erro de ortografia em uma mensagem de saída do programa é considerado um defeito do tipo Cosmetic.

A Tabela 4.3, a Tabela 4.4 e a Tabela 4.5 apresentam os defeitos dos programas utilizados no experimento organizados por Classe e Tipo.

\begin{tabular}{|l|l|c|}
\hline Defeito & \multicolumn{1}{|c|}{ Classe } & Tipo \\
\hline Defeito 1 & Omission & Data \\
\hline Defeito 2 & Commission & Control \\
\hline Defeito 3 & Omission & Data \\
\hline Defeito 4 & Commission & Cosmetic \\
\hline Defeito 5 & Omission & Control \\
\hline Defeito 6 & Omission & Control \\
\hline Defeito 7 & Commission & Cosmetic \\
\hline Defeito 8 & Commission & Interface \\
\hline
\end{tabular}

Tabela 4.3 - Ntree: Tipos e classes de defeitos.

\begin{tabular}{|l|c|c|}
\hline Defeito & Classe & Tipo \\
\hline Defeito 1 & Commission & Initialization \\
\hline Defeito 2 & Commission & Cosmetic \\
\hline Defeito 3 & Commission & Interface \\
\hline Defeito 4 & Commission & Control \\
\hline Defeito 5 & Commission & Data \\
\hline Defeito 6 & Commission & Initialization \\
\hline Defeito 7 & Omission & Control \\
\hline Defeito 8 & Commission & Interface \\
\hline Defeito 9 & Omission & Interface \\
\hline
\end{tabular}

Tabela 4.4 - Cmdline: Tipos e classes de defeitos. 


\begin{tabular}{|l|c|c|}
\hline Defeito & Classe & Tipo \\
\hline Defeito 1 & Commission & Data \\
\hline Defeito 2 & Omission & Computation \\
\hline Defeito 3 & Omission & Data \\
\hline Defeito 4 & Omission & Control \\
\hline Defeito 5 & Omission & Interface \\
\hline Defeito 6 & Commission & Cosmetic \\
\hline Defeito 7 & Commission & Control \\
\hline Defeito 8 & Omission & Control \\
\hline
\end{tabular}

Tabela 4.5 - Nametbl: Tipos e classes de defeitos.

As especificações e os códigos fontes dos programas utilizados tanto na fase de treinamento como na execução do experimento encontram-se disponíveis junto ao pacote de replicação disponível eletronicamente em http://nt-labes.icmc.sc.usp.br/projetos/nsf-cnpq.

\subsection{Procedimentos}

Um total de 12 alunos da pós-graduação foi selecionado para participar do experimento. A Tabela 4.6 apresenta o perfil dos indivíduos com relação ao nível de proficiência em Inglês, experiência em programação e experiência na linguagem C.

A Tabela 4.7 apresenta o esquema de classificação utilizado para determinar o nível de conhecimento dos indivíduos na linguagem C. Quanto mais alto o nível maior é o conhecimento da linguagem. O indivíduo com identificação número 1, por exemplo, tem 25 anos de experiência em programação e um conhecimento básico da linguagem C. Nesse caso, mesmo o indivíduo tendo um conhecimento básico da linguagem $\mathrm{C}$ foi atribuído a ele o conceito Nível 2 (em vez de Nível 1 por exemplo), pelo fato da sua longa experiência em programação.

O objetivo desse esquema de classificação é melhorar o conceito em função da experiência em programação e também evitar que, por exemplo, um indivíduo que tenha pouca experiência em programação (iniciante) e que relatou nos formulários de entrevista que é expert em linguagem $\mathrm{C}$ fique classificado com o nível mais alto. Como pode ser observado na Tabela 4.7, nesses casos não se aplica (N/A) o conceito mais alto e sim um conceito de menor significância. 


\begin{tabular}{|l|c|c|c|}
\hline $\begin{array}{c}\text { ID dos } \\
\text { Indivíduos }\end{array}$ & $\begin{array}{c}\text { Nível de proficiência } \\
\text { em Inglês (leitura) }\end{array}$ & $\begin{array}{c}\text { Experiência em } \\
\text { programação (anos) }\end{array}$ & $\begin{array}{c}\text { Experiência na } \\
\text { linguagem C }\end{array}$ \\
\hline Indivíduo 01 & Avançado & 25 & Nível 2 \\
\hline Indivíduo 02 & Avançado & 18 & Nível 1 \\
\hline Indivíduo 03 & Avançado & 6 & Nível 5 \\
\hline Indivíduo 04 & Avançado & 16 & Nível 3 \\
\hline Indivíduo 05 & Médio & 7 & Nível 5 \\
\hline Indivíduo 06 & Médio & 6 & Nível 4 \\
\hline Indivíduo 07 & Médio & 5 & Nível 3 \\
\hline Indivíduo 08 & Médio & 14 & Nível 4 \\
\hline Indivíduo 09 & Avançado & 4 & Nível 5 \\
\hline Indivíduo 10 & Expert & 4 & Nível 5 \\
\hline Indivíduo 11 & Expert & 14 & Nível 4 \\
\hline Indivíduo 12 & Avançado & 4 & \\
\hline
\end{tabular}

Tabela 4.6 - Perfil dos indivíduos com relação a experiência em programação e proficiência em Inglês.

\begin{tabular}{|l|l|l|l|c|}
\hline $\begin{array}{c}\text { Experiência na } \\
\text { linguagem C }\end{array}$ & Sênior & Master & Júnior & Iniciante \\
\hline Expert & Nível 5 & Nível 5 & Nível 4 & N/A \\
\hline Avançado & Nível 4 & Nível 4 & Nível 3 & N/A \\
\hline Médio & Nível 4 & Nível 3 & Nível 3 & Nível 2 \\
\hline Básico & Nível 3 & Nível 2 & Nível 1 & Nível 1 \\
\hline
\end{tabular}

Tabela 4.7 - Esquema de classificação da experiência na linguagem C.

A fase de treinamento foi realizada em dois dias consecutivos e contou com um total de 5 sessões de $2 \mathrm{~h} 30 \mathrm{~min}$ cada, uma para cada técnica. Durante as sessões, 40 minutos foram destinados à apresentação teórica das técnicas e 110 minutos foram destinados para aplicação prática das técnicas. Foram realizadas as seguintes sessões de treinamento: (1 $\left.{ }^{\mathrm{a}}\right)$ Treinamento na técnica Leitura de Código utilizando o programa de treinamento "count.c"; (2a ) Treinamento na técnica Teste Funcional utilizando o programa de treinamento "series.c"; ( $\left.3^{\mathrm{a}}\right)$ Treinamento na técnica Teste Incremental utilizando o programa de treinamento "tokens.c". A $3^{\mathrm{a}}$ fase do treinamento foi subdividida em 3: (3.1) Treinamento nos critérios baseados em fluxo de controle: Todos-Nós e Todos-Arcos; (3.2) Treinamento nos critérios baseados em fluxo de dados: TodosUsos e Todos-Potenciais-Usos; (3.3) Treinamento no critério Análise de Mutantes.

A fase de execução do experimento foi realizada ao longo de 3 semanas consecutivas. $\mathrm{Na}$ $1^{\text {a }}$ semana ocorreram 3 sessões de inspeção utilizando o programa "ntree.c", uma utilizando a técnica Leitura de Código com duração de 6 horas, uma utilizando a técnica Teste Funcional com duração de 6 horas, e outra utilizando a técnica Teste Incremental com duração de 12 horas. Os indivíduos que aplicaram a técnica Teste Incremental gastaram 2 dias e os que aplicaram as outras técnicas gastaram apenas 1 dia. Foram utilizados laboratórios e salas de aulas para realizar 
os experimentos. Os indivíduos que aplicaram a técnica Leitura de Código utilizam uma sala de aula, enquanto que os indivíduos que aplicaram as técnicas de teste utilizaram laboratórios. As salas e laboratórios foram monitorados durante todo o experimento. A organização da $2^{\mathrm{a}}$ e $3^{\mathrm{a}}$ semana é similar à descrita acima, alternando somente os programas. $\mathrm{Na} 2^{\mathrm{a}}$ semana foi utilizado o programa "cmdline.c" e na $3^{\mathrm{a}}$ semana o programa "nametbl.c".

Os materiais utilizados nas fases de treinamento e na execução do experimento, bem como todos os formulários utilizados para coletar informações da execução encontram-se no pacote de replicação disponível eletronicamente em http://ntlabes.icmc.sc.usp.br/projetos/nsf-cnpq.

\subsection{Resultados}

Esta seção apresenta os principais resultados obtidos durante a replicação desse experimento. Na Seção 4.7.1 são apresentados os resultados referentes aos defeitos isolados, na Seção 4.7.2 são apresentados os resultados referentes as falhas observadas, e na Seção 4.7.3 é apresentada a análise dos resultados obtidos por meio da aplicação de técnicas estatísticas.

\subsubsection{Análise dos Defeitos}

A seguir apresentam-se as análises referentes aos defeitos isolados pelas técnicas em cada um dos programas utilizados durante a replicação do experimento. Conforme apresentado na Seção 4.3, para cada um dos programas têm-se: 4 indivíduos aplicando a técnica Leitura de Código (CR), 4 indivíduos aplicando a técnica Teste Funcional (FT) e 4 indivíduos aplicando a técnica Teste Incremental (IT).

Os defeitos isolados pelas técnicas em cada um dos programas são apresentados em 3 diferentes visões. A visão 1 apresenta a efetividade das técnicas por grupo de indivíduos; a visão 2 apresenta a efetividade das técnicas pelo número de ocorrências de defeitos; e a visão 3 apresenta a identificação da melhor técnica por defeito. 


\section{Análise dos defeitos do programa NTREE}

A Figura 4.1 apresenta as quantidades de cada defeito que foram isolados por cada técnica quando aplicadas no programa "ntree.c".

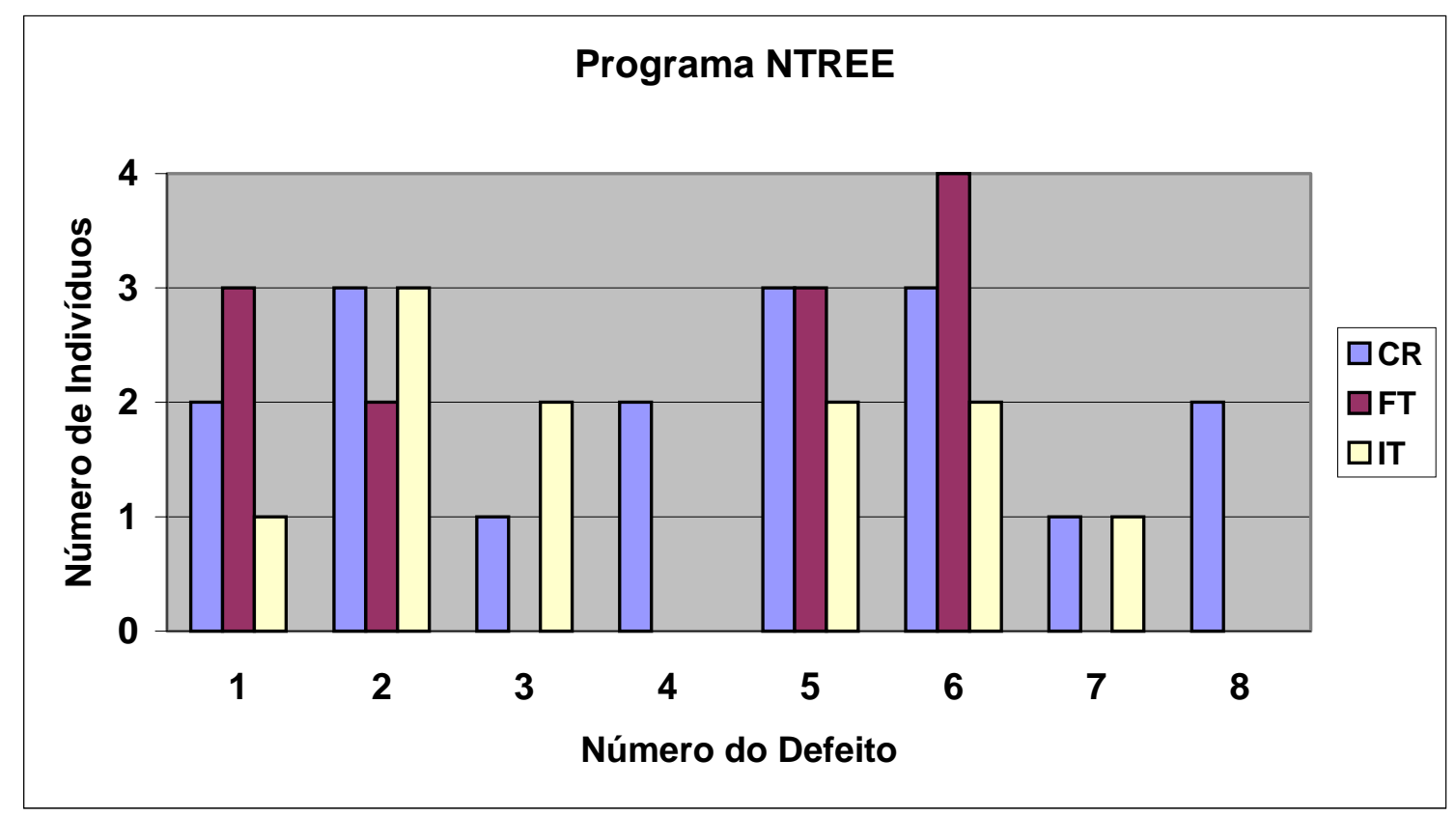

Figura 4.1 - Programa Ntree: Defeitos isolados pelas técnicas.

\begin{tabular}{|l|c|c|}
\cline { 2 - 3 } \multicolumn{1}{c|}{} & $\begin{array}{c}\text { Média de experiência } \\
\text { com programação }\end{array}$ & $\begin{array}{c}\text { Membros do } \\
\text { grupos }\end{array}$ \\
\hline Leitura de Código & 8 & Indivíduos 06, 10, 12, 02 \\
\hline Teste Funcional & 12,5 & Indivíduos 01, 05, 09, 11 \\
\hline Teste Incremental & 10,3 & Indivíduos 03, 04, 07, 08 \\
\hline
\end{tabular}

Tabela 4.8 - Ntree: Média de experiência dos indivíduos com programação em cada técnica.

\begin{tabular}{|l|c|c|}
\cline { 2 - 3 } \multicolumn{1}{c|}{} & \multicolumn{1}{c|}{$\begin{array}{c}\text { Possibilidades de } \\
\text { isolamento }\end{array}$} & $\begin{array}{c}\text { Defeitos } \\
\text { Isolados }\end{array}$ \\
\hline Leitura de Código & 32 & 17 \\
\hline Teste Funcional & 32 & 12 \\
\hline Teste Incremental & 32 & 11 \\
\hline
\end{tabular}

Tabela 4.9 - Ntree: Possibilidades de isolamento e quantidades isoladas de defeitos por técnica.

Em uma análise preliminar, conforme pode ser observado na Tabela 4.9, a técnica Leitura de Código isolou um número maior de defeitos que as outras técnicas. Das 32 possibilidades de 
isolamento de defeitos, obtida pela razão entre a quantidade de defeitos (8) contidos no programa "ntree.c" e a quantidade de indivíduos (4) que aplicaram a técnica, 17 foram isolados. A experiência com programação não influenciou nos resultados obtidos pelos indivíduos. $\mathrm{O}$ grupo de indivíduos que aplicou a técnica Leitura de Código tem a menor média de experiência com programação entre todos os participantes, conforme pode ser visto na Tabela 4.8.

\begin{tabular}{|c|c|c|c|c|c|c|c|c|}
\hline & & \multicolumn{7}{|c|}{ Programa 1 - NTREE } \\
\hline & & \multirow{2}{*}{$\begin{array}{c}\text { Quantidade } \\
\text { de defeitos } \\
\text { originais }\end{array}$} & \multicolumn{2}{|c|}{ Leitura de Código } & \multicolumn{2}{|c|}{ Teste Funcional } & \multicolumn{2}{|c|}{ Teste Incremental } \\
\hline & & & \begin{tabular}{|c|}
$\begin{array}{c}\text { Quantidade } \\
\text { isolada }\end{array}$ \\
\end{tabular} & $\%$ & \begin{tabular}{c|} 
Quantidade \\
isolada
\end{tabular} & $\%$ & \begin{tabular}{|c|} 
Quantidade \\
isolada \\
\end{tabular} & $\%$ \\
\hline \multirow[t]{2}{*}{ Classe } & Omission & 4 & 9 & 56,25 & 10 & 62,50 & 7 & 43,75 \\
\hline & Commission & 4 & 8 & 50,00 & 2 & 12,50 & 4 & 25,00 \\
\hline \multirow[t]{6}{*}{ Tipo } & Initialization & $\overline{0}$ & 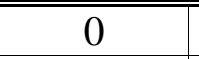 & 0,00 & 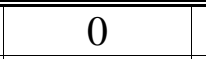 & 0,00 & 0 & 0,00 \\
\hline & Computation & 0 & 0 & 0,00 & 0 & 0,00 & 0 & 0,00 \\
\hline & Control & 3 & 9 & 75,00 & 9 & 75,00 & 7 & 58,33 \\
\hline & Interface & 1 & 2 & 50,00 & 0 & 0,00 & 0 & 0,00 \\
\hline & Data & 2 & 3 & 37,50 & 3 & 37,50 & 3 & 37,50 \\
\hline & Cosmetic & 2 & 3 & 37,50 & 0 & 0,00 & 1 & 12,50 \\
\hline
\end{tabular}

Tabela 4.10 - Ntree: Quantidade e percentual (do total possível) de defeitos isolados por tipos e classes.

A Tabela 4.10 apresenta um detalhamento das quantidades e percentuais (dos totais possíveis) de defeitos isolados pelas técnicas organizados por classes e tipos de defeitos. Os resultados mostram que as técnicas foram mais efetivas no isolamento de defeitos da classe Omission e do tipo Control.

A Figura 4.2 apresenta um detalhamento dos defeitos isolados pelos critérios que compõem a técnica Teste Incremental. Parte significativa dos defeitos foram isolados pelo critério todos-nós, em contrapartida, somente o critério análise de mutantes revelou os defeitos número 1 e 3, que são do tipo Data. Os critérios baseados em fluxo de dados não isolaram nenhum defeito.

As taxas médias de cobertura que os indivíduos alcançaram com cada critério do Teste Incremental podem ser vistas na Figura 4.3. Em uma análise preliminar, observa-se que vários indivíduos não conseguiram aplicar os critérios completamente, ou seja, não conseguiram alcançar a cobertura total possível. O indivíduo 7, por exemplo, aplicando o critério Todos-Nós alcançou somente 95,6\% de cobertura contra um total possível de 98,4\%. Em termos práticos isso significa que o indivíduo não conseguiu determinar casos de teste suficientes para executar todas os comandos do programa. 


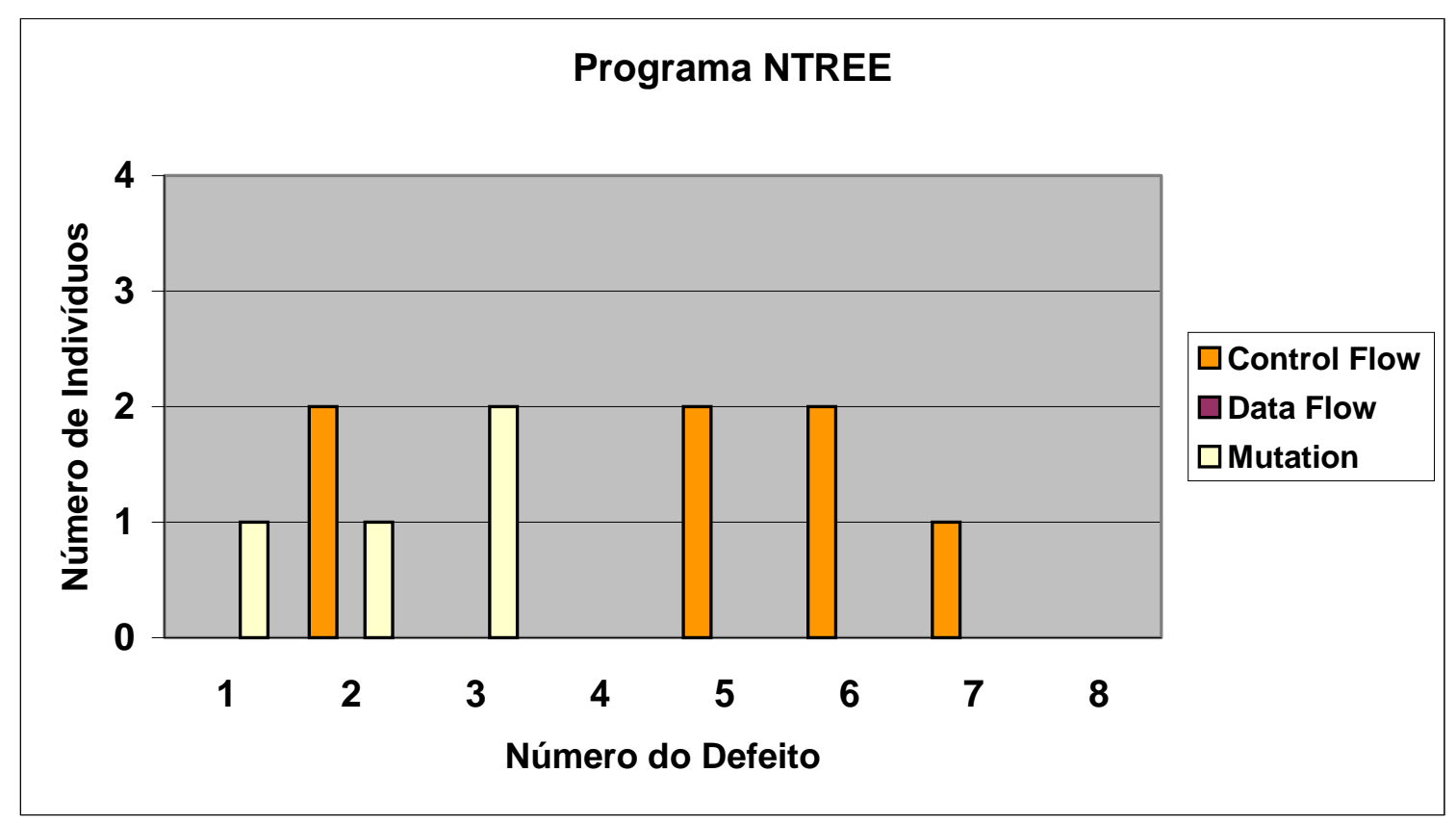

Figura 4.2 - Ntree: Defeitos isolados pelo Teste Incremental.

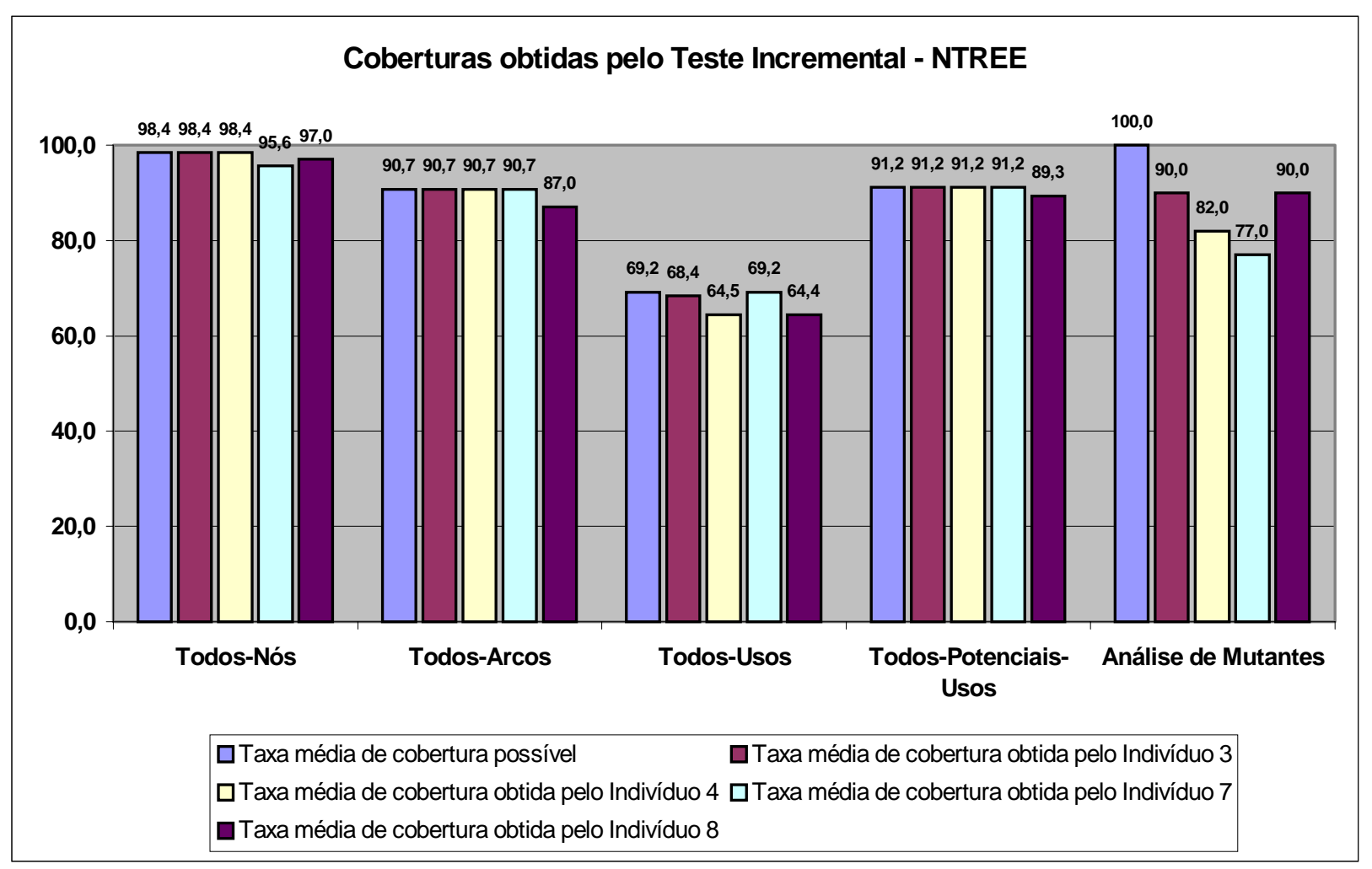

Figura 4.3 - Ntree: Coberturas obtidas pelos indivíduos aplicando o Teste Incremental. 
A Tabela 4.11 apresenta um detalhamento dos casos de teste que foram necessários para alcançar as coberturas mencionadas na Figura 4.3. O indivíduo 8, por exemplo, obteve um conjunto de 8 casos de teste e isolou 2 defeitos aplicando o critério Todos-Nós. Ao conjunto inicial foram adicionados mais 3 casos de teste por meio da aplicação do critério Todos-Arcos, conforme prevê o Teste Incremental. Pode-se observar que estes novos casos de teste não foram suficientes para isolar novos defeitos e não permitiram alcançar a cobertura máxima possível para o critério, ou seja, houve um custo adicional desnecessário na ordem de 37,5\% em relação ao conjunto anterior. De forma similar o conjunto evoluiu sem efeitos práticos até o critério Análise de Mutantes. Para o critério Análise de Mutantes o custo adicional para isolar um novo defeito foi de $62,5 \%$.

\begin{tabular}{|c|c|c|c|c|c|c|c|c|c|c|c|c|c|c|}
\hline & \multicolumn{2}{|c|}{ Todos-Nós } & \multicolumn{3}{|c|}{ Todos-Arcos } & \multicolumn{3}{|c|}{ Todos-Usos } & \multicolumn{3}{|c|}{$\begin{array}{c}\text { Todos-Potenciais- } \\
\text { Usos }\end{array}$} & \multicolumn{3}{|c|}{$\begin{array}{l}\text { Análise de } \\
\text { Mutantes }\end{array}$} \\
\hline & T1 & Q1 & T2 & $\% 1$ & Q2 & T3 & $\% 2$ & Q3 & T4 & $\% 3$ & Q4 & T5 & $\% 4$ & Q5 \\
\hline Indivíduo 3 & 6 & 4 & 7 & $16,6 \%$ & 0 & 9 & $50,0 \%$ & 0 & 9 & $0 \%$ & 0 & 11 & $83,3 \%$ & 2 \\
\hline Indivíduo 4 & 7 & 1 & 7 & $0 \%$ & 0 & 7 & $0 \%$ & 0 & 7 & $0 \%$ & 0 & 7 & $0 \%$ & 0 \\
\hline Indivíduo 7 & 14 & 0 & 16 & $14,2 \%$ & 0 & 16 & $0 \%$ & 0 & 16 & $0 \%$ & 0 & 16 & $0 \%$ & 1 \\
\hline Indivíduo 8 & 8 & 2 & 11 & $37,5 \%$ & 0 & 12 & $50,0 \%$ & 0 & 12 & $0 \%$ & 0 & 13 & $62,5 \%$ & 1 \\
\hline & & & ant & $\begin{array}{l}\text { ade de } \\
\%_{\mathbf{n}}-\mathrm{P} \\
\text { lade de }\end{array}$ & & & & & & & & & & \\
\hline
\end{tabular}

Tabela 4.11 - Custo e eficiência dos conjuntos de casos de teste obtidos com cada critério do Teste Incremental.

A seguir, apresentam-se três diferentes visões dos dados apresentados na Figura 4.1:

A visão 1 permite verificar quais defeitos foram isolados pelas técnicas e qual a efetividade absoluta de cada grupo de indivíduos. Como pode ser observado na Figura 4.4 (a), a técnica Leitura de Código isolou: 2 defeitos que nenhuma outra técnica isolou, são eles: 4 e 8 (ver Figura 4.4 (b)); 2 defeitos que também foram isolados pela técnica Teste Incremental, são eles: 3 e 7; 4 defeitos que também foram isolados pelas técnicas Teste Funcional e Teste Incremental, são eles: 1, 2, 5 e 6. A técnica Leitura de Código obteve uma efetividade de 100\%, ou seja, dos 8 defeitos existentes no programa "ntree.c" todos foram descobertos. É importante ressaltar que somente a técnica Leitura de Código isolou os defeitos 4 e 8 . Estes defeitos são do tipo Cosmetic e Interface, respectivamente. Acredita-se que a técnica descobriu esses defeitos uma vez que se baseia fundamentalmente na leitura do código fonte. 
Visão 1 - Efetividade das técnicas por grupo de indivíduos

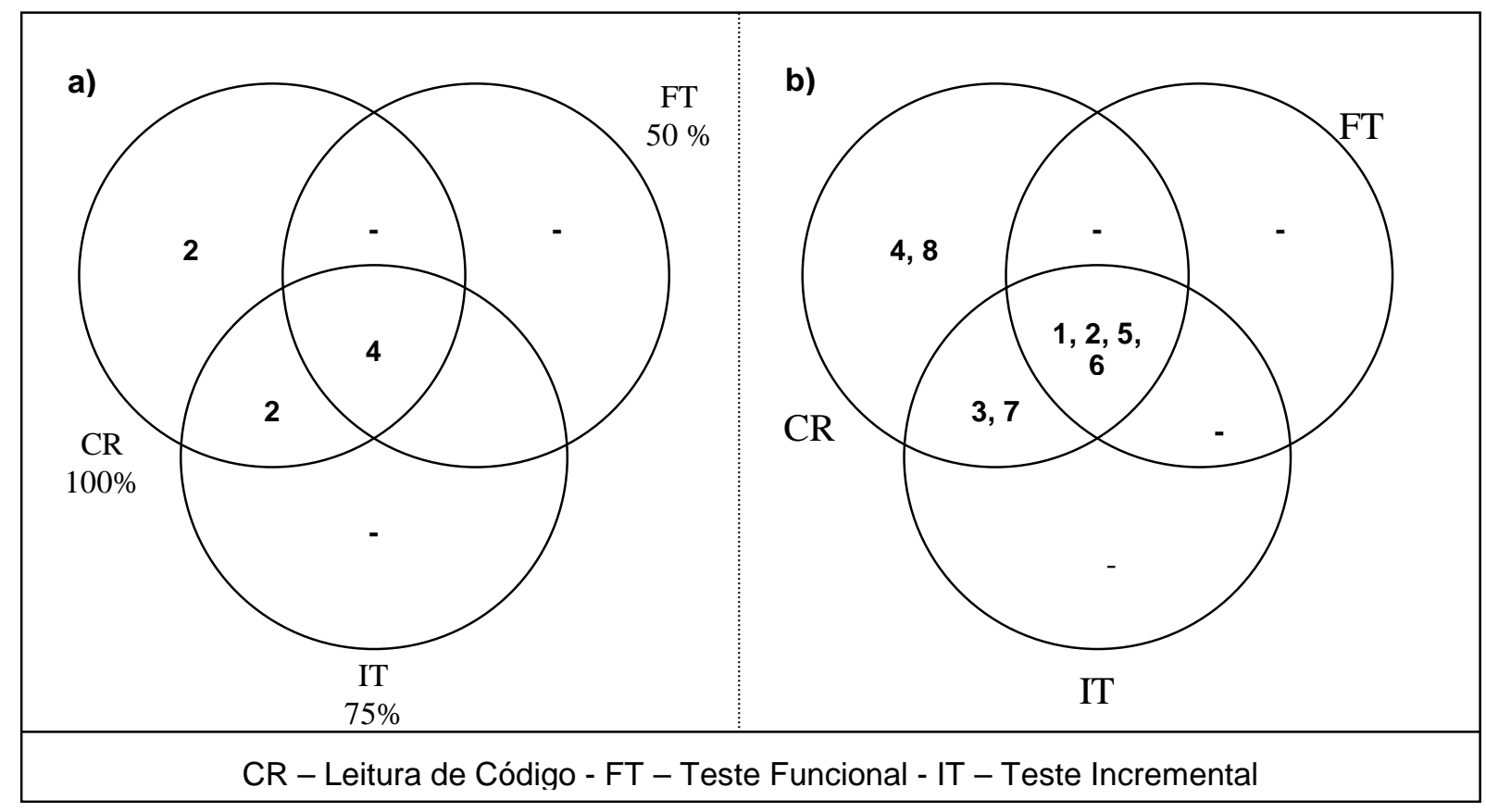

Figura 4.4 - Ntree: (a) Quantidade e percentual de defeitos isolados pelas técnicas; (b) Identificação dos defeitos isolados pelas técnicas.

Visão 2 - Efetividade das técnicas pelo número de ocorrências de defeitos

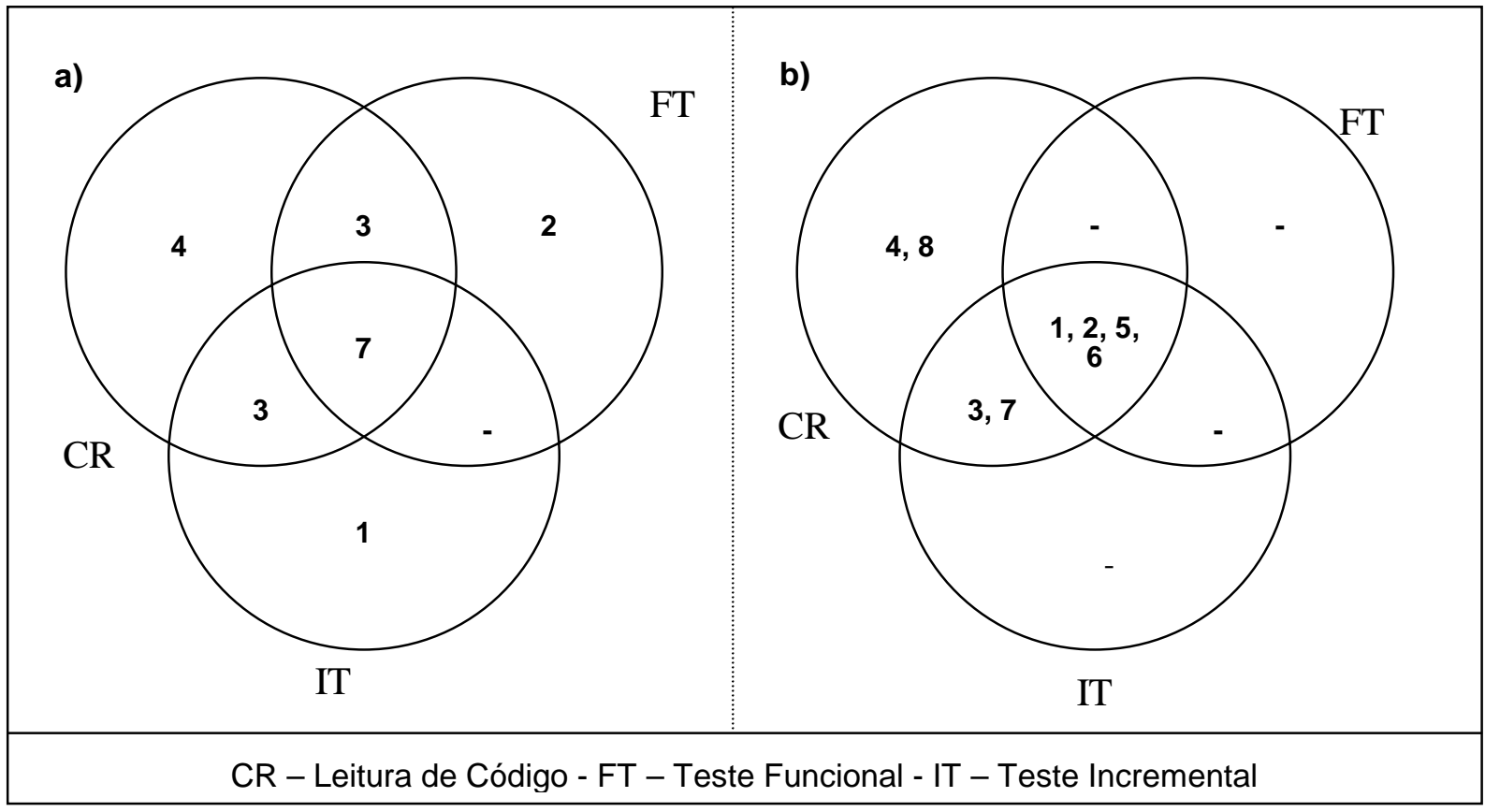

Figura 4.5 - Ntree: (a) Número de ocorrências de defeitos isolados pelas técnicas; (b) Identificação dos defeitos isolados pelas técnicas. 
A visão 2 permite verificar qual técnica conseguiu ser mais efetiva em número de ocorrências no isolamento de determinados defeitos que foram isolados, por exemplo, por todas as técnicas. Como pode ser observado na Figura 4.5 (b), os defeitos 1, 2, 5 e 6 foram isolados por todas as técnicas. No caso os defeitos 1 e 6 foram isolados mais vezes pela técnica Teste Funcional do que pelas outras técnicas. As quantidades totalizadas de ocorrências de defeitos isolados pelas técnicas são apresentados na Figura 4.5 (a).

A visão 3 permite verificar para quais defeitos a técnica obteve melhor ou igual desempenho que as outras técnicas. Conforme pode ser observado na Figura 4.6 (b), o defeito 3, por exemplo, foi isolado tanto pela técnica Leitura de Código como pela técnica Teste Incremental, mas a técnica Teste Incremental foi mais efetiva, ou seja, isolou uma quantidade maior deste defeito do que a técnica Leitura de Código. A Figura 4.6 (a) apresenta a identificação dos defeitos onde a técnica obteve melhor ou igual desempenho que as outras técnicas.

Visão 3 - Identificação da melhor técnica por defeito

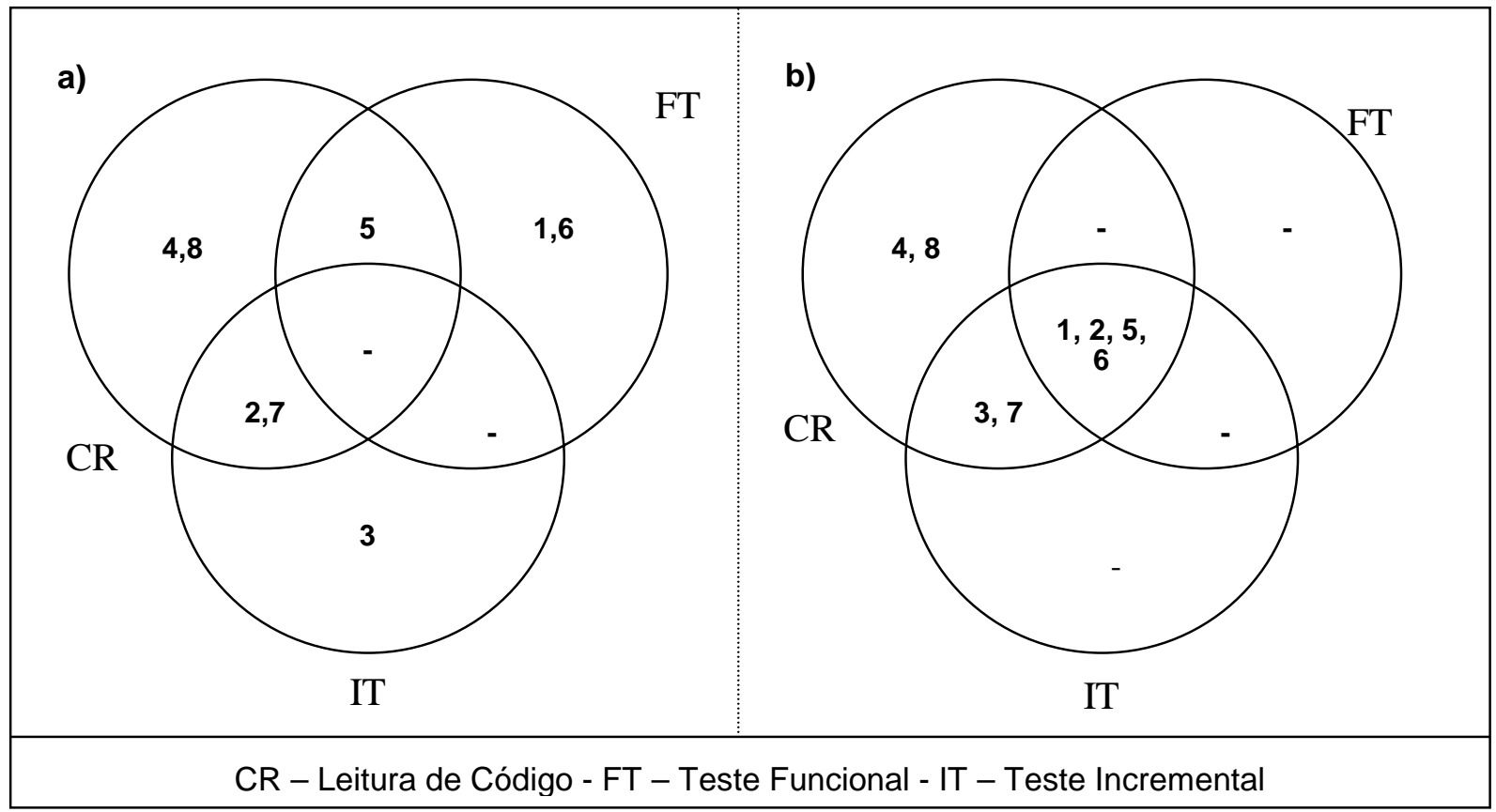

Figura 4.6 - Ntree: (a) Identificação dos defeitos onde a técnica obteve melhor ou igual desempenho que às outras técnicas; (b) Identificação dos defeitos isolados pelas técnicas. 


\section{Análise dos defeitos do programa CMDLINE}

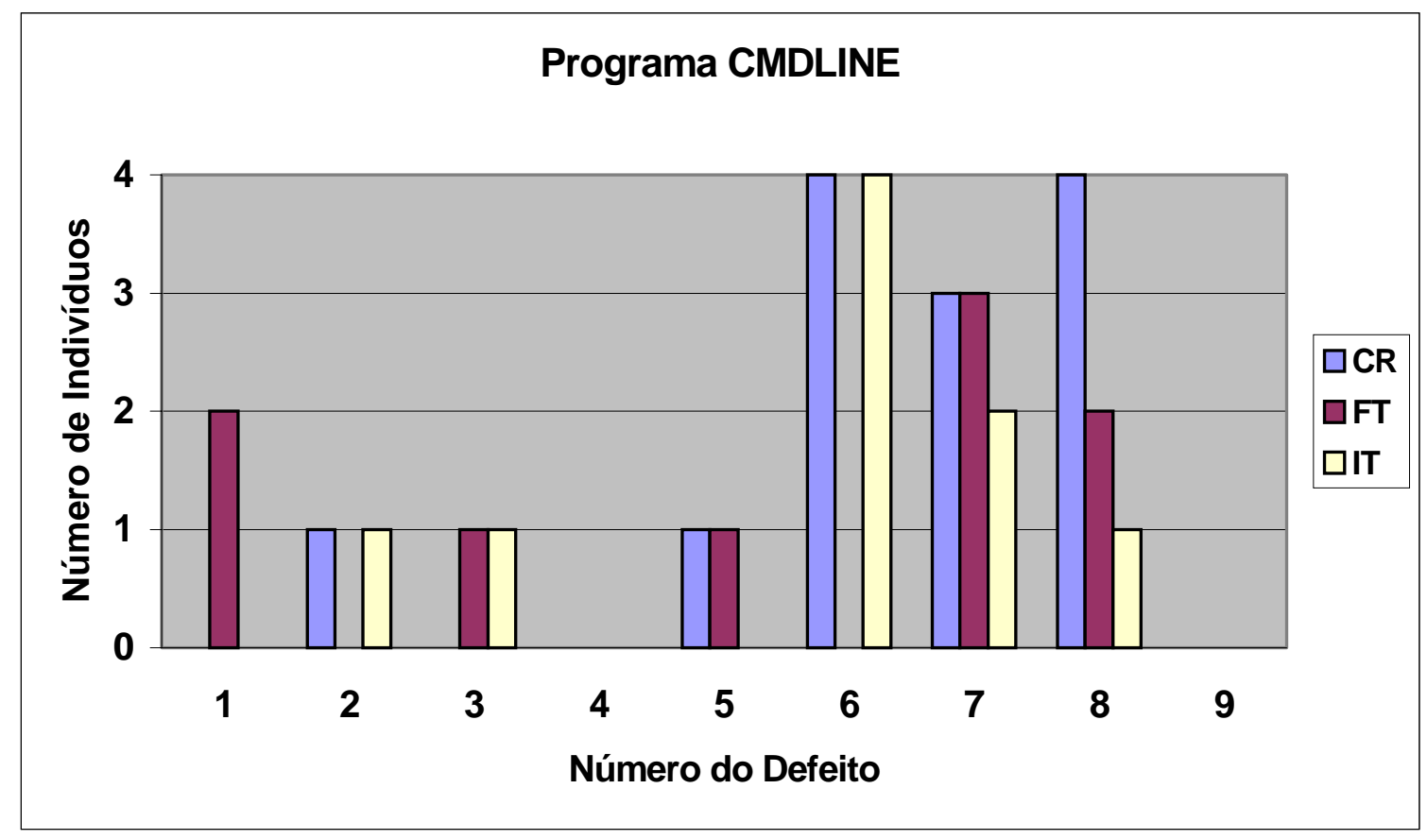

Figura 4.7 - Cmdline: Defeitos isolados pelas técnicas.

A Figura 4.7 apresenta as quantidades de cada defeito que foram isolados por cada técnica quando aplicadas no programa "cmdline.c".

\begin{tabular}{|l|c|c|}
\cline { 2 - 3 } \multicolumn{1}{c|}{} & $\begin{array}{c}\text { Média de experiência } \\
\text { com programação }\end{array}$ & $\begin{array}{c}\text { Membros do } \\
\text { grupos }\end{array}$ \\
\hline Leitura de Código & 13,3 & Indivíduos 01, 04, 05, 07 \\
\hline Teste Funcional & 11,0 & Indivíduos 02, 03, 06, 08 \\
\hline Teste Incremental & 6,5 & Indivíduos 09, 10, 11, 12 \\
\hline
\end{tabular}

Tabela 4.12 - Cmdline: Média de experiência dos indivíduos com programação em cada técnica.

\begin{tabular}{|l|c|c|}
\cline { 2 - 3 } \multicolumn{1}{c|}{} & \multicolumn{1}{c|}{$\begin{array}{c}\text { Possibilidades de } \\
\text { isolamento }\end{array}$} & $\begin{array}{c}\text { Defeitos } \\
\text { isolados }\end{array}$ \\
\hline Leitura de Código & 36 & 13 \\
\hline Teste Funcional & 36 & 09 \\
\hline Teste Incremental & 36 & 09 \\
\hline
\end{tabular}

Tabela 4.13 - Cmdline: Possibilidades de isolamento e quantidades isoladas de defeitos por técnica.

Em outra análise preliminar, conforme pode ser observado na Tabela 4.13, a técnica Leitura de Código isolou um número maior de defeitos que as outras técnicas. Das 36 
possibilidades de isolamento de defeitos, obtida pela razão entre a quantidade de defeitos (9) contidos no programa "cmdline.c" e a quantidade de indivíduos (4) que aplicaram a técnica, 13 foram isolados. A experiência com programação pode ter de alguma forma influenciado nos resultados obtidos pelos indivíduos, uma vez que o grupo tem a maior média de experiência com programação entre todos os participantes, conforme pode ser visto na Tabela 4.12.

A Tabela 4.14 apresenta um detalhamento das quantidades e percentuais (dos totais possíveis) de defeitos isolados pelas técnicas organizados por classes e tipos de defeitos. Os resultados mostram que as técnicas foram mais efetivas no isolamento de defeitos da classe Omission. No caso da técnica Teste Incremental o percentual obtido para defeitos da classe Omission e Commission é o mesmo (25\%). As técnicas Leitura de Código e Teste Incremental foram mais efetivas no isolamento de defeitos do tipo Initialization, enquanto que a técnica Teste Funcional foi mais efetiva no isolamento de defeitos do tipo Control.

\begin{tabular}{|l|l|c|c|c|c|c|c|c|}
\cline { 3 - 9 } \multicolumn{2}{c|}{} & \multicolumn{9}{c|}{ Programa 2 - CMDLINE } \\
\cline { 3 - 9 } \multicolumn{2}{c|}{} & $\begin{array}{c}\text { Quantidade } \\
\text { de defeitos } \\
\text { originais }\end{array}$ & \begin{tabular}{c} 
Leitura de Código \\
\cline { 3 - 9 }
\end{tabular} & $\begin{array}{c}\text { Quantidade } \\
\text { isolada }\end{array}$ & $\%$ & $\begin{array}{c}\text { Tuantidade Funcional } \\
\text { isolada }\end{array}$ & $\%$ & \multicolumn{2}{c|}{ Teste Incremental } \\
isolidada & $\%$ \\
\hline Classe & Omission & 2 & 3 & 37,50 & 3 & 37,50 & 2 & 25,00 \\
\hline & Commission & 7 & 10 & 35,71 & 6 & 21,43 & 7 & 25,00 \\
\hline \hline Tipo & Initialization & 2 & 4 & 50,00 & 2 & 25,00 & 4 & 50,00 \\
\hline & Computation & 0 & 0 & 0,00 & 0 & 0,00 & 0 & 0,00 \\
\hline & Control & 2 & 3 & 37,50 & 3 & 37,50 & 2 & 25,00 \\
\hline & Interface & 3 & 4 & 33,33 & 3 & 25,00 & 2 & 16,67 \\
\hline & Data & 1 & 1 & 25,00 & 1 & 25,00 & 0 & 0,00 \\
\hline & Cosmetic & 1 & 1 & 25,00 & 0 & 0,00 & 1 & 25,00 \\
\hline \hline
\end{tabular}

Tabela 4.14 - Cmdline: Quantidade e percentual (do total possível) de defeitos isolados por tipos e classes.

A Figura 4.8 apresenta um detalhamento dos defeitos isolados pelos critérios que compõem a técnica Teste Incremental. Parte significativa dos defeitos foram isolados pelo critério Todos-Nós, em contrapartida, somente o critério análise de mutantes revelou os defeitos 3 e 8 , que são do tipo Interface.

As taxas médias de cobertura que os indivíduos alcançaram com cada critério do Teste Incremental podem ser vistas na Figura 4.9 Em outra análise preliminar, observa-se que vários indivíduos não conseguiram aplicar os critérios completamente, ou seja, não conseguiram alcançar a cobertura total possível. O indivíduo 9, por exemplo, aplicando o critério Todos-Nós alcançou somente $87,4 \%$ de cobertura contra um total possível de $96,0 \%$. Em termos práticos isso significa que o indivíduo não conseguiu determinar casos de teste suficientes para executar todos os comandos do programa. 


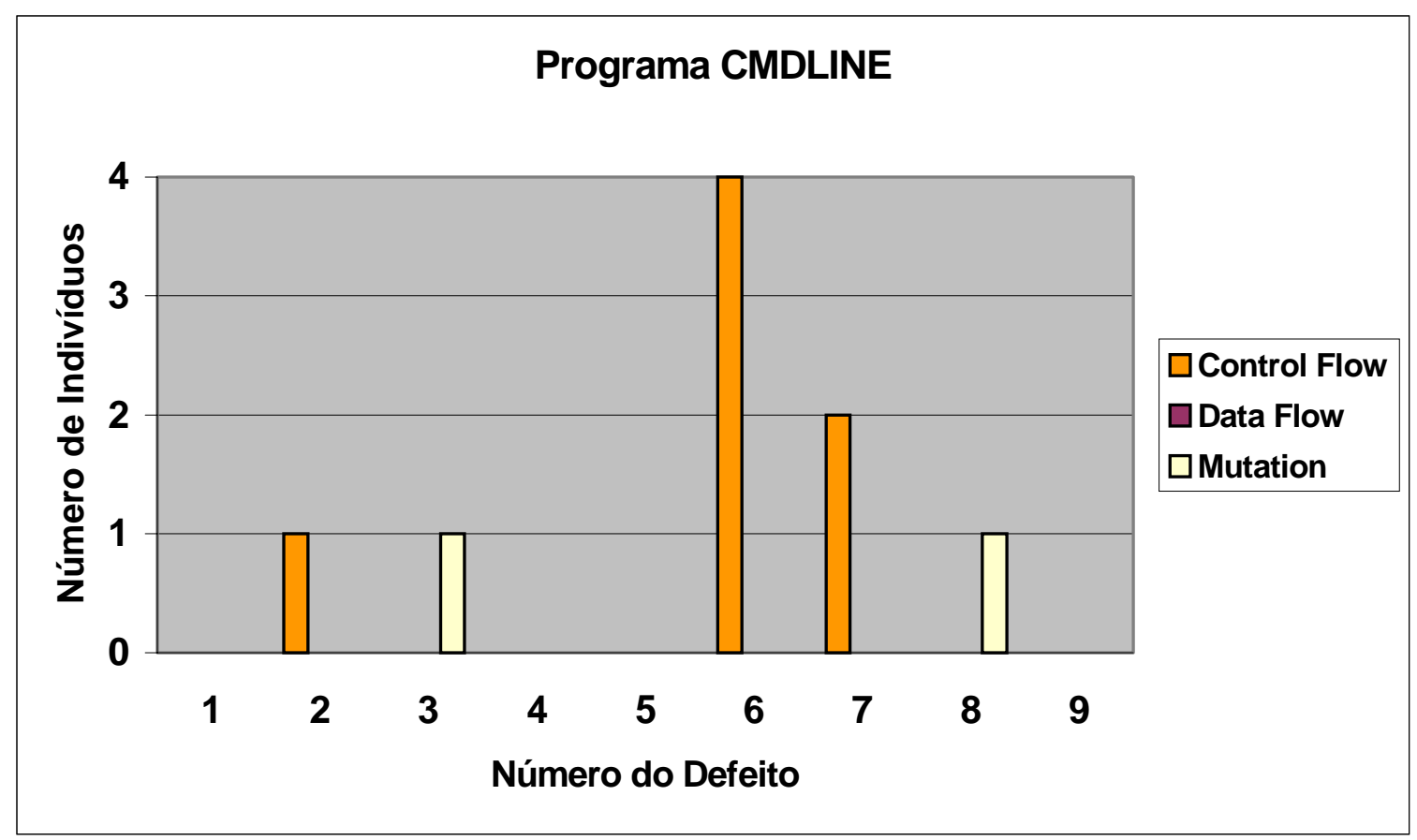

Figura 4.8 - Cmdline: Defeitos isolados pelo Teste Incremental.

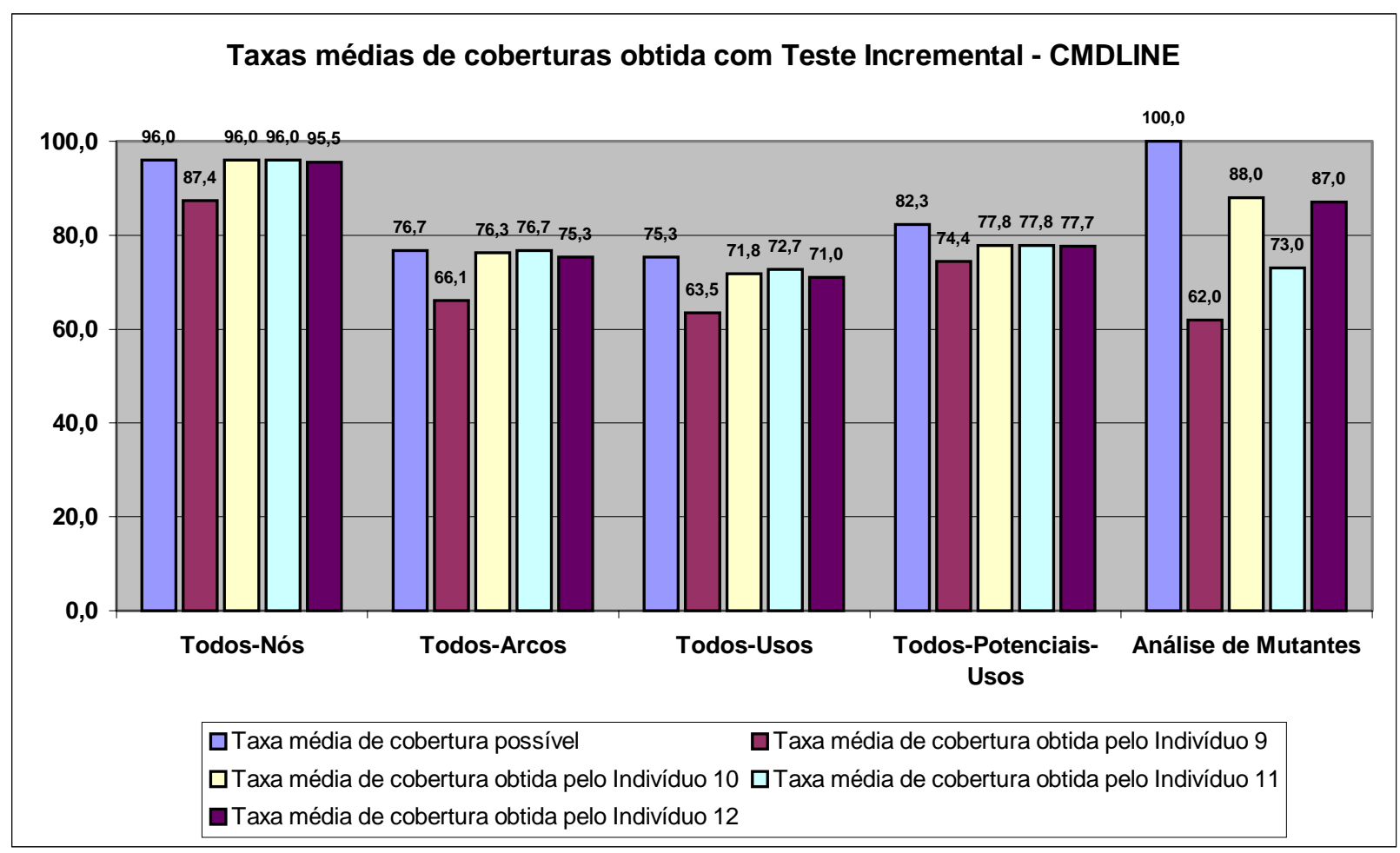

Figura 4.9 - Cmdline: Coberturas obtidas pelos indivíduos aplicando o Teste Incremental. 
A Tabela 4.15 apresenta um detalhamento dos casos de teste que foram necessários para alcançar as coberturas mencionadas na Figura 4.9. O indivíduo 9, por exemplo, obteve um conjunto de 11 casos de teste e isolou somente 1 defeito aplicando o critério Todos-Nós. Ao conjunto inicial foram adicionados mais 7 casos de teste por meio da aplicação do critério Todos-Arcos, conforme prevê o Teste Incremental. Pode-se observar que estes novos casos de teste não foram suficientes para isolar novos defeitos e não permitiram alcançar a cobertura máxima possível para o critério, ou seja, houve um custo adicional desnecessário na ordem de $63,6 \%$ em relação ao conjunto anterior. De forma similar o conjunto evoluiu sem efeitos práticos até o critério Análise de Mutantes. Neste caso o custo adicional para isolar um novo defeito foi de $62,5 \%$.

\begin{tabular}{|c|c|c|c|c|c|c|c|c|c|c|c|c|c|c|}
\hline & \multicolumn{2}{|c|}{ Todos-Nós } & \multicolumn{3}{|c|}{ Todos-Arcos } & \multicolumn{3}{|c|}{ Todos-Usos } & \multicolumn{3}{|c|}{$\begin{array}{c}\text { Todos-Potenciais- } \\
\text { Usos }\end{array}$} & \multicolumn{3}{|c|}{$\begin{array}{l}\text { Análise de } \\
\text { Mutantes }\end{array}$} \\
\hline & T1 & Q1 & T2 & $\% 1$ & Q2 & T3 & $\% 2$ & Q3 & T4 & $\% 3$ & Q4 & T5 & $\% 4$ & Q5 \\
\hline Indivíduo 9 & 11 & 1 & 18 & $63,6 \%$ & 0 & 18 & $0 \%$ & 0 & 18 & $0 \%$ & 0 & 18 & $0 \%$ & 0 \\
\hline Indivíduo 10 & 56 & 2 & 56 & $0 \%$ & 0 & 56 & $0 \%$ & 0 & 56 & $0 \%$ & 0 & 80 & $42,8 \%$ & 1 \\
\hline Indivíduo 11 & 30 & 0 & 30 & $0 \%$ & 0 & 30 & $0 \%$ & 0 & 30 & $0 \%$ & 0 & 40 & $33,3 \%$ & 1 \\
\hline Indivíduo 12 & 26 & 3 & 26 & $0 \%$ & 0 & 26 & $0 \%$ & 0 & 26 & $0 \%$ & 0 & 35 & $34,1 \%$ & 1 \\
\hline & & $\mathrm{T}_{\mathrm{n}}$ & & & & & & & & & & & & \\
\hline
\end{tabular}

Tabela 4.15 - Custo e eficiência dos conjuntos de casos de teste obtidos com cada critério do Teste Incremental

A seguir, apresentam-se três diferentes visões dos dados apresentados na Figura 4.7:

Como pode ser observado na Figura 4.10 (a), a técnica Teste Funcional isolou: 1 defeito que nenhuma outra técnica isolou, que é o defeito 1 (ver Figura 4.10 (b)); 1 defeito que também foi isolado pela técnica Leitura de Código, que é o defeito 5; 1 defeito que também foi isolado pela técnica Teste Incremental, que é o defeito 3; 2 defeitos que também foram isolados pelas técnicas Leitura de Código e Teste Incremental, são eles: 7 e 8 . Todas as técnicas obtiveram uma efetividade de 55,55\%, ou seja, dos 9 defeitos existentes no programa "cmdline.c" somente 5 foram descobertos por cada técnica. É importante ressaltar que somente a técnica Teste Funcional isolou o defeito 1, que é do tipo Initialization. 
Visão 1 - Efetividade das técnicas por grupo de indivíduos

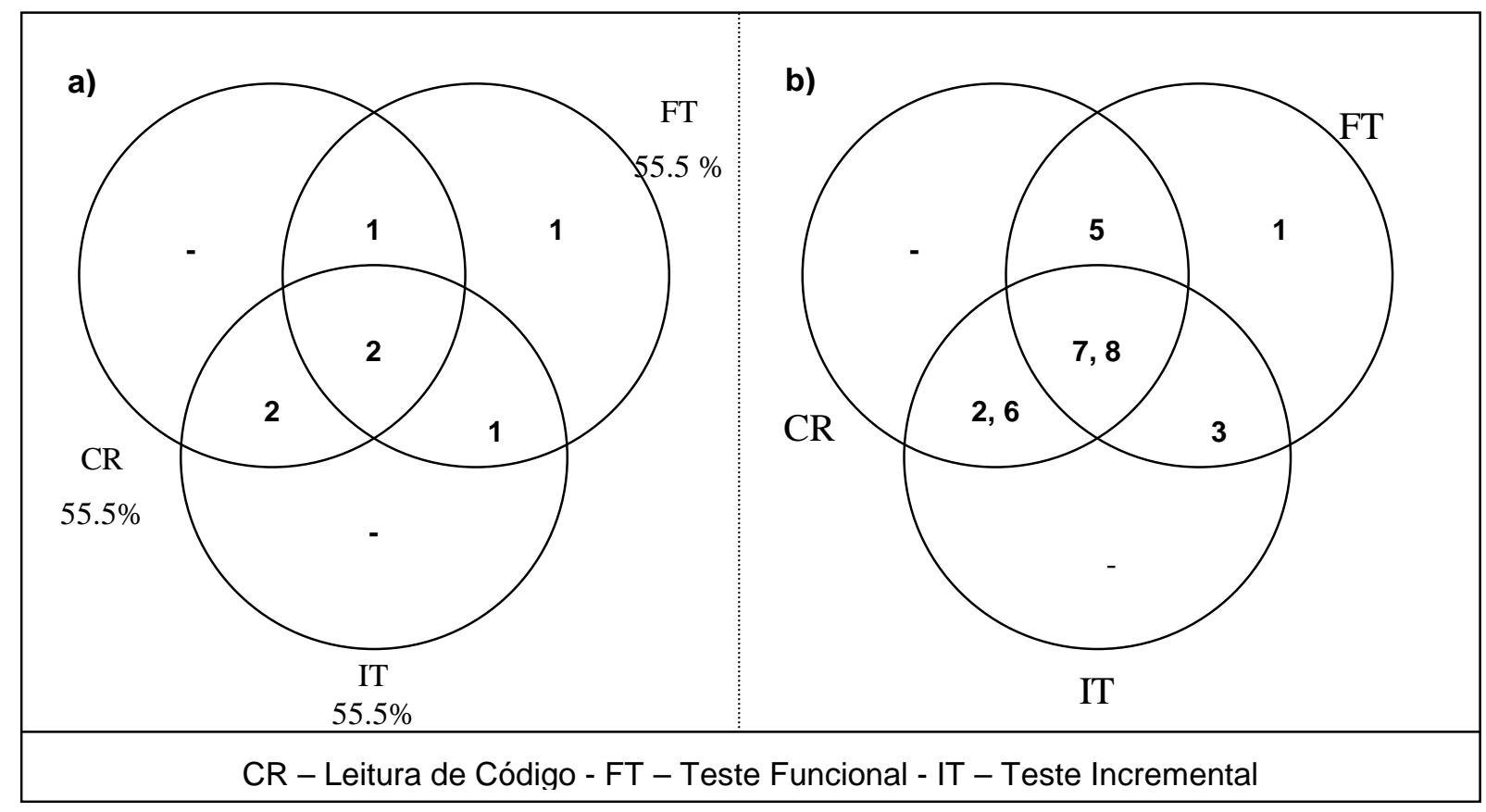

Figura 4.10 - Cmdline: (a) Quantidade e percentual de defeitos isolados pelas técnicas; (b) Identificação dos defeitos isolados pelas técnicas.

Visão 2 - Efetividade das técnicas pelo número de ocorrências de defeitos

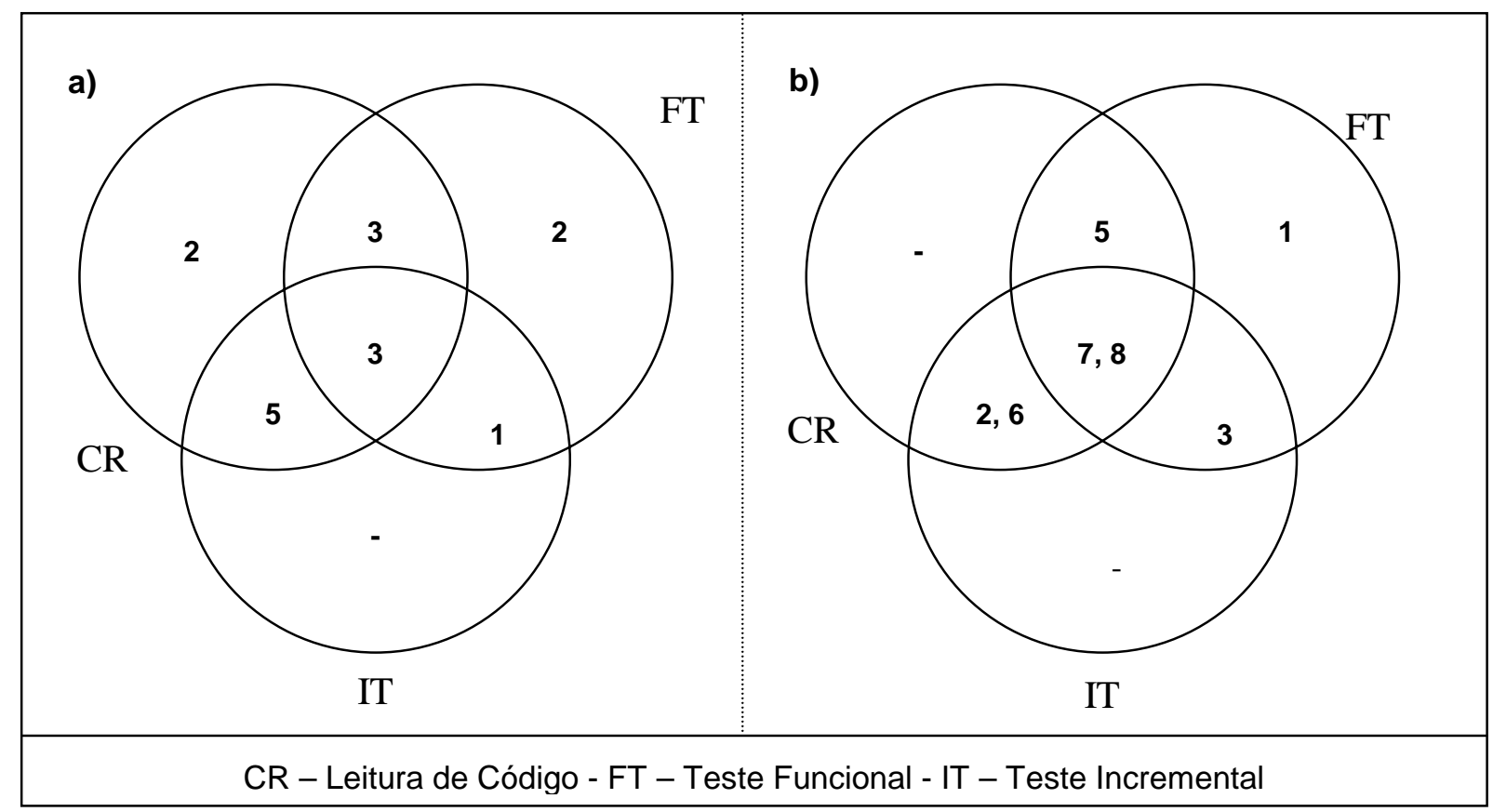

Figura 4.11 - Cmdline: (a) Número de ocorrências de defeitos isolados pelas técnicas; (b) Identificação dos defeitos isolados pelas técnicas. 
Como pode ser observado na Figura 4.11 (b), os defeitos 7 e 8 foram isolados por todas as técnicas. No caso o defeito 8 foi isolado mais vezes pela técnica Leitura de Código do que pelas outras técnicas. As quantidades totalizadas de ocorrências de defeitos isolados pelas técnicas são apresentados na Figura 4.11 (a).

Conforme pode ser observado na Figura 4.12 (b), o defeito 7, por exemplo, foi isolado por todas as técnicas, mas as técnicas Leitura de Código e Teste funcional foram mais efetivas, ou seja, isolaram uma quantidade maior e igual deste defeito do que a técnica Teste Incremental. A Figura 4.12 (a) apresenta a identificação dos defeitos onde a técnica obteve melhor ou igual desempenho que às outras técnicas.

Visão 3 - Identificação da melhor técnica por defeito

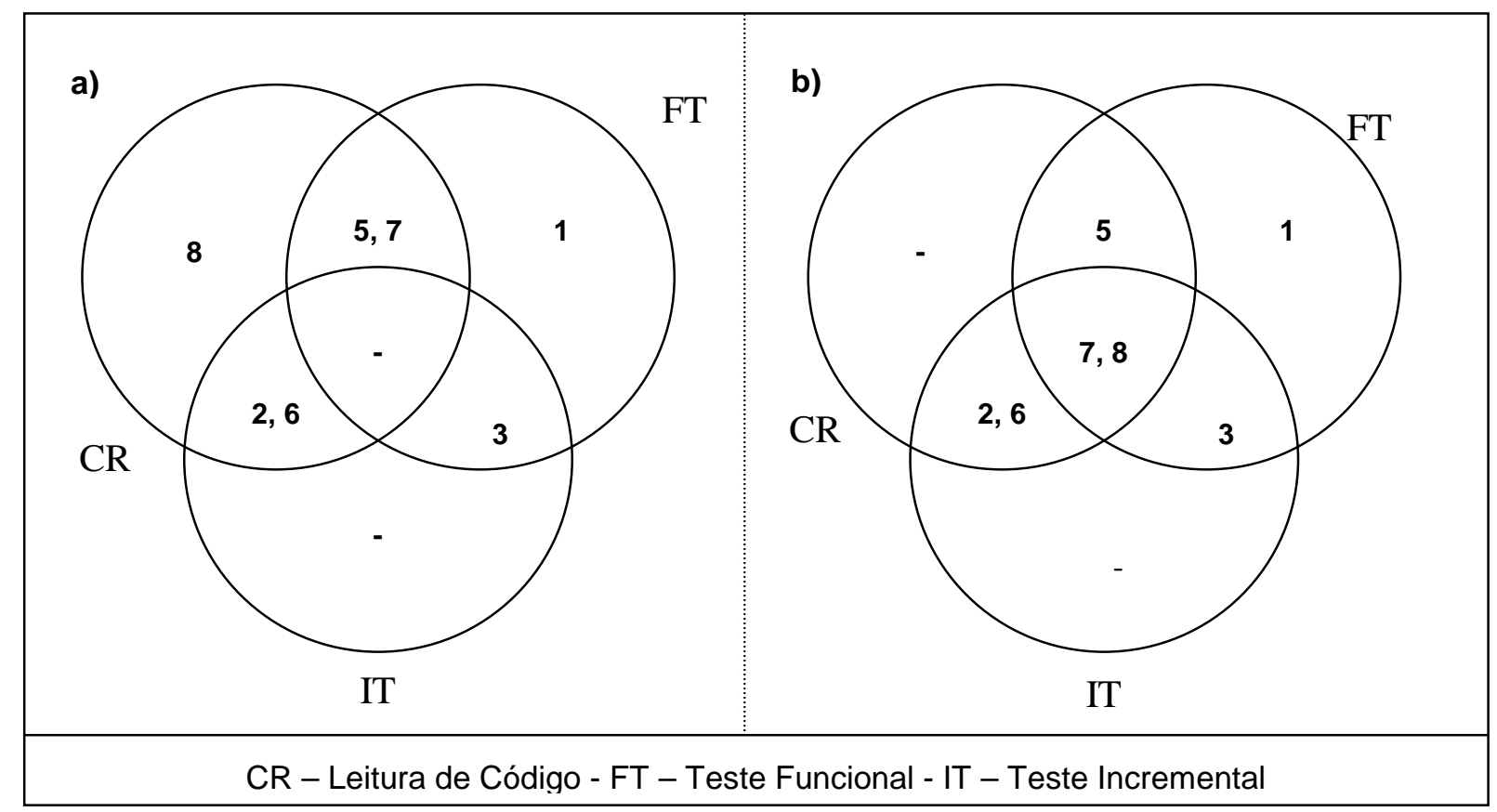

Figura 4.12 - Cmdline: (a) Identificação dos defeitos onde a técnica obteve melhor ou igual desempenho que às outras técnicas; (b) Identificação dos defeitos isolados pelas técnicas. 


\section{Análise dos defeitos do programa NAMETBL}

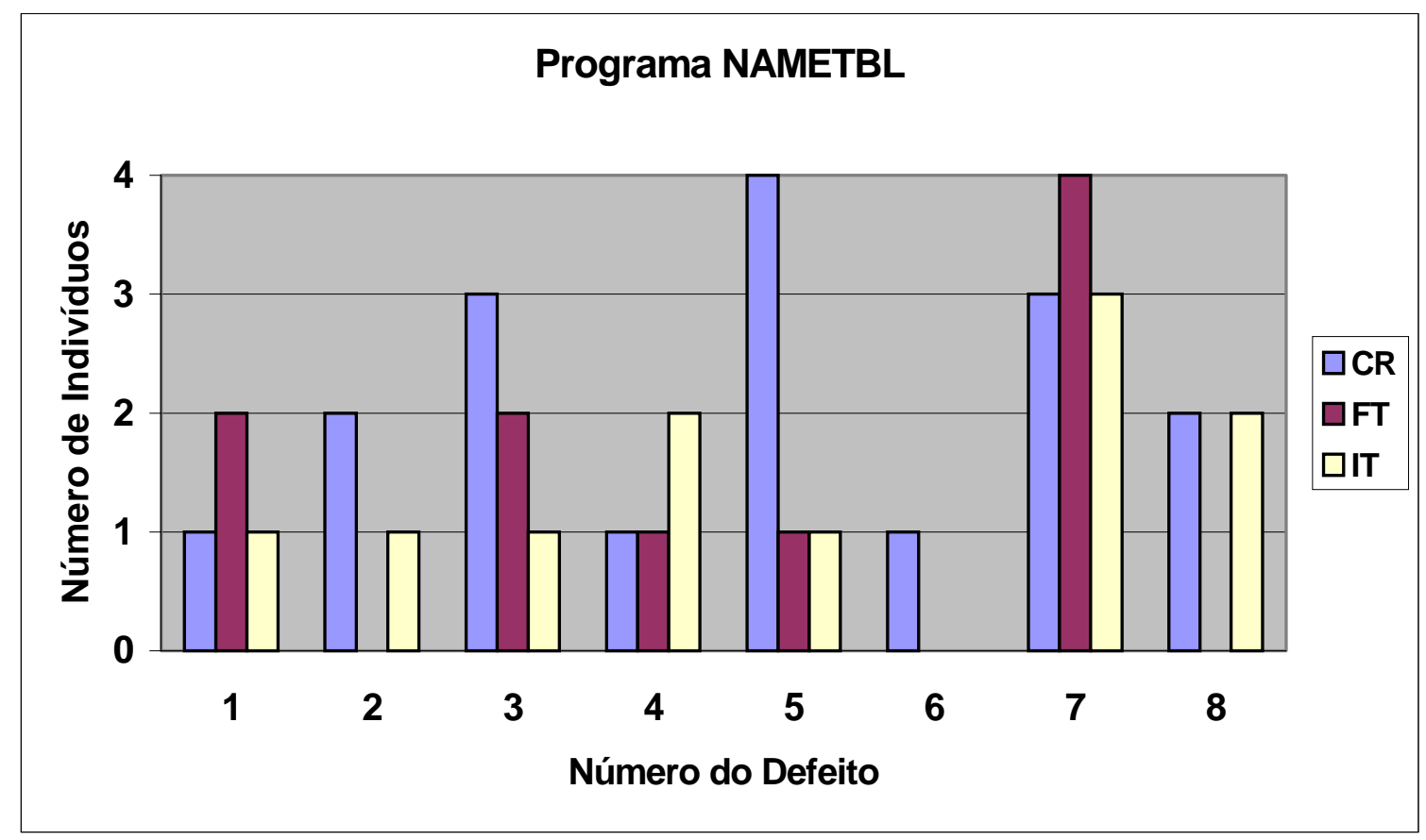

Figura 4.13 - Nametbl: Defeitos isolados pelas técnicas.

A Figura 4.13 apresenta as quantidades de cada defeito que foram isolados por cada técnica quando aplicadas no programa "nametbl.c".

\begin{tabular}{|l|c|c|}
\cline { 2 - 3 } \multicolumn{1}{c|}{} & $\begin{array}{c}\text { Média de experiência } \\
\text { com programação }\end{array}$ & $\begin{array}{c}\text { Membros do } \\
\text { grupos }\end{array}$ \\
\hline Leitura de Código & 9,5 & Indivíduos 03, 08, 09, 11 \\
\hline Teste Funcional & 7,3 & Indivíduos 04, 07, 10, 12 \\
\hline Teste Incremental & 14,0 & Indivíduos 01, 02, 05, 06 \\
\hline
\end{tabular}

Tabela 4.16 - Nametbl: Média de experiência dos indivíduos com programação em cada técnica.

\begin{tabular}{|l|c|c|}
\cline { 2 - 3 } \multicolumn{1}{c|}{} & \multicolumn{1}{c|}{$\begin{array}{c}\text { Possibilidades de } \\
\text { isolamento }\end{array}$} & $\begin{array}{c}\text { Defeitos } \\
\text { isolados }\end{array}$ \\
\hline Leitura de Código & 32 & 17 \\
\hline Teste Funcional & 32 & 10 \\
\hline Teste Incremental & 32 & 11 \\
\hline
\end{tabular}

Tabela 4.17 - Nametbl: Possibilidades de isolamento e quantidades isoladas de defeitos por técnica.

Em outra análise preliminar, conforme pode ser observado na Tabela 4.17, a técnica Leitura de Código isolou um número maior de defeitos que as outras técnicas. Das 32 possibilidades de isolamento de defeitos, obtida pela razão entre a quantidade de defeitos (8) 
contidos no programa "nametbl.c" e a quantidade de indivíduos (4) que aplicaram a técnica, 17 foram isolados. A experiência com programação pode ter tido alguma influência nos resultados obtidos pelos indivíduos, uma vez que o grupo tem a $2^{\text {a }}$ maior média de experiência com programação entre todos os participantes, conforme pode ser visto na Tabela 4.16.

\begin{tabular}{|c|c|c|c|c|c|c|c|c|}
\hline & \multicolumn{7}{|c|}{ Programa 3 - NAMETBL } \\
\hline & & \multirow{2}{*}{$\begin{array}{c}\text { Quantidade } \\
\text { de defeitos } \\
\text { originais }\end{array}$} & \multicolumn{2}{|c|}{ Leitura de Código } & \multicolumn{2}{|c|}{ Teste Funcional } & \multicolumn{2}{|c|}{ Teste Incremental } \\
\hline & & & $\begin{array}{c}\text { Quantidade } \\
\text { isolada }\end{array}$ & $\%$ & $\begin{array}{c}\text { Quantidade } \\
\text { isolada }\end{array}$ & $\%$ & $\begin{array}{c}\text { Quantidade } \\
\text { isolada }\end{array}$ & $\%$ \\
\hline \multirow{2}{*}{ Classe } & Omission & 5 & 12 & 60,00 & 4 & 20,00 & 7 & 35,00 \\
\hline & Commission & 3 & 5 & 41,67 & 6 & 50,00 & 4 & 33,33 \\
\hline \multirow{6}{*}{ Tipo } & Initialization & 0 & 0 & 0,00 & 0 & 0,00 & 0 & 0,00 \\
\hline & Computation & 1 & 2 & 50,00 & 0 & 0,00 & 1 & 25,00 \\
\hline & Control & 3 & 6 & 50,00 & 5 & 41,67 & 7 & 58,33 \\
\hline & Interface & 1 & 4 & 100,00 & 1 & 25,00 & 1 & 25,00 \\
\hline & Data & 2 & 4 & 50,00 & 4 & 50,00 & 2 & 25,00 \\
\hline & Cosmetic & 1 & 1 & 25,00 & 0 & 0,00 & 0 & 0,00 \\
\hline
\end{tabular}

Tabela 4.18 - Nametbl: Quantidade e percentual (do total possível) de defeitos isolados por tipos e classes.

A Tabela 4.18 apresenta um detalhamento das quantidades e percentuais (dos totais possíveis) de defeitos isolados pelas técnicas organizados por classes e tipos de defeitos. Os resultados mostram que as técnicas foram efetivas no isolamento de defeitos de diferentes classes e tipos. As técnicas Leitura de Código e Teste Incremental foram mais efetivas no isolamento de defeitos da classe Omission e a técnica Teste Funcional foi mais efetiva no isolamento de defeitos da classe Commission. A técnica Leitura de Código foi mais efetiva no isolamento de defeitos do tipo Interface, a técnica Teste Funcional foi mais efetiva no isolamento de defeitos do tipo Data e a técnica Teste Incremental foi mais efetiva no isolamento de defeitos do tipo Control.

A Figura 4.14 apresenta um detalhamento dos defeitos isolados pelos critérios que compõem a técnica Teste Incremental. Todos os defeitos foram isolados pelo critério Todos-Nós.

As taxas médias de cobertura que os indivíduos alcançaram com cada critério do Teste Incremental podem ser vistas na Figura 4.15. Em uma análise preliminar, observa-se que vários indivíduos não conseguiram aplicar os critérios completamente, ou seja, não conseguiram alcançar a cobertura total possível. O indivíduo 2, por exemplo, aplicando o critério Todos-Nós alcançou somente $95,76 \%$ de cobertura contra um total possível de 99,6\%. Em termos práticos isso significa que o indivíduo não conseguiu determinar casos de teste suficientes para executar todas as declarações do programa. 


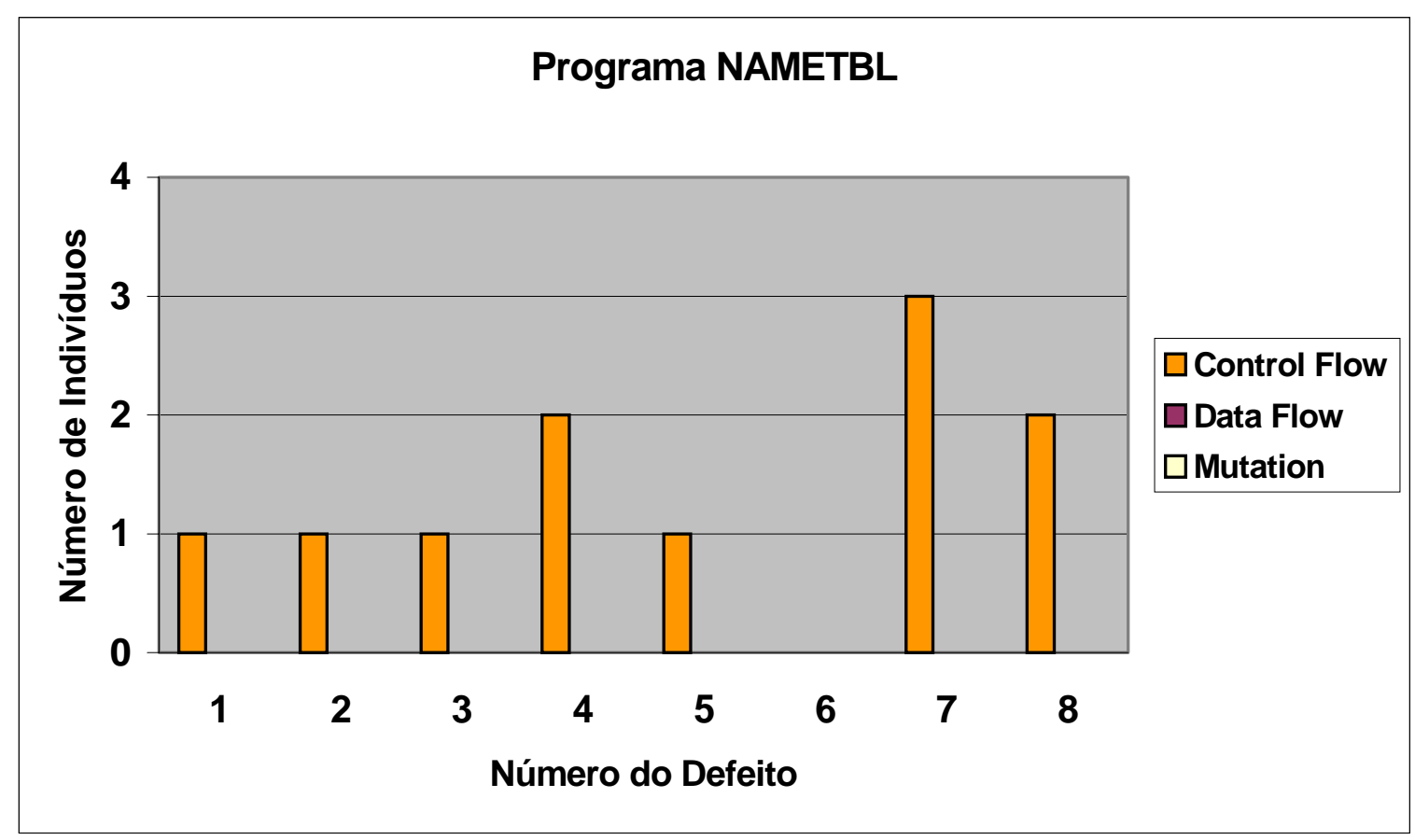

Figura 4.14 - Nametbl: Defeitos isolados pelo Teste Incremental.

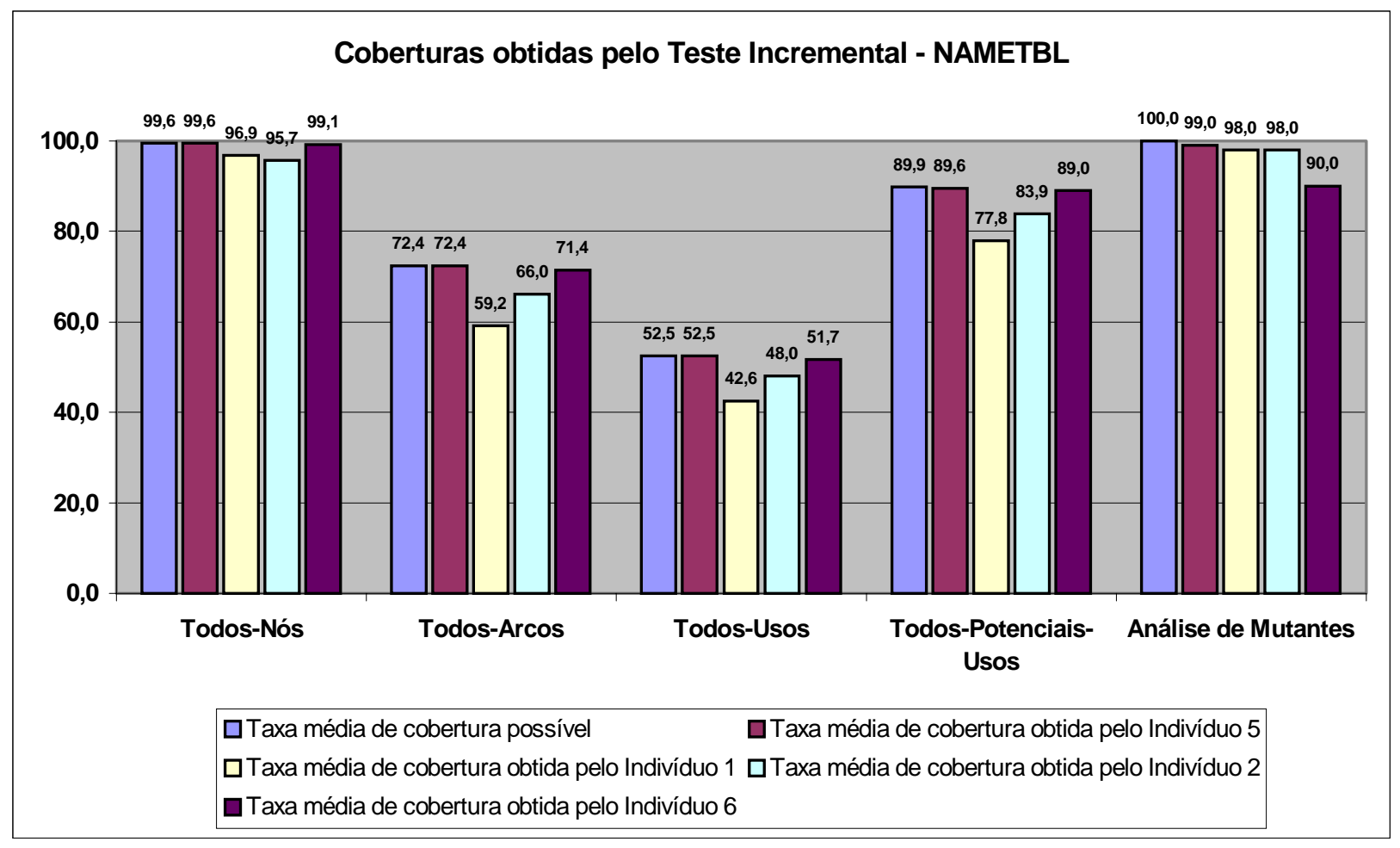

Figura 4.15 - Nametbl: Coberturas obtidas pelos indivíduos aplicando o Teste Incremental. 
A Tabela 4.19 apresenta um detalhamento dos casos de teste que foram necessários para alcançar as coberturas mencionadas na Figura 4.15. O indivíduo 5, por exemplo, obteve um conjunto de 10 casos de teste e isolou 1 defeito aplicando os critério Todos-Nós. Aplicando o critério Todos-Arcos o indivíduo isolou mais 1 defeito com um custo adicional de 10\%. Com os critérios baseados em fluxo de dados não houve melhoramento do conjunto. Ao conjunto inicial foram acrescidos mais 5 novos casos de teste quando da aplicação do critério Análise de Mutante. Um custo adicional de 50\% que não resultou em efeitos práticos.

\begin{tabular}{|c|c|c|c|c|c|c|c|c|c|c|c|c|c|c|}
\hline & \multicolumn{2}{|c|}{ Todos-Nós } & \multicolumn{3}{|c|}{ Todos-Arcos } & \multicolumn{3}{|c|}{ Todos-Usos } & \multicolumn{3}{|c|}{$\begin{array}{c}\text { Todos-Potenciais- } \\
\text { Usos }\end{array}$} & \multicolumn{3}{|c|}{$\begin{array}{l}\text { Análise de } \\
\text { Mutantes }\end{array}$} \\
\hline & T1 & Q1 & T2 & $\% 1$ & Q2 & T3 & $\% 2$ & Q3 & T4 & $\% 3$ & Q4 & T5 & $\% 4$ & Q5 \\
\hline Indivíduo 1 & 6 & 3 & 8 & $33,3 \%$ & 0 & 8 & $0 \%$ & 0 & 8 & $0 \%$ & 0 & 12 & $100 \%$ & 0 \\
\hline \begin{tabular}{|l} 
Indivíduo 2 \\
\end{tabular} & 8 & 1 & 11 & $37,5 \%$ & 0 & 11 & $0 \%$ & 0 & 11 & $0 \%$ & 0 & 19 & \begin{tabular}{|l|}
$137 \%$ \\
\end{tabular} & 0 \\
\hline Indivíduo 5 & 10 & 1 & 11 & $10,0 \%$ & 1 & 11 & $0 \%$ & 0 & 11 & $0 \%$ & 0 & 15 & $50 \%$ & 0 \\
\hline Indivíduo 6 & 8 & 5 & 8 & $0 \%$ & 0 & 8 & $0 \%$ & 0 & 8 & $0 \%$ & 0 & 8 & $0 \%$ & 0 \\
\hline & & & & $\mathrm{de} \mathrm{de}$ & efer & sola & aplic & & deter & iado c & & & & \\
\hline
\end{tabular}

Tabela 4.19 - Custo e eficiência dos conjuntos de casos de teste obtidos com cada critério do Teste Incremental.

A seguir, apresentam-se três diferentes visões dos dados apresentados na Figura 4.13:

Como pode ser observado na Figura 4.16 (a), a técnica Leitura de Código isolou: 1 defeito que nenhuma outra técnica isolou, que é o defeito 6 (ver Figura 4.16 (b)); 2 defeitos que também foram isolados pela técnica Teste Incremental, são eles: 2 e 8; 5 defeitos que também foram isolados pelas técnicas Teste Funcional e Teste Incremental, são eles: 1, 3, 4, 5 e 7 . A técnica Leitura de Código obteve uma efetividade de $100 \%$, ou seja, dos 8 defeitos existentes no programa "nametbl.c" todos foram descobertos. É importante ressaltar que somente a técnica Leitura de Código isolou o defeito 6. Este defeito é do tipo Cosmetic. Acredita-se que a técnica descobriu estes defeitos uma vez que se baseia fundamentalmente na leitura do código fonte. 
Visão 1 - Efetividade das técnicas por grupo de indivíduos

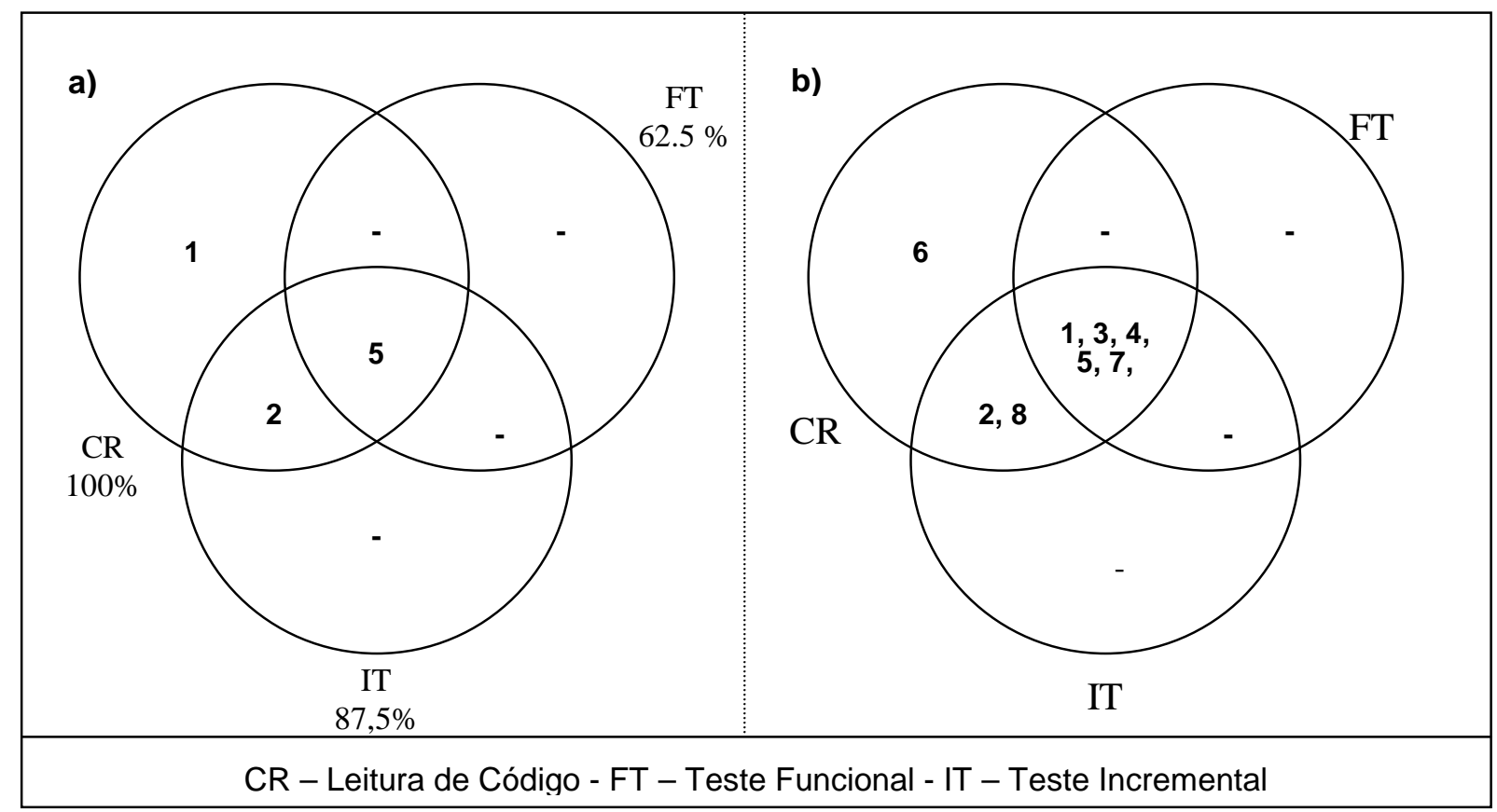

Figura 4.16 - Nametbl: (a) Quantidade e percentual de defeitos isolados pelas técnicas; (b) Identificação dos defeitos isolados pelas técnicas.

Visão 2 - Efetividade das técnicas pelo número de ocorrências de defeitos

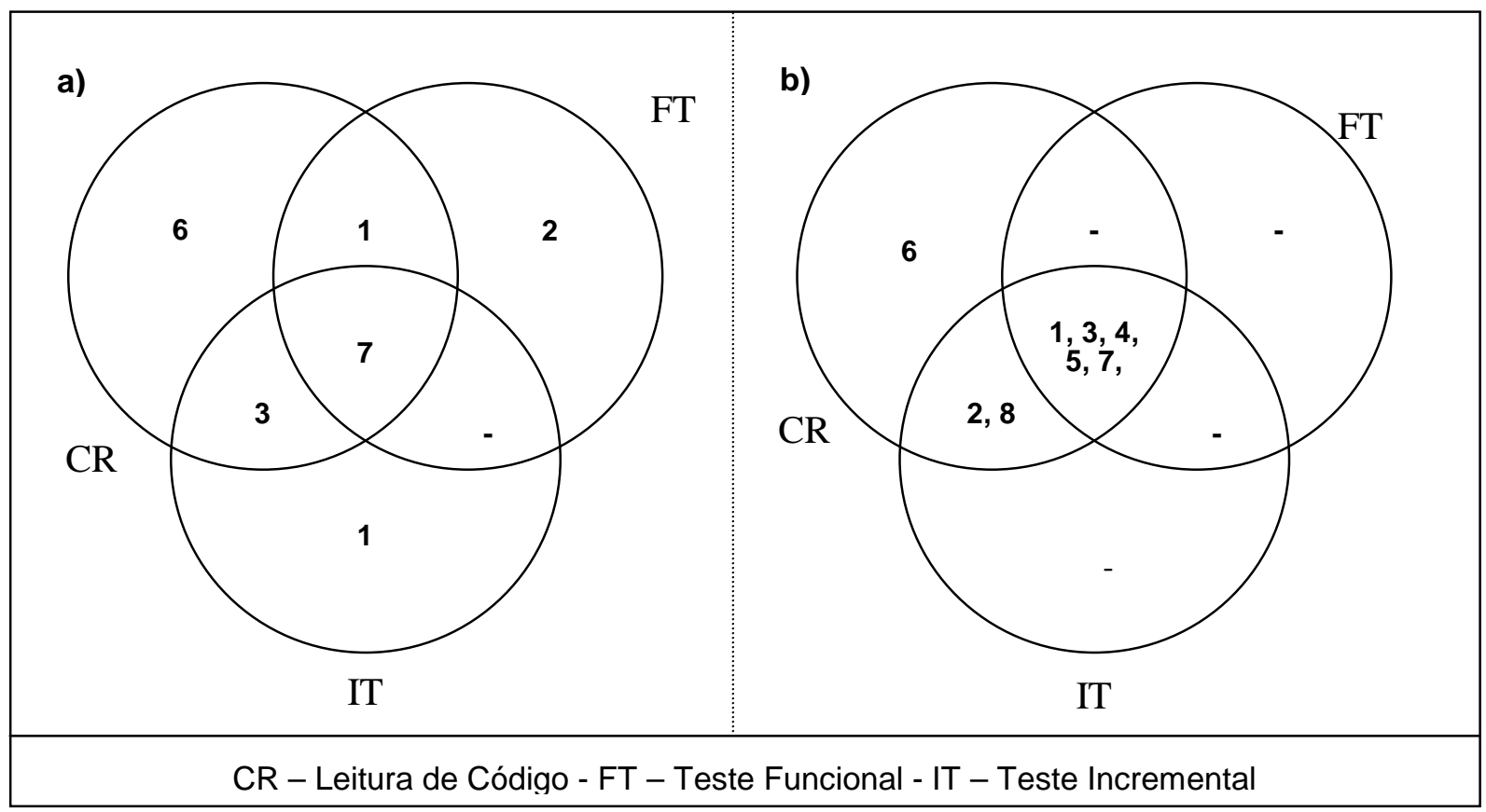

Figura 4.17 - Nametbl: (a) Número de ocorrências de defeitos isolados pelas técnicas; (b) Identificação dos defeitos isolados pelas técnicas. 
Como pode ser observado na Figura 4.17 (b), os defeitos 1, 3, 4, 5 e 7 foram isolados por todas as técnicas. No caso o defeito 4 foi isolado mais vezes pela técnica Teste Incremental do que pelas outras técnicas. As quantidades totalizadas de ocorrências de defeitos isolados pelas técnicas são apresentados na Figura 4.17 (a).

Visão 3 - Identificação da melhor técnica por defeito

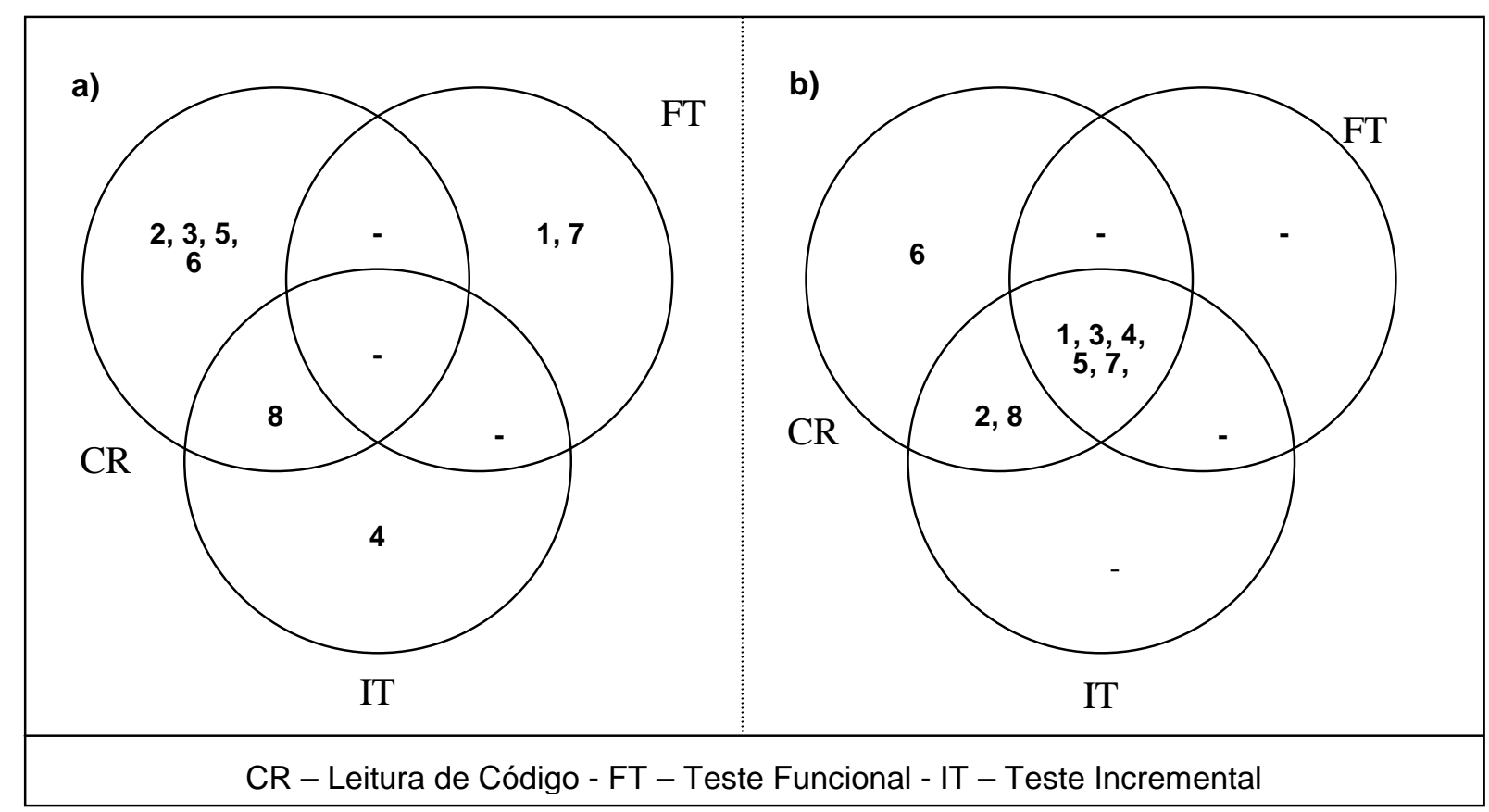

Figura 4.18 - Nametbl: (a) Identificação dos defeitos onde a técnica obteve melhor ou igual desempenho que às outras técnicas; (b) Identificação dos defeitos isolados pelas técnicas.

Conforme pode ser observado na Figura 4.18 (b), o defeito 2, por exemplo, foi isolado tanto pela técnica Leitura de Código como pela técnica Teste Incremental, mas a técnica Leitura de Código foi mais efetiva, ou seja, isolou uma quantidade maior deste defeito do que a técnica Teste Incremental. A Figura 4.18 (a) apresenta a identificação dos defeitos onde a técnica obteve melhor ou igual desempenho que as outras técnicas. 


\section{Análise em conjunto dos defeitos dos programas NTREE, CMDLINE e NAMETBL}

A Tabela 4.20 apresenta as quantidades de defeitos isolados e os tempos gastos no isolamento de defeitos obtidos por cada indivíduo em cada fase do experimento. A partir desta organização de dados, foram calculados: a média de defeitos isolados por indivíduo; o percentual médio de defeitos isolados por cada técnica; e a taxa de isolamento de defeitos das técnicas.

\begin{tabular}{|c|c|c|c|c|c|c|c|c|c|}
\hline & \multicolumn{3}{|c|}{ Leitura de Código } & \multicolumn{3}{|c|}{ Teste Funcional } & \multicolumn{3}{|c|}{ Teste Incremental } \\
\hline & ID & $\mathbf{Q U}$ & TI & ID & $\mathbf{Q U}$ & TI & ID & $\mathbf{Q U}$ & TI \\
\hline \multirow{4}{*}{$\begin{array}{c}\text { Ntree.c } \\
(8 \text { defeitos })\end{array}$} & S06 & 5 & 234 & S01 & 3 & 235 & S03 & 6 & 155 \\
\hline & $\mathrm{S} 10$ & 5 & 206 & S05 & 3 & 204 & S04 & 1 & 570 \\
\hline & $\mathrm{S} 12$ & 7 & 165 & S09 & 3 & 295 & S07 & 1 & 150 \\
\hline & S02 & 0 & 245 & $\mathrm{~S} 11$ & 3 & 90 & S08 & 3 & 435 \\
\hline \multirow{4}{*}{$\begin{array}{l}\text { Cmdline.c } \\
\text { (9 defeitos) }\end{array}$} & S01 & 4 & 240 & S02 & 2 & 208 & S09 & 1 & 635 \\
\hline & S04 & 3 & 240 & S03 & 3 & 90 & $\mathrm{~S} 10$ & 3 & 474 \\
\hline & S05 & 3 & 170 & S06 & 1 & 238 & $\mathrm{~S} 11$ & 1 & 81 \\
\hline & S07 & 3 & 260 & S08 & 3 & 165 & $\mathrm{~S} 12$ & 4 & 180 \\
\hline \multirow{4}{*}{$\begin{array}{l}\text { Nametbl.c } \\
\text { (8 defeitos) }\end{array}$} & $\mathrm{S} 03$ & 3 & 91 & S04 & 4 & 190 & S01 & 3 & 295 \\
\hline & S08 & 5 & 195 & S07 & 2 & 215 & S02 & 1 & 176 \\
\hline & S09 & 3 & 180 & S10 & 1 & 116 & S05 & 2 & 168 \\
\hline & $\mathrm{S} 11$ & 6 & 122 & $\mathrm{~S} 12$ & 3 & 195 & S06 & 5 & 351 \\
\hline
\end{tabular}

Tabela 4.20 - Quantidade de defeitos isolados e tempo gasto (em minutos) pelos indivíduos.

\begin{tabular}{|l|c|c|c|}
\hline \multicolumn{1}{|c|}{ Técnica } & Média & Desvio padrão & $\begin{array}{c}\text { Número de } \\
\text { indivíduos }\end{array}$ \\
\hline \hline Leitura de Código & 3,92 & 1,83 & 12 \\
\hline Teste Funcional & 2,58 & 0,90 & 12 \\
\hline Teste Incremental & 2,58 & 1,73 & 12 \\
\hline
\end{tabular}

Tabela 4.21 - Média de defeitos isolados pelos indivíduos utilizando cada técnica. 


\begin{tabular}{|l|c|c|}
\hline \multicolumn{1}{|c|}{ Técnica } & $\begin{array}{c}\text { Percentual médio de } \\
\text { defeitos isolados } \\
\text { (do total possível) }\end{array}$ & $\begin{array}{c}\text { Taxa de isolamento } \\
\text { de defeitos } \\
\text { (hora) }\end{array}$ \\
\hline Leitura de Código & $47,45 \%$ & 1,35 \\
\hline Teste Funcional & $31,25 \%$ & 0,95 \\
\hline Teste Incremental & $31,25 \%$ & 0,69 \\
\hline
\end{tabular}

Tabela 4.22 - Percentual médio de defeitos isolados (do total possível) e taxa de isolamento de defeitos por técnica.

Conforme pode ser observado na Tabela 4.21 e na Tabela 4.22, a técnica Leitura de Código obteve a melhor média de defeitos isolados por indivíduo, o melhor percentual médio de defeitos isolados (do total possível) e a melhor taxa de isolamento de defeitos.

A média de defeitos isolados por indivíduo para cada técnica foi calculada por meio da divisão entre a somatória das quantidades de defeitos isolados por cada indivíduo em cada fase do experimento e a quantidade de indivíduos. O percentual médio de defeitos isolados para cada técnica foi calculado por meio da divisão entre a somatória dos percentuais individuais de isolamento de defeitos ${ }^{1}$ obtidos em cada fase do experimento e a quantidade de indivíduos. A taxa de isolamento de defeitos para cada técnica foi calculada por meio da divisão entre a somatória das taxas individuais de isolamento de defeitos ${ }^{2}$ obtidas em cada fase do experimento e a quantidade de indivíduos.

\begin{tabular}{|c|c|c|c|c|}
\hline & & $\begin{array}{c}\text { Leitura de } \\
\text { Código }\end{array}$ & $\begin{array}{c}\text { Teste } \\
\text { Funcional }\end{array}$ & $\begin{array}{c}\text { Teste } \\
\text { Incremental }\end{array}$ \\
\hline \multirow{2}{*}{ Classe } & Omission & $51,25 \%$ & $40,00 \%$ & $34,58 \%$ \\
\hline & Commission & $42,46 \%$ & $27,98 \%$ & $27,78 \%$ \\
\hline \multirow[t]{6}{*}{ Tipo } & Initialization & $16,67 \%$ & $08,33 \%$ & $16,67 \%$ \\
\hline & Computation & $16,67 \%$ & $00,00 \%$ & $8,33 \%$ \\
\hline & Control & $54,17 \%$ & $51,39 \%$ & $47,22 \%$ \\
\hline & Interface & $61,11 \%$ & $16,67 \%$ & $13,89 \%$ \\
\hline & Data & $37,50 \%$ & $37,50 \%$ & $20,83 \%$ \\
\hline & Cosmetic & $29,17 \%$ & $00,00 \%$ & $12,50 \%$ \\
\hline
\end{tabular}

Tabela 4.23 - Percentual médio de defeitos isolados (do total possível) por tipos e classes.

\footnotetext{
${ }^{1}$ Os percentuais foram calculados a partir da seguinte expressão: $(x \star 100) / y$. Onde $x$ é a quantidade de defeitos isolados pelo indivíduo e y é a quantidade de defeitos existente no programa.

${ }^{2}$ As taxas foram calculadas a partir da seguinte expressão: $\mathrm{x} /(\mathrm{y} / 60)$. Onde $\mathrm{x}$ é a quantidade de defeitos isolados pelo indivíduo e y é a quantidade de tempo gasto no isolamento.
} 
A Tabela 4.23 apresenta um resumo geral dos percentuais de defeitos isolados por cada técnica organizados por classes e tipos de defeitos, considerando os dados obtidos durante todo experimento. As técnicas foram mais efetivas no isolamento de defeitos da classe Omission. As técnicas Teste Funcional e Teste Incremental foram mais efetivas no isolamento de defeitos do tipo Control, enquanto que a técnica Leitura de Código foi mais efetiva para defeitos do tipo Interface. Em uma análise mais detalhada, a técnica Leitura de Código foi mais efetiva para quase todas as classes e tipos de defeitos. Entre as técnicas Teste Funcional e Teste Incremental não houve diferenças tão significativas. A técnica Teste Funcional foi mais efetiva tanto no isolamento de defeitos da classe Omission quanto da classe Commission, bem como, mais efetiva no isolamento de defeitos dos tipos: Control, Interface e Data. Em contrapartida, a técnica Teste Incremental foi mais efetiva para defeitos dos tipos Initialization, Computation e Cosmetic. Enquanto a técnica Teste Funcional não isolou nenhum defeito dos tipos Computation e Cosmetic, a técnica Teste Incremental isolou um percentual de 8,33\% e 12,50\%, respectivamente.

A Figura 4.19 apresenta o percentual médio geral de defeitos isolados por cada indivíduo, considerando os resultados obtidos por ele durante o experimento. O indivíduo 12 foi quem obteve o melhor percentual $(56,48 \%)$ entre todos os participantes. O perfil do indivíduo é nível avançado de proficiência com leitura em Inglês, experiência de 4 anos com programação e conhecimento avançado na linguagem C. O percentual médio de defeitos isolados por cada indivíduo utilizando cada técnica pode ser visto na Figura 4.20, na Figura 4.21 e na Figura 4.22.

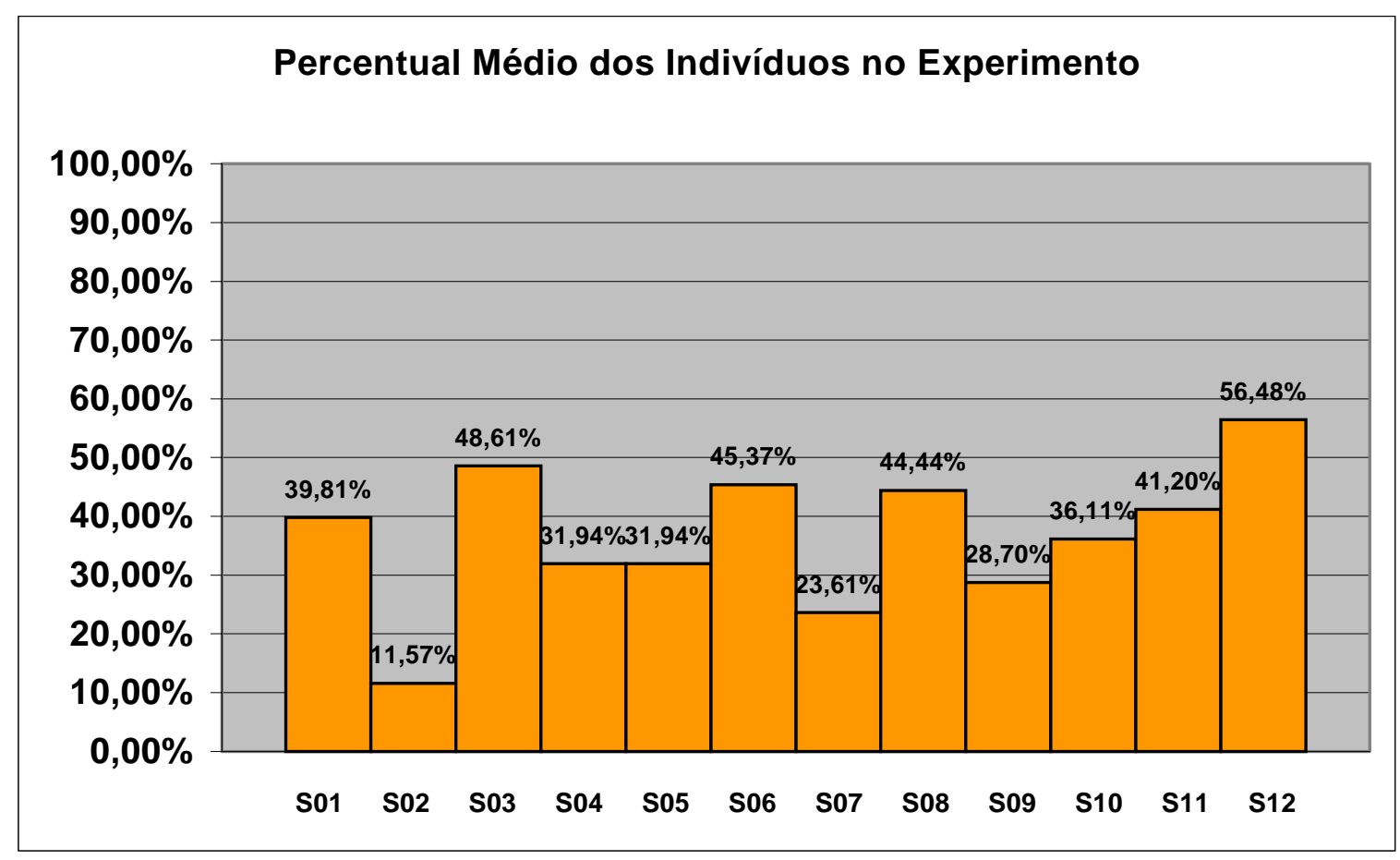

Figura 4.19 - Percentual médio geral dos indivíduos no experimento. 


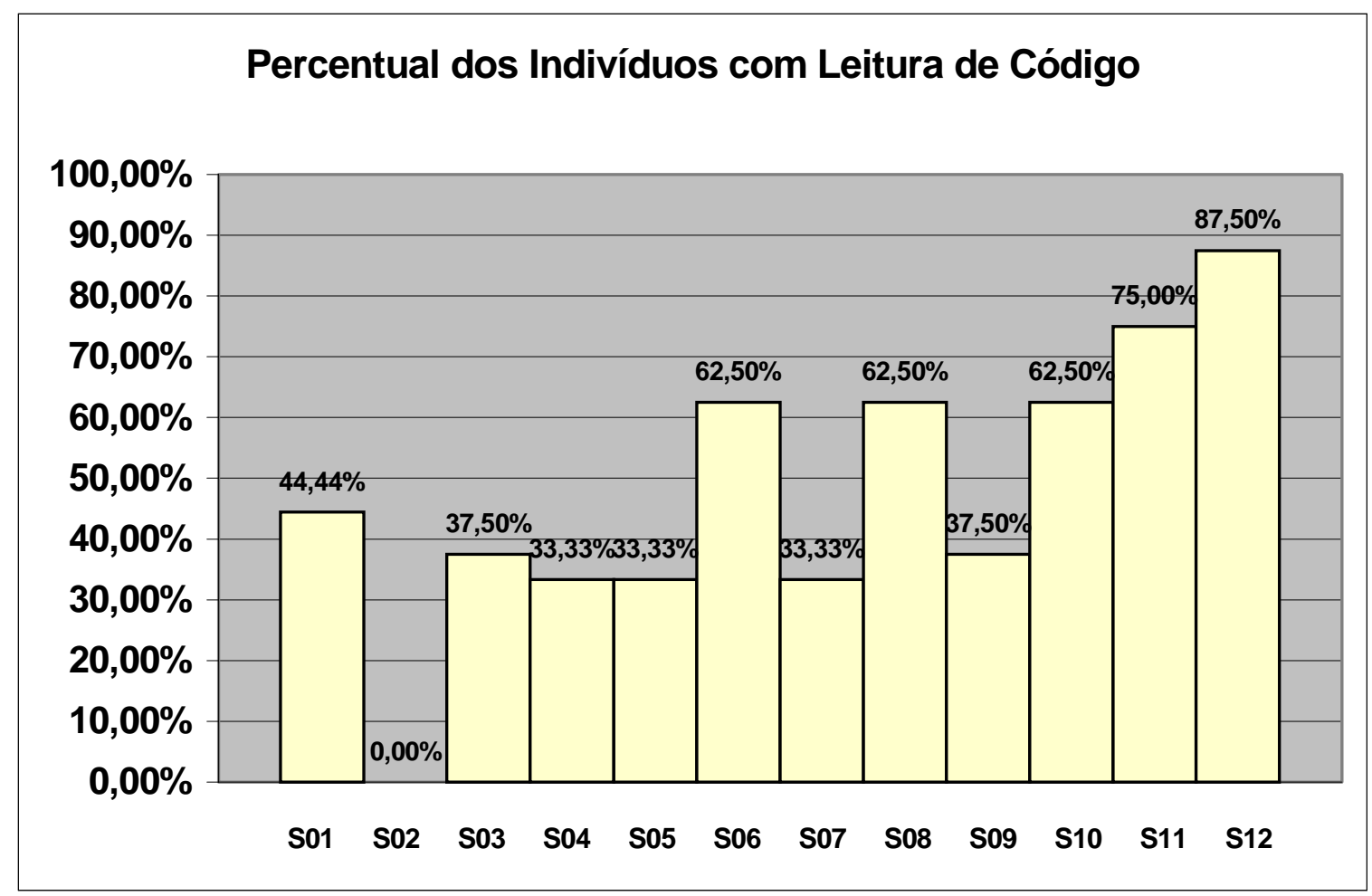

Figura 4.20 - Percentual (do total possível) de defeitos isolados pelos indivíduos com Leitura de Código.

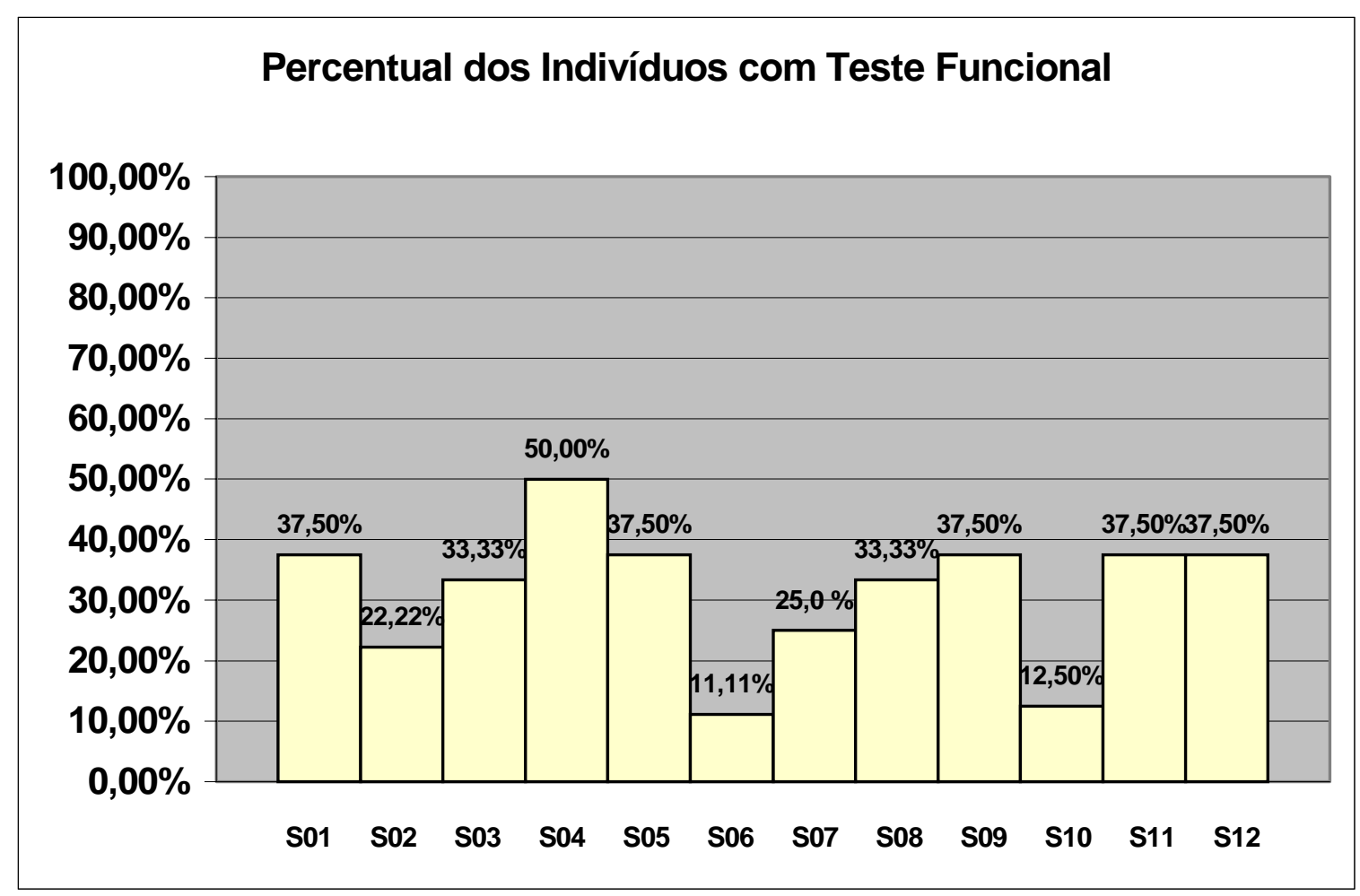

Figura 4.21 - Percentual (do total possível) de defeitos isolados pelos indivíduos com Teste Funcional. 


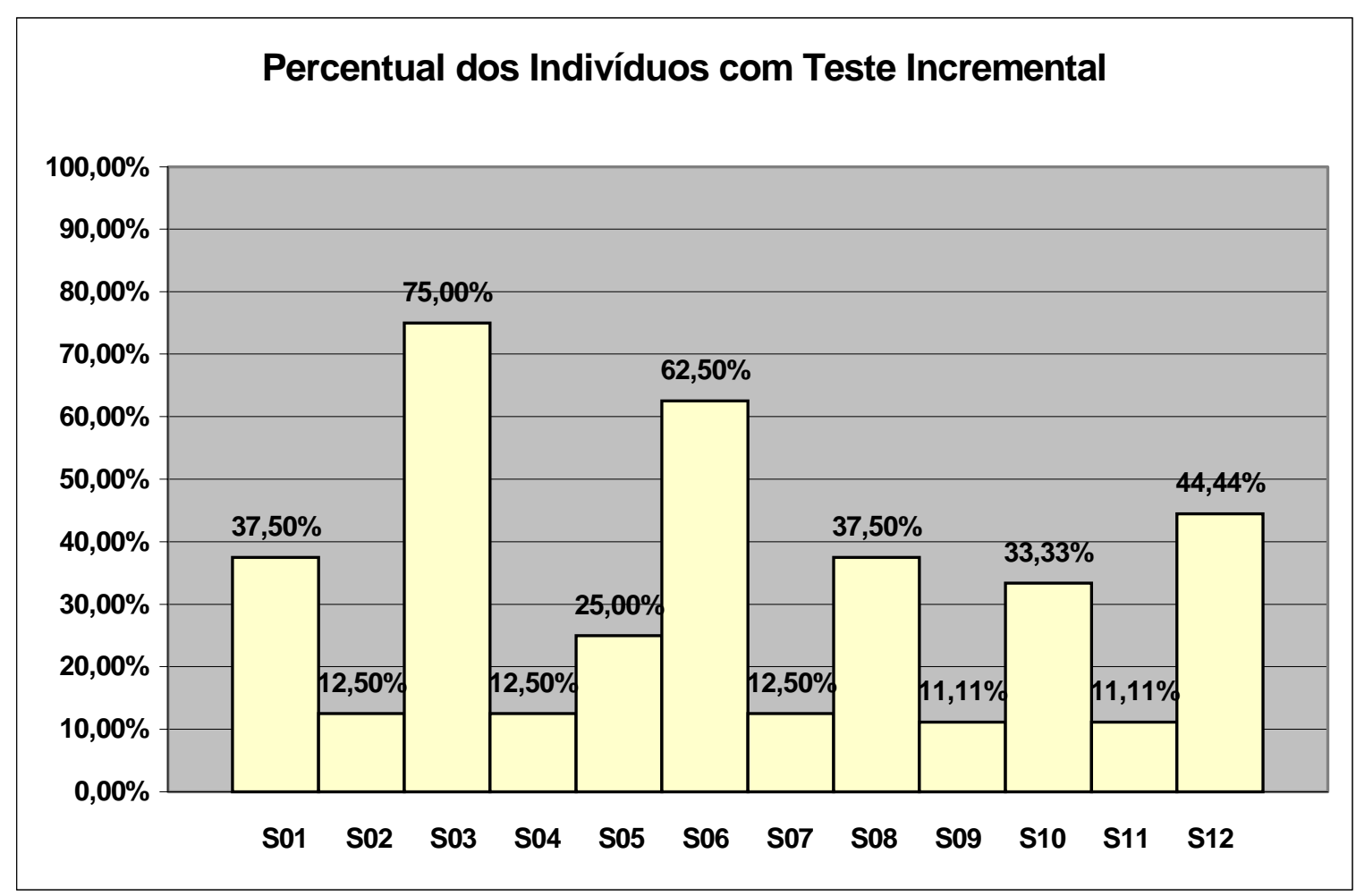

Figura 4.22 - Percentual (do total possível) de defeitos isolados pelos indivíduos com Teste Incremental.

\begin{tabular}{|c|c|c|c|c|}
\hline $\begin{array}{c}\text { ID } \\
\text { Indivíduos }\end{array}$ & Técnica & $\begin{array}{c}\text { Percentual médio de } \\
\text { defeitos isolados } \\
\text { do total possível) }\end{array}$ & $\begin{array}{c}\text { Percentual obtido } \\
\text { pelo indivíduo }\end{array}$ & $\begin{array}{c}\text { Percentual } \\
\text { acima da } \\
\text { média }\end{array}$ \\
\hline Indivíduo 12 & CR & $47,45 \%$ & $87,50 \%$ & $40,05 \%$ \\
\hline Indivíduo 04 & FT & $31,25 \%$ & $50,00 \%$ & $18,75 \%$ \\
\hline Indivíduo 03 & IT & $31,25 \%$ & $75,00 \%$ & $43,75 \%$ \\
\hline \multicolumn{5}{|r|}{ CR - Leitura de Código - FT - Teste Funcional - IT - Teste Incremental } \\
\hline
\end{tabular}

Tabela 4.24 - Indivíduos que obtiveram a melhor performance com cada técnica.

\begin{tabular}{|l|c|c|c|c|c|c|}
\hline $\begin{array}{c}\text { ID } \\
\text { Indivíduos }\end{array}$ & Técnica & $\begin{array}{c}\text { Percentual } \\
\text { obtido pelo } \\
\text { indivíduo }\end{array}$ & $\begin{array}{c}\text { Percentual } \\
\text { acima da } \\
\text { média }\end{array}$ & Técnica & $\begin{array}{c}\text { Percentual } \\
\text { obtido pelo } \\
\text { indivíduo }\end{array}$ & $\begin{array}{c}\text { Percentual } \\
\text { acima da } \\
\text { média }\end{array}$ \\
\hline Indivíduo 12 & FT & $37,50 \%$ & $6,25 \%$ & IT & $44,44 \%$ & $13,19 \%$ \\
\hline Indivíduo 04 & CR & $33,33 \%$ & abaixo da média & IT & $12,50 \%$ & abaixo da média \\
\hline Indivíduo 03 & CR & $37,50 \%$ & abaixo da média & FT & $33,33 \%$ & $2,08 \%$ \\
\hline \multicolumn{7}{|l}{ CR - Leitura de Código - FT - Teste Funcional - IT - Teste Incremental } \\
\hline
\end{tabular}

Tabela 4.25 - Outros resultados obtidos pelos indivíduos que obtiveram as melhores performance com cada técnica. 
As informações constantes na Tabela 4.24 e na Tabela 4.25 apresentam os melhores desempenhos individuais obtidos durante a execução do experimento. A informações foram extraídas dos dados apresentados na Figura 4.20, na Figura 4.21 e na Figura 4.22.

O indivíduo 12, por exemplo, foi o que obteve melhor desempenho utilizando a técnica Leitura de Código. O percentual de defeitos isolados pelo indivíduo foi de 87,50\% contra um percentual médio de 47,45\%, ou seja, de um total de 8 defeitos o indivíduo isolou 7. A Tabela 4.25 apresenta os outros resultados obtidos pelos indivíduos que obtiveram o melhor desempenho em cada técnica. O indivíduo 12, por exemplo, obteve o melhor resultado com a técnica Leitura de Código e ainda obteve percentuais acima da média utilizando as técnicas Teste Funcional e Teste Incremental.

A Figura 4.23 e Tabela 4.26 apresentam a performance geral de cada técnica em cada fase do experimento, ou seja, para cada programa. No caso do programa "cmdline.c", por exemplo, todas as técnicas obtiveram a mesma performance, de um total de 9 defeitos somente 5 foram isolados $(55,55 \%)$. Com o objetivo de explorar os aspectos complementares das técnicas foi realizada uma combinação, por meio de simulação, dos resultados obtidos por um par de técnicas. Para o programa "cmdline.c" o pior resultado obtido por um par de técnicas, especificamente o par Leitura de Código mais Teste Incremental (CR+IT), foi melhor que os resultados obtidos pelas técnicas individualmente, mostrando a importância de se combinar as técnicas.

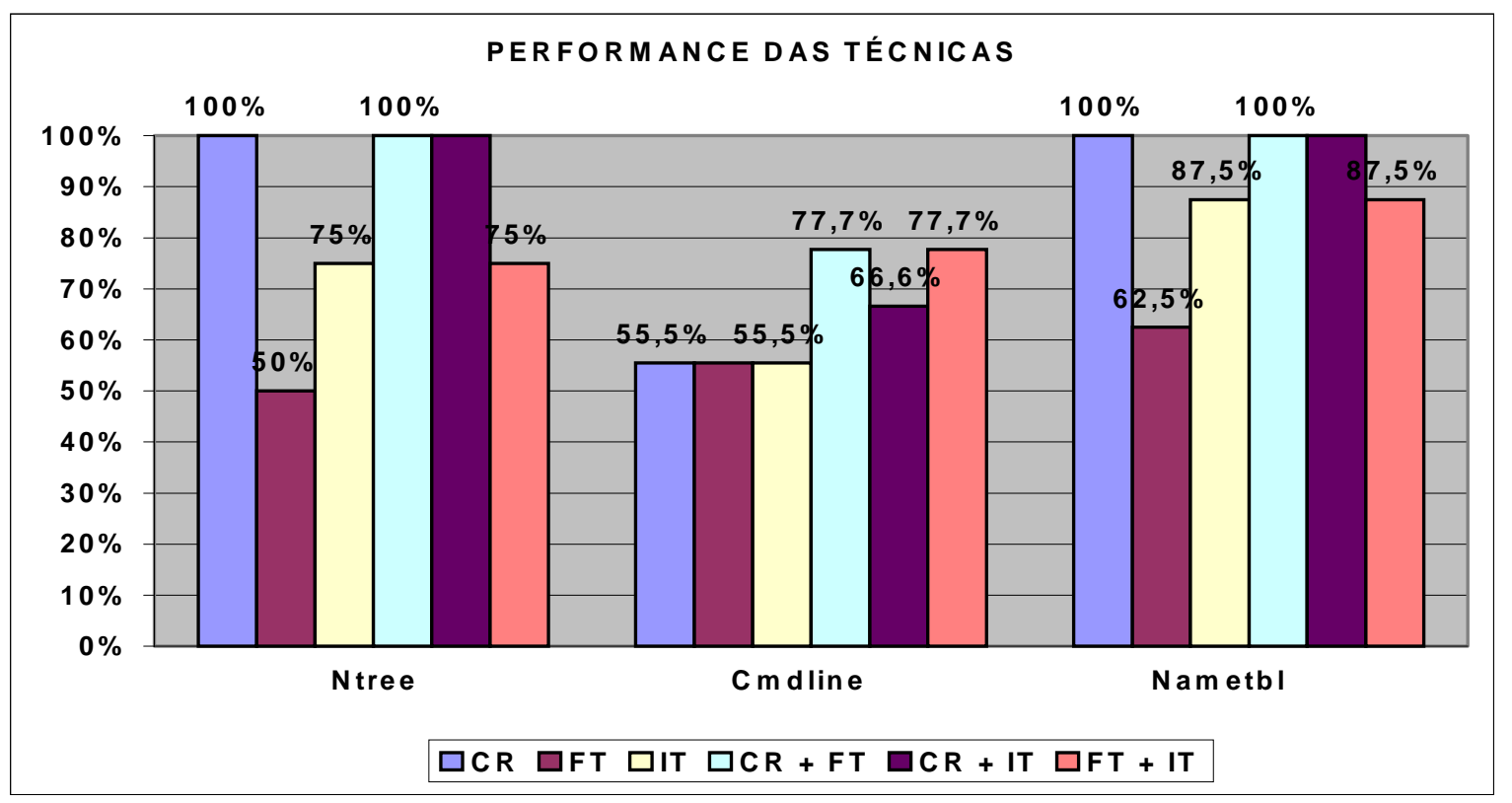

Figura 4.23 - Técnica que obteve melhor/pior performance em cada programa e técnicas que obtiveram (dois-a-dois) melhor/pior performance em cada programa. 


\begin{tabular}{|l|c|c|c|}
\cline { 2 - 4 } \multicolumn{1}{c|}{} & Ntree & Cmdline & Nametbl \\
\hline $\begin{array}{l}\text { Melhor técnica } \\
\text { individualmente }\end{array}$ & $100 \%(\mathrm{CR})$ & $55,5 \%(\mathrm{CR}, \mathrm{FT}, \mathrm{IT})$ & $100 \%(\mathrm{CR})$ \\
\hline $\begin{array}{l}\text { Pior técnica } \\
\text { individualmente }\end{array}$ & $50 \%(\mathrm{FT})$ & - & $62,5 \%(\mathrm{FT})$ \\
\hline $\begin{array}{l}\text { Melhor par combinado } \\
\text { de técnicas }\end{array}$ & $\begin{array}{c}100 \% \\
(\mathrm{CR}+\mathrm{FT})(\mathrm{CR}+\mathrm{IT})\end{array}$ & $\begin{array}{c}77,7 \% \\
(\mathrm{CR}+\mathrm{FT})(\mathrm{FT}+\mathrm{IT})\end{array}$ & $(\mathrm{CR}+\mathrm{FT})(\mathrm{CR}+\mathrm{IT})$ \\
\hline $\begin{array}{l}\text { Pior par combinado } \\
\text { de técnicas }\end{array}$ & $75 \%(\mathrm{FT}+\mathrm{IT})$ & $66,6 \%(\mathrm{CR}+\mathrm{IT})$ & $87,5 \%(\mathrm{FT}+\mathrm{IT})$ \\
\hline \multicolumn{2}{|r|}{$\mathrm{CR}-$ Leitura de Código - FT - Teste Funcional - IT - Teste Incremental } \\
\hline
\end{tabular}

Tabela 4.26 - Técnica que obteve melhor/pior performance em cada programa e técnicas que obtiveram (dois-a-dois) melhor/pior performance em cada programa.

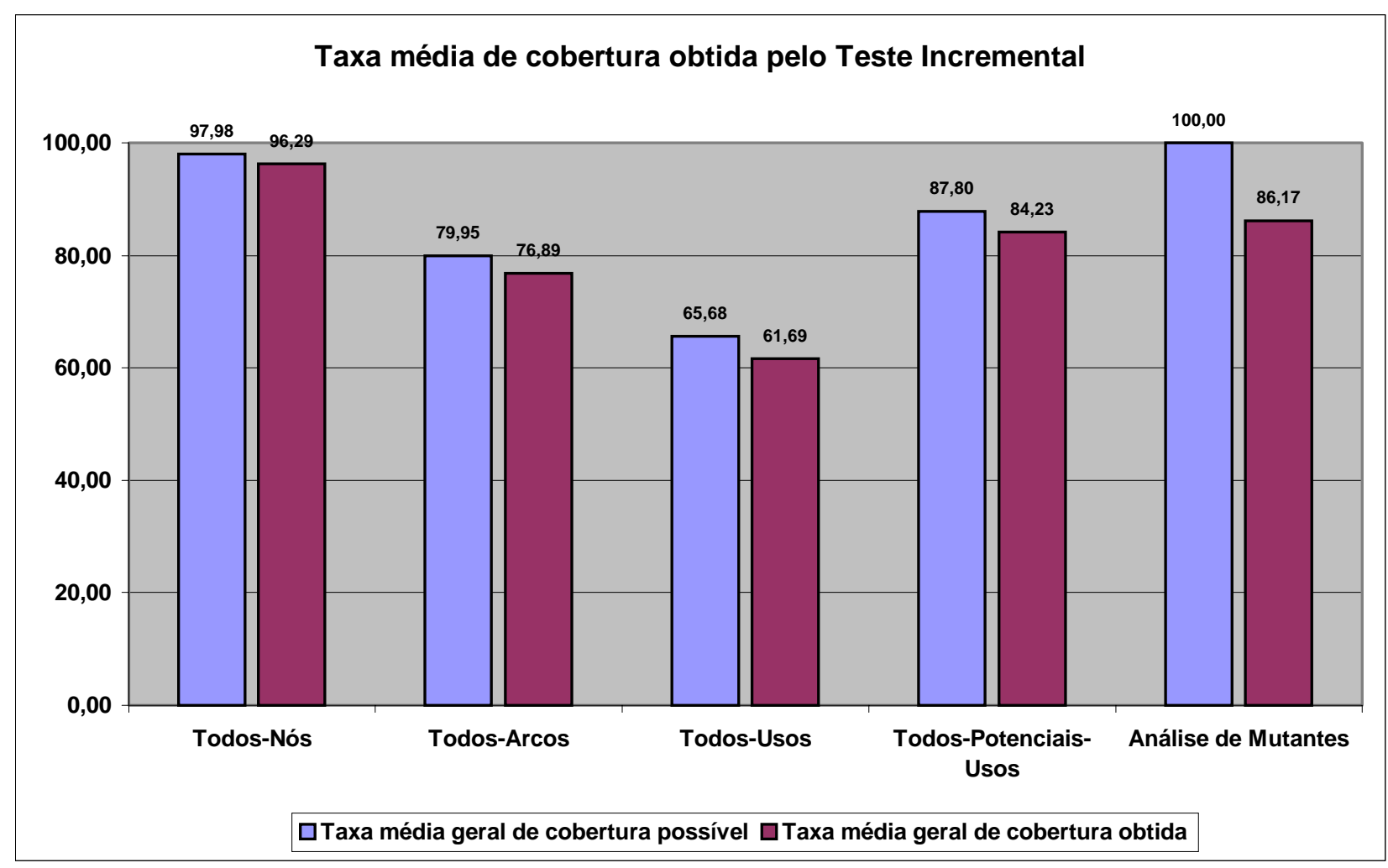

Figura 4.24 - Taxa média de cobertura obtida pelo Teste Incremental.

A Figura 4.24 apresenta a taxa média de cobertura obtida pelos indivíduos durante as 3 fases do experimento utilizando o Teste Incremental. Uma observação preliminar mostra que os indivíduos não conseguiram aplicar os critérios na sua totalidade, ou seja, as taxas médias obtidas pelos indivíduos são inferiores as taxas médias possíveis de serem alcançadas. 
Outra observação importante está relacionada às taxas médias de cobertura obtidas antes e depois da aplicação de um determinado critério. Dados dois critérios $C_{1}$ e $C_{2}$, o conjunto de casos de teste $C_{1}$-adequado é avaliado em relação ao critério $C_{2}$, fornecendo uma medida de cobertura. Em seguida, analisando-se os requisitos de teste requeridos pelo critério $C_{2}$ o conjunto de casos de teste $C_{1}$-adequado é melhorado até tornar-se $C_{2}$-adequado, caracterizando assim o Teste Incremental. Por exemplo, o conjunto de casos de teste Todos-Nós adequado é capaz de satisfazer, na média, $75,82 \%$ dos requisitos de teste exigidos pelo critério Todos-Arcos. Obtido o conjunto de casos de teste Todos-Arcos adequado, este determina uma cobertura de 76,89\%, ou seja, não houve um melhora significativa após a aplicação do critério Todos-Arcos. Da mesma forma, o conjunto de casos de teste Todos-Arcos adequado é capaz de satisfazer, na média, $61,68 \%$ dos requisitos de teste exigidos pelo critério Todos-Usos. Obtido o conjunto de casos de teste Todos-Usos adequado, este determina uma cobertura de 61,69\%, ou seja, não houve um melhora significativa após a aplicação do critério Todos-Usos. De forma similar, o critério Todos-Potenciais-Usos também não apresentou melhora significativa após sua aplicação. Em contrapartida, o critério Análise de Mutantes apresentou uma melhora de 25,71\% após sua aplicação.

\begin{tabular}{|c|c|c|c|c|c|c|c|c|c|c|c|c|c|c|}
\hline & \multicolumn{2}{|c|}{$\begin{array}{l}\text { Todos } \\
\text { Nós }\end{array}$} & \multicolumn{3}{|c|}{$\begin{array}{l}\text { Todos } \\
\text { Arcos }\end{array}$} & \multicolumn{3}{|c|}{$\begin{array}{l}\text { Todos } \\
\text { Usos }\end{array}$} & \multicolumn{3}{|c|}{$\begin{array}{c}\text { Todos } \\
\text { Potenciais-Usos }\end{array}$} & \multicolumn{3}{|c|}{$\begin{array}{l}\text { Análise de } \\
\text { Mutantes }\end{array}$} \\
\hline & T1 & Q1 & T2 & $\% 1$ & Q2 & T3 & $\% 2$ & Q3 & T4 & $\% 3$ & Q4 & T5 & $\% 4$ & Q5 \\
\hline Indivíduo 1 & 6 & 3 & 8 & $33,3 \%$ & 0 & 8 & $0 \%$ & 0 & 8 & $0 \%$ & 0 & 12 & $100 \%$ & 0 \\
\hline Indivíduo 2 & 8 & 1 & 11 & $37,5 \%$ & 0 & 11 & $0 \%$ & 0 & 11 & $0 \%$ & 0 & 19 & $137 \%$ & 0 \\
\hline Indivíduo 3 & 6 & 4 & 7 & $16,6 \%$ & 0 & 9 & $50,0 \%$ & 0 & 9 & $0 \%$ & 0 & 11 & $83,3 \%$ & 2 \\
\hline Indivíduo 4 & 7 & 1 & 7 & $0 \%$ & 0 & 7 & $0 \%$ & 0 & 7 & $0 \%$ & 0 & 7 & $0 \%$ & 0 \\
\hline Indivíduo 5 & 10 & 1 & 11 & $10,0 \%$ & 1 & 11 & $0 \%$ & 0 & 11 & $0 \%$ & 0 & 15 & $50 \%$ & 0 \\
\hline Indivíduo 6 & 8 & 5 & 8 & $0 \%$ & 0 & 8 & $0 \%$ & 0 & 8 & $0 \%$ & 0 & 8 & $0 \%$ & 0 \\
\hline Indivíduo 7 & 14 & 0 & 16 & $14,2 \%$ & 0 & 16 & $0 \%$ & 0 & 16 & $0 \%$ & 0 & 16 & $0 \%$ & 1 \\
\hline Indivíduo 8 & 8 & 2 & 11 & $37,5 \%$ & 0 & 12 & $50,0 \%$ & 0 & 12 & $0 \%$ & 0 & 13 & $62,5 \%$ & 1 \\
\hline Indivíduo 9 & 11 & 1 & 18 & $63,6 \%$ & 0 & 18 & $0 \%$ & 0 & 18 & $0 \%$ & 0 & 18 & $0 \%$ & 0 \\
\hline Indivíduo 10 & 56 & 2 & 56 & $0 \%$ & 0 & 56 & $0 \%$ & 0 & 56 & $0 \%$ & 0 & 80 & $42,8 \%$ & 1 \\
\hline Indivíduo 11 & 30 & 0 & 30 & $0 \%$ & 0 & 30 & $0 \%$ & 0 & 30 & $0 \%$ & 0 & 40 & $33,3 \%$ & 1 \\
\hline Indivíduo 12 & 26 & 3 & 26 & $0 \%$ & 0 & 26 & $0 \%$ & 0 & 26 & $0 \%$ & 0 & 35 & $34,1 \%$ & 1 \\
\hline Médias & 14,62 & 1,77 & 16,08 & $9,98 \%$ & 0,08 & 16,31 & $11,5 \%$ & 0,0 & 16,31 & $0 \%$ & 0,0 & 21,08 & $44,1 \%$ & 0,54 \\
\hline & & $T_{n}-$ & Quantid & $\begin{array}{l}\text { lade de c } \\
\%_{\text {n }}-\mathrm{Pe}\end{array}$ & $\begin{array}{l}\text { asos de } \\
\text { centua }\end{array}$ & $\begin{array}{l}\text { teste de } \\
\text { de acré }\end{array}$ & $\begin{array}{l}\text { finidos } \\
\text { scimo er }\end{array}$ & $\begin{array}{l}\mathrm{m} \text { um } \\
\mathrm{n} \text { relac }\end{array}$ & $\begin{array}{l}\text { determiı } \\
\text { óo a T1 }\end{array}$ & lado $\mathrm{cr}$ & ério & & & \\
\hline
\end{tabular}

Tabela 4.27 - Coberturas médias obtida pelos indivíduos aplicando o Teste Incremental. 
A Tabela 4.27 apresenta um detalhamento das quantidades médias de casos de teste necessários para se alcançar as taxas médias de cobertura apresentadas na Figura 4.24, bem como, a quantidade média de defeitos isolados com esses casos de teste e o percentual médio adicional para se isolar novos defeitos durante a aplicação dos critérios que compõe o Teste Incremental. Pode-se observar que foram construídos na média 14 casos de teste quando da aplicação do critério Todos-Nós e na média foi isolado 1 defeito. Os critérios Todos-Arcos, Todos-Usos e Todos-Potenciais-Usos acarretaram juntos, na média, um custo adicional acima de $21 \%$ na construção de novos casos de teste sem efeitos significativos. O critério Análise de Mutantes acarretou um custo adicional de $44 \%$ na média, mas com um benefício médio de 0,5 novos defeitos isolados. 


\subsubsection{Análise das Falhas}

A seguir apresentam-se as análises referentes às falhas observadas em cada um dos programas utilizados durante a replicação do experimento. A estrutura do texto segue a mesma organização utilizada para a apresentação dos defeitos.

É importante ressaltar que Basili e Selby [BAS87] em seu experimento original não tem um passo destinado a isolamento de defeitos. Em contrapartida, Kamsties \& Lott [KAM95] tem o passo para observação de falhas e isolamento de defeitos. No contexto deste trabalho, são apresentadas as análises referentes aos defeitos isolados e as falhas observadas para fins de comparação.

\section{Análise das falhas do programa NTREE}

A Figura 4.25 apresenta as quantidades de cada falha que foram observadas por cada técnica quando aplicadas no programa "ntree.c".

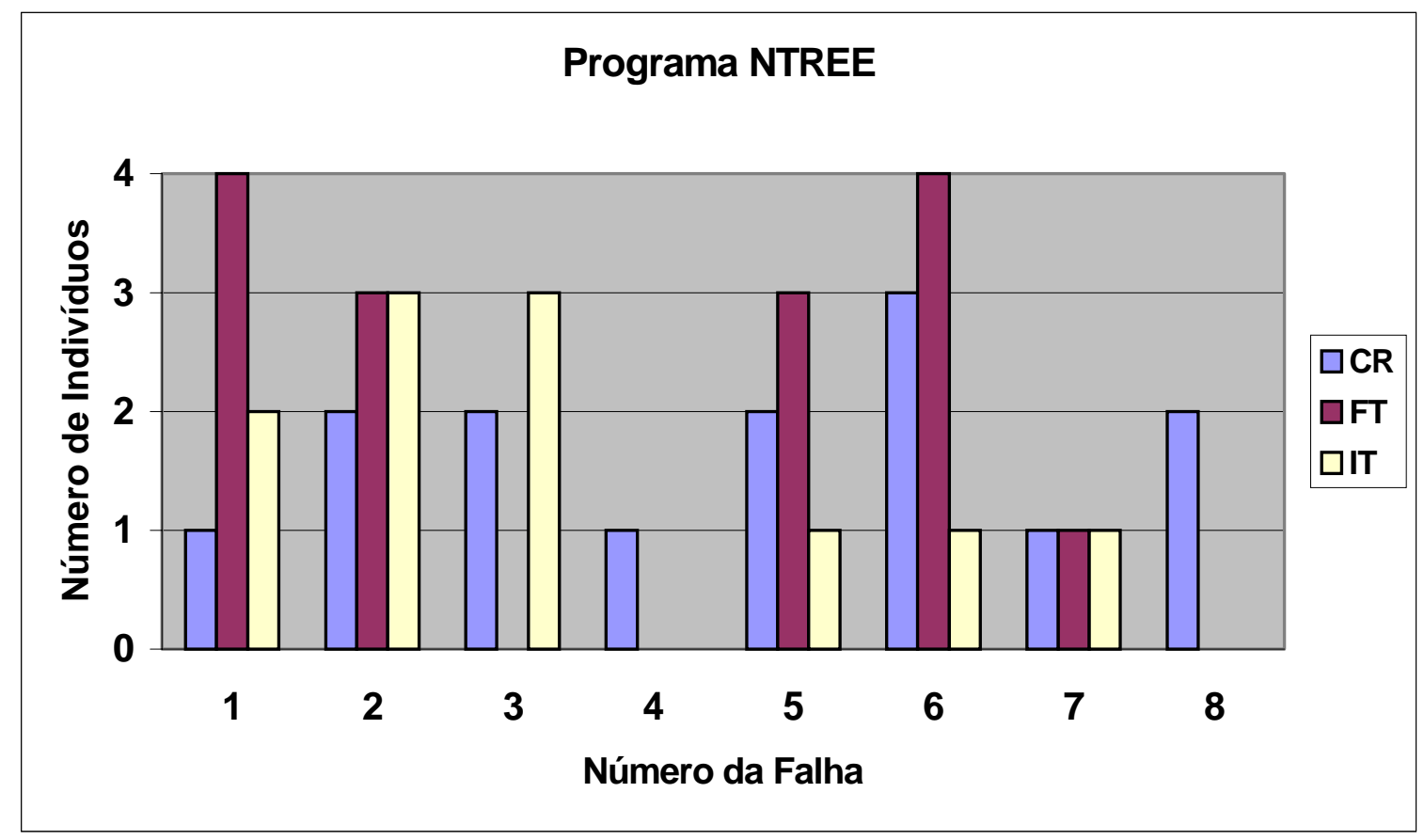

Figura 4.25 - Ntree: Falhas observadas pelas técnicas. 


\begin{tabular}{|l|c|c|}
\cline { 2 - 3 } \multicolumn{1}{c|}{} & \multicolumn{1}{c|}{$\begin{array}{c}\text { Possibilidades de } \\
\text { observação }\end{array}$} & $\begin{array}{c}\text { Falhas } \\
\text { observadas }\end{array}$ \\
\hline Leitura de Código & 32 & 14 \\
\hline Teste Funcional & 32 & 15 \\
\hline Teste Incremental & 32 & 11 \\
\hline
\end{tabular}

Tabela 4.28 - Ntree: Possibilidades de observação e quantidades observadas de falhas por técnica.

Em uma análise preliminar, conforme pode ser observado na Tabela 4.28, a técnica Teste Funcional observou um número maior de falhas que as outras técnicas. Das 32 possibilidades de observação de falhas, obtida pela razão entre a quantidade de falhas (8) possíveis de serem observadas no programa "ntree.c" e a quantidade de indivíduos (4) que aplicaram a técnica, 15 foram observadas. A experiência com programação pode ter influenciado nos resultados obtidos pelos indivíduos, uma vez que o grupo tem a maior média de experiência com programação entre todos os participantes, conforme pode ser visto na Tabela 4.8 .

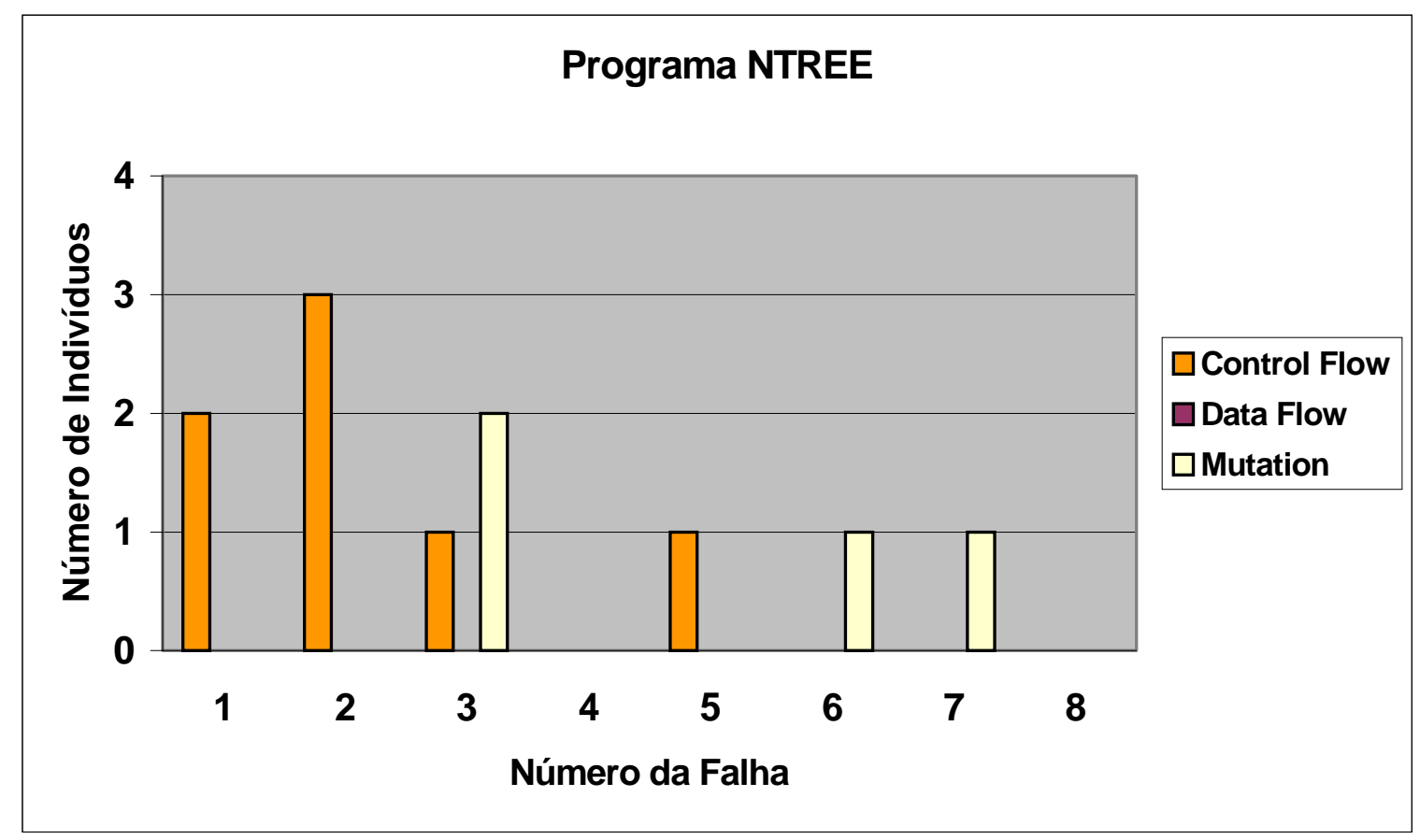

Figura 4.26 - Ntree: Falhas observadas pelo Teste Incremental.

A Figura 4.26 apresenta um detalhamento das falhas observadas pelos critérios que compõem a técnica Teste Incremental. Das 11 falhas observadas, 7 foram observadas pelo critério todos-nós e 4 foram observadas pelo critério análise de mutantes.

A seguir, apresentam-se três diferentes visões dos dados apresentados na Figura 4.25: 
Visão 1 - Efetividade das técnicas por grupo de indivíduos

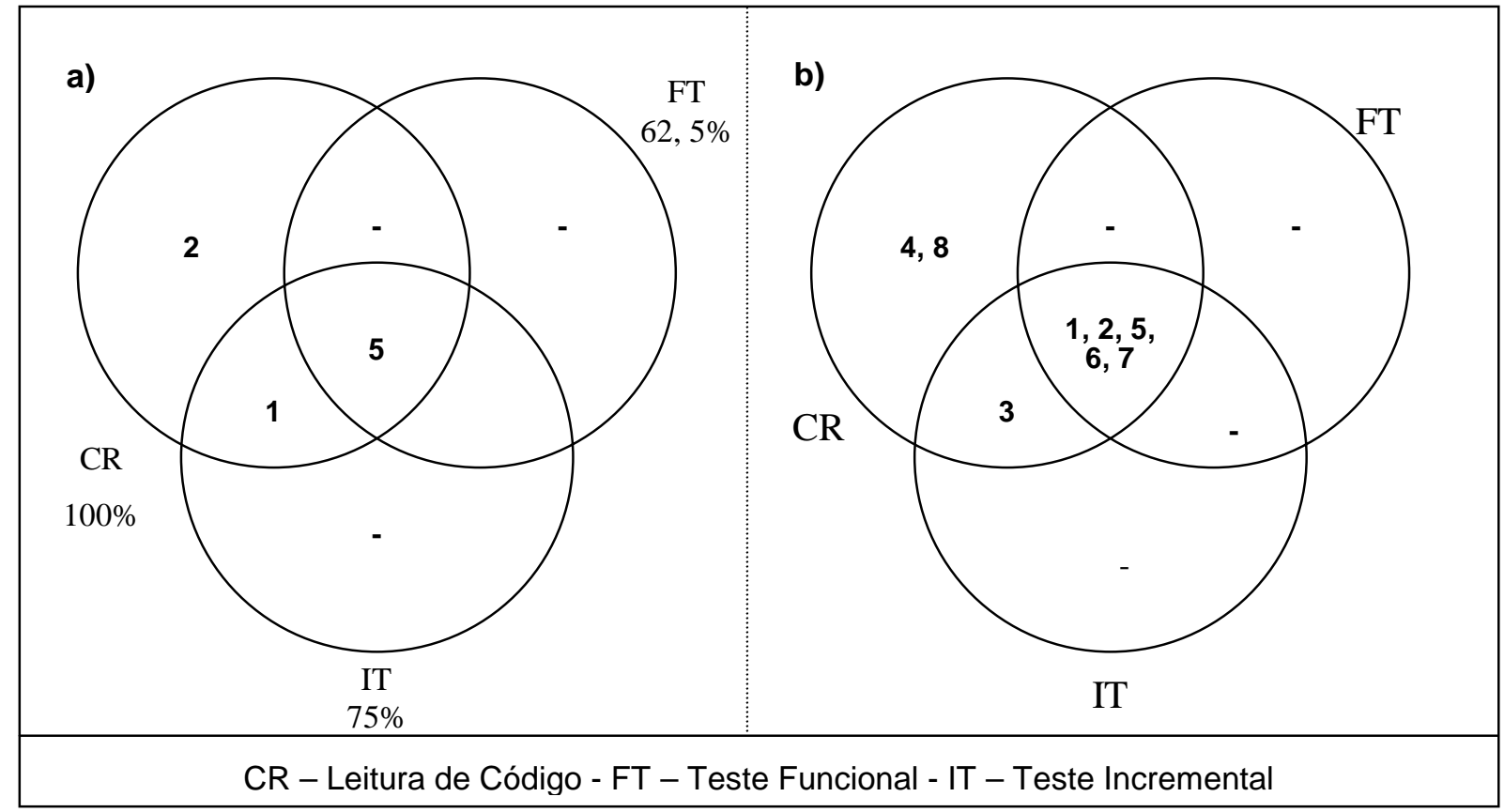

Figura 4.27 - Ntree: (a) Quantidade e percentual de falhas observadas pelas técnicas; (b) Identificação das falhas observadas pelas técnicas.

Visão 2 - Efetividade das técnicas pelo número de ocorrências de falhas

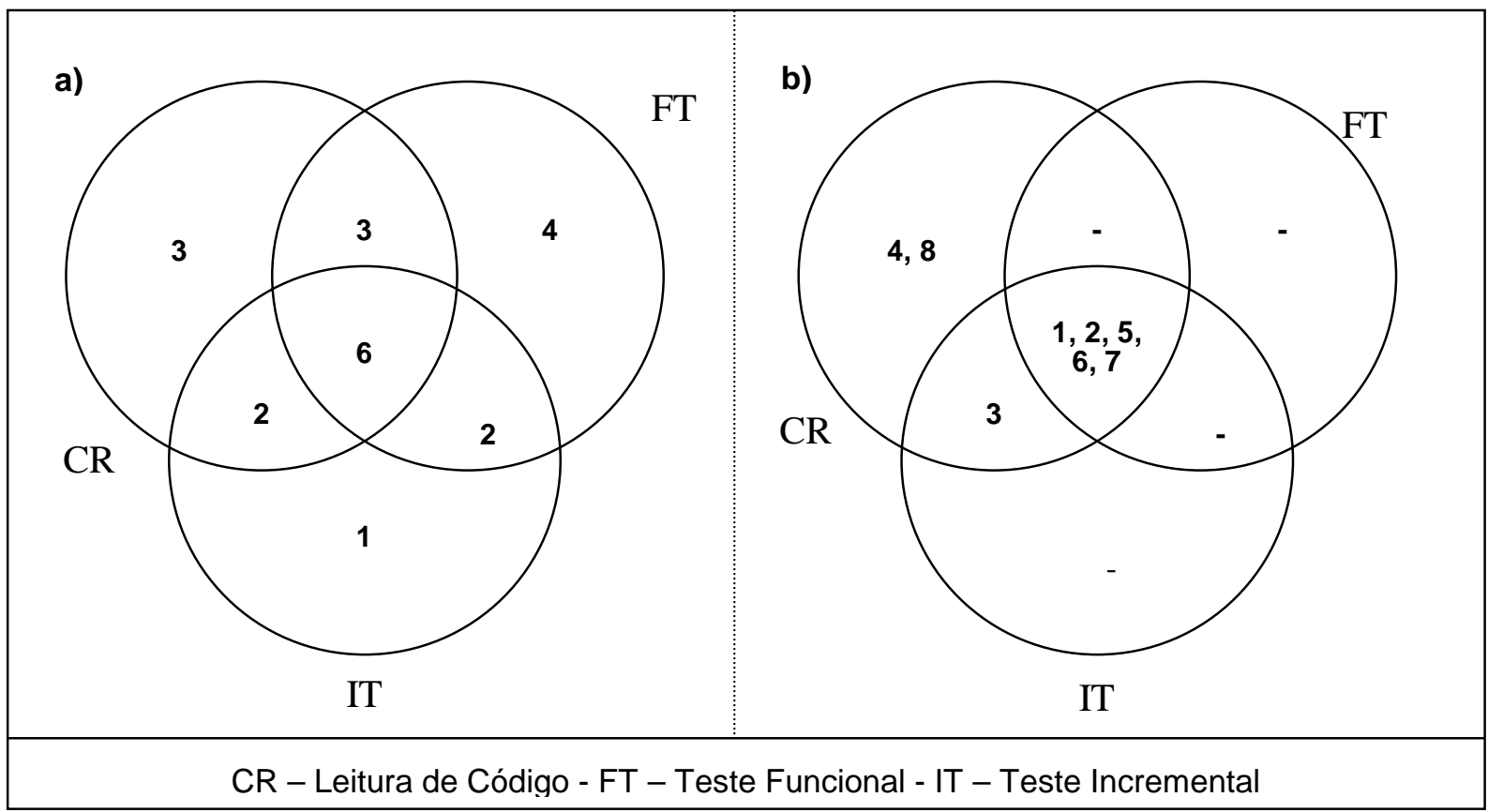

Figura 4.28 - Ntree: (a) Número de ocorrências de falhas observadas pelas técnicas; (b) Identificação das falhas observadas pelas técnicas. 
Como pode ser observado na Figura 4.27 (a), a técnica Leitura de Código observou: 2 falhas que nenhuma outra técnica observou, são elas: 4 e 8 (ver Figura 4.27 (b)); 1 falha que também foi observada pela técnica Teste Incremental, que é a falha 3; 5 falhas que também foram observadas pelas técnicas Teste Funcional e Teste Incremental, são elas: 1, 2, 5, 6 e 7. A técnica Leitura de Código obteve uma efetividade de 100\%, ou seja, das 8 falhas possíveis de serem observadas no programa "ntree.c" todas foram descobertas. É importante ressaltar que somente a técnica Leitura de Código observou as falhas 4 e 8. Estas falhas são decorrentes de defeitos do tipo Cosmetic e Interface, respectivamente.

Como pode ser observado na Figura 4.28 (b), as falhas 1, 2, 5, 6 e 7 foram observadas por todas as técnicas. No caso as falhas 1,5 e 6 foram observadas mais vezes pela técnica Teste Funcional do que pelas outras técnicas. As quantidades totalizadas de ocorrências de falhas observadas pelas técnicas são apresentados na Figura 4.28 (a).

Visão 3 - Identificação da melhor técnica por falha

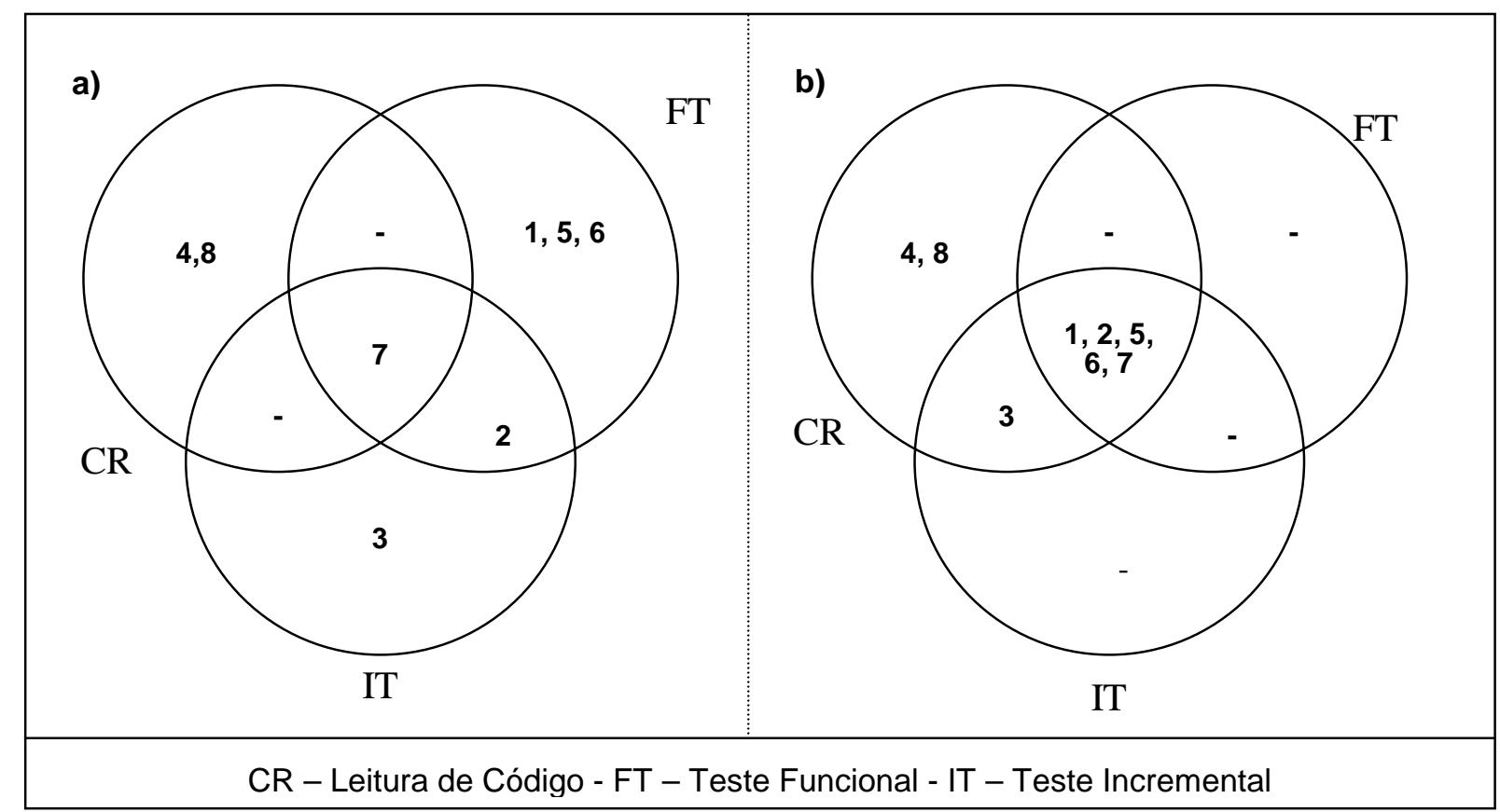

Figura 4.29 - Ntree: (a) Identificação das falhas onde a técnica obteve melhor ou igual desempenho que as outras técnicas; (b) Identificação das falhas observadas pelas técnicas.

Conforme pode ser observado na Figura 4.29 (b), a falha 3, por exemplo, foi observada tanto pela técnica Leitura de Código como pela técnica Teste Incremental, mas a técnica Teste Incremental foi mais efetiva, ou seja, observou uma quantidade maior desta falha do que a técnica Leitura de Código. A Figura 4.29 (a) apresenta a identificação das falhas onde a técnica obteve melhor ou igual desempenho que as outras técnicas. 


\section{Análise das falhas do programa CMDLINE}

A Figura 4.30 apresenta as quantidades de cada falha que foram observadas por cada técnica quando aplicadas no programa "cmdline.c".

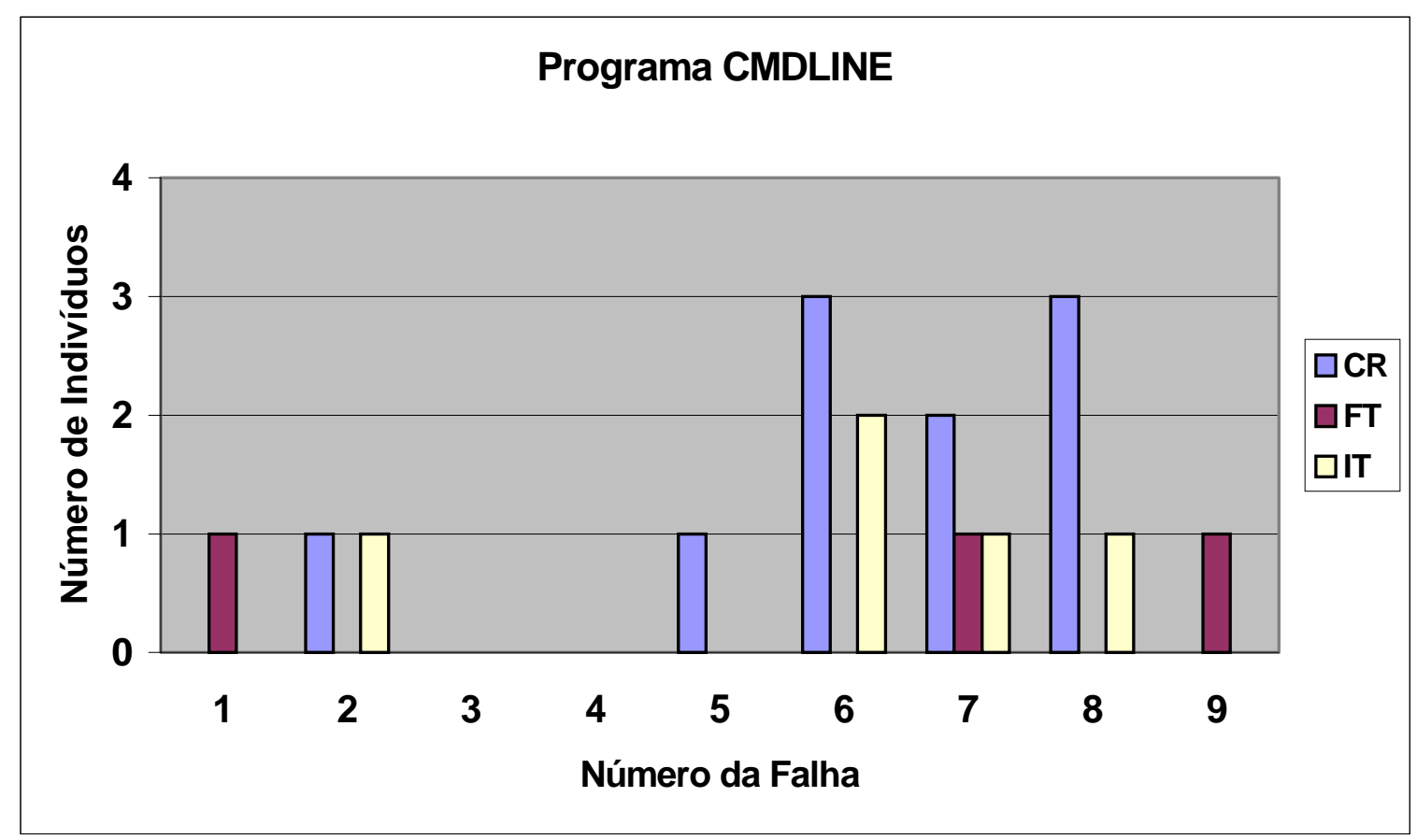

Figura 4.30 - Cmdline: Falhas observadas pelas técnicas.

\begin{tabular}{|l|c|c|}
\cline { 2 - 3 } \multicolumn{1}{c|}{} & \multicolumn{1}{c|}{$\begin{array}{c}\text { Possibilidades de } \\
\text { observação }\end{array}$} & $\begin{array}{c}\text { Falhas } \\
\text { observadas }\end{array}$ \\
\hline Leitura de Código & 36 & 10 \\
\hline Teste Funcional & 36 & 03 \\
\hline Teste Incremental & 36 & 05 \\
\hline
\end{tabular}

Tabela 4.29 - Cmdline: Possibilidades de observação e quantidades observadas de falhas por técnica.

Em outra análise preliminar, conforme pode ser observado na Tabela 4.29, a técnica Leitura de Código observou um número maior de falhas que as outras técnicas. Das 36 possibilidades de observação de falhas, obtida pela razão entre a quantidade de falhas (9) possíveis de serem observadas no programa "cmdline.c" e a quantidade de indivíduos (4) que aplicaram a técnica, 10 foram observadas. A experiência com programação pode ter influenciado nos resultados obtidos pelos indivíduos, uma vez que o grupo tem a maior média de experiência com programação entre todos os participantes, conforme pode ser visto na Tabela 4.12. 


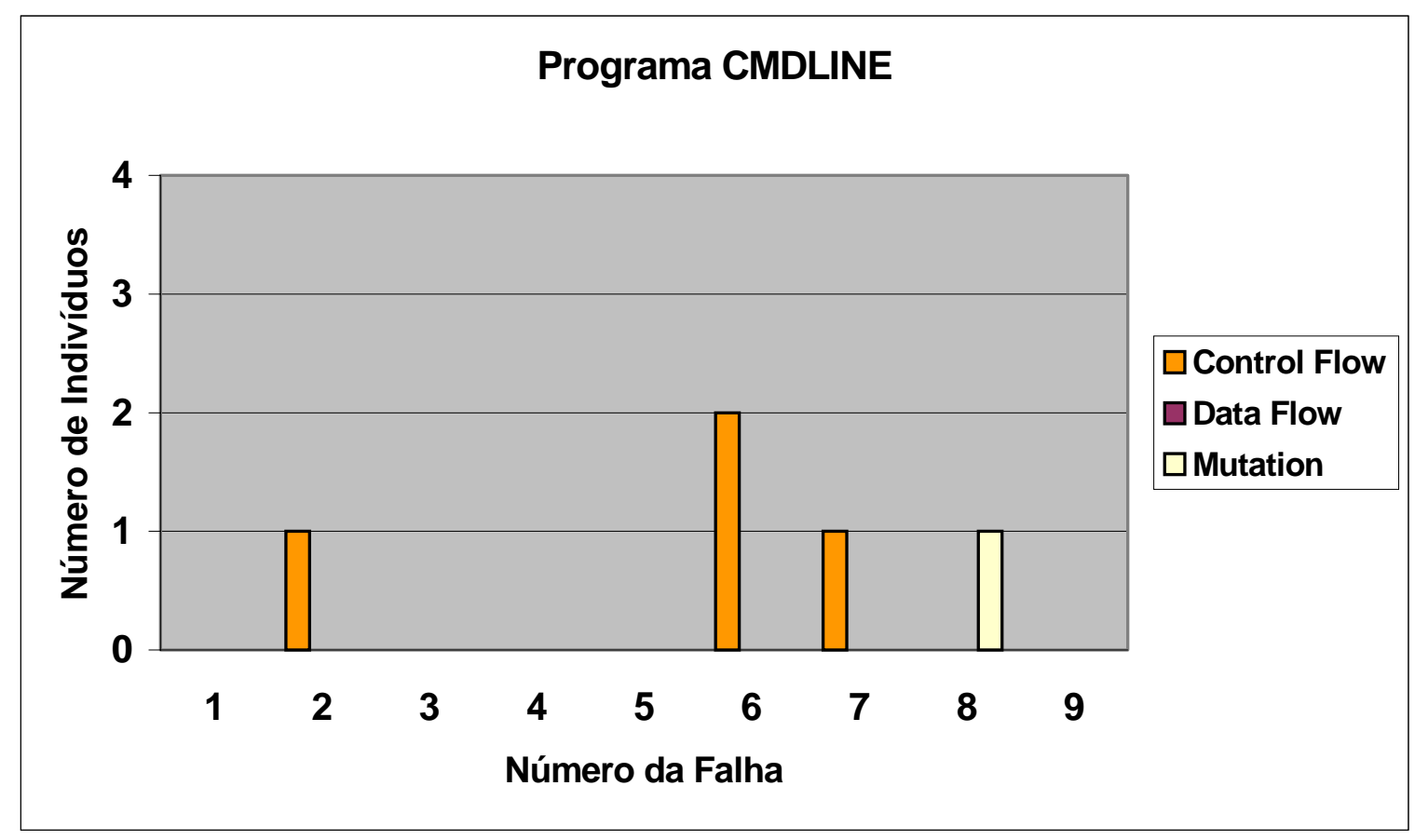

Figura 4.31 - Cmdline: Falhas observadas pelo Teste Incremental.

A Figura 4.31 apresenta um detalhamento das falhas observadas pelos critérios que compõem a técnica Teste Incremental. Das 05 falhas observadas, 4 foram observadas pelo critério todos-nós e 1 foi observada pelo critério análise de mutantes.

A seguir, apresentam-se três diferentes visões dos dados apresentados na Figura 4.30:

Como pode ser observado na Figura 4.32 (a), a técnica Leitura de Código observou: 1 falha que nenhuma outra técnica observou, que é a falha 5 (ver Figura 4.32 (b)); 3 falhas que também foram observadas pela técnica Teste Incremental, são elas: 2, 6 e 8; 1 falha que também foi observada pelas técnicas Teste Funcional e Teste Incremental, que é a falha 7. A técnica Leitura de Código obteve uma efetividade de 55,5\%, ou seja, das 9 falhas possíveis de serem observadas no programa "cmdline.c" somente 5 foram descobertas por cada técnica. É importante ressaltar que somente a técnica Leitura de Código observou a falha 5. Esta falha é decorrente de um defeito do tipo Data. 
Visão 1 - Efetividade das técnicas por grupo de indivíduos

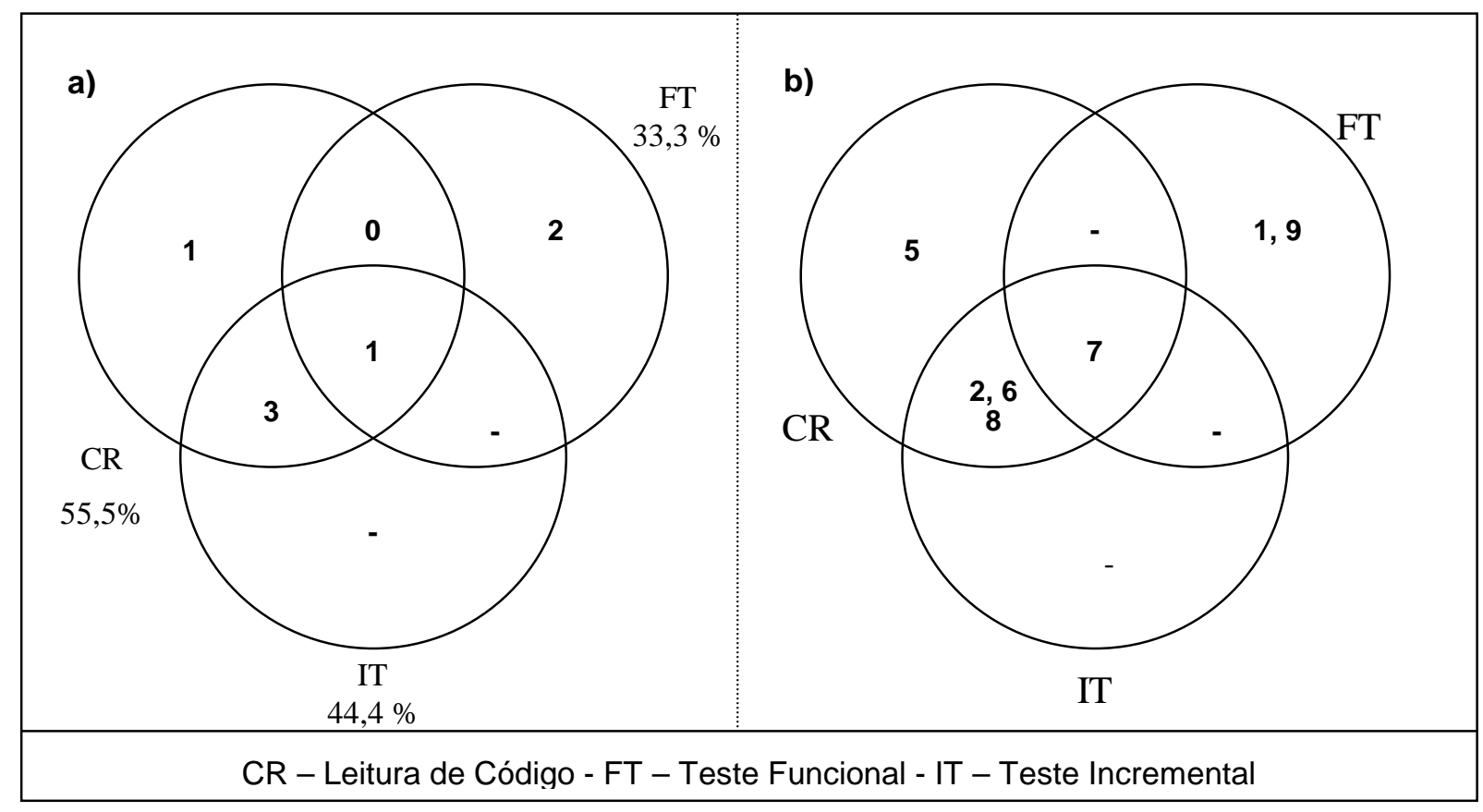

Figura 4.32 - Cmdline: (a) Quantidade e percentual de falhas observadas pelas técnicas; (b) Identificação das falhas observadas pelas técnicas.

Visão 2 - Efetividade das técnicas pelo número de ocorrências de falhas

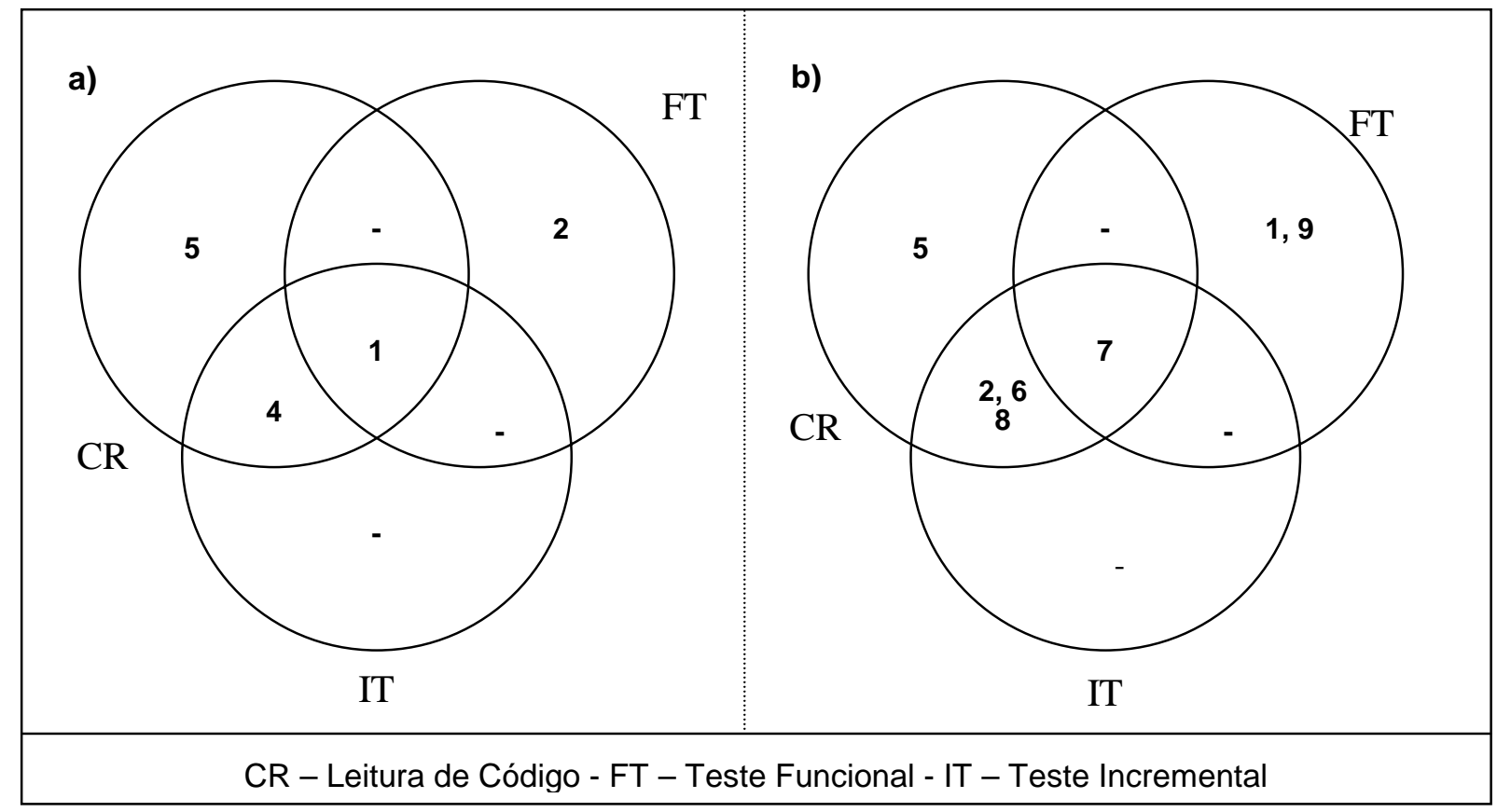

Figura 4.33 - Cmdline: (a) Número de ocorrências de falhas observadas pelas técnicas; (b) Identificação das falhas observadas pelas técnicas. 
Como pode ser observado na Figura 4.33 (b), a falha 7 foi observada por todas as técnicas. No caso a falha 7 foi observada mais vezes pela técnica Leitura de Código. As quantidades totalizadas de ocorrências de falhas observadas pelas técnicas são apresentados na Figura 4.33 (a).

Visão 3 - Identificação da melhor técnica por falha

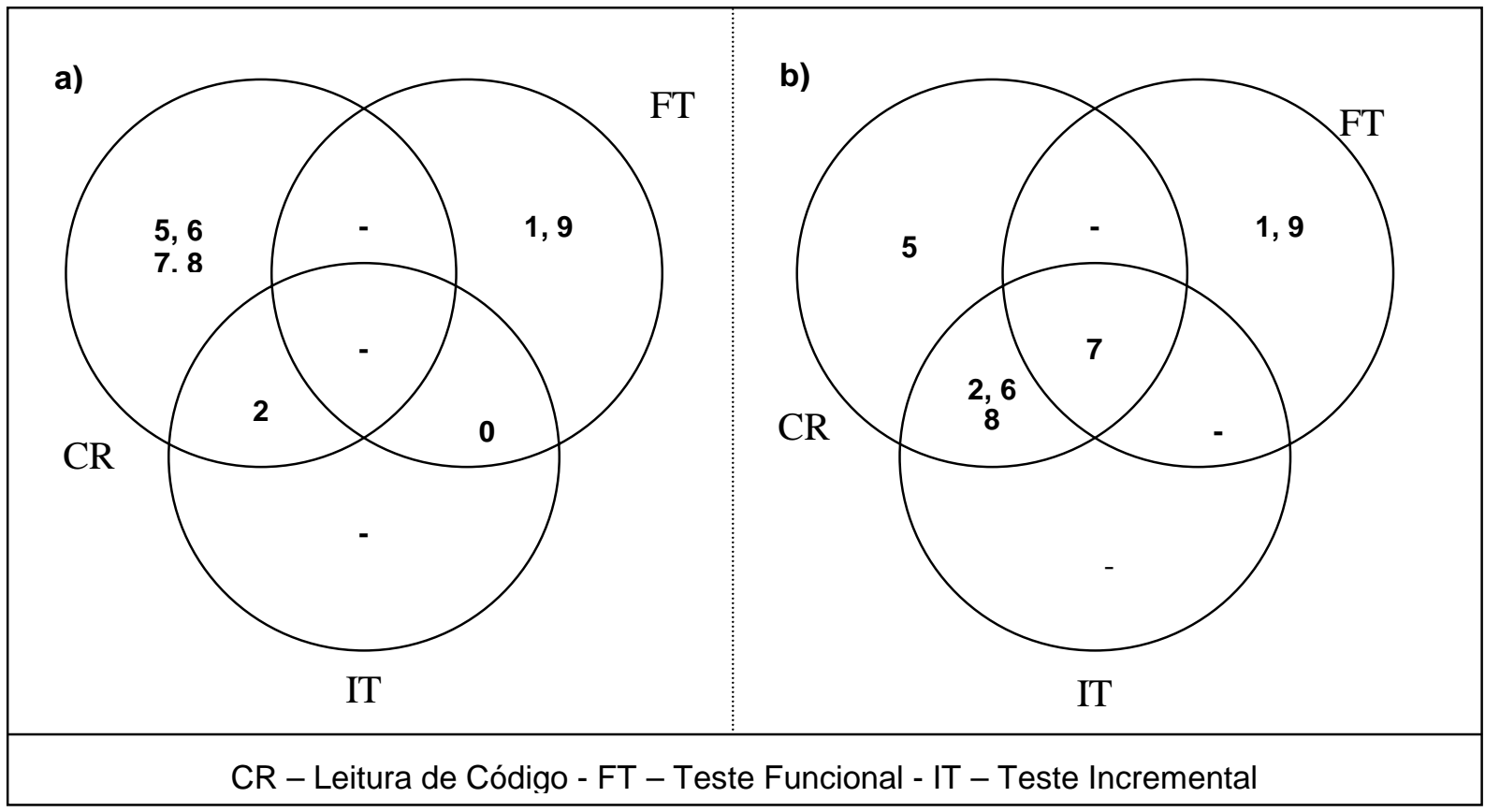

Figura 4.34 - Cmdline: (a) Identificação das falhas onde a técnica obteve melhor ou igual desempenho que as outras técnicas; (b) Identificação das falhas observadas pelas técnicas.

Conforme pode ser observado na Figura 4.34 (b), as falhas 2, 6 e 8, por exemplo, foram observadas tanto pela técnica Leitura de Código como pela técnica Teste Incremental, mas a técnica Leitura de Código foi mais efetiva na observação das falhas 6 e 8, ou seja, observou uma quantidade maior desta falha do que a técnica Teste Incremental. A Figura 4.34 (a) apresenta a identificação das falhas onde a técnica obteve melhor ou igual desempenho que as outras técnicas. 


\section{Análise das falhas do programa NAMETBL}

A Figura 4.35 apresenta as quantidades de cada falha que foram observadas por cada técnica quando aplicadas no programa "nametbl.c".

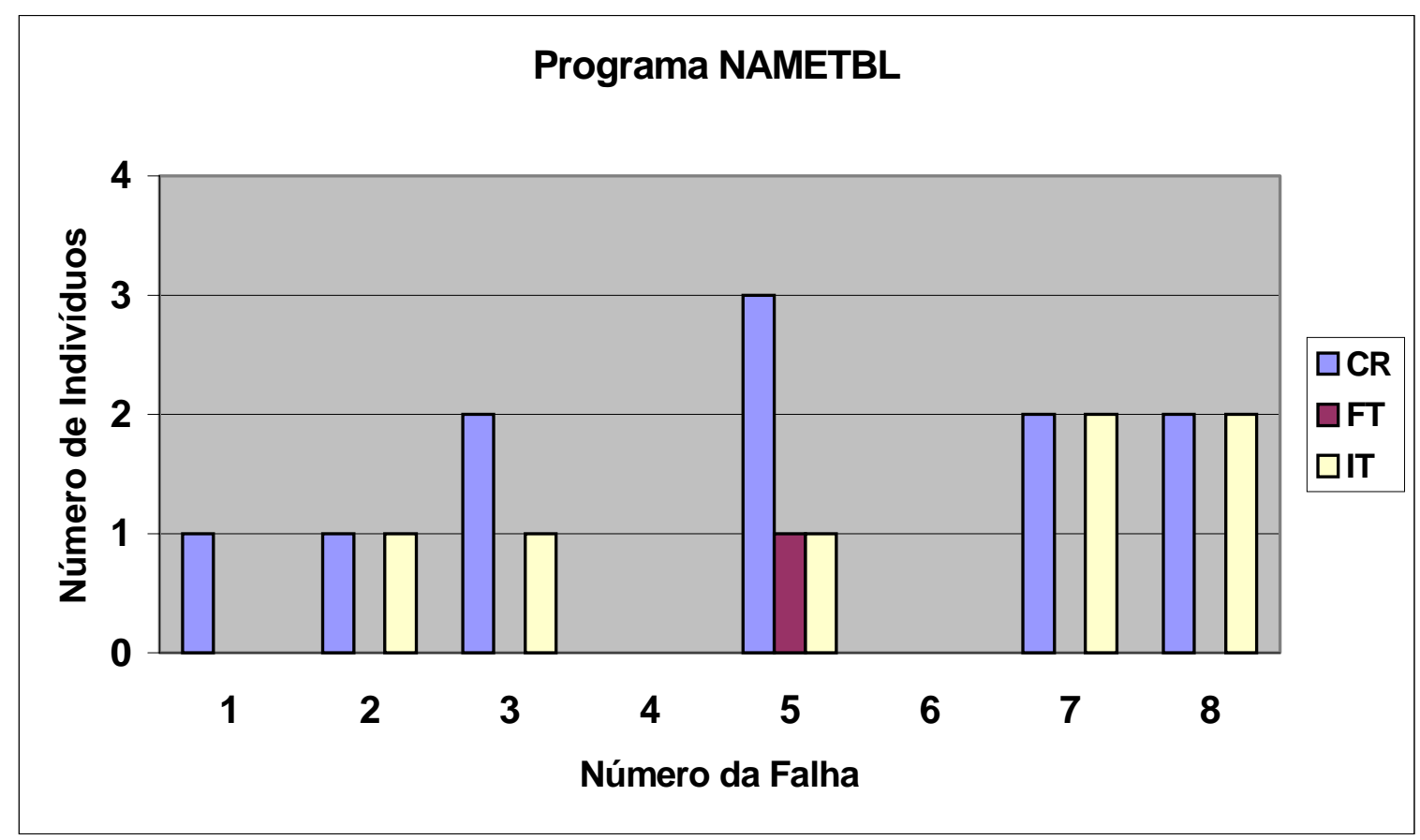

Figura 4.35 - Nametbl: Falhas observadas pelas técnicas.

\begin{tabular}{|l|c|c|}
\cline { 2 - 3 } \multicolumn{1}{c|}{} & \multicolumn{1}{c|}{$\begin{array}{c}\text { Possibilidades de } \\
\text { observação }\end{array}$} & $\begin{array}{c}\text { Falhas } \\
\text { observadas }\end{array}$ \\
\hline Leitura de Código & 32 & 11 \\
\hline Teste Funcional & 32 & 01 \\
\hline Teste Incremental & 32 & 07 \\
\hline
\end{tabular}

Tabela 4.30 - Nametbl: Possibilidades de observação e quantidades observadas de falhas por técnica.

Em outra análise preliminar, conforme pode ser observado na Tabela 4.30, a técnica Leitura de Código observou um número maior de falhas que as outras técnicas. Das 32 possibilidades de observação de falhas, obtida pela razão entre a quantidade de falhas (8) possíveis de serem observadas no programa "nametbl.c" e a quantidade de indivíduos (4) que aplicaram a técnica, 11 foram observadas. A experiência com programação pode ter influenciado nos resultados obtidos pelos indivíduos, uma vez que o grupo tem a $2^{\mathrm{a}}$ maior média de experiência com programação entre todos os participantes, conforme pode ser visto na Tabela 4.16. 


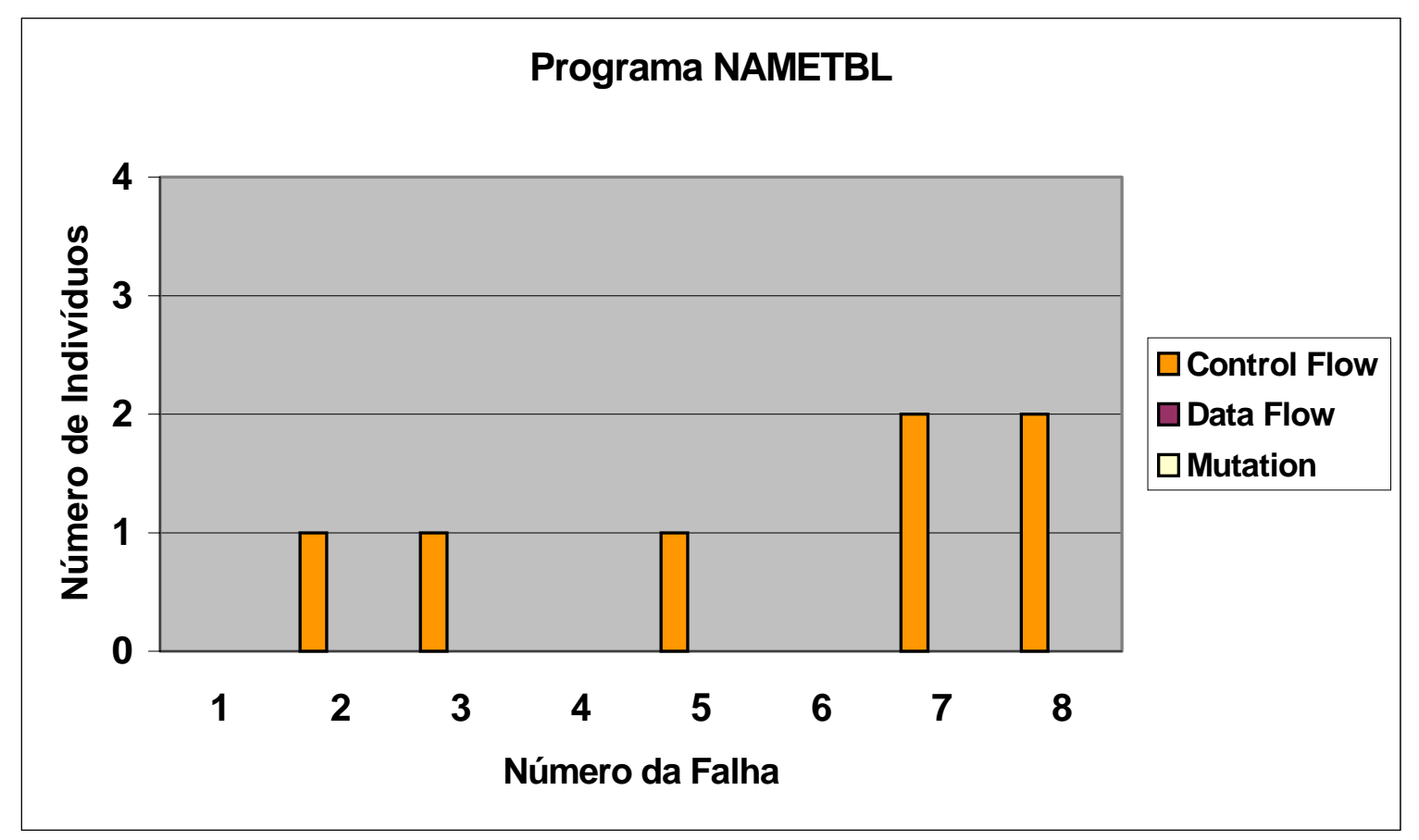

Figura 4.36 - Nametbl: Falhas observadas pelo Teste Incremental.

A Figura 4.36 apresenta um detalhamento das falhas observadas pelos critérios que compõem a técnica Teste Incremental. Todas as falhas foram observadas pelo critério todos-nós.

A seguir, apresentam-se três diferentes visões dos dados apresentados na Figura 4.35:

Como pode ser observado na Figura 4.37 (a), a técnica Leitura de Código observou: 1 falha que nenhuma outra técnica observou, que é a falha 1 (ver Figura 4.37 (b)); 4 falhas que também foram observadas pela técnica Teste Incremental, são elas: 2, 3, 7 e 8; 1 falha que também foi observada pelas técnicas Teste Funcional e Teste Incremental, que é a falha 5. A técnica Leitura de Código obteve uma efetividade de 75\%, ou seja, das 8 falhas possíveis de serem observadas no programa "nametbl.c" 6 foram descobertas. É importante ressaltar que somente a técnica Leitura de Código observou a falha 1. Esta falha é decorrente de um defeito do tipo Data. 
Visão 1 - Efetividade das técnicas por grupo de indivíduos

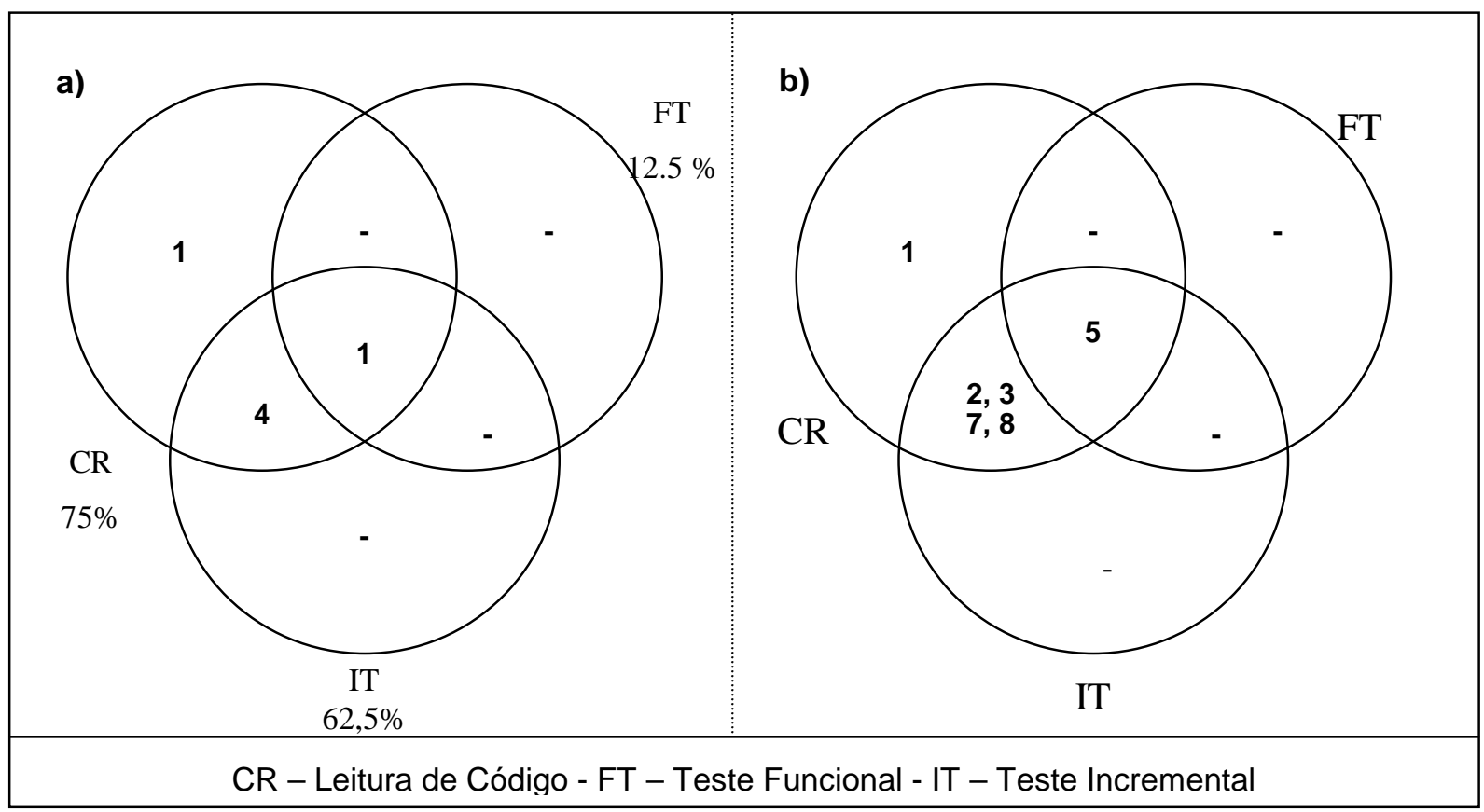

Figura 4.37 - Nametbl: (a) Quantidade e percentual de falhas observadas pelas técnicas; (b) Identificação dos falhas observadas pelas técnicas.

Visão 2 - Efetividade das técnicas pelo número de ocorrências de falhas

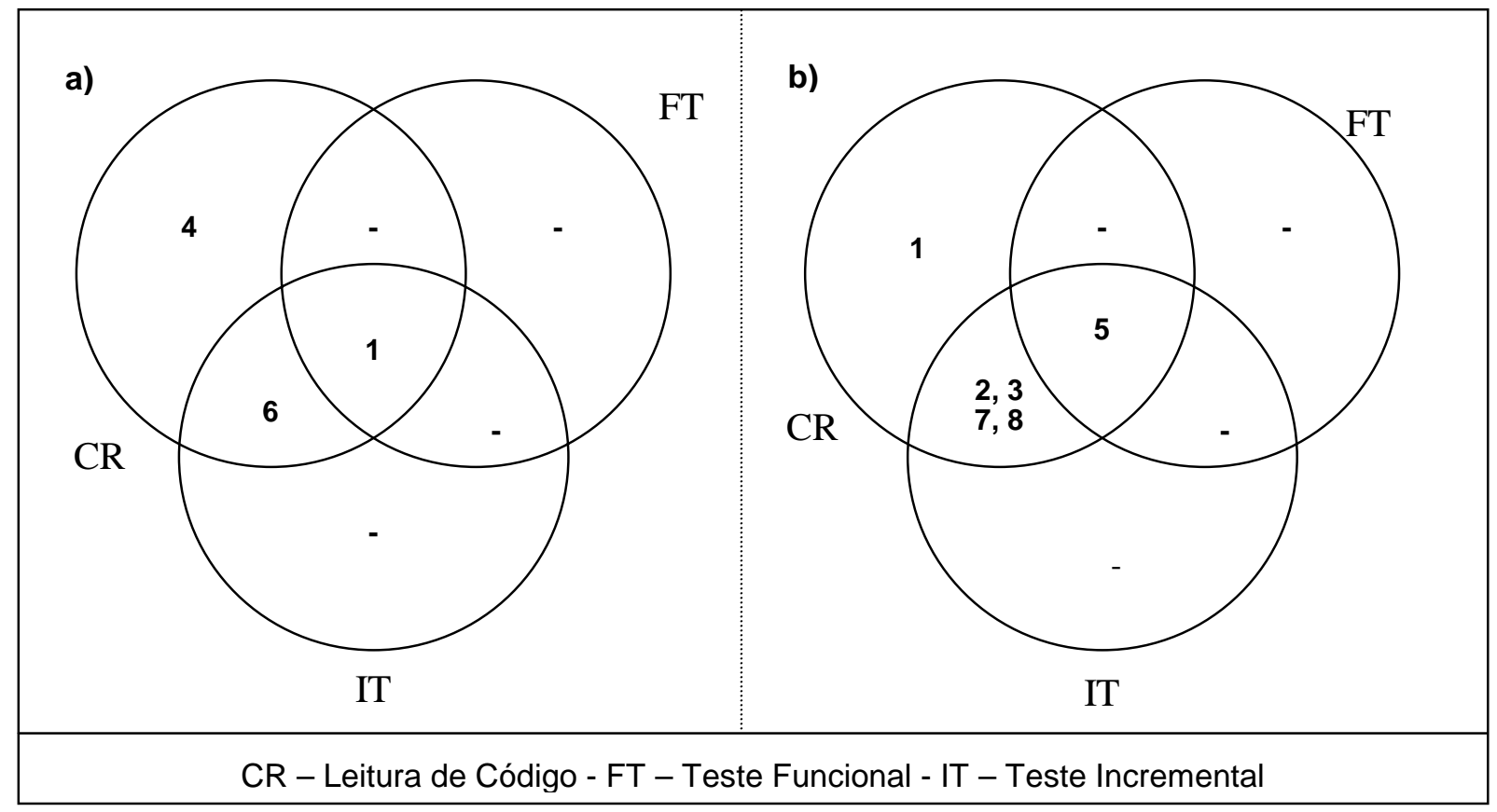

Figura 4.38 - Nametbl: (a) Número de ocorrências de falhas observadas pelas técnicas; (b) Identificação das falhas observadas pelas técnicas. 
Como pode ser observado na Figura 4.38 (b), a falhas 2, 3, 7 e 8 foram observadas tanto pela técnica Leitura de Código como pela técnica Teste Incremental. No caso a falha 3 foi observada mais vezes pela técnica Leitura de Código. As quantidades totalizadas de ocorrências de falhas observadas pelas técnicas são apresentados na Figura 4.38 (a).

Visão 3 - Identificação da melhor técnica por falha

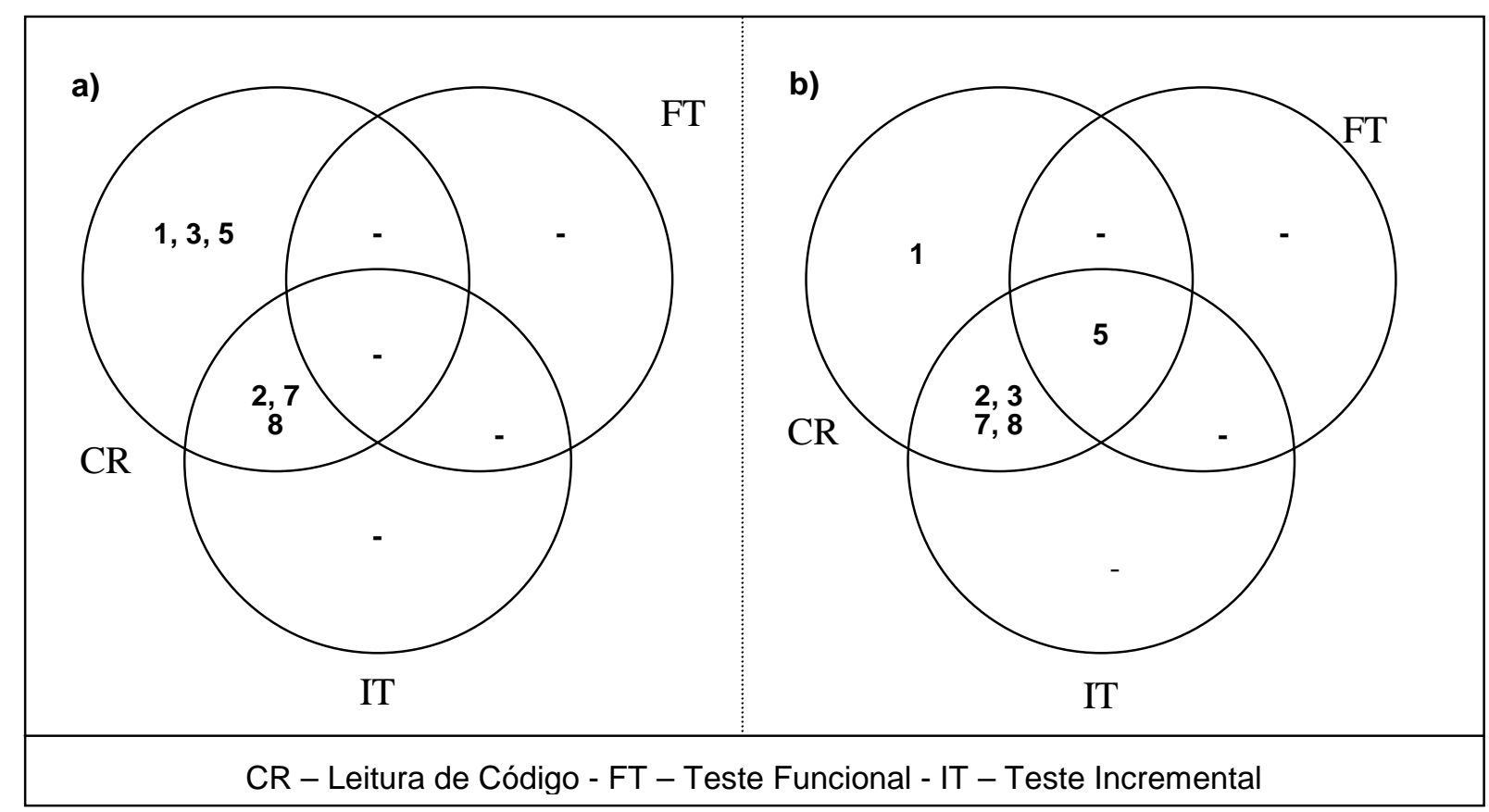

Figura 4.39 - Nametbl: (a) Identificação das falhas onde a técnica obteve melhor ou igual desempenho que às outras técnicas; (b) Identificação das falhas observadas pelas técnicas.

Conforme pode ser observado na Figura 4.39 (b), a falha 5, por exemplo, foi observada por todas as técnicas, mas a técnica Leitura de Código foi mais efetiva, ou seja, observou uma quantidade maior desta falha do que a técnica Teste Incremental. A Figura 4.39 (a) apresenta a identificação das falhas onde a técnica obteve melhor ou igual desempenho que as outras técnicas.

\section{Análise em conjunto das falhas dos programas NTREE, CMDLINE e NAMETBL}

A Tabela 4.31 apresenta as quantidades de falhas observadas e os tempos gastos na observação de falhas obtidas por cada indivíduo em cada fase do experimento. A partir desta organização de dados, foram calculados: a média de falhas observadas por indivíduo; o percentual médio de falhas observadas por cada técnica; e a taxa de observação de falhas das técnicas. 


\begin{tabular}{|c|c|c|c|c|c|c|c|c|c|}
\cline { 2 - 9 } \multicolumn{1}{c|}{} & \multicolumn{3}{c|}{ Leitura de Código } & \multicolumn{2}{c|}{ Teste Funcional } & \multicolumn{2}{c|}{ Teste Incremental } \\
\cline { 2 - 9 } & ID & QU & TI & ID & QU & TI & ID & QU & TI \\
\hline \multirow{3}{*}{ Ntree.c } & S06 & 0 & 180 & S01 & 3 & 145 & S03 & 6 & 110 \\
(8 falhas) & S10 & 5 & 176 & S05 & 4 & 109 & S04 & 1 & 365 \\
& S12 & 5 & 125 & S09 & 3 & 180 & S07 & 1 & 120 \\
& S02 & 4 & 245 & S11 & 5 & 48 & S08 & 3 & 320 \\
\hline \multirow{4}{*}{ Cmdline.c } & S01 & 4 & 185 & S02 & 0 & 130 & S09 & 0 & 565 \\
(9 falhas) & S04 & 2 & 180 & S03 & 2 & 55 & S10 & 0 & 434 \\
& S05 & 1 & 155 & S06 & 1 & 88 & S11 & 1 & 66 \\
& S07 & 3 & 230 & S08 & 0 & 85 & S12 & 4 & 145 \\
\hline \multirow{4}{*}{ Nametbl.c } & S03 & 1 & 75 & S04 & 0 & 105 & S01 & 2 & 250 \\
(8 falhas) & S08 & 4 & 143 & S07 & 0 & 125 & S02 & 1 & 161 \\
& S09 & 3 & 165 & S10 & 1 & 48 & S05 & 1 & 140 \\
\hline & S11 & 3 & 106 & S12 & 0 & 105 & S06 & 3 & 290 \\
\hline
\end{tabular}

Tabela 4.31 - Quantidade de falhas observadas e tempo gasto (em minutos) pelos indivíduos.

\begin{tabular}{|l|c|c|c|}
\hline \multicolumn{1}{|c|}{ Técnica } & Média & Desvio padrão & $\begin{array}{c}\text { Número de } \\
\text { indivíduos }\end{array}$ \\
\hline Leitura de Código & 2,92 & 1,62 & 12 \\
\hline Teste Funcional & 1,58 & 1,78 & 12 \\
\hline Teste Incremental & 1,92 & 1,78 & 12 \\
\hline
\end{tabular}

Tabela 4.32 - Média de falhas observadas pelos indivíduos utilizando cada técnica.

\begin{tabular}{|l|c|c|}
\hline \multicolumn{1}{|c|}{ Técnica } & $\begin{array}{c}\text { Percentual médio de } \\
\text { falhas observadas } \\
\text { (do total possível) }\end{array}$ & $\begin{array}{c}\text { Taxa de observação de } \\
\text { falhas } \\
\text { (hora) }\end{array}$ \\
\hline Leitura de Código & $35,30 \%$ & 1,14 \\
\hline Teste Funcional & $19,44 \%$ & 1,23 \\
\hline Teste Incremental & $26,16 \%$ & 0,75 \\
\hline
\end{tabular}

Tabela 4.33 - Percentual médio de falhas observadas (do total possível) e taxa de observação de falhas por técnica.

Conforme pode ser observado na Tabela 4.32 e na Tabela 4.33, a técnica Leitura de Código obteve a melhor média de falhas observadas por indivíduo, o melhor percentual médio de falhas observadas (do total possível) e a melhor taxa de observação de falhas. A média de falhas observadas por indivíduo para cada técnica foi calculada por meio da divisão entre a somatória 
das quantidades de falhas observadas por cada indivíduo em cada fase do experimento e a quantidade de indivíduos. O percentual médio de falhas observadas para cada técnica foi calculado por meio da divisão entre a somatória dos percentuais individuais de observação de falhas $^{3}$ obtidos em cada fase do experimento e a quantidade de indivíduos. A taxa de observação de falhas para cada técnica foi calculada por meio da divisão entre a somatória das taxas individuais de observação de falhas ${ }^{4}$ obtidas em cada fase do experimento e a quantidade de indivíduos.

\begin{tabular}{|c|c|c|c|c|}
\hline & & \\
\hline & & $\begin{array}{l}\text { Leitura de } \\
\text { Código }\end{array}$ & $\begin{array}{c}\text { Teste } \\
\text { Funcional }\end{array}$ & $\begin{array}{c}\text { Teste } \\
\text { Incremental }\end{array}$ \\
\hline \multirow[t]{2}{*}{ Classe } & Omission & $38.33 \%$ & $32.92 \%$ & $27.08 \%$ \\
\hline & Commission & $30.36 \%$ & $09.52 \%$ & $21.43 \%$ \\
\hline \multirow[t]{6}{*}{ Tipo } & Initialization & $16.67 \%$ & $04.17 \%$ & $08.33 \%$ \\
\hline & Computation & $08.33 \%$ & $00.00 \%$ & $08.33 \%$ \\
\hline & Control & $38.89 \%$ & $31.94 \%$ & $29.17 \%$ \\
\hline & Interface & $47.22 \%$ & $11.11 \%$ & $11.11 \%$ \\
\hline & Data & $33.33 \%$ & $16.67 \%$ & $25.00 \%$ \\
\hline & Cosmetic & $16.67 \%$ & $04.17 \%$ & $12.50 \%$ \\
\hline
\end{tabular}

Tabela 4.34 - Percentual médio de falhas observadas (do total possível) por tipos e classes.

A Tabela 4.34 apresenta um resumo geral dos percentuais de falhas observadas por cada técnica organizadas por classes e tipos dos defeitos que as originaram, considerando os dados obtidos durante as 3 fases do experimento. As técnicas foram efetivas na observação de falhas derivadas dos defeitos da classe Omission. As técnicas Teste Funcional e Teste Incremental foram mais efetivas na observação de falhas derivadas dos defeitos do tipo Control, enquanto que a técnica Leitura de Código foi mais efetiva na observação das falhas derivadas dos defeitos do tipo Interface.

A Figura 4.40 apresenta o percentual médio geral de falhas observadas por cada indivíduo, considerando os resultados obtidos por ele durante todas as fases do experimento. $\mathrm{O}$ indivíduo 11 foi quem obteve o melhor percentual $(37,04 \%)$ entre todos os participantes do experimento. O perfil do indivíduo é nível expert de proficiência com leitura em Inglês, experiência de 14 anos com programação e conhecimento avançado na linguagem C. $\mathrm{O}$ percentual médio de defeitos isolados por cada indivíduo em uma fase específica do experimento pode ser visto na Figura 4.41, na Figura 4.42 e na Figura 4.43.

\footnotetext{
${ }^{3}$ Os percentuais foram calculados a partir da seguinte expressão: $(x \star 100) / y$. Onde $x$ é a quantidade de falhas observadas pelo indivíduo e y é a quantidade de falhas possíveis de serem observadas no programa.

${ }^{4}$ As taxas foram calculadas a partir da seguinte expressão: $\mathrm{x} /(\mathrm{y} / 60)$. Onde $\mathrm{x}$ é a quantidade de falhas observadas pelo indivíduo e y é a quantidade de tempo gasto na observação.
} 


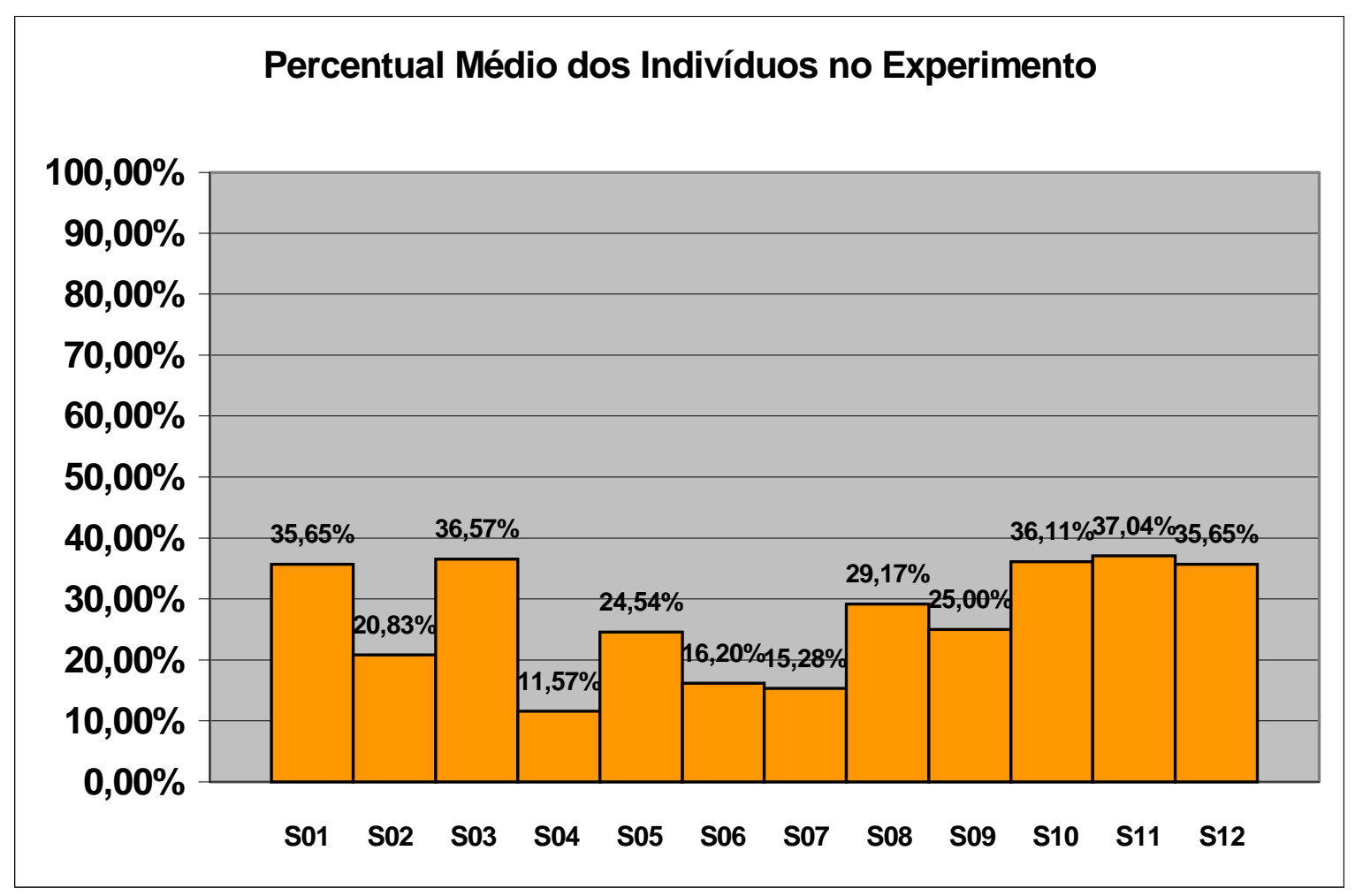

Figura 4.40 - Percentual médio dos indivíduos no experimento

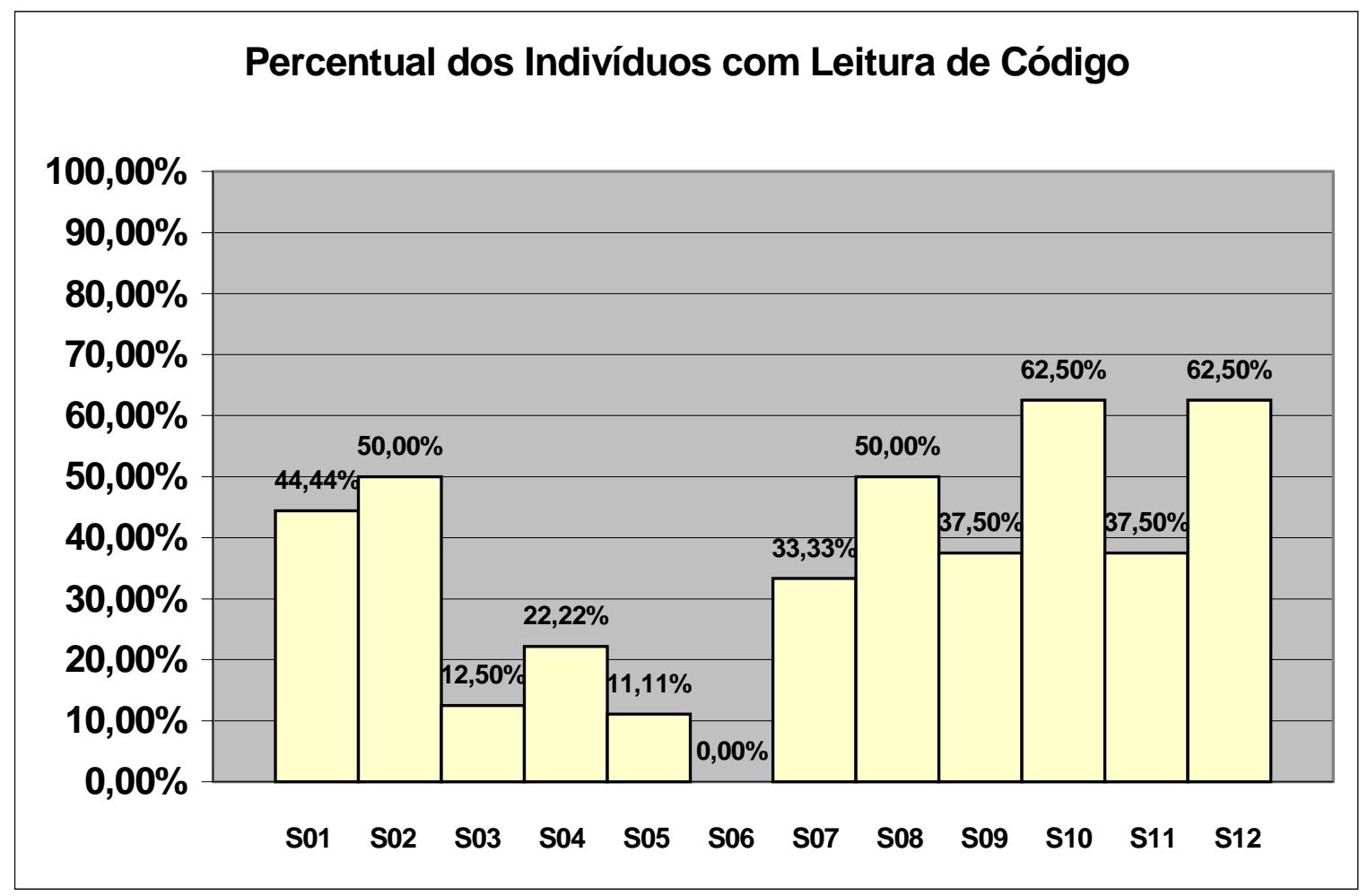

Figura 4.41 - Percentual (do total possível) de defeitos isolados pelos indivíduos com Leitura de Código. 


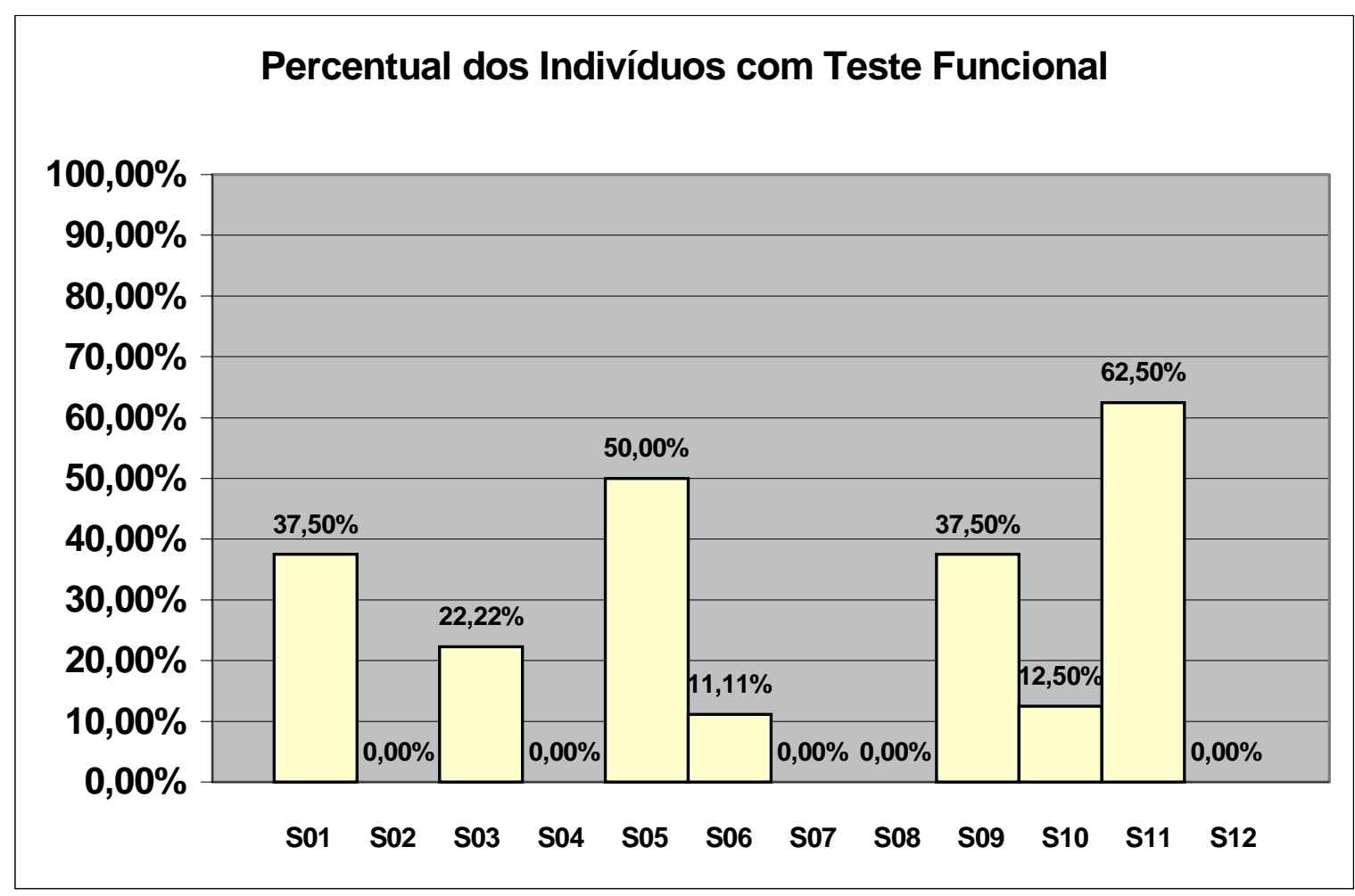

Figura 4.42 - Percentual (do total possível) de defeitos isolados pelos indivíduos com Teste Funcional.

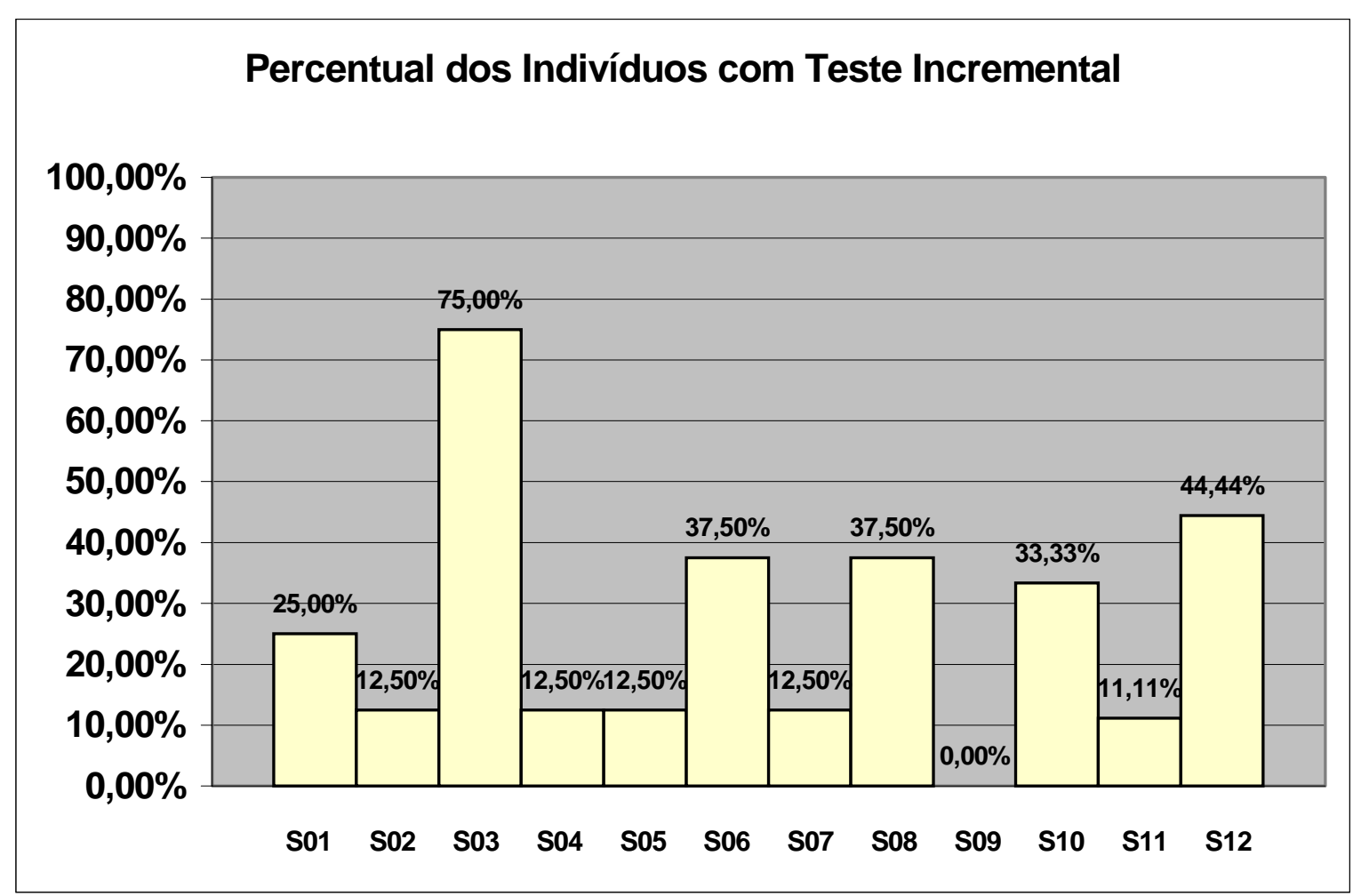

Figura 4.43 - Percentual (do total possível) de defeitos isolados pelos indivíduos com Teste Incremental. 


\begin{tabular}{|c|c|c|c|c|}
\hline $\begin{array}{c}\text { ID } \\
\text { Indivíduos }\end{array}$ & Técnica & $\begin{array}{c}\text { Percentual médio de } \\
\text { falhas observadas } \\
\text { (do total possível) }\end{array}$ & $\begin{array}{c}\text { Percentual obtido } \\
\text { pelo indivíduo }\end{array}$ & $\begin{array}{c}\text { Percentual } \\
\text { acima da } \\
\text { média }\end{array}$ \\
\hline Indivíduo 10 & CR & $35,30 \%$ & $62,50 \%$ & $27,20 \%$ \\
\hline Indivíduo 12 & CR & $35,30 \%$ & $62,50 \%$ & $27,20 \%$ \\
\hline Indivíduo 11 & FT & $19,44 \%$ & $62,50 \%$ & $43,06 \%$ \\
\hline Indivíduo 03 & IT & $26,16 \%$ & $75,00 \%$ & $48,84 \%$ \\
\hline \multicolumn{5}{|r|}{ CR - Leitura de Código - FT - Teste Funcional - IT - Teste Incremental } \\
\hline
\end{tabular}

Tabela 4.35 - Indivíduos que obtiveram a melhor performance com cada técnica.

\begin{tabular}{|l|c|c|c|c|c|c|}
\hline $\begin{array}{c}\text { ID } \\
\text { Indivíduos }\end{array}$ & Técnica & $\begin{array}{c}\text { Percentual } \\
\text { obtido pelo } \\
\text { indivíduo }\end{array}$ & $\begin{array}{c}\text { Percentual } \\
\text { acima da } \\
\text { média }\end{array}$ & Técnica & $\begin{array}{c}\text { Percentual } \\
\text { obtido pelo } \\
\text { indivíduo }\end{array}$ & $\begin{array}{c}\text { Percentual } \\
\text { acima da } \\
\text { média }\end{array}$ \\
\hline Indivíduo 10 & FT & $12,50 \%$ & abaixo da média & IT & $33,33 \%$ & $7,17 \%$ \\
\hline Indivíduo 12 & FT & $0,00 \%$ & abaixo da média & IT & $44,44 \%$ & $18,28 \%$ \\
\hline Indivíduo 11 & CR & $37,50 \%$ & $2,20 \%$ & IT & $11,11 \%$ & abaixo da média \\
\hline Indivíduo 03 & CR & $12,50 \%$ & abaixo da média & FT & $22,22 \%$ & $2,78 \%$ \\
\hline \multicolumn{7}{|c|}{ CR - Leitura de Código - FT - Teste Funcional - IT - Teste Incremental } \\
\hline
\end{tabular}

Tabela 4.36 - Outros resultados obtidos pelos indivíduos que obtiveram as melhores performance com cada técnica.

As informações constantes na Tabela 4.35 e na Tabela 4.36 apresentam os melhores desempenhos individuais obtidos durante a execução do experimento e foram extraídos dos dados apresentados na Figura 4.41, na Figura 4.42 e na Figura 4.43. Os indivíduos 11 e 12, por exemplo, foram os que obtiveram melhor desempenho utilizando a técnica Leitura de Código. $\mathrm{O}$ percentual de falhas observadas pelos indivíduos foi de $62,50 \%$ contra um percentual médio de $35,30 \%$, ou seja, de um total de 8 falhas possíveis de serem observadas os indivíduos observaram 5. A Tabela 4.36 apresenta os outros resultados obtidos pelos indivíduos que obtiveram o melhor desempenho para uma determinada técnica. Os indivíduos 11 e 12, por exemplo, obtiveram o melhor resultado com a técnica Leitura de Código e percentuais acima da média quando aplicaram a técnica Teste Incremental. Os indivíduos 11 e 12 obtiveram percentuais abaixo da média quando aplicaram a técnica Teste Funcional.

A Figura 4.44 e a Tabela 4.37 apresentam a performance geral de cada técnica em cada fase do experimento, ou seja, para cada programa. No caso do programa "cmdline.c", por exemplo, a técnica Leitura de Código obteve a melhor performance, de um total de 9 defeitos somente 5 foram isolados $(55,55 \%)$. Com o objetivo de explorar os aspectos complementares das técnicas foi realizada uma combinação, por meio de simulação, dos resultados obtidos por um par de técnicas. Para o programa "cmdline.c" o pior resultado obtido por um par de técnicas, especificamente o par Leitura de Código mais Teste Funcional (CR+FT), foi melhor que os 
resultados obtidos pelas técnicas individualmente, mostrando a importância de se combinar as técnicas.

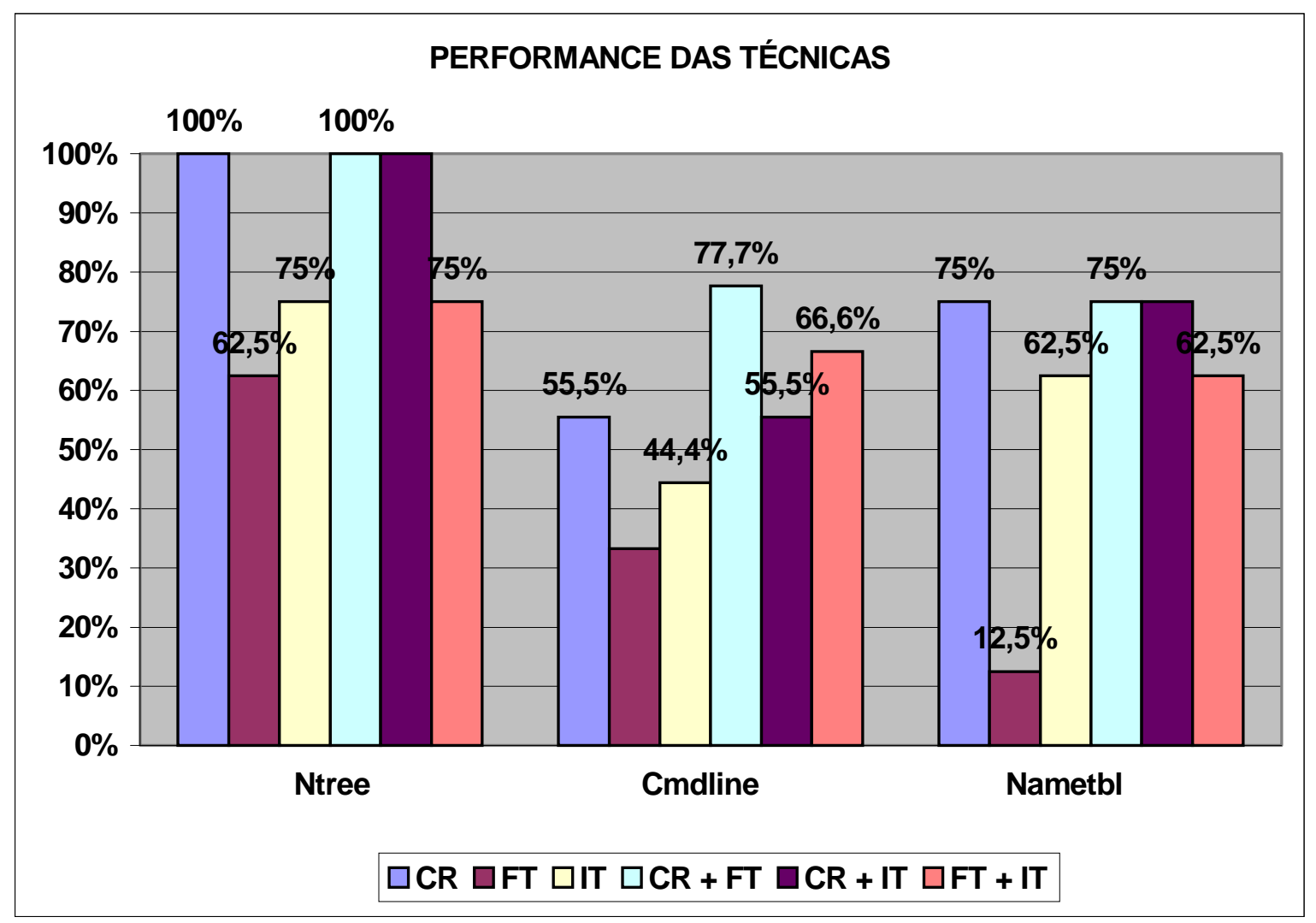

Figura 4.44: Técnica que obteve melhor/pior performance em cada programa e técnicas que obtiveram (dois-a-dois) melhor/pior performance em cada programa.

\begin{tabular}{|l|c|c|c|}
\cline { 2 - 4 } \multicolumn{1}{c|}{} & Ntree & Cmdline & Nametbl \\
\hline $\begin{array}{l}\text { Melhor técnica } \\
\text { individualmente }\end{array}$ & $100 \%(\mathrm{CR})$ & $55,5 \%(\mathrm{CR})$ & $75 \%(\mathrm{CR})$ \\
\hline $\begin{array}{l}\text { Pior técnica } \\
\text { individualmente }\end{array}$ & $62,5 \%(\mathrm{FT})$ & $33,3 \%(\mathrm{FT})$ & $12,5 \%(\mathrm{FT})$ \\
\hline $\begin{array}{l}\text { Melhor par combinado } \\
\text { de técnicas }\end{array}$ & $\begin{array}{c}100 \% \\
(\mathrm{CR}+\mathrm{FT})(\mathrm{CR}+\mathrm{IT})\end{array}$ & $77,7 \%(\mathrm{CR}+\mathrm{FT})$ & $\begin{array}{c}75 \% \\
(\mathrm{CR}+\mathrm{FT})(\mathrm{CR}+\mathrm{IT})\end{array}$ \\
\hline $\begin{array}{l}\text { Pior par combinado } \\
\text { de técnicas }\end{array}$ & $75 \%(\mathrm{FT}+\mathrm{IT})$ & $55,5 \%(\mathrm{CR}+\mathrm{IT})$ & $62,5 \%(\mathrm{FT}+\mathrm{IT})$ \\
\hline \multicolumn{2}{|c|}{$\mathrm{CR}$ - Leitura de Código - FT - Teste Funcional - IT - Teste Incremental } \\
\hline
\end{tabular}

Tabela 4.37 - Técnica que obteve melhor/pior performance em cada programa e técnicas que obtiveram (dois-a-dois) melhor/pior performance em cada programa. 


\subsubsection{Análise Estatística}

O objetivo desta seção é apresentar as análises estatísticas dos dados obtidos no experimento e avaliar as hipóteses propostas na Seção 7.2. A análise das hipóteses foi realizada aplicando uma técnica de análise de variância (ANOVA) nos dados coletados durante o experimento. Além de apresentar as análises estatísticas, esta seção tem como objetivo apresentar a sequiência de passos necessária para se obter tais análises no software MINITAB for WINDOWS, versão 11.21.

Segundo Gomes [GOM85], pode-se definir a Estatística como a Matemática aplicada aos dados de observação. Mas tais dados são, em vários casos, obtidos por meio de trabalhos feitos propositalmente e em condições previamente determinadas, ou seja, especificadas. Nesse caso, temos então os dados experimentais, obtidos por meio de experimentos. O que dificulta o trabalho do experimentador e exige a análise estatística é a presença, em todos os dados obtidos, de efeitos de fatores não controlados (que podem ser controláveis ou não). Esses efeitos, sempre presentes, não podem ser conhecidos individualmente e alteram, pouco ou muito, os resultados. Eles são indicados pela variação do acaso ou variação aleatória. O efeito dessa variação do acaso é tal que pode alterar completamente os resultados do experimento. Assim, ao comparar duas técnicas, a pior das duas poderá, por simples acaso, por ter sido favorecida por uma série de pequenos fatores não controlados, ser superior que a outra. É tarefa do experimentador verificar se as diferenças observadas num experimento têm ou não têm valor, isto é, se são ou não significativas. Uma diferença não significativa se aceita como possivelmente devida ao acaso e é deixada de lado, até que novos resultados venham confirmá-las ou negá-las. Por outro lado, uma diferença significativa demonstra que os elementos experimentados não são equivalentes, dão resultados que devem ser aceitos como realmente diferentes.

\section{Análise da Hipótese 1}

As técnicas (Leitura de Código pelo Stepwise Abstraction, Teste Funcional e Teste Incremental) diferem em termos da efetividade, isto é, do percentual (do total possível) de defeitos isolados e falhas observadas.

Respondendo as seguintes perguntas é possível testar a Hipótese 1:

1. Qual a influência que cada variável independente (técnica e programa) tem na efetividade, isto é, no percentual de defeitos isolados?

2. Qual a influência que cada variável independente (técnica e programa) tem na efetividade, isto é, no percentual de falhas observadas? 


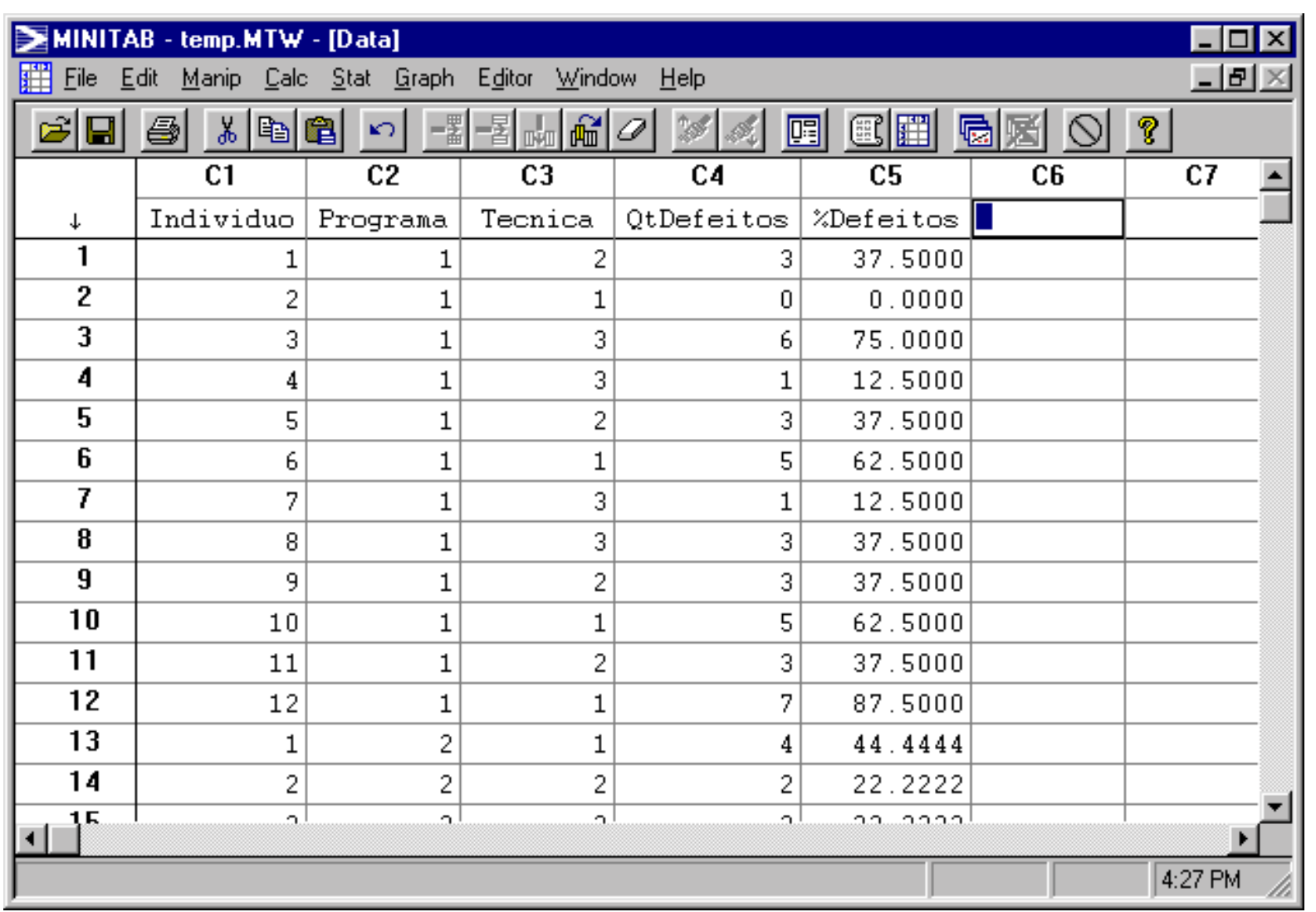

Figura 4.45 - Organização do dados em uma planilha do software MINITAB.

A influência das variáveis independentes pode ser testada isolando-se uma das outras, e aplicando um teste de hipóteses analisar a discrepância dos dados. Esta análise permite determinar qual discrepância nos resultados é devida aos procedimentos experimentais e qual é devido às variáveis independentes (técnica e programa). Para testar a influência das variáveis independentes é necessário seguir os seguintes passos:

$\left.\mathbf{1}^{\mathbf{0}}\right)$ Iniciar o software MINITAB. Após a inicialização, uma planilha em branco será apresentada. Nesta planilha deverão ser organizados os dados obtidos durante as 3 fases do experimento, seguindo a estrutura apresentada na Figura 4.45. A coluna C1 deve conter uma seqüência de números que identificam os indivíduos. Neste experimento foram utilizados 12 indivíduos na $1^{\mathrm{a}}$ fase, portanto, a sequiência vai de 1 a 12. A coluna $\mathbf{C 2}$ deve conter um número para identificar o programa utilizado numa fase específica do experimento. Neste experimento foram utilizados 3 programas, portanto, o número 1 identifica o programa "ntree.c" que foi utilizado na $1^{\text {a }}$ fase. A coluna C3 deve conter um número para identificar a técnica que um determinado indivíduo aplicou em um determinado programa. Neste experimento foram utilizadas 3 técnicas, portanto, o número 1 identifica a técnica Leitura de Código, o número 2 a técnica Teste Funcional e o número 3 o Teste Incremental. A coluna $\mathbf{C 4}$ deve conter a quantidade de defeitos isolados por 
um determinado indivíduo que aplicou determinada técnica em um determinado programa. A coluna C5 deve conter os valores em percentual dos valores informados na coluna C4. É importante ressaltar que este bloco de dados deve ser repetido mais duas vezes na seqüência, alternando-se os programas. No total a planilha deverá conter 36 linhas (12 indivíduos x 3 programas).

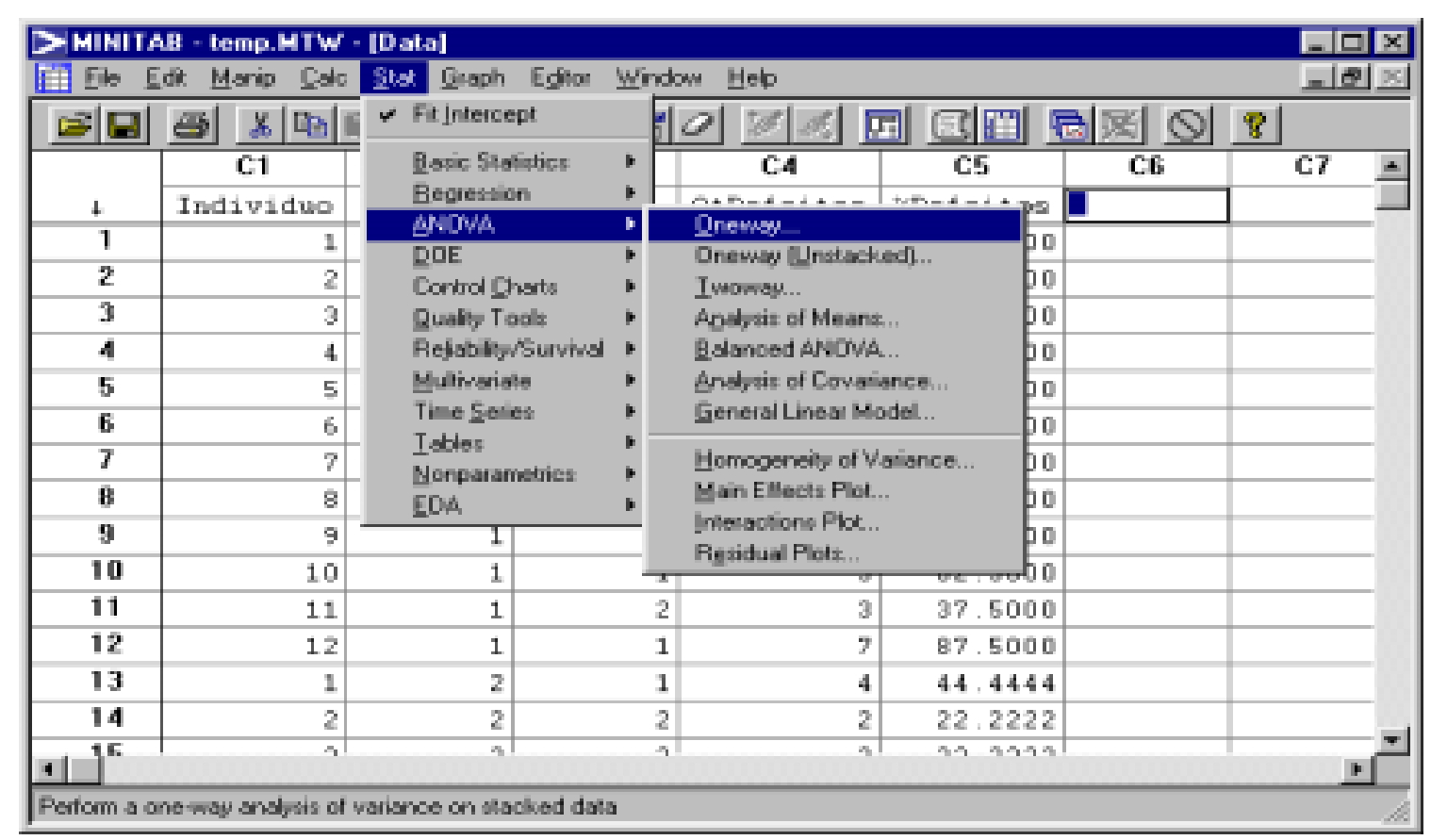

Figura 4.46 - Opção do menu utilizada para realizar análise ANOVA .

$\mathbf{2}^{\mathbf{0}}$ ) Após concluir a organização dos dados, selecione no menu a opção Stat $\rightarrow$ ANOVA $\rightarrow$ Oneway, conforme mostra a Figura 4.46.

$\mathbf{3}^{\mathbf{0}}$ ) Após realizar o $2^{\circ}$ passo, será apresentado uma tela similar à da Figura 4.47. Para testar a influência que cada variável independente tem na efetividade (percentual de defeitos isolados) é necessário digitar no campo Response o nome da coluna C4 (QtDefeitos), digitar no campo Factor o nome da coluna C5 (Tecnica) e pressionar o botão OK. Neste caso será avaliada a influência da variável independente Técnica no percentual de defeitos isolados por cada técnica. 


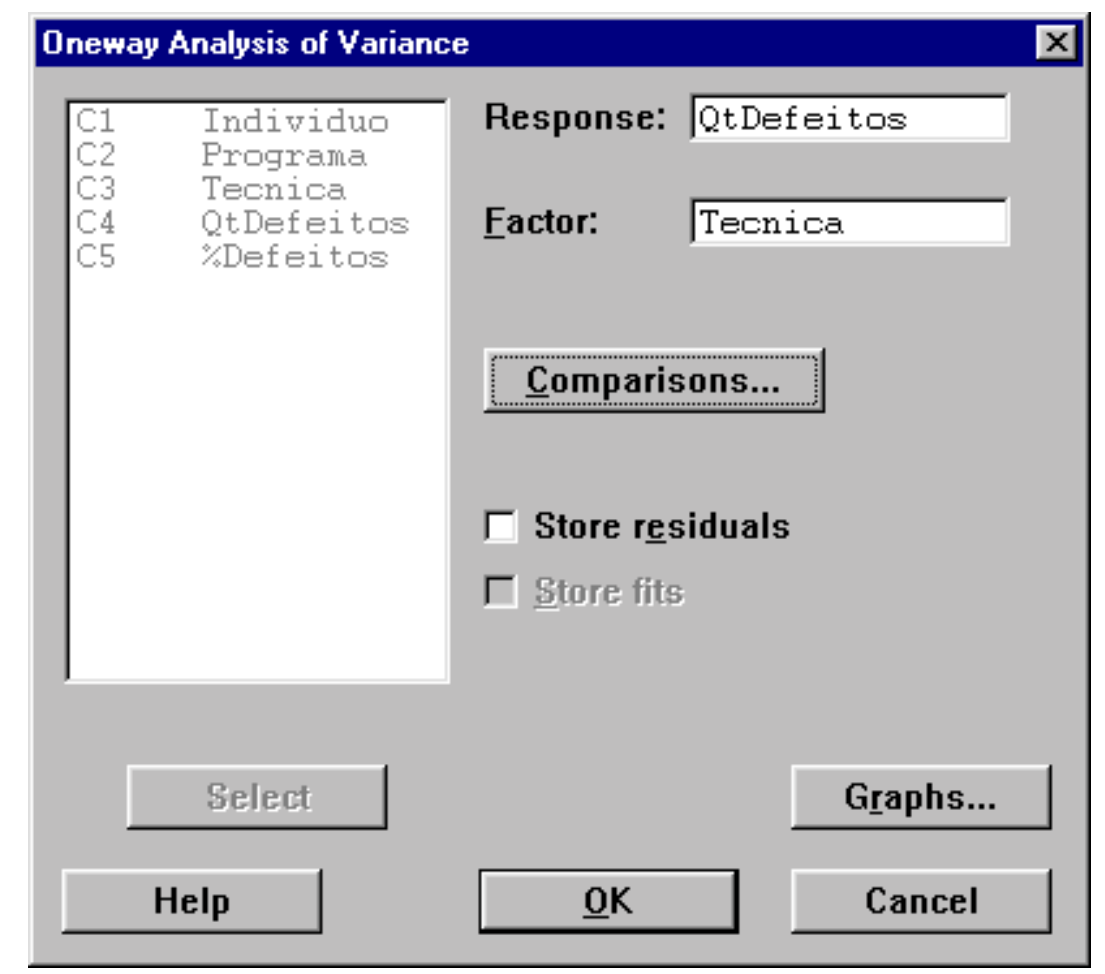

Figura 4.47 - Tela de seleção da variável independente e da variável resposta.

$4^{\mathbf{0}}$ ) Após realizar o $3^{\circ}$ passo, será emitido um relatório similar ao da Figura 4.48. Neste relatório é possível identificar o percentual médio de defeitos isolados por cada técnica (ver Rótulo 1 na Figura 4.48) e o nível de influência da variável independente técnica na efetividade das técnicas (ver Rótulo 2 na Figura 4.48).

Os passos acima apresentam o processo para se obter os dados referentes à influência da variável independente técnica no percentual de defeitos isolados. O processo completo necessário para analisar a Hipótese 1 inclui ainda a obtenção dos dados referentes à influência da variável independente programa no percentual de defeitos isolados, e a influência da variável independente técnica e programa no percentual de falhas observadas. Essas análises e as demais análises apresentadas durante esta seção podem ser obtidas utilizando a mesma seqüência de passos apresentada acima, alterando somente os dados referentes a variável resposta. Nesse contexto a variável resposta é o resultado das variáveis dependentes, como por exemplo: percentual de defeitos isolados e percentual de falhas observadas. A Tabela 4.38 apresenta um resumo dos resultados necessários para realizar a análise da Hipótese 1. 


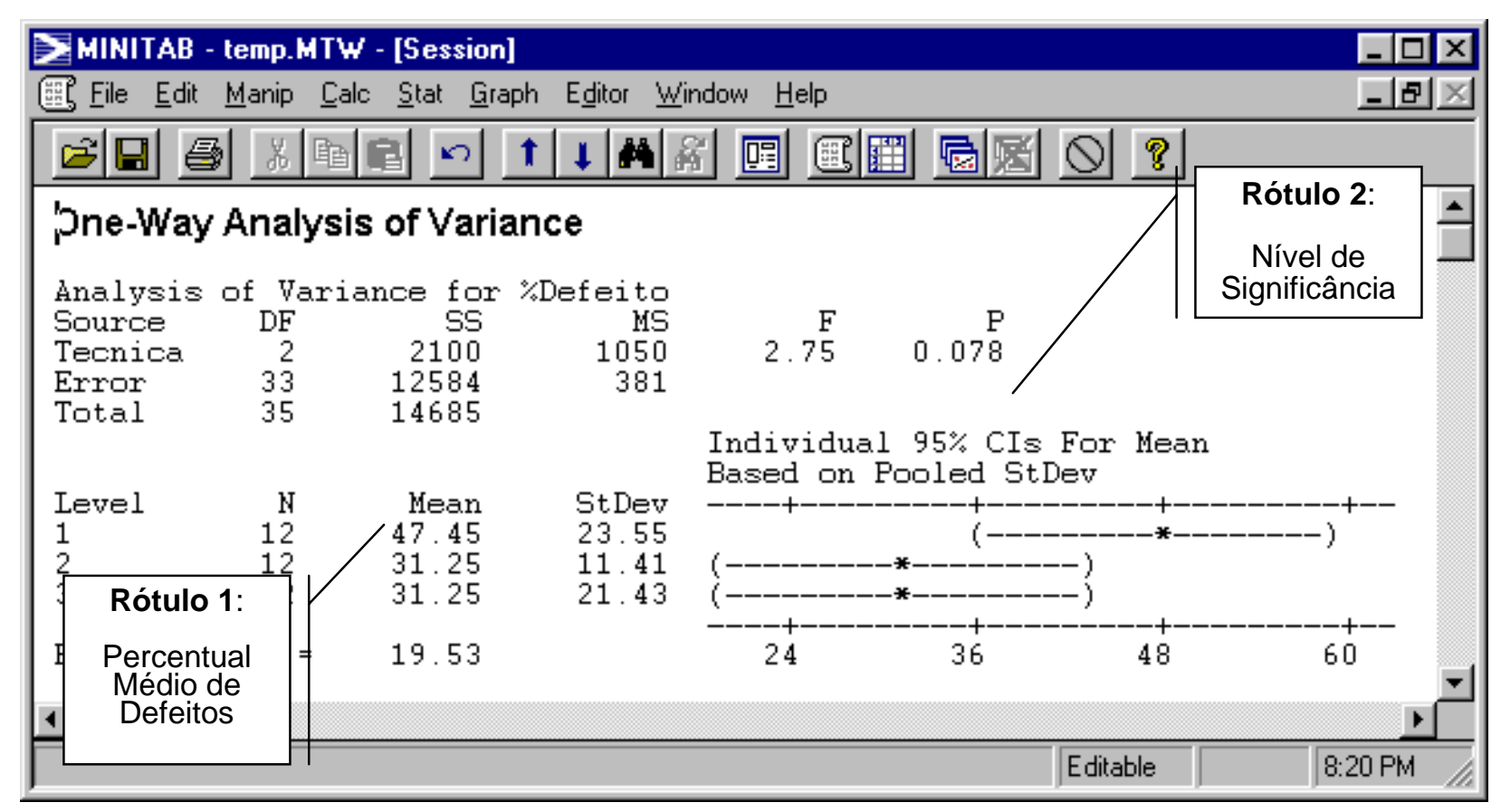

Figura 4.48 - Relatório contendo informações sobre a influência das variáveis independentes.

Posteriormente, duas hipóteses nulas são definidas a partir das questões 1 e 2: Hipótese nula 1 - Nenhuma das variáveis independentes afetam a efetividade, isto é, o percentual (do total possível) dos defeitos isolados; Hipótese nula 2 - Nenhuma das variáveis independentes afetam a efetividade, isto é, o percentual (do total possível) das falhas observadas. As hipóteses nulas podem ser aceitas ou rejeitadas dependendo do nível de significância que uma determinada variável independente tem no percentual médio (do total possível) de defeitos isolados.

\begin{tabular}{|c|c|c|c|c|c|c|c|c|c|}
\hline $\begin{array}{c}\text { Variável } \\
\text { Independente }\end{array}$ & $\begin{array}{r}\text { Percentu } \\
\text { possí }\end{array}$ & $\begin{array}{l}\text { al médio } \\
\text { vel) de de } \\
\text { isolados }\end{array}$ & $\begin{array}{l}\text { (do total } \\
\text { feitos }\end{array}$ & $S S_{\mathrm{T}}$ & $V_{\mathrm{T}}$ & $S S_{\mathrm{R}}$ & $V_{\mathrm{R}}$ & $\mathrm{F}$ & $\mathrm{P}$ \\
\hline Técnica & $\mathrm{T} 1=47.45$ & $\mathrm{~T} 2=31.25$ & $\mathrm{~T} 3=31.25$ & 2100 & 2 & 12584 & 33 & 2.75 & 0.078 \\
\hline Programa & $\mathrm{P} 1=41.67$ & $\mathrm{P} 2=28.70$ & P3 $=39.58$ & 1163 & 2 & 13522 & 33 & 1.42 & 0.256 \\
\hline
\end{tabular}

Tabela 4.38 - Análise One-Way do percentual médio (do total possível) de defeitos isolados.

\begin{tabular}{|c|c|c|c|c|c|c|c|c|c|}
\hline $\begin{array}{c}\text { Variável } \\
\text { Independente }\end{array}$ & $\begin{array}{r}\text { Percentu } \\
\text { poss }\end{array}$ & $\begin{array}{l}\text { lal médio } \\
\text { ível) de fa } \\
\text { observada }\end{array}$ & $\begin{array}{l}\text { do total } \\
\text { lhas }\end{array}$ & $S S_{\mathrm{T}}$ & $V_{\mathrm{T}}$ & $S S_{\mathrm{R}}$ & $V_{\mathrm{R}}$ & $\mathrm{F}$ & $\mathrm{P}$ \\
\hline Técnica & $\mathrm{T} 1=35.30$ & \begin{tabular}{|l|} 
T2 $=19.44$ \\
\end{tabular} & $\mathrm{~T} 3=26.16$ & 1520 & 2 & 14673 & 33 & 1.71 & 0.197 \\
\hline Programa & $\mathrm{P} 1=41.67$ & $\mathrm{P} 2=19.44$ & $\mathrm{P} 3=19.79$ & 3890 & 2 & 12304 & 33 & 5.22 & $0.011^{\curlyvee}$ \\
\hline
\end{tabular}

Tabela 4.39 - Análise One-Way do percentual médio (do total possível) de falhas observadas. 
Legenda:

T1 = Técnica 1 - Leitura de Código

T2 = Técnica 2 - Teste Funcional

T3 = Técnica 3 - Teste Incremental

$S S_{\mathrm{T}}=$ Soma dos quadrados entre os tratamentos

$V_{\mathrm{T}}=$ Graus de liberdade entre os tratamentos

$S S_{\mathrm{R}}=$ Soma dos quadrados dos resíduos
$\mathrm{P} 1$ = Programa $1-$ Ntree

$\mathrm{P} 2=$ Programa $2-$ Cmdline

$\mathrm{P} 3=$ Programa $3-$ Nametbl

$V_{\mathrm{R}}=$ Graus de liberdade dos resíduos

$\mathrm{F}=$ Teste estatístico

$\mathrm{P}=$ Nível de significância

Conforme mostra a Tabela 4.38, não se pode rejeitar a hipótese nula 1 com relação às técnicas e programas, pois, o nível de significância (coluna $\mathrm{P}$ da Tabela 4.38) ficou acima de 5\%. Aceitar a hipótese nula 1 significa dizer que nenhuma variável independente teve influência nos resultados obtidos, em outras palavras, significa dizer que os resultados obtidos não foram alcançados, por exemplo, por uma técnica ser mais efetiva que a outra. Um nível de significância abaixo de 5\% (0.05) significa que o percentual médio de defeitos isolados por uma técnica, por exemplo, teve influência direta da variável independente.

Conforme mostra a Tabela 4.39, não se pode rejeitar a hipótese nula 2 com relação às técnicas, pois, o nível de significância também ficou acima de 5\%, mas pode-se rejeitar a hipótese nula 2 com relação à influência do programa. Suspeita-se que as falhas do programa "ntree.c" sejam mais fáceis de se observar. Este resultado, especificamente, está em consonância com outra replicação deste experimento [KAM95].

Em resumo, não se pode afirmar estatisticamente que as técnicas Leitura de Código, Teste Funcional e Teste Incremental diferem em termos da efetividade em isolar defeitos e observar falhas.

Ainda com relação à efetividade das técnicas em isolar defeitos, a Tabela 4.40 e a Tabela 4.41 apresentam análises complementares (Análise de Covariância) que verificam quais influências nos resultados são devidas a: experiência em programação dos indivíduos, e; nível de proficiência em Inglês com leitura. Pode-se observar também os efeitos de interação entre as técnicas x programas.

\begin{tabular}{c|c|c|c|c|c|c}
$\begin{array}{c}\text { Variável } \\
\text { Independente }\end{array}$ & $S S_{\mathrm{T}}$ & $V_{\mathrm{T}}$ & $S S_{\mathrm{R}}$ & $V_{\mathrm{R}}$ & $\mathrm{F}$ & $\mathrm{P}$ \\
\hline Técnica & 2100.5 & 2 & 11014.6 & 26 & 2.48 & 0.103 \\
\hline Programa & 1163.0 & 2 & 11014.6 & 26 & 1.37 & 0.271 \\
\hline Tec. X Pro. & 172.5 & 4 & 11014.6 & 26 & 0.10 & 0.981 \\
\hline Experiência & 250.9 & 1 & 11014.6 & 26 & 0.59 & 0.449 \\
\hline
\end{tabular}

Tabela 4.40 - Análise de Covariância utilizando a experiência em programação. 


\begin{tabular}{c|c|c|c|c|c|c}
$\begin{array}{c}\text { Variável } \\
\text { Independente }\end{array}$ & $S S_{\mathrm{T}}$ & $V_{\mathrm{T}}$ & $S S_{\mathrm{R}}$ & $V_{\mathrm{R}}$ & $\mathrm{F}$ & $\mathrm{P}$ \\
\hline Técnica & 2100.5 & 2 & 11263.1 & 26 & 2.42 & 0.108 \\
\hline Programa & 1163.0 & 2 & 11263.1 & 26 & 1.34 & 0.279 \\
\hline Tec. X Pro. & 143.6 & 4 & 11263.1 & 26 & 0.08 & 0.987 \\
\hline \hline Inglês & 2.4 & 1 & 11263.1 & 26 & 0.01 & 0.942 \\
\hline
\end{tabular}

Tabela 4.41 - Análise de Covariância utilizando nível de proficiência em Inglês (leitura).

Em resumo, nenhum resultado significativo foi observado com relação à influência da experiência em programação e do nível de proficiência em Inglês com leitura nos resultados obtidos pelos indivíduos.

\section{Análise da Hipótese 2}

As técnicas (Leitura de Código pelo Stepwise Abstraction, Teste Funcional e Teste Incremental) diferem em termos da eficiência, isto é, do percentual (do total possível) de defeitos isolados e de falhas observadas dividido pelo tempo gasto no isolamento e observação.

Respondendo as seguintes perguntas é possível testar a Hipótese 2:

1. Qual a influência que cada variável independente (técnica e programa) tem na eficiência, isto é, no percentual (do total possível) de defeitos isolados dividido pelo tempo gasto no isolamento?

2. Qual a influência que cada variável independente (técnica e programa) tem na eficiência, isto é, no percentual (do total possível) de falhas observadas dividido pelo tempo gasto na observação?

\begin{tabular}{c|c|c|c|c|c|c|c|c|c}
$\begin{array}{c}\text { Variável } \\
\text { Independente }\end{array}$ & \multicolumn{2}{|c|}{$\begin{array}{c}\text { Média de tempo de } \\
\text { isolamento de defeitos }\end{array}$} & $S S_{\mathrm{T}}$ & $V_{\mathrm{T}}$ & $S S_{\mathrm{R}}$ & $V_{\mathrm{R}}$ & $\mathrm{F}$ & $\mathrm{P}$ \\
\hline Técnica & $\mathrm{T} 1=31.92$ & $\mathrm{~T} 2=84.83$ & $\mathrm{~T} 3=71.17$ & 18110 & 2 & 110498 & 33 & 2.70 & 0.082 \\
\hline Programa & $\mathrm{P} 1=84.25$ & $\mathrm{P} 2=55.25$ & $\mathrm{P} 3=48.42$ & 8687 & 2 & 119921 & 33 & 1.20 & 0.315 \\
\hline
\end{tabular}

Tabela 4.42 - Análise One-Way do tempo de isolamento de defeitos. 


\begin{tabular}{|c|c|c|c|c|c|c|c|c|c|}
\hline $\begin{array}{c}\text { Variável } \\
\text { Independente }\end{array}$ & \multicolumn{3}{|c|}{$\begin{array}{l}\text { Média de tempo de } \\
\text { observação de falhas }\end{array}$} & $S S_{\mathrm{T}}$ & $V_{\mathrm{T}}$ & $S S_{\mathrm{R}}$ & $V_{\mathrm{R}}$ & $\frac{S S_{\mathrm{T}} / V_{\mathrm{T}}}{S S_{\mathrm{R}} / V_{\mathrm{R}}}$ & $\mathrm{P}$ \\
\hline Técnica & $\mathrm{T} 1=71.58$ & $\mathrm{~T} 2=50.25$ & $\mathrm{~T} 3=104.17$ & 17695 & 2 & 199513 & 33 & 1.46 & 0.246 \\
\hline Programa & $\mathrm{P} 1=100.17$ & $\mathrm{P} 2=76.83$ & $\mathrm{P} 3=49.00$ & 15749 & 2 & 201459 & 33 & 1.29 & 0.289 \\
\hline
\end{tabular}

Tabela 4.43 - Análise One-Way do tempo de observação de falhas.

Com base na mesma seqüência utilizada para realizar a análise da hipótese 1 , duas hipóteses nulas são definidas a partir das questões 1 e 2: Hipótese nula 1 - Nenhuma das variáveis independentes afetam a eficiência, isto é, o percentual (do total possível) dos defeitos isolados dividido pelo tempo gasto no isolamento; Hipótese nula 2 - Nenhuma das variáveis independentes afetam a eficiência, isto é, o percentual (do total possível) das falhas observadas dividido pelo tempo gasto na observação.

Antes de analisar o impacto das variáveis independentes na eficiência obtida pelas técnicas é importante destacar que não houve nenhuma influência das variáveis independentes no tempo gasto para o isolamento de defeitos e observação de falhas, conforme pode ser observado na Tabela 4.42 e na Tabela 4.43.

Conforme mostra a Tabela 4.44, não se pode rejeitar a hipótese nula 1 com relação aos programas, pois o nível de significância $(\mathrm{P})$ ficou acima de 5\%. Da mesma forma, não se pode rejeitar a hipótese nula 1 com relação à técnica, contudo, acredita-se que a técnica Leitura de Código obteve uma taxa de isolamento de defeitos mais significativa do que as outras técnicas porque um dos requisitos básicos para sua aplicação é a leitura do código fonte. Basicamente, indivíduos são instruídos ao receber o código fonte a criarem uma especificação para o programa, por meio da construção de abstrações funcionais. Ao receber a especificação original os indivíduos comparam as especificações em busca de inconsistências. O processo de leitura do código fonte para construir as abstrações apresenta-se como um fator que pode afetar a taxa de isolamento de defeitos. Conforme mostra a Tabela 4.45, não se pode rejeitar a hipótese nula 2 com relação as técnicas e programas, pois o nível de significância ficou acima de 5\%, contudo, suspeita-se que as falhas do programa "ntree.c" sejam mais fáceis de se observar.

\begin{tabular}{c|c|c|c|c|c|c|c|c|c}
$\begin{array}{c}\text { Variável } \\
\text { Independente }\end{array}$ & \multicolumn{2}{|c|}{$\begin{array}{c}\text { Taxa média de tempo de } \\
\text { isolamento de defeitos }\end{array}$} & $S S_{\mathrm{T}}$ & $V_{\mathrm{T}}$ & $S S_{\mathrm{R}}$ & $V_{\mathrm{R}}$ & $\mathrm{F}$ & $\mathrm{P}$ \\
\hline Técnica & $\mathrm{T} 1=1.35$ & $\mathrm{~T} 2=0.95$ & $\mathrm{~T} 3=0.69$ & 2.668 & 2 & 15.018 & 33 & 2.93 & 0.067 \\
\hline Programa & $\mathrm{P} 1=1.065$ & $\mathrm{P} 2=0.830$ & $\mathrm{P} 3=1.104$ & 0.525 & 2 & 17.160 & 33 & 0.50 & 0.608 \\
\hline
\end{tabular}

Tabela 4.44 - Análise One-Way da taxa de isolamento de defeitos. 


\begin{tabular}{c|c|c|c|c|c|c|c|c|c}
$\begin{array}{c}\text { Variável } \\
\text { Independente }\end{array}$ & \multicolumn{2}{|c|}{$\begin{array}{c}\text { Taxa média de tempo de } \\
\text { observação de falhas }\end{array}$} & $S S_{\mathrm{T}}$ & $V_{\mathrm{T}}$ & $S S_{\mathrm{R}}$ & $V_{\mathrm{R}}$ & $\mathrm{F}$ & $\mathrm{P}$ \\
\hline Técnica & $\mathrm{T} 1=1.14$ & $\mathrm{~T} 2=1.23$ & $\mathrm{~T} 3=0.74$ & 1.60 & 2 & 48.25 & 33 & 0.55 & 0.583 \\
\hline Programa & $\mathrm{P} 1=1.707$ & $\mathrm{P} 2=0.713$ & $\mathrm{P} 3=0.702$ & 7.99 & 2 & 41.86 & 33 & 3.15 & 0.056 \\
\hline
\end{tabular}

Tabela 4.45 - Análise One-Way da taxa de observação de falhas

\section{Análise da Hipótese 3}

As técnicas (Leitura de Código pelo Stepwise Abstraction, Teste Funcional e Teste Incremental) diferem em termos da efetividade no isolamento e na observação de diferentes tipos e classes de defeitos.

Respondendo as seguintes perguntas é possível testar a Hipótese 3:

1. Qual a influência que a variável independente técnica tem na efetividade, isto é, no percentual (do total possível) de defeitos isolados por determinados tipos e classes de defeitos?

2. Qual a influência que a variável independente técnica tem na efetividade, isto é, no percentual (do total possível) de falhas observadas por determinados tipos e classes de defeitos?

Com base na mesma seqüência utilizada para realizar a análise da hipótese 1, duas hipóteses nulas são definidas a partir das questões 1 e 2: Hipótese nula 1 - As técnicas são igualmente efetivas no isolamento de determinados tipos e classes de defeitos; Hipótese nula 2 As técnicas são igualmente efetivas na observação de falhas causadas por determinados tipos e classes de defeitos.

Conforme mostra a Tabela 4.46, não se pode rejeitar a hipótese nula 1 com relação aos defeitos do tipo INTERFACE. A técnica Leitura de Código apresentou um percentual melhor para este tipo de defeito, uma vez que, os indivíduos têm um contato direto com o código fonte durante a aplicação da técnica. Conforme pode ser observado na Tabela 4.47, a hipótese nula 2 também não pode ser rejeitada para defeitos da classe COMISSION e tipo INTERFACE no que se refere à técnica Leitura de Código. 


\begin{tabular}{c|c|c|c|c|c|c|c|c|c}
$\begin{array}{c}\text { Classes e } \\
\text { Tipos }\end{array}$ & $\begin{array}{c}\text { Percentual médio (do total } \\
\text { possível) de defeitos } \\
\text { isolados por tipo celasse }\end{array}$ & $S S_{\mathrm{T}}$ & $V_{\mathrm{T}}$ & $S S_{\mathrm{R}}$ & $V_{\mathrm{R}}$ & $\mathrm{F}$ & $\mathrm{P}$ \\
\hline Omission & $\mathrm{T} 1=51.25$ & $\mathrm{~T} 2=40.00$ & $\mathrm{~T} 3=34.58$ & 1735 & 2 & 29229 & 33 & 0.98 & 0.386 \\
\hline Commission & $\mathrm{T} 1=42.46$ & $\mathrm{~T} 2=27.98$ & $\mathrm{~T} 3=27.98$ & 1702 & 2 & 18872 & 33 & 1.49 & 0.241 \\
\hline Initialization & $\mathrm{T} 1=16.67$ & $\mathrm{~T} 2=8.33$ & $\mathrm{~T} 3=16.67$ & 2639 & 2 & 48125 & 33 & 0.90 & 0.414 \\
\hline Computation & $\mathrm{T} 1=16.67$ & $\mathrm{~T} 2=0.00$ & $\mathrm{~T} 3=8.33$ & 1667 & 2 & 25833 & 33 & 1.06 & 0.356 \\
\hline Control & $\mathrm{T} 1=54.17$ & $\mathrm{~T} 2=51.39$ & $\mathrm{~T} 3=47.22$ & 293 & 2 & 34120 & 33 & 0.14 & 0.868 \\
\hline Interface & $\mathrm{T} 1=61.11$ & $\mathrm{~T} 2=16.67$ & $\mathrm{~T} 3=13.89$ & 16852 & 2 & 39537 & 33 & 7.03 & 0.003 \\
\hline Data & $\mathrm{T} 1=37.50$ & $\mathrm{~T} 2=37.50$ & $\mathrm{~T} 3=20.83$ & 2222 & 2 & 48542 & 33 & 0.76 & 0.478 \\
\hline Cosmetic & $\mathrm{T} 1=29.71$ & $\mathrm{~T} 2=0.00$ & $\mathrm{~T} 3=12.50$ & 5139 & 2 & 32917 & 33 & 2.58 & 0.091 \\
\hline
\end{tabular}

Tabela 4.46 - Análise One-Way do percentual médio (do total possível) de defeitos isolados por tipos e classes.

\begin{tabular}{c|c|c|c|c|c|c|c|c|c}
$\begin{array}{c}\text { Classes e } \\
\text { Tipos }\end{array}$ & $\begin{array}{c}\text { Percentual médio (do total } \\
\text { possível) de falhas } \\
\text { observadas por tipo e } \\
\text { classe de defeitos }\end{array}$ & $S S_{\mathrm{T}}$ & $V_{\mathrm{T}}$ & $S S_{\mathrm{R}}$ & $V_{\mathrm{R}}$ & $\mathrm{F}$ & $\mathrm{P}$ \\
\hline Omission & $\mathrm{T} 1=38.33$ & $\mathrm{~T} 2=32.92$ & $\mathrm{~T} 3=27.08$ & 760 & 2 & 34513 & 33 & 0.36 & 0.698 \\
\hline Commission & $\mathrm{T} 1=30.36$ & $\mathrm{~T} 2=9.52$ & $\mathrm{~T} 3=21.43$ & 2622 & 2 & 12150 & 33 & 3.56 & $0.040 \smile$ \\
\hline Initialization & $\mathrm{T} 1=16.67$ & $\mathrm{~T} 2=4.17$ & $\mathrm{~T} 3=8.33$ & 972 & 2 & 13125 & 33 & 1.22 & 0.308 \\
\hline Computation & $\mathrm{T} 1=8.33$ & $\mathrm{~T} 2=0.00$ & $\mathrm{~T} 3=8.33$ & 556 & 2 & 18333 & 33 & 0.50 & 0.611 \\
\hline Control & $\mathrm{T} 1=38.89$ & $\mathrm{~T} 2=31.94$ & $\mathrm{~T} 3=29.17$ & 602 & 2 & 40509 & 33 & 0.25 & 0.784 \\
\hline Interface & $\mathrm{T} 1=47.22$ & $\mathrm{~T} 2=11.11$ & $\mathrm{~T} 3=11.11$ & 10432 & 2 & 44722 & 33 & 3.85 & $0.031 \checkmark$ \\
\hline Data & $\mathrm{T} 1=33.33$ & $\mathrm{~T} 2=16.67$ & $\mathrm{~T} 3=25.00$ & 1667 & 2 & 35833 & 33 & 0.77 & 0.472 \\
\hline Cosmetic & $\mathrm{T} 1=16.67$ & $\mathrm{~T} 2=4.17$ & $\mathrm{~T} 3=12.50$ & 972 & 2 & 29583 & 33 & 0.54 & 0.587 \\
\hline
\end{tabular}

Tabela 4.47 - Análise One-Way do percentual médio (do total possível) de falhas observadas por tipos e classes de defeito.

\subsection{Comparando os Resultados}

\section{- Quanto às falhas}

Conforme mencionado no Capítulo 1, um pacote de laboratório descreve um experimento em termos específicos permitindo replicação, oportunidades de variação e um contexto para combinação de resultados em diferentes tipos de tratamentos experimentais. Os pacotes de laboratório suportam replicações futuras com uma variedade de metas, como por exemplo, confirmando/negando resultados originais. Nesta perspectiva, esta seção objetiva comparar os resultados obtidos na replicação do experimento baseado em códigos fontes com os resultados de experimentos similares. 
Com relação às falhas, pode-se observar que em uma análise preliminar a técnica Leitura de Código foi mais efetiva na observação de falhas do que as demais técnicas, mas em uma análise mais detalhada, ou seja, uma análise estatística observou-se que não existem diferenças significativas entre as técnicas. Este resultado não está totalmente em consonância com os resultados obtidos por Basili \& Selby [BAS87], que por sua vez observou resultados similares, mas com diferenças significativas entre as técnicas. Em contrapartida, os resultados obtidos por Kamsties \& Lott [KAM95] também não apresentaram diferenças significativas entre as técnicas, sendo a técnica Leitura de Código e a técnica Teste Funcional mais efetivas na observação de falhas.

A técnica Teste Funcional foi mais eficiente que as demais técnicas na observação de falhas, mas não foram diferenças significativas como nos experimentos de Basili \& Selby [BAS87] e Kamsties \& Lott [KAM95].

Basili \& Selby [BAS87] e Kamsties \& Lott [KAM95] relataram que na média somente $50 \%$ das falhas possíveis de serem descobertas foram observadas. Ao final desta replicação constatou-se que os indivíduos observaram um percentual de apenas $26.96 \%$ das falhas possíveis de serem descobertas.

\section{- Quanto aos defeitos}

Com relação aos defeitos, pode-se observar que a técnica Leitura de Código foi mais efetiva no isolamento de defeitos que as outras técnicas, mas em uma análise mais detalhada, ou seja, uma análise estatística observou-se que não existem diferenças significativas entre as técnicas. Este resultado não está totalmente em consonância com os resultados obtidos por Kamsties \& Lott [KAM95], que por sua vez observou a técnica Teste Funcional como sendo a mais efetiva no isolamento de defeitos e com diferenças significativas entre as técnicas.

Como no experimento de Kamsties \& Lott [KAM95] não foram observadas correlações significativas entre a experiência dos indivíduos e os resultados obtidos.

Os resultados mostram que o percentual de falhas observadas e defeitos isolados pelos indivíduos poderia ter sido maior se as técnicas tivessem sido aplicadas em conjunto, ou seja, explorando os aspectos complementares de cada técnica. Os piores resultados obtidos por qualquer combinação de técnicas foi melhor que os piores resultados obtidos, individualmente, por uma determinada técnica. Wood et. al. [WOO97] também relatam que as técnicas são muito mais efetivas quando usadas em combinação com as outras técnicas. 


\subsection{Considerações Finais}

Neste capítulo foram apresentados, inicialmente, os detalhes operacionais pertinentes a replicação do experimento baseado em códigos fontes. Os detalhes operacionais envolveram a definição das hipóteses, técnicas utilizadas, programas utilizados, procedimentos de treinamento e execução.

$\mathrm{Na}$ seqüência foram apresentados os resultados obtidos durante a replicação do experimento organizados em duas subseções: análise dos defeitos e análise das falhas por programa. Posteriormente foram apresentadas as análises gerais contemplando todos os programas. A análise estatística dos resultados foi apresentada, juntamente, com os procedimentos necessários para obter-las utilizando o software Minitab. Finalmente, um comparativo entre os resultados obtidos nesta replicação e resultados obtidos em experimentos similares foi apresentado.

Uma das contribuições principais da replicação do experimento foi adicionar ao pacote de replicação original a Técnica denominada Teste Incremental. Em síntese pode-se observar que a técnica não trouxe em um primeiro momento benefícios significativos, principalmente, se analisarmos os critérios baseados em fluxo de dados. No contexto do experimento, o custo adicional para aplicação desses critérios foi relevante, mas não representou efetivamente um aumento no número de defeitos isolados. Em contrapartida, observou-se que na média os indivíduos não conseguiram aplicar esses critérios completamente.

É importante destacar que o critério Análise de Mutantes também teve um custo adicional para aplicação, mas com a vantagem de apresentar um melhoramento na taxa de defeitos isolados pelos indivíduos.

No próximo capítulo apresentam-se os resultados obtidos na replicação do experimento baseado em especificações de requisitos. 


\section{CAPÍtUlo 5}

\section{Documentos de Especificação de}

Requisitos: Replicação de Experimento

\subsection{Considerações Iniciais}

Neste capítulo descreve-se a replicação do experimento de Basili et. al. [BAS96a], que utiliza documentos de especificação de requisitos.

$\mathrm{Na}$ Seção 5.2 é apresentado o projeto experimental, ou seja, a organização do experimento em função dos participantes, técnicas e documentos de especificação de requisitos utilizados. Na Seção 5.3 são apresentados as técnicas e os documentos de especificação de requisitos utilizados durante o experimento, bem como, as classes e os tipos de defeitos associados a cada documento de especificação de requisitos. Na Seção 5.4 são apresentados o perfil dos participantes, a organização das sessões de treinamento e a organização das execuções do experimento. Na Seção 5.5 são apresentados os principais resultados obtidos durante a replicação.

\subsection{Projeto Experimental}

A Tabela 5.1 apresenta o projeto experimental utilizado na replicação do experimento. Inicialmente, os indivíduos foram divididos em dois grupos (Grupo 1 e Grupo 2). Cada grupo foi dividido em 3 subgrupos contendo 2 indivíduos cada. Cada subgrupo foi relacionado a uma das perspectivas (Projeto, Teste e Uso) da técnica Perspective Based Reading (PBR). No primeiro dia os indivíduos dos Grupos 1 e 2 utilizaram as técnicas convencionais Ad Hoc e Checklist para 
revisarem os documentos de domínio genérico ATM e PG. No segundo dia, cada indivíduo foi treinado em uma das perspectivas (Projeto, Teste e Uso) da técnica PBR para então iniciar o processo de revisão dos documentos de domínio genérico PG e ATM. Esse projeto experimental garante que cada indivíduo aplique cada técnica somente uma vez e que todas as combinações de documentos de especificação de requisitos e técnicas ocorram.

\begin{tabular}{|c|c|c|c|c|c|c|c|}
\hline & \multicolumn{3}{|c|}{ Grupo 1 - 9 Indivíduos } & \multicolumn{3}{|c|}{ Grupo 2 - 9 Indivíduos } & \\
\hline \multirow{3}{*}{$\begin{array}{c}\text { Técnica } \\
\text { Conven- } \\
\text { cional }\end{array}$} & $\begin{array}{c}\text { Projeto } \\
3 \text { Indivíduos }\end{array}$ & $\begin{array}{c}\text { Teste } \\
\mathbf{3} \text { Indivíduos }\end{array}$ & $\begin{array}{c}\text { Uso } \\
\mathbf{3} \text { Indivíduos }\end{array}$ & $\begin{array}{c}\text { Projeto } \\
\mathbf{3} \text { Indivíduos }\end{array}$ & \begin{tabular}{|c|} 
Teste \\
$\mathbf{3}$ Indivíduos \\
\end{tabular} & $\begin{array}{c}\text { Uso } \\
3 \text { Indivíduos }\end{array}$ & \multirow{3}{*}{$\begin{array}{c}\text { Primeiro } \\
\text { Dia }\end{array}$} \\
\hline & \multicolumn{3}{|c|}{ Treinamento } & \multicolumn{3}{|c|}{ Treinamento } & \\
\hline & \multicolumn{3}{|c|}{ ATM } & \multicolumn{3}{|c|}{ PG } & \\
\hline \multirow{3}{*}{$\begin{array}{c}\text { Técnica } \\
\text { PBR }\end{array}$} & \multicolumn{6}{|c|}{ Teoria sobre a Técnica Perspective Based Reading (PBR) } & \multirow{3}{*}{$\begin{array}{c}\text { Segundo } \\
\text { Dia }\end{array}$} \\
\hline & \multicolumn{3}{|c|}{ Treinamento } & \multicolumn{3}{|c|}{ Treinamento } & \\
\hline & \multicolumn{3}{|c|}{ PG } & \multicolumn{3}{|c|}{ ATM } & \\
\hline
\end{tabular}

Tabela 5.1 - Projeto experimental.

\subsection{Técnicas e Documentos de Especificação de Requisitos}

As técnicas de detecção de defeitos utilizadas no experimento foram basicamente as mesmas do experimento de Basili et. al. [BAS96a], exceção feita às técnicas convencionais. Nesta replicação foram consideradas técnicas convencionais as técnicas Ad Hoc e Checklist. A seguir apresentam-se as técnicas utilizadas na replicação do experimento:

- Perspective Based Reading: É uma técnica de leitura utilizada para detectar defeitos em especificações de requisitos e requer um indivíduo para em um primeiro momento criar uma abstração de um produto de software e então responder questões baseadas na análise da abstração a partir de uma responsabilidade específica (a responsabilidade representa perspectivas diferentes, em outras palavras, pontos de vista diferentes) que o indivíduo assume. Os detalhes procedimentais da técnica estão detalhados no Capítulo 2, na Seção 2.2.3.2.

- Ad Hoc e Checklist: São duas técnicas freqüentemente usadas para detecção de defeitos em especificações de requisitos. A técnica $A d$ Hoc não estabelece uma responsabilidade específica para cada revisor, ou seja, é uma técnica não sistemática. A técnica Checklist é similar à técnica Ad Hoc. A única diferença é que cada revisor recebe um checklist, onde os itens desse checklist capturam importantes lições apreendidas em revisões anteriores. Itens individuais de um checklist podem enumerar defeitos característicos, priorizar diferentes defeitos ou propor questões para ajudar o revisor a descobrir defeitos. O checklist utilizado 
na replicação do experimento está disponível no material de replicação. Os esquemas de classificação de defeitos utilizados pelos revisores que aplicaram a técnica Ad Hoc e Checklist são descritos na sequiência desta seção.

\begin{tabular}{|l|l|l|}
\hline \multicolumn{1}{|c|}{ Defeito } & \multicolumn{1}{|c|}{ Classe } & \multicolumn{1}{c|}{ Tipo } \\
\hline Defeito 1 & Commission & Extraneous Information \\
Defeito 2 & Omission & Ambiguous Information \\
Defeito 3 & Omission & Ambiguous Information \\
Defeito 4 & Commission & Incorrect Fact \\
Defeito 5 & Omission & Ambiguous Information \\
Defeito 6 & Omission & Missing Information \\
Defeito 7 & Omission & Inconsistent Information \\
Defeito 8 & Omission & Ambiguous Information \\
Defeito 9 & Omission & Ambiguous Information \\
Defeito 10 & Commission & Incorrect Fact \\
Defeito 11 & Commission & Incorrect Fact \\
Defeito 12 & Omission & Ambiguous Information \\
Defeito 13 & Omission & Missing Information \\
Defeito 14 & Commission & Incorrect Fact \\
Defeito 15 & Omission & Ambiguous Information \\
Defeito 16 & Commission & Incorrect Fact \\
Defeito 17 & Commission & Incorrect Fact \\
Defeito 18 & Omission & Missing Information \\
Defeito 19 & Commission & Incorrect Fact \\
Defeito 20 & Commission & Incorrect Fact \\
Defeito 21 & Omission & Missing Information \\
Defeito 22 & Omission & Missing Information \\
Defeito 23 & Commission & Miscellaneous Defeito \\
Defeito 24 & Omission & Missing Information \\
Defeito 25 & Omission & Missing Information \\
Defeito 26 & Omission & Missing Information \\
Defeito 27 & Omission & Missing Information \\
Defeito 28 & Commission & Ambiguous Information \\
Defeito 29 & Commission & Inconsistent Information \\
Defeito 30 & Commission & Inconsistent Information \\
Defeito 31 & Omission & Missing Information \\
Defeito 32 & Commission & Miscellaneous Defeito \\
Defeito 33 & Omission & Missing Information \\
Defeito 34 & Omission & Missing Information \\
Defeito 35 & Commission & Missing Information \\
Defeito 36 & Commission & Inconsistent Information \\
Defeito 37 & Omission & Missing Information \\
\hline
\end{tabular}

Tabela 5.2 - ATM: Classes e tipos de defeitos.

Os documentos de especificação de requisitos utilizados são os mesmos do experimento de Basili et. al. [BAS96a]. Os documentos utilizados na execução do experimento foram: 
Automatic Teller Machine (ATM) e Parking Garage Control System (PG). O documento utilizado na fase de treinamento foi: ABC Video System. A Tabela 5.2 e a Tabela 5.3 apresentam as classes e tipos dos defeitos dos documento ATM e PG.

\begin{tabular}{|l|l|l|}
\hline \multicolumn{1}{|c|}{ Defeito } & \multicolumn{1}{|c|}{ Classe } & \multicolumn{1}{c|}{ Tipo } \\
\hline Defeito 1 & Commission & Inconsistent Information \\
Defeito 2 & Commission & Incorrect Fact \\
Defeito 3 & Commission & Ambiguous Information \\
Defeito 4 & Omission & Inconsistent Information \\
Defeito 5 & Omission & Missing Information \\
Defeito 6 & Omission & Missing Information \\
Defeito 7 & Omission & Inconsistent Information \\
Defeito 8 & Omission & Missing Information \\
Defeito 9 & Omission & Missing Information \\
Defeito 10 & Commission & Incorrect Fact \\
Defeito 11 & Commission & Inconsistent Information \\
Defeito 12 & Omission & Ambiguous Information \\
Defeito 13 & Commission & Inconsistent Information \\
Defeito 14 & Commission & Inconsistent Information \\
Defeito 15 & Omission & Missing Information \\
Defeito 16 & Omission & Ambiguous Information \\
Defeito 17 & Commission & Inconsistent Information \\
Defeito 18 & Commission & Inconsistent Information \\
Defeito 19 & Commission & Inconsistent Information \\
Defeito 20 & Omission & Missing Information \\
Defeito 21 & Commission & Inconsistent Information \\
Defeito 22 & Commission & Extraneous Information \\
Defeito 23 & Commission & Miscellaneous Defeito \\
Defeito 24 & Omission & Missing Information \\
Defeito 25 & Commission & Miscellaneous Defeito \\
Defeito 26 & Omission & Missing Information \\
Defeito 27 & Commission & Ambiguous Information \\
Defeito 28 & Omission & Missing Information \\
Defeito 29 & Omission & Missing Information \\
Defeito 30 & Commission & Miscellaneous Defeito \\
Defeito 31 & Omission & Missing Information \\
Defeito 32 & Commission & Ambiguous Information \\
\hline
\end{tabular}

Tabela 5.3 - PG: Classes e tipos de defeitos.

Os defeitos foram classificados de acordo com os esquemas de classificação do experimento de Basili et. al. [BAS96a], são eles: 


\section{(1) Classe de Defeito}

- Omission - São defeitos causados por falta de informações na especificação de requisitos;

- Commission - São defeitos causados por informações presentes na especificação de requisitos.

\section{(2) Tipo de Defeito}

- Ambiguous Information: Um termo importante, frase ou sentença essencial para o entendimento do comportamento do sistema não foi definido ou foi definido de maneira que pode causar confusão ou engano;

- Extraneous Information: Informação que é fornecida não é necessária ou utilizada;

- Inconsistent Information: Duas sentenças contidas na especificação de requisitos se contradizem ou expressam ações que não podem estar corretas ou não podem ser executadas;

- Incorrect Fact: Alguma sentença contida na especificação de requisitos afirma um fato que não pode ser verdade sobre as condições especificadas na especificação de requisitos;

- Missing Informationn: Informação necessária sobre o sistema foi omitida da especificação de requisitos.

As especificações de requisitos utilizadas tanto na fase de treinamento como na execução do experimento encontram-se disponíveis junto ao pacote de replicação.

\subsection{Procedimentos}

Um total de 18 alunos de graduação foi selecionado para participar do experimento. A Tabela 5.4 apresenta o perfil dos indivíduos com relação ao nível de proficiência com leitura em Inglês (Q1), aos anos/meses de experiência na função de Gerente, Desenvolvedor, Testador e Analista (Q2), aos anos/meses de experiência usando documentos de requisitos $(\mathbf{Q 3})$ e aos anos de experiência escrevendo documento de requisitos $(\mathbf{Q 4})$.

A fase de treinamento foi realizada em dois dias consecutivos e contou com um total de 2 sessões de $2 \mathrm{~h} 10 \mathrm{~min}$ cada. Durante as sessões, 30 minutos foram destinados à apresentação teórica das técnicas e 01h40min foram destinados para aplicação das técnicas. Foram realizadas as seguintes sessões de treinamento: $\left(1^{\mathrm{a}}\right)$ Treinamento nas técnicas Ad hoc e Checklist utilizando o documento de requisitos ABC Video System; $\left(2^{\mathrm{a}}\right)$ Treinamento na técnica PBR utilizando o documento de requisitos ABC Video System 
A fase de execução do experimento foi realizada em 2 dias consecutivos. No $1^{\circ}$ dia ocorreu 1 sessão de inspeção com duração de 4 horas aplicando as técnicas Ad Hoc e Checklist nos documentos ATM e PG. No $2^{\circ}$ dia ocorreu 1 sessão de inspeção com duração de 4 horas aplicando a técnica PBR nos documentos PG e ATM.

\begin{tabular}{|c|c|c|c|c|c|c|c|}
\hline & \multirow{2}{*}{ Q1 } & \multicolumn{4}{|c|}{ Q2 } & \multirow{2}{*}{ Q3 } & \multirow{2}{*}{ Q4 } \\
\hline & & Gerente & Desenvolvedor & Testador & Analista & & \\
\hline S1 & Médio & 0,0 & 5,0 & 3,0 & 2,0 & 2,0 & 2,0 \\
\hline S10 & Avançado & 0,0 & 3,0 & 0,3 & 0,2 & 0,3 & 0,1 \\
\hline S11 & Avançado & 0,0 & 2,0 & 0,1 & 0,5 & 0,5 & 0,5 \\
\hline $\mathrm{S} 12$ & Avançado & 1,0 & 1,0 & 0,1 & 0,5 & 0,5 & 0,3 \\
\hline $\mathrm{S} 13$ & Avançado & 0,0 & 0,3 & 0,1 & 0,1 & 0,3 & 0,1 \\
\hline S14 & Médio & 0,0 & 0,3 & 0,1 & 0,2 & 0,3 & 0,1 \\
\hline S15 & Avançado & 0,0 & 0,0 & 0,0 & 0,0 & 0,0 & 0,0 \\
\hline S16 & - & - & - & - & - & - & - \\
\hline $\mathrm{S} 17$ & - & - & - & - & - & - & - \\
\hline S18 & Avançado & 0,0 & 0,0 & 0,0 & 0,0 & 0,5 & 0,5 \\
\hline $\mathrm{S} 2$ & Médio & 0,0 & 2,0 & 0,1 & 0,3 & 0,3 & 0,3 \\
\hline S3 & Médio & 0,0 & 2,0 & 0,1 & 0,2 & 0,3 & 0,3 \\
\hline S4 & Avançado & 0,0 & 2,0 & 0,2 & 0,0 & 0,3 & 0,2 \\
\hline S5 & Médio & 0,0 & 2,0 & 0,1 & 0,0 & 0,5 & 0,5 \\
\hline S6 & Médio & 0,0 & 2,0 & 0,4 & 0,4 & 0,4 & 0,4 \\
\hline S7 & Avançado & 0,0 & 2,0 & 0,3 & 0,3 & 0,3 & 0,0 \\
\hline S8 & Avançado & 0,2 & 0,0 & 0,2 & 0,0 & 0,1 & 0,1 \\
\hline S9 & Expert & 0,0 & 0,3 & 0,1 & 0,2 & 0,3 & 0,3 \\
\hline
\end{tabular}

Tabela 5.4: Perfil dos indivíduos que participaram do experimento. 


\subsection{Resultados}

Esta seção apresenta os principais resultados obtidos durante a replicação desse experimento. Na seção 5.1.1 são apresentados os resultados referentes aos defeitos observados durante as duas fases do experimento.

\subsubsection{Análise dos Defeitos}

\subsubsection{ATM - Automatic Teller Machine}

A Figura 5.1 apresenta as quantidades de cada defeito que foram observados pela técnica Ad Hoc/Checklist quando aplicada no documento de especificação de requisitos ATM (Automatic Teller Machine).

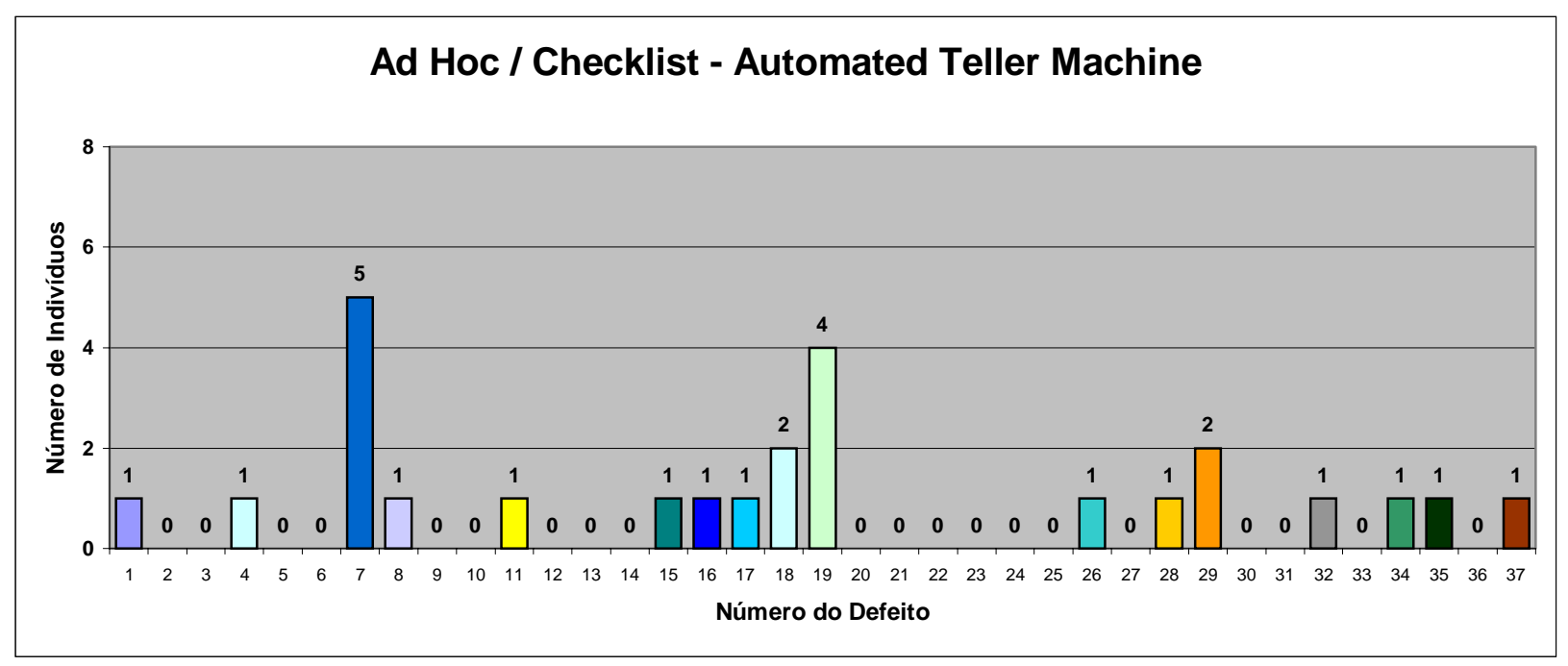

Figura 5.1 - Ad Hoc/Checklist: Defeitos encontrados pela técnica.

\begin{tabular}{|c|c|c|c|c|c|c|c|}
\hline & \multirow{2}{*}{ Q1 } & \multicolumn{4}{|c|}{ Q2 } & \multirow{2}{*}{ Q3 } & \multirow{2}{*}{ Q4 } \\
\hline & & Gerente & Desenvolvedor & Testador & Analista & & \\
\hline $\mathrm{S} 2$ & Médio & 0,0 & 2,0 & 0,1 & 0,3 & 0,3 & 0,3 \\
\hline S5 & Médio & 0,0 & 2,0 & 0,1 & 0,0 & 0,5 & 0,5 \\
\hline S7 & Avançado & 0,0 & 2,0 & 0,3 & 0,3 & 0,3 & 0,0 \\
\hline S9 & Expert & 0,0 & 0,3 & 0,1 & 0,2 & 0,3 & 0,3 \\
\hline S10 & Avançado & 0,0 & 3,0 & 0,3 & 0,2 & 0,3 & 0,1 \\
\hline S11 & Avançado & 0,0 & 2,0 & 0,1 & 0,5 & 0,5 & 0,5 \\
\hline S12 & Avançado & 1,0 & 1,0 & 0,1 & 0,5 & 0,5 & 0,3 \\
\hline S14 & Médio & 0,0 & 0,3 & 0,1 & 0,2 & 0,3 & 0,1 \\
\hline S18 & Avançado & 0,0 & 0,0 & 0,0 & 0,0 & 0,5 & 0,5 \\
\hline & Média (anos) & $\mathbf{0 , 1 1}$ & 1,40 & $\mathbf{0 , 1 3}$ & 0,24 & $\mathbf{0 , 3 9}$ & $\mathbf{0 , 2 9}$ \\
\hline
\end{tabular}

Tabela 5.5 - Perfil dos indivíduos que aplicaram a técnica Ad Hoc/Checklist no documento ATM. 


\begin{tabular}{|c|c|c|}
\hline Técnica & Número máximo & Defeitos observados \\
\hline \hline Ad Hoc / Checklist & 333 & 26 \\
\hline
\end{tabular}

Tabela 5.6 - Número máximo de possibilidades de observação de defeitos e número de defeitos observados pela técnica.

A técnica Ad Hoc/Checklist observou 26 ocorrências de defeitos das 333 possibilidades de observação de defeitos, que é obtida pela razão entre a quantidade de defeitos (37) contidos no documento ATM e a quantidade de indivíduos (9) que aplicaram a técnica, conforme pode ser observado na Tabela 5.6. A Tabela 5.5 apresenta o perfil dos indivíduos que aplicaram a técnica. Pode-se observar que na média os indivíduos têm maior experiência com atividades de desenvolvimento.

\begin{tabular}{|l|l|c|c|c|}
\cline { 3 - 4 } \multicolumn{2}{c|}{} & \multicolumn{3}{c|}{ Documento: ATM } \\
\cline { 3 - 5 } \multicolumn{2}{c|}{} & $\begin{array}{c}\text { Quantidade de } \\
\text { defeitos } \\
\text { originais }\end{array}$ & $\begin{array}{c}\text { Quantidade } \\
\text { de defeitos } \\
\text { observados }\end{array}$ & $\%$ \\
\hline Classe & Commission & 16 & 14 & $9,72 \%$ \\
\hline & Omission & 21 & 12 & $6,35 \%$ \\
\hline \hline Tipo & Ambiguous Information & 8 & 3 & $4,17 \%$ \\
\hline & Extraneous Information & 1 & 1 & $11,11 \%$ \\
\hline & Inconsistent Information & 4 & 7 & $19,44 \%$ \\
\hline & Incorrect Fact & 8 & 8 & $11,11 \%$ \\
\hline & Miscellaneous Defeito & 2 & 1 & $5,56 \%$ \\
\hline & Missing Information & 14 & 6 & $4,76 \%$ \\
\hline
\end{tabular}

Tabela 5.7 - Quantidade e percentual (do total possível) de defeitos observados por classe e tipo utilizando a técnica Ad Hoc /Checklist.

A Tabela 5.7 apresenta um resumo geral dos percentuais de defeitos observados pela técnica organizados por classes e tipos de defeitos. A técnica foi mais efetiva na observação de defeitos da classe Commission e do tipo Inconsistent Information.

\begin{tabular}{|c|c|c|c|}
\hline Técnica & Média & Desvio padrão & $\begin{array}{c}\text { Número de } \\
\text { indivíduos }\end{array}$ \\
\hline \hline Ad Hoc/Checklist & 2,89 & 2,26 & 9 \\
\hline
\end{tabular}

Tabela 5.8 - Média de defeitos observados por cada indivíduo. 


\begin{tabular}{|c|c|c|}
\hline Técnica & $\begin{array}{c}\text { Percentual médio de } \\
\text { defeitos observados } \\
\text { (do total possível) }\end{array}$ & $\begin{array}{c}\text { Taxa de observação } \\
\text { de defeitos } \\
\text { (horas) }\end{array}$ \\
\hline Ad Hoc / Checklist & $7,81 \%$ & 2,13 \\
\hline
\end{tabular}

Tabela 5.9 - Percentual médio de defeitos observados (do total possível) e taxa de observação de defeitos.

Conforme mostra a Tabela 5.8 e a Tabela 5.9, os indivíduos observaram na média 2,89 defeitos a uma taxa de observação de 2,13 defeitos por hora. O percentual médio de defeitos observados (do total possível) foi de 7,81\%. A média de defeitos observados pelos indivíduos foi calculada por meio da divisão entre a somatória das quantidades de defeitos observados por cada indivíduo e a quantidade de indivíduos. O percentual médio de defeitos observados foi calculado por meio da divisão entre a somatória dos percentuais individuais de observação de defeitos ${ }^{5}$ e a quantidade de indivíduos. A taxa de observação de defeitos foi calculada por meio da divisão entre a somatória das taxas individuais de observação de defeitos ${ }^{6}$ e a quantidade de indivíduos.

Em resumo se observou que dos 37 defeitos existentes no documento ATM os indivíduos conseguiram observar 17 defeitos, o que significa uma efetividade de 45,94\% do total possível.

A Figura 5.2 apresenta as quantidades de cada defeito que foram observados pelas perspectivas da técnica Perspective Based Reading (PBR) quando aplicadas no documento de especificação de requisitos ATM (Automatic Teller Machine).

\footnotetext{
${ }^{5}$ Os percentuais foram calculados a partir da seguinte expressão: $(x \star 100) / y$. Onde x é a quantidade de defeitos observados pelo indivíduo e y é a quantidade de defeitos existente no documento.

${ }^{6}$ As taxas foram calculadas a partir da seguinte expressão: $\mathrm{x} /(\mathrm{y} / 60)$. Onde $\mathrm{x}$ é a quantidade de defeitos observados pelo indivíduo e y é a quantidade de tempo gasto na observação.
} 


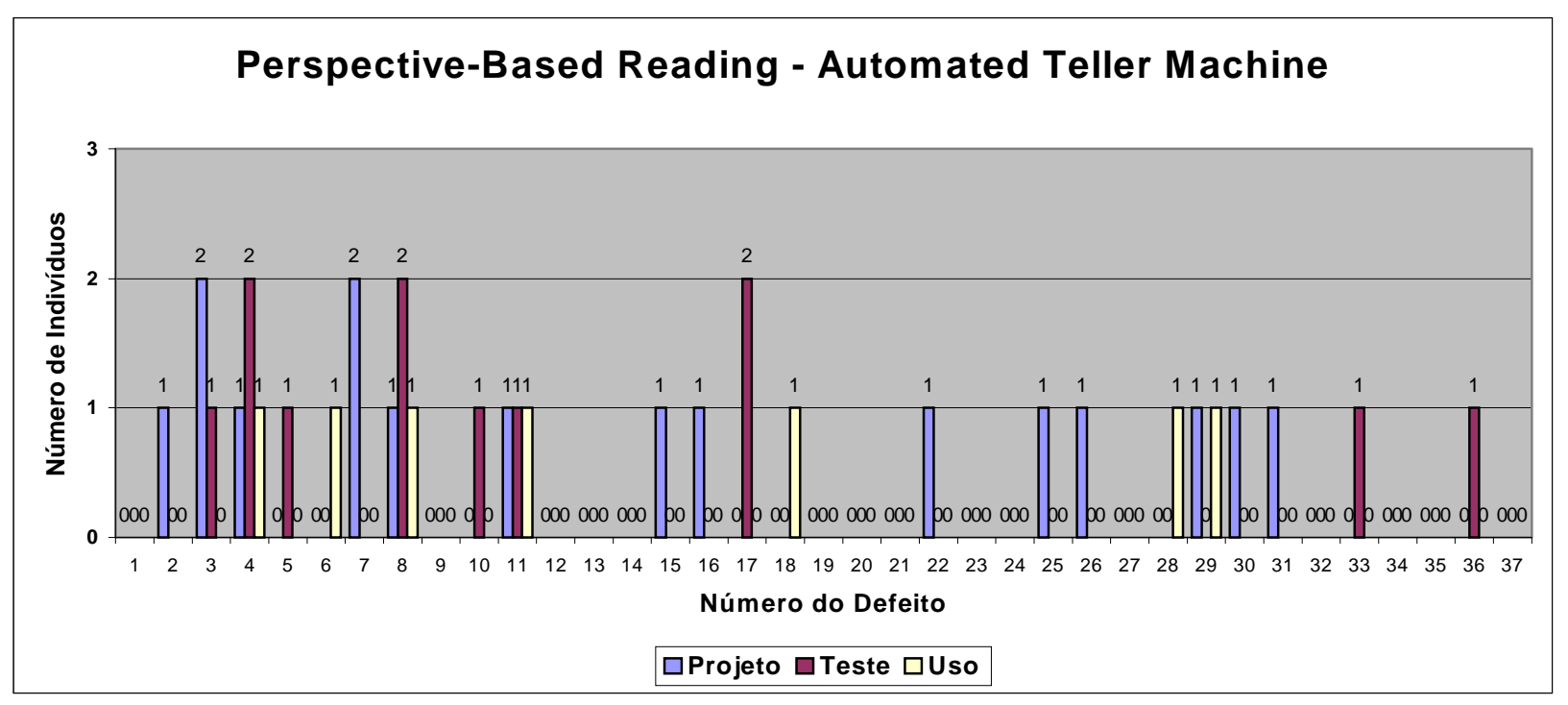

Figura 5.2 - PBR: Defeitos encontrados pela técnica.

\begin{tabular}{|c|c|c|c|c|c|c|c|}
\hline & \multirow{2}{*}{ Q1 } & \multicolumn{4}{|c|}{ Q2 } & \multirow{2}{*}{ Q3 } & \multirow{2}{*}{ Q4 } \\
\hline & & Gerente & Desenvolvedor & Testador & Analista & & \\
\hline $\mathrm{S} 1$ & Médio & 0,0 & 5,0 & 3,0 & 2,0 & 2,0 & 2,0 \\
\hline S3 & Médio & 0,0 & 2,0 & 0,1 & 0,2 & 0,3 & 0,3 \\
\hline \multirow[t]{2}{*}{ S15 } & Avançado & 0,0 & 0,0 & 0,0 & 0,0 & 0,0 & 0,0 \\
\hline & $\begin{array}{l}\text { Média } \\
\text { (anos) }\end{array}$ & $\mathbf{0 , 0 0}$ & 2,33 & 1,03 & $\mathbf{0 , 7 3}$ & 0,77 & $\mathbf{0 , 7 7}$ \\
\hline
\end{tabular}

Tabela 5.10 - Perfil dos indivíduos que aplicaram a técnica PBR (perspectiva do projeto) no documento ATM.

\begin{tabular}{|c|c|c|c|c|c|c|c|}
\hline & \multirow{2}{*}{ Q1 } & \multicolumn{4}{|c|}{ Q2 } & \multirow{2}{*}{ Q3 } & \multirow{2}{*}{ Q4 } \\
\hline & & Gerente & Desenvolvedor & Testador & Analista & & \\
\hline $\mathrm{S} 4$ & Avançado & 0,0 & 2,0 & 0,2 & 0,0 & 0,3 & 0,2 \\
\hline S6 & Médio & 0,0 & 2,0 & 0,4 & 0,4 & 0,4 & 0,4 \\
\hline \multirow[t]{2}{*}{$\mathrm{S} 8$} & Avançado & 0,2 & 0,0 & 0,2 & 0,0 & 0,1 & 0,1 \\
\hline & $\begin{array}{l}\text { Média } \\
\text { (anos) }\end{array}$ & $\mathbf{0 , 0 7}$ & 1,33 & 0,27 & $\mathbf{0 , 1 3}$ & $\mathbf{0 , 2 7}$ & 0,23 \\
\hline
\end{tabular}

Tabela 5.11 - Perfil dos indivíduos que aplicaram a técnica PBR (perspectiva do teste) no documento ATM. 


\begin{tabular}{|c|c|c|c|c|c|c|c|}
\cline { 2 - 7 } \multicolumn{1}{c|}{} & \multirow{2}{*}{ Q1 } & \multicolumn{4}{c|}{ Q2 } & \multirow{2}{*}{ Q3 } & \multirow{2}{*}{ Q4 } \\
\cline { 2 - 7 } \multicolumn{1}{c|}{} & Gerente & Desenvolvedor & Testador & Analista & 0,3 & 0,1 \\
\hline S13 & Avançado & 0,0 & 0,3 & -3 & - & - & - \\
\hline S16 & - & - & - & - & - & - & - \\
\hline S17 & - & - & - & $\mathbf{0 , 0 3}$ & $\mathbf{0 , 0 3}$ & $\mathbf{0 , 1}$ & $\mathbf{0 , 0 3}$ \\
\hline
\end{tabular}

Tabela 5.12 - Perfil dos indivíduos que aplicaram a técnica PBR (perspectiva do uso) no documento ATM.

\begin{tabular}{|l|c|c|}
\hline \multicolumn{1}{|c|}{ Perspectiva } & Número máximo & Defeitos encontrados \\
\hline \hline Projeto & 111 & 16 \\
\hline Teste & 111 & 12 \\
\hline Uso & 37 & 7 \\
\hline \hline Total & $\mathbf{2 5 9}$ & $\mathbf{3 5}$ \\
\hline
\end{tabular}

Tabela 5.13 - Número máximo de possibilidades de observação de defeitos e número de defeitos observados pela técnica.

Conforme pode ser observado na Tabela 5.13, a perspectiva do Projeto observou um número maior de ocorrências de defeitos que as outras perspectivas. Das 111 possibilidades de observação de defeitos, obtida pela razão entre a quantidade de defeitos (37) contidos no documento ATM e a quantidade de indivíduos (3) que aplicaram a perspectiva, 16 foram observados. A experiência em atividades de desenvolvimento e com documentos de requisitos pode ter de alguma forma influenciado nos resultados obtidos pelos indivíduos da perspectiva do Projeto, conforme pode ser observado na Tabela 5.10. A Tabela 5.11 e a Tabela 5.12 apresentam as experiências dos indivíduos que aplicaram as perspectivas do Teste e do Uso.

A Tabela 5.14 apresenta um resumo geral dos percentuais de defeitos observados pelas perspectivas da técnica PBR organizados por classes e tipos de defeitos. A perspectiva do Projeto foi mais efetiva na observação de defeitos da classe Omission e defeitos do tipo Inconsistent Information. A perspectiva do Teste foi mais efetiva na observação de defeitos da classe Commission e defeitos do tipo Incorrect Fact. A perspectiva do Uso foi mais efetiva na observação de defeitos da classe Commission e defeitos dos tipos: Ambiguous Information, Inconsistent Information e Incorrect Fact. Na média as perspectivas foram mais efetivas na observação de defeitos da classe Commission e do tipo Inconsistent Information. 


\begin{tabular}{|c|c|c|c|c|c|c|c|c|c|c|}
\hline & \multicolumn{9}{|c|}{ Documento: ATM } \\
\hline & & $\begin{array}{c}\text { Quantidad } \\
\text { e de } \\
\text { defeitos } \\
\text { originais }\end{array}$ & $\begin{array}{l}\text { Quantidade } \\
\text { de defeitos } \\
\text { observados } \\
\text { PROJETO }\end{array}$ & $\%$ & $\begin{array}{l}\text { Quantidade } \\
\text { de defeitos } \\
\text { observados } \\
\text { TESTE }\end{array}$ & $\%$ & $\begin{array}{c}\text { Quantidade } \\
\text { de defeitos } \\
\text { observados } \\
\text { USO }\end{array}$ & $\%$ & $\begin{array}{c}\text { Total } \\
\text { geral } \\
\text { defeitos } \\
\text { observado } \\
\text { s }\end{array}$ & Média \\
\hline \multirow[t]{2}{*}{ Classe } & Commission & 16 & 5 & $10,42 \%$ & 7 & $\begin{array}{c}14,58 \\
\%\end{array}$ & 4 & $25,00 \%$ & 16 & $16,67 \%$ \\
\hline & Omission & 21 & 11 & $17,46 \%$ & 5 & $7,94 \%$ & 3 & $14,29 \%$ & 19 & $13,23 \%$ \\
\hline \multirow[t]{6}{*}{ Tipo } & $\begin{array}{l}\text { Ambiguous } \\
\text { Information }\end{array}$ & 8 & 5 & $20,83 \%$ & 4 & $\begin{array}{c}16,67 \\
\%\end{array}$ & 2 & $25,00 \%$ & 11 & $20,83 \%$ \\
\hline & $\begin{array}{l}\text { Extraneous } \\
\text { Information }\end{array}$ & 1 & 0 & $0,00 \%$ & 0 & $0,00 \%$ & 0 & $0,00 \%$ & $\mathbf{0}$ & $0,00 \%$ \\
\hline & $\begin{array}{l}\text { Inconsistent } \\
\text { Information }\end{array}$ & 4 & 4 & $33,33 \%$ & 1 & $8,33 \%$ & 1 & $25,00 \%$ & 6 & $22,22 \%$ \\
\hline & $\begin{array}{l}\text { Incorrect } \\
\text { Fact }\end{array}$ & 8 & 3 & $12,50 \%$ & 6 & $\begin{array}{c}25,00 \\
\% \\
\end{array}$ & 2 & $25,00 \%$ & 11 & $20,83 \%$ \\
\hline & $\begin{array}{l}\text { Miscellaneous } \\
\text { Defeito }\end{array}$ & 2 & 0 & $0,00 \%$ & 0 & $0,00 \%$ & 0 & $0,00 \%$ & $\mathbf{0}$ & $0,00 \%$ \\
\hline & $\begin{array}{l}\text { Missing } \\
\text { Information }\end{array}$ & 14 & 4 & $9,52 \%$ & 1 & $2,38 \%$ & 2 & $14,29 \%$ & 7 & $8,73 \%$ \\
\hline
\end{tabular}

Tabela 5.14 - Quantidade e percentual (do total possível) de defeitos observados por tipos e classes utilizando a técnica PBR.

A seguir, apresentam-se três diferentes visões dos dados apresentados na Figura 5.2: 
Visão 1 - Efetividade das perspectivas por grupo de indivíduos

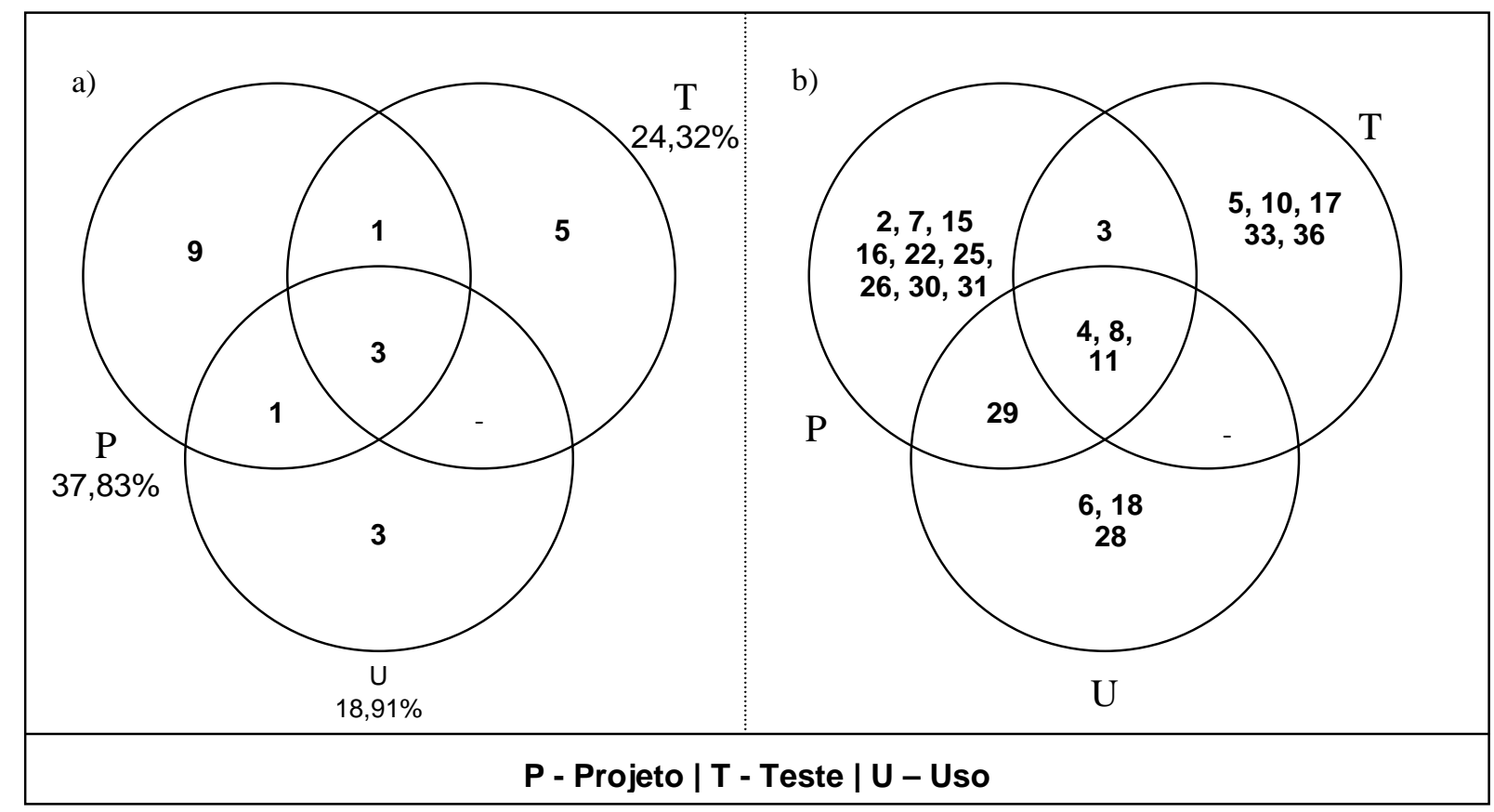

Figura 5.3 - (a) Quantidade e percentual de defeitos observados pelas perspectivas; (b) Identificação dos defeitos observados pelas perspectivas.

Visão 2 - Efetividade das perspectivas por número de ocorrências de defeitos

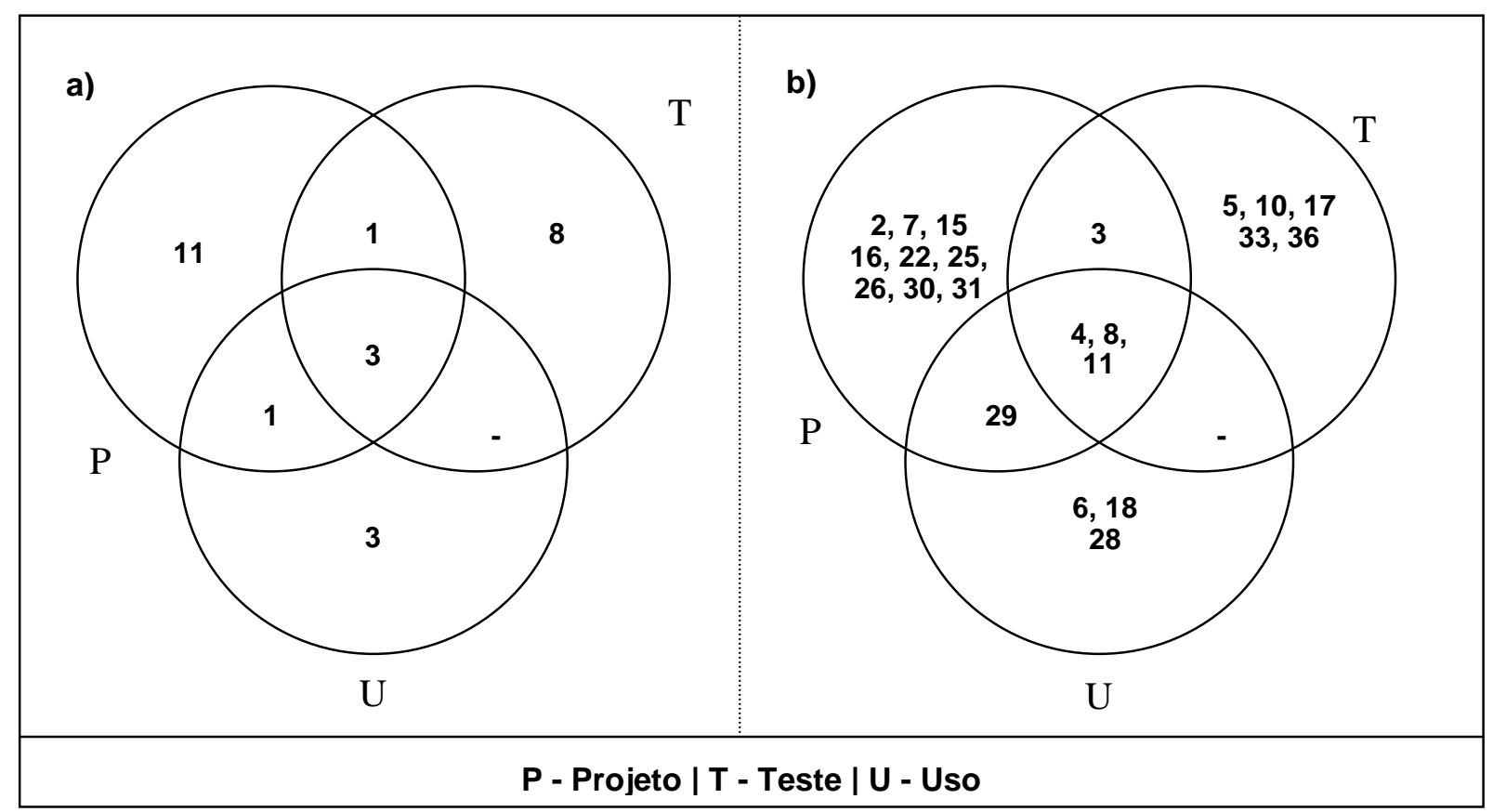

Figura 5.4 - (a) Número de ocorrências de defeitos observados pelas perspectivas; (b) Identificação dos defeitos observados pelas perspectivas. 
Visão 3 - Identificação da melhor perspectiva por defeito

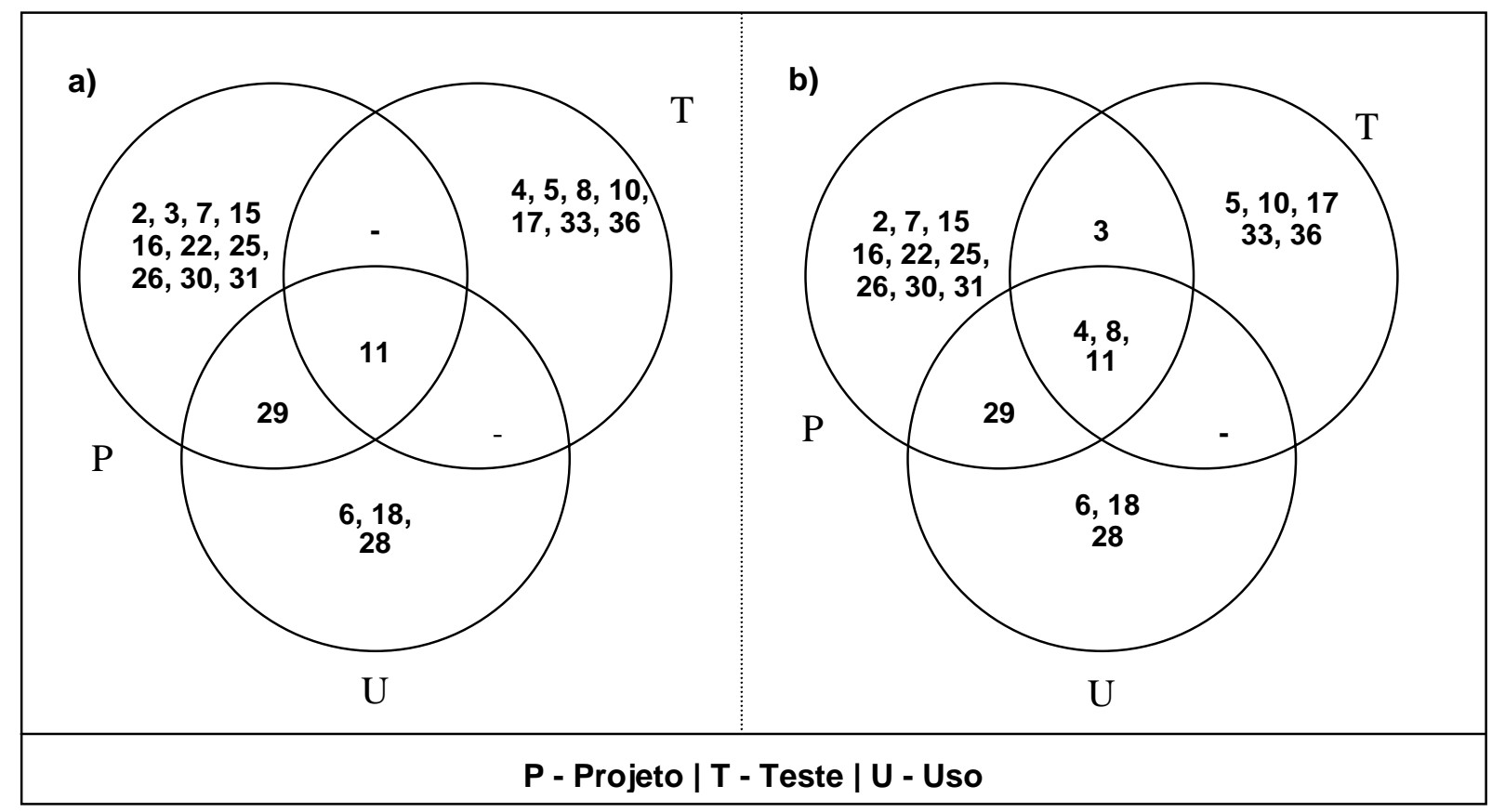

Figura 5.5 - (a) Identificação dos defeitos onde as perspectivas obtiveram performance melhor ou igual com relação as outras perspectivas; (b) Identificação dos defeitos observados pelas perspectivas.

Como pode ser observado na Figura 5.3 (a), a perspectiva do Projeto observou: 9 defeitos que nenhuma outra perspectiva observou, são eles: 2, 7, 15, 16, 22, 25, 26, 30 e 31 (ver Figura 5.3 (b)); 1 defeito que também foi observado pela perspectiva do Teste, que é o defeito $3 ; 1$ defeito que também foi observado pela perspectiva do Uso, que é o defeito 29; 3 defeitos que também foram observados pelas perspectivas do Teste e do Uso, são eles: 4, 8 e 11. A perspectiva do Projeto obteve uma efetividade de 37,83\%, ou seja, dos 37 defeitos existentes no documento ATM 14 foram observados.

Como pode ser observado na Figura 5.4 (b), os defeitos 4, 8 e 11 foram observados por todas as perspectivas, mas o defeito 8 foi observado mais vezes pela perspectiva do Teste do que pelas outras perspectivas. As quantidades totalizadas de ocorrências de defeitos observados pelas perspectivas são apresentadas na Figura 5.4 (a).

Como pode ser observado na Figura 5.5 (b), os defeitos 4 e 8, por exemplo, foram observados por todas as perspectivas. No caso a perspectiva do Teste foi mais efetiva, ou seja, observou uma quantidade maior desses defeitos do que as outras perspectivas. A Figura 5.5 (a) apresenta a identificação dos defeitos onde a perspectiva obteve melhor ou igual desempenho que às outras perspectivas. 


\begin{tabular}{|l|c|c|c|}
\hline \multicolumn{1}{|c|}{ Perspectiva } & Média & Desvio padrão & $\begin{array}{c}\text { Número de } \\
\text { indivíduos }\end{array}$ \\
\hline \hline Projeto & 5,33 & 2,08 & 3 \\
\hline Teste & 4,00 & 0,00 & 3 \\
\hline Uso & 7,00 & - & 1 \\
\hline \hline Média & $\mathbf{5 , 4 4}$ & - & - \\
\hline
\end{tabular}

Tabela 5.15 - Média de defeitos observados por cada indivíduo.

\begin{tabular}{|l|c|c|}
\hline Perspectiva & $\begin{array}{c}\text { Percentual médio de } \\
\text { defeitos encontrados } \\
\text { (do total possível) }\end{array}$ & $\begin{array}{c}\text { Taxa de observação } \\
\text { de defeitos } \\
\text { (horas) }\end{array}$ \\
\hline Projeto & $14,41 \%$ & 5,26 \\
\hline Teste & $10,81 \%$ & 3,44 \\
\hline Uso & $18,92 \%$ & 4,20 \\
\hline Média & $\mathbf{1 4 , 7 1 \%}$ & $\mathbf{4 , 3 0}$ \\
\hline
\end{tabular}

Tabela 5.16 - Percentual médio de defeitos observados (do total possível) e taxa de observação de defeitos.

Conforme mostra a Tabela 5.15 e a Tabela 5.16, o indivíduo da perspectiva do USO, por exemplo, observou na média 7,00 defeitos a uma taxa de observação de 4,30 defeitos por hora. $\mathrm{O}$ percentual médio de defeitos observados (do total possível) foi de 18,92\%. A média de defeitos observados pelos indivíduos foi calculada por meio da divisão entre a somatória das quantidades de defeitos observados por cada indivíduo com cada perspectiva e a quantidade de indivíduos. $\mathrm{O}$ percentual médio de defeitos observados foi calculado por meio da divisão entre a somatória dos percentuais individuais de observação de defeitos ${ }^{7}$ em cada perspectiva e a quantidade de indivíduos. A taxa de observação de defeitos foi calculada por meio da divisão entre a somatória

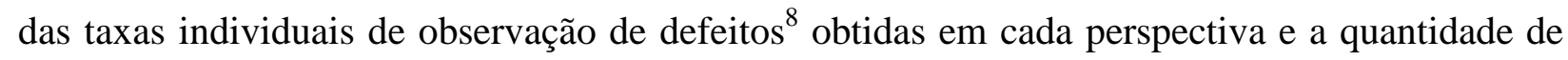
indivíduos.

Em resumo se observou que dos 37 defeitos existentes no documento ATM os indivíduos em grupo conseguiram, combinado os resultados de cada perspectiva, observar 22 defeitos. Isto significa uma efetividade de $59,45 \%$ do total possível.

\footnotetext{
${ }^{7}$ Os percentuais foram calculados a partir da seguinte expressão: $(x \star 100) / y$. Onde $x$ é a quantidade de defeitos observados pelo indivíduo e y é a quantidade de defeitos existente no documento.

${ }^{8}$ As taxas foram calculadas a partir da seguinte expressão: $\mathrm{x} /(\mathrm{y} / 60)$. Onde $\mathrm{x}$ é a quantidade de defeitos observados pelo indivíduo e y é a quantidade de tempo gasto no observação.
} 


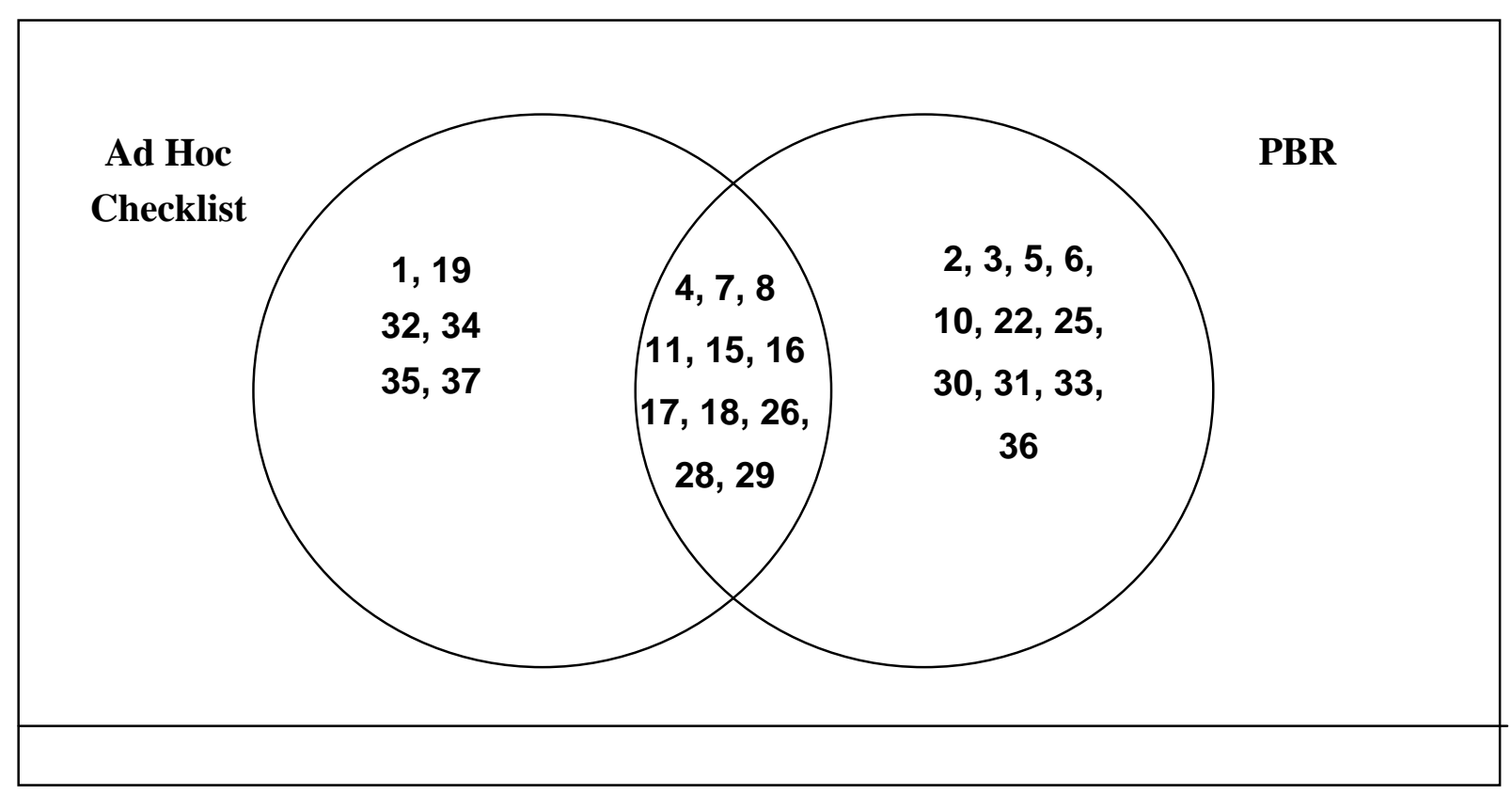

Figura 5.6 - Resumo dos resultados com o documento ATM.

A Figura 5.6 apresenta um resumo dos defeitos observados pela técnica Ad Hoc/Checklist e pela técnica PBR quando aplicadas no documento ATM. A técnica Ad Hoc/Checklist observou 6 defeitos que a técnica PBR não observou. Em contrapartida a técnica PBR observou 11 defeitos que a técnica Ad Hoc/Checklist não observou. Em comum as técnicas observaram 11 defeitos.

\subsubsection{PG - Parking Garage Control System}

A Figura 5.7 apresenta as quantidades de cada defeito que foram observados pela técnica Ad Hoc/Checklist quando aplicada no documento de especificação de requisitos PG (Parking Garage Control System). 


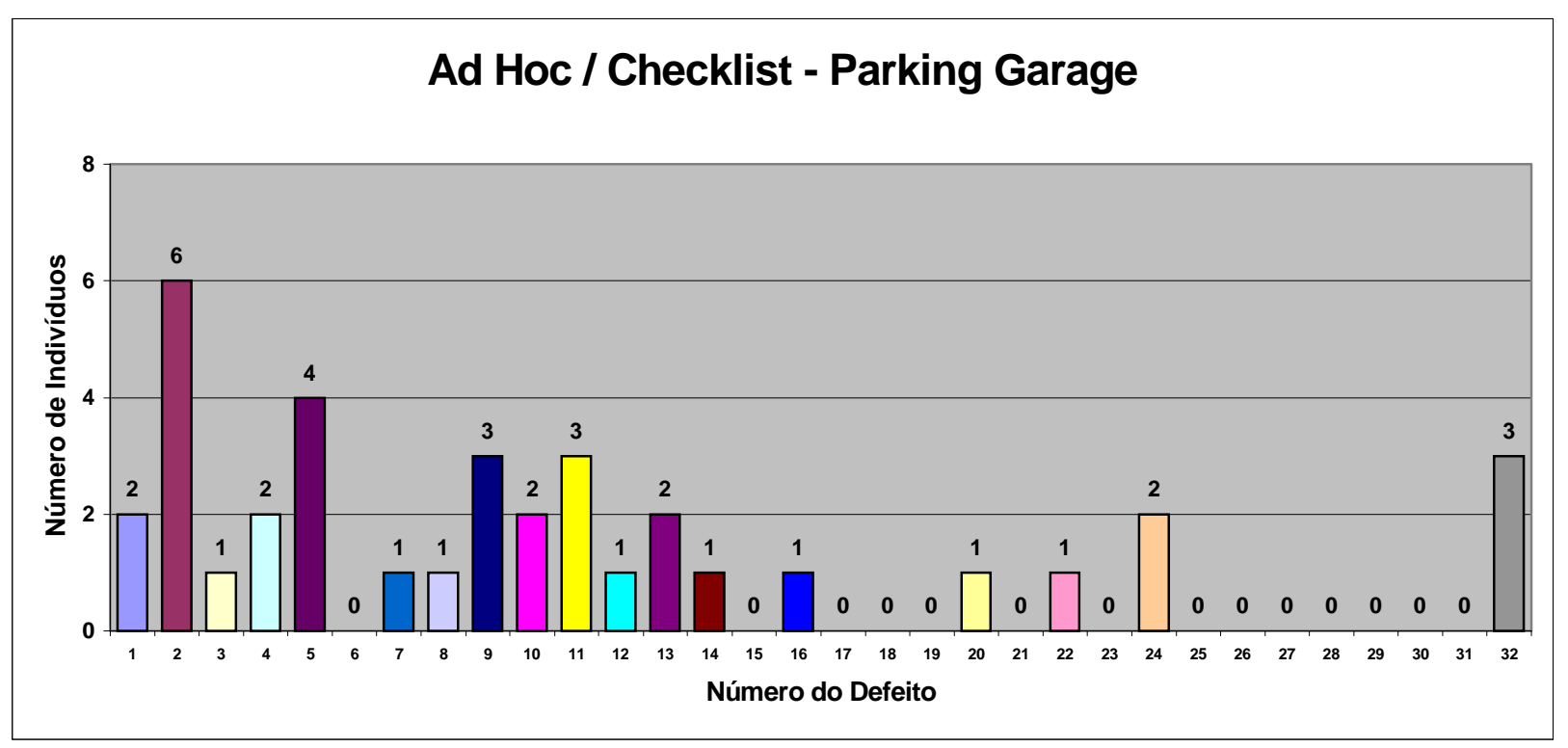

Figura 5.7 - Ad Hoc/Checklist: Defeitos encontrados pela técnicas.

\begin{tabular}{|c|c|c|c|c|c|c|c|}
\hline & \multirow{2}{*}{ Q1 } & \multicolumn{4}{|c|}{ Q2 } & \multirow{2}{*}{ Q3 } & \multirow{2}{*}{ Q4 } \\
\hline & & Gerente & Desenvolvedor & \begin{tabular}{|l|} 
Testador \\
\end{tabular} & Analista & & \\
\hline $\mathrm{S} 1$ & Médio & 0,0 & 5,0 & 3,0 & 2,0 & 2,0 & 2,0 \\
\hline S3 & Médio & 0,0 & 2,0 & 0,1 & 0,2 & 0,3 & 0,3 \\
\hline $\mathrm{S} 4$ & Avançado & 0,0 & 2,0 & 0,2 & 0,0 & 0,3 & 0,2 \\
\hline S6 & Médio & 0,0 & 2,0 & 0,4 & 0,4 & 0,4 & 0,4 \\
\hline $\mathrm{S} 8$ & Avançado & 0,2 & 0,0 & 0,2 & 0,0 & 0,1 & 0,1 \\
\hline S13 & Avançado & 0,0 & 0,3 & 0,1 & 0,1 & 0,3 & 0,1 \\
\hline $\mathrm{S} 15$ & Avançado & 0,0 & 0,0 & 0,0 & 0,0 & 0,0 & 0,0 \\
\hline S16 & - & - & - & - & - & - & - \\
\hline \multirow[t]{2}{*}{ S17 } & - & - & - & - & - & - & - \\
\hline & $\begin{array}{l}\text { Média } \\
\text { (anos) }\end{array}$ & $\mathbf{0 , 0 3}$ & 1,61 & $\mathbf{0 , 5 7}$ & $\mathbf{0 , 3 9}$ & 0,49 & 0,44 \\
\hline
\end{tabular}

Tabela 5.17 - Perfil dos indivíduos que aplicaram a técnica Ad Hoc/Checklist no documento PG.

\begin{tabular}{|c|c|c|}
\hline Técnica & Número máximo & Defeitos observados \\
\hline \hline Ad Hoc / Checklist & 224 & 37 \\
\hline
\end{tabular}

Tabela 5.18 - Número máximo de possibilidades de observação de defeitos e número de defeitos observados pela técnica.

A técnica Ad Hoc/Checklist observou 37 ocorrências de defeitos das 224 possibilidades de observação de defeitos, que é obtida pela razão entre a quantidade de defeitos (32) contidos no documento PG e a quantidade de indivíduos (7) que aplicaram a técnica, conforme pode ser observado na Tabela 5.18. A Tabela 5.17 apresenta o perfil dos indivíduos que aplicaram a 
técnica. Pode-se observar que na média os indivíduos têm maior experiência com atividades de desenvolvimento.

\begin{tabular}{|c|c|c|c|c|}
\hline & \multicolumn{3}{|c|}{ Documento: PG } \\
\hline & & $\begin{array}{c}\text { Quantidade de } \\
\text { defeitos } \\
\text { originais }\end{array}$ & $\begin{array}{l}\text { Quantidade } \\
\text { de defeitos } \\
\text { observados }\end{array}$ & $\%$ \\
\hline \multirow[t]{2}{*}{ Classe } & Commission & 17 & 21 & $13,73 \%$ \\
\hline & Omission & 15 & 16 & $11,85 \%$ \\
\hline \multirow[t]{6}{*}{ Tipo } & Ambiguous Information & 5 & 6 & $13,33 \%$ \\
\hline & Extraneous Information & 1 & 1 & $11,11 \%$ \\
\hline & Inconsistent Information & 9 & 11 & $13,58 \%$ \\
\hline & Incorrect Fact & 2 & 8 & $44,44 \%$ \\
\hline & Miscellaneous Defeito & 4 & 0 & $0,00 \%$ \\
\hline & Missing Information & 11 & 11 & $11,11 \%$ \\
\hline
\end{tabular}

Tabela 5.19 - Quantidade e percentual (do total possível) de defeitos observados por classe e tipo utilizando as técnicas Ad Hoc / Checklist.

A Tabela 5.19 apresenta um resumo geral dos percentuais de defeitos observados pela técnica organizados por classes e tipos de defeitos. A técnica foi mais efetiva na observação de defeitos da classe Commission e do tipo Incorrect Fact.

\begin{tabular}{|c|c|c|c|}
\hline Técnica & Média & Desvio padrão & $\begin{array}{c}\text { Número de } \\
\text { indivíduos }\end{array}$ \\
\hline \hline Ad Hoc / Checklist & 5,29 & 2,75 & 7 \\
\hline
\end{tabular}

Tabela 5.20 - Média de defeitos observados por cada indivíduo.

\begin{tabular}{|c|c|c|}
\hline Técnica & $\begin{array}{c}\text { Percentual médio de } \\
\text { defeitos encontrados } \\
\text { (do total possível) }\end{array}$ & $\begin{array}{c}\text { Taxa de observação } \\
\text { de defeitos } \\
\text { (horas) }\end{array}$ \\
\hline Ad Hoc / Checklist & $16,52 \%$ & 3,78 \\
\hline
\end{tabular}

Tabela 5.21 - Percentual médio de defeitos observados (do total possível) e taxa de observação de defeitos.

Conforme mostra a Tabela 5.20 e a Tabela 5.21, os indivíduos observaram na média 5,29 defeitos a uma taxa de observação de 3,78 defeitos por hora. O percentual médio de defeitos observados (do total possível) foi de 16,52\%. A média de defeitos observados pelos indivíduos foi calculada por meio da divisão entre a somatória das quantidades de defeitos observados por cada indivíduo e a quantidade de indivíduos. O percentual médio de defeitos observados foi calculado por meio da divisão entre a somatória dos percentuais individuais de observação de 
defeitos $^{9}$ e a quantidade de indivíduos. A taxa de observação de defeitos foi calculada por meio da divisão entre a somatória das taxas individuais de observação de defeitos ${ }^{10}$ e a quantidade de indivíduos.

Em resumo se observou que dos 32 defeitos existentes no documento PG os indivíduos conseguiram observar 18 defeitos, o que significa uma efetividade de 56,25\% do total possível.

A Figura 5.8 apresenta as quantidades de cada defeito que foram observados pelas perspectivas da técnica Perspective Based Reading (PBR) quando aplicadas no documento de especificação de requisitos PG (Parking Garage Control System).

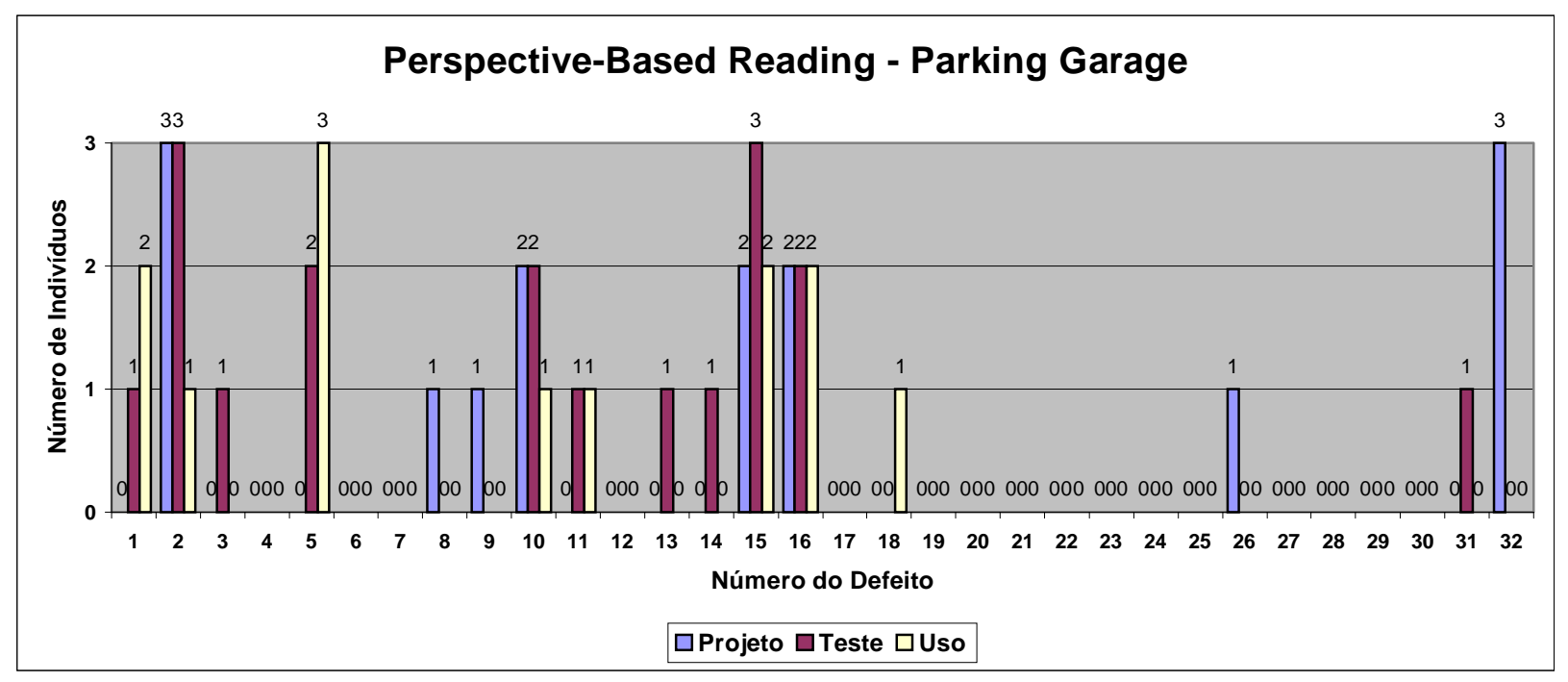

Figura 5.8 - PBR: Defeitos encontrados pela técnica.

\begin{tabular}{|c|c|c|c|c|c|c|c|}
\hline & \multirow{2}{*}{ Q1 } & \multicolumn{4}{|c|}{$\mathbf{Q 2}$} & \multirow{2}{*}{ Q3 } & \multirow{2}{*}{ Q4 } \\
\hline & & Gerente & Desenvolvedor & Testador & Analista & & \\
\hline S9 & Expert & 0,0 & 0,3 & 0,1 & 0,2 & 0,3 & 0,3 \\
\hline S10 & Avançado & 0,0 & 3,0 & 0,3 & 0,2 & 0,3 & 0,1 \\
\hline \multirow[t]{2}{*}{ S12 } & Avançado & 1,0 & 1,0 & 0,1 & 0,5 & 0,5 & 0,3 \\
\hline & $\begin{array}{l}\text { Média } \\
\text { (anos) }\end{array}$ & $\mathbf{0 , 3 3}$ & 1,43 & $\mathbf{0 , 1 7}$ & $\mathbf{0 , 3 0}$ & $\mathbf{0 , 3 7}$ & 0,23 \\
\hline
\end{tabular}

Tabela 5.22 - Perfil dos indivíduos que aplicaram a técnica PBR (perspectiva do projeto) no documento $P G$.

\footnotetext{
${ }^{9}$ Os percentuais foram calculados a partir da seguinte expressão: $(x \star 100) / y$. Onde x é a quantidade de defeitos observados pelo indivíduo e y é a quantidade de defeitos existente no documento.

${ }^{10}$ As taxas foram calculadas a partir da seguinte expressão: $\mathrm{x} /(\mathrm{y} / 60)$. Onde $\mathrm{x}$ é a quantidade de defeitos observados pelo indivíduo e y é a quantidade de tempo gasto na observação.
} 


\begin{tabular}{|c|c|c|c|c|c|c|c|}
\hline & \multirow{2}{*}{ Q1 } & \multicolumn{4}{|c|}{ Q2 } & \multirow{2}{*}{ Q3 } & \multirow{2}{*}{ Q4 } \\
\hline & & Gerente & Desenvolvedor & Testador & Analista & & \\
\hline $\mathrm{S} 7$ & Avançado & 0,0 & 2,0 & 0,3 & 0,3 & 0,3 & 0,0 \\
\hline S14 & Médio & 0,0 & 0,3 & 0,1 & 0,2 & 0,3 & 0,1 \\
\hline \multirow[t]{2}{*}{ S18 } & Avançado & 0,0 & 0,0 & 0,0 & 0,0 & 0,5 & 0,5 \\
\hline & $\begin{array}{l}\text { Média } \\
\text { (anos) }\end{array}$ & $\mathbf{0 , 0 0}$ & 0,77 & $\mathbf{0 , 1 3}$ & $\mathbf{0 , 1 7}$ & $\mathbf{0 , 3 7}$ & $\mathbf{0 , 2 0}$ \\
\hline
\end{tabular}

Tabela 5.23 - Perfil dos indivíduos que aplicaram a técnica PBR (perspectiva do teste) no documento $P G$.

\begin{tabular}{|c|c|c|c|c|c|c|c|}
\cline { 3 - 8 } \multicolumn{1}{c|}{} & \multirow{2}{*}{ Q1 } & \multicolumn{4}{c|}{ Q2 } & \multirow{2}{*}{ Q3 } & \multirow{2}{*}{ Q4 } \\
\cline { 2 - 8 } & Gerente & Desenvolvedor & Testador & Analista & 0,3 & 0,3 \\
\hline S2 & Médio & 0,0 & 2,0 & 0,1 & 0,3 & 0,3 & 0,5 \\
\hline S5 & Médio & 0,0 & 2,0 & 0,1 & 0,0 & 0,5 & 0,5 \\
\hline S11 & Avançado & 0,0 & 2,0 & 0,1 & 0,5 & 0,5 & 0,5 \\
& $\begin{array}{c}\text { Média } \\
\text { (anos) }\end{array}$ & $\mathbf{0 , 0 0}$ & $\mathbf{2 , 0 0}$ & $\mathbf{0 , 1 0}$ & $\mathbf{0 , 2 7}$ & $\mathbf{0 , 4 3}$ & $\mathbf{0 , 4 3}$ \\
\hline
\end{tabular}

Tabela 5.24 - Perfil dos indivíduos que aplicaram a técnica PBR (perspectiva do uso) no documento PG.

\begin{tabular}{|l|c|c|}
\hline \multicolumn{1}{|c|}{ Perspectiva } & Número máximo & Defeitos encontrados \\
\hline \hline Projeto & 96 & 15 \\
\hline Teste & 96 & 18 \\
\hline Uso & 96 & 13 \\
\hline \hline Total & $\mathbf{2 8 8}$ & $\mathbf{4 6}$ \\
\hline
\end{tabular}

Tabela 5.25 - Número máximo de possibilidades de observação de defeitos e número de defeitos observados pela técnica.

Conforme pode ser observado na Tabela 5.25, a perspectiva do Teste observou um número maior de ocorrências de defeitos que as outras perspectivas. Das 96 possibilidades de observação de defeitos, obtida pela razão entre a quantidade de defeitos (32) contidos no documento PG e a quantidade de indivíduos (3) que aplicaram a perspectiva, 18 foram observados. As experiências dos indivíduos não tiveram influência nos resultados obtidos pelos indivíduos da perspectiva do Teste, uma vez que as médias de experiência são as menores entre as 3 perspectivas, conforme pode ser observado na Tabela 5.23. A Tabela 5.22 e a Tabela 5.24 apresentam as experiências dos indivíduos que aplicaram as perspectivas do Projeto e do Uso. 
A Tabela 5.26 apresenta um resumo geral dos percentuais de defeitos observados pelas perspectivas da técnica PBR organizados por classes e tipos de defeitos. A perspectiva do Projeto foi igualmente efetiva na observação de defeitos das classes Omission e Commission, e defeitos do tipo Incorrect Fact. A perspectiva do Teste foi mais efetiva na observação de defeitos da classe Commission e defeitos do tipo Incorrect Fact. A perspectiva do Uso foi mais efetiva na observação de defeitos da classe Omission e defeitos do tipos Incorrect Fact. Na média as perspectivas foram mais efetivas na observação de defeitos da classe Omission e do tipo Incorrect Fact.

\begin{tabular}{|c|c|c|c|c|c|c|c|c|c|c|}
\hline & \multicolumn{9}{|c|}{ Documento: PG } \\
\hline & & $\mid \begin{array}{c}\text { Quantidade } \\
\text { de defeitos } \\
\text { originais }\end{array}$ & $\begin{array}{l}\text { Quantidade } \\
\text { de defeitos } \\
\text { observados } \\
\text { PROJETO }\end{array}$ & $\%$ & $\begin{array}{l}\text { Quantidade } \\
\text { de defeitos } \\
\text { observados } \\
\text { TESTE }\end{array}$ & $\%$ & $\begin{array}{l}\text { Quantidade } \\
\text { de defeitos } \\
\text { observados } \\
\text { USO }\end{array}$ & $\%$ & $\mid \begin{array}{c}\text { Total geral } \\
\text { defeitos } \\
\text { observados }\end{array}$ & Média \\
\hline \multirow{2}{*}{ Classe } & Commission & 17 & 8 & $15,69 \%$ & 10 & $19,61 \%$ & 6 & $11,76 \%$ & 24 & $15,69 \%$ \\
\hline & Omission & 15 & 7 & $15,56 \%$ & 8 & $17,78 \%$ & 7 & $15,56 \%$ & 22 & $16,30 \%$ \\
\hline \multirow[t]{3}{*}{ Tipo } & $\begin{array}{l}\text { Ambiguous } \\
\text { Information }\end{array}$ & 5 & 5 & $33,33 \%$ & 3 & $20,00 \%$ & 2 & $13,33 \%$ & 10 & $22,22 \%$ \\
\hline & $\begin{array}{l}\text { Extraneous } \\
\text { Information }\end{array}$ & 1 & 0 & $0,00 \%$ & 0 & $0,00 \%$ & 0 & $0,00 \%$ & $\mathbf{0}$ & $0,00 \%$ \\
\hline & $\begin{array}{l}\text { Inconsistent } \\
\text { Information }\end{array}$ & 10 & 0 & $0,00 \%$ & 4 & $14,81 \%$ & 3 & $11,11 \%$ & 7 & $8,64 \%$ \\
\hline & $\begin{array}{l}\text { Incorrect } \\
\text { Fact }\end{array}$ & 2 & 5 & $83,33 \%$ & 5 & $83,33 \%$ & 2 & $33,33 \%$ & 12 & $66,67 \%$ \\
\hline & $\begin{array}{l}\text { Miscellaneo } \\
\text { us Defeito }\end{array}$ & 3 & 0 & $0,00 \%$ & 0 & $0,00 \%$ & 0 & $0,00 \%$ & $\mathbf{0}$ & $0,00 \%$ \\
\hline & $\begin{array}{l}\text { Missing } \\
\text { Information }\end{array}$ & 11 & 5 & $15,15 \%$ & 6 & $18,18 \%$ & 5 & $15,15 \%$ & 16 & $16,16 \%$ \\
\hline
\end{tabular}

Tabela 5.26 - Quantidade e percentual (do total possível) de defeitos observados por tipos e classes utilizando a técnica PBR.

A seguir, apresentam-se três diferentes visões dos dados apresentados na Figura 5.8: 
Visão 1 - Efetividade das perspectivas por grupo de indivíduos

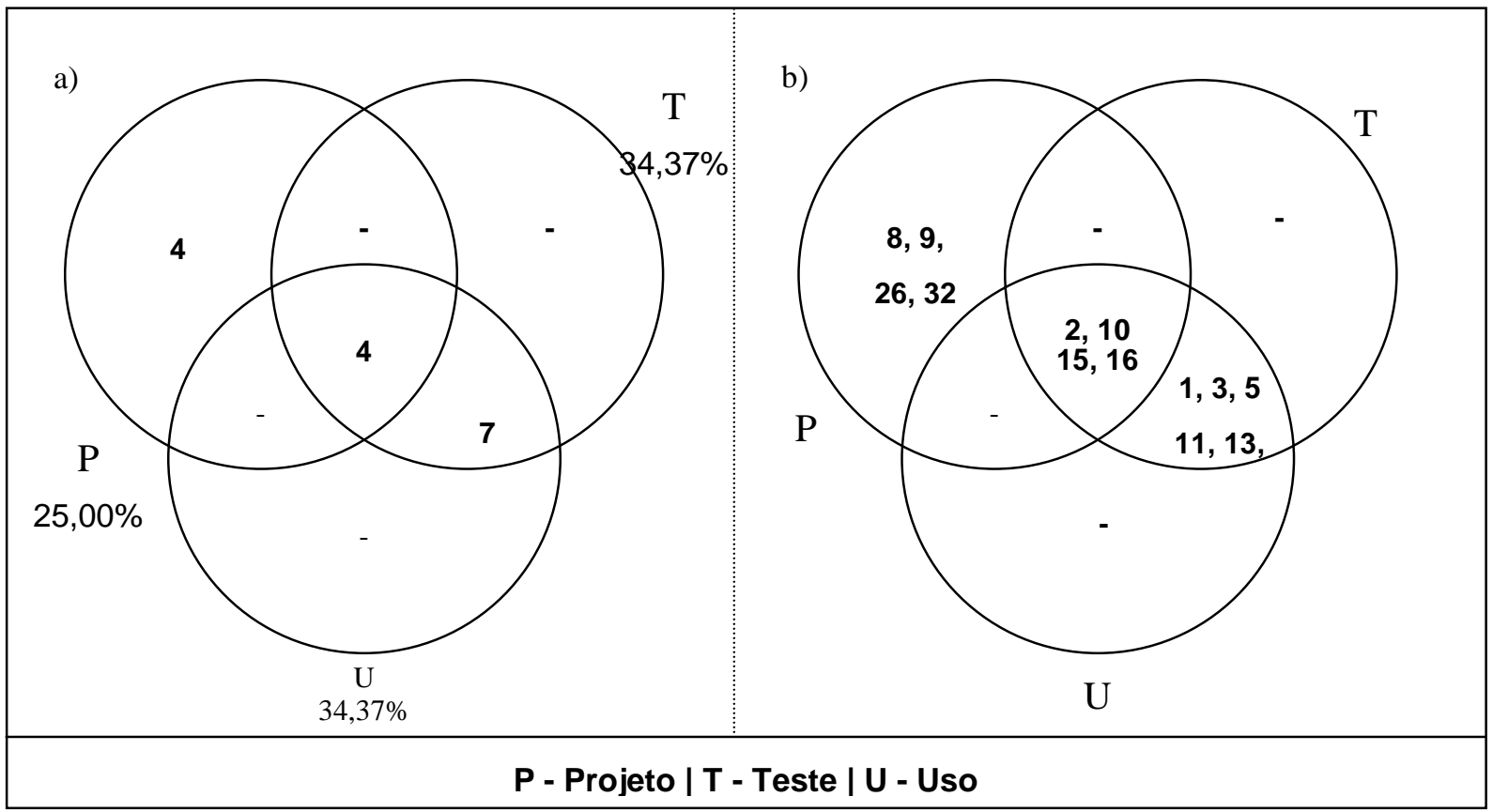

Figura 5.9 - (a) Quantidade e percentual de defeitos observados pelas perspectivas; (b) Identificação dos defeitos observados pelas perspectivas.

Visão 2 - Efetividade das perspectivas por número de ocorrências de defeitos

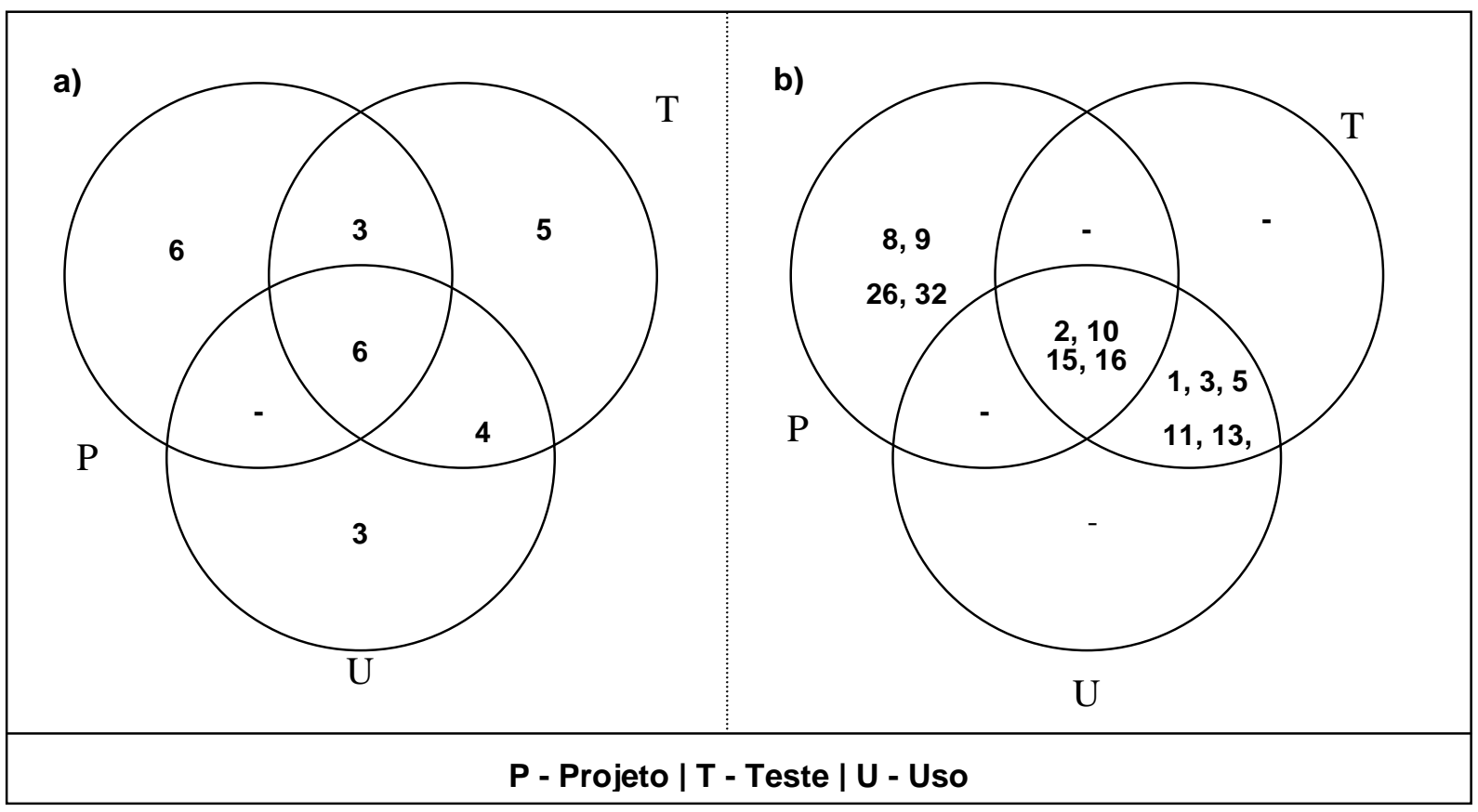

Figura 5.10 - (a) Número de ocorrências de defeitos observados pelas perspectivas; (b) Identificação dos defeitos observados pelas perspectivas. 
Visão 3 - Identificação da melhor perspectiva por defeito

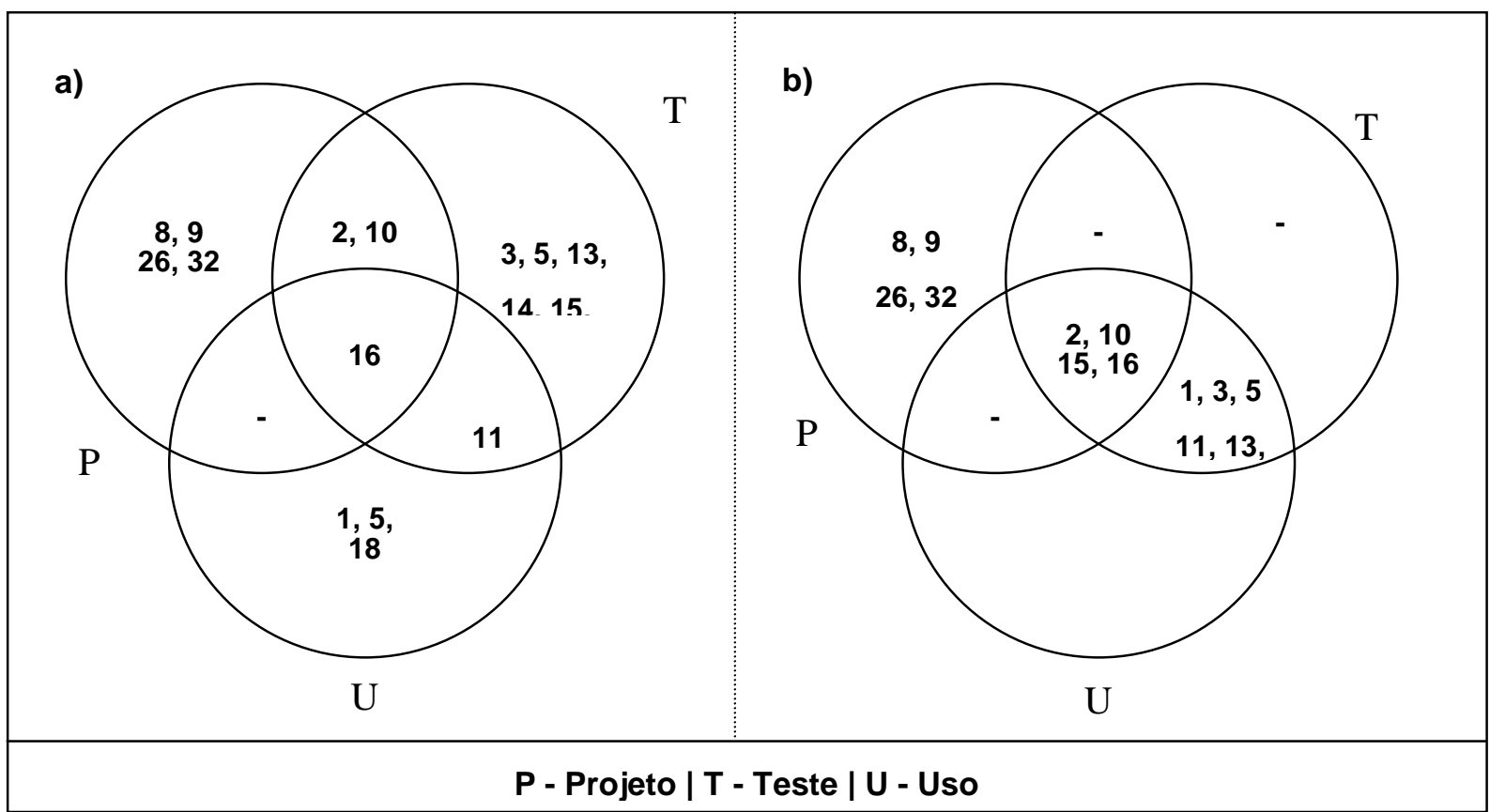

Figura 5.11 - (a) Identificação dos defeitos onde as perspectivas obtiveram um melhor ou igual performance com relação as outras perspectivas; (b) Identificação dos defeitos observados pelas perspectivas.

Como pode ser observado na Figura 5.9 (a), a perspectiva do Teste e do Uso observaram: 7 defeitos que a perspectiva do Projeto não observou, são eles: 1, 3, 5, 11 e 13 (ver Figura 5.9 (b)); 4 defeitos que também foram observados pela perspectiva do Projeto, são eles: 2, 10, 15 e 16. As perspectivas do Teste e do Uso obtiveram uma efetividade de $34,37 \%$, ou seja, dos 32 defeitos existentes no documento PG 11 foram observados.

Como pode ser observado na Figura 5.10 (b), o defeito 15 foi observado por todas as perspectivas mas, foi observado mais vezes pela perspectiva do Teste do que pelas outras perspectivas. As quantidades totalizadas de ocorrências de defeitos observados pelas perspectivas são apresentadas na Figura 5.10 (a).

Como pode ser observado na Figura 5.11 (b), os defeitos 2 e 10, por exemplo, foram observados por todas as perspectivas. No caso, as perspectivas do Projeto e do Teste foram igualmente efetivas, ou seja, observaram uma quantidade maior desses defeitos do que a perspectiva do Uso. A Figura 5.11 (a) apresenta a identificação dos defeitos onde a perspectiva obteve melhor ou igual desempenho que às outras perspectivas. 


\begin{tabular}{|l|c|c|c|}
\hline \multicolumn{1}{|c|}{ Perspectiva } & Média & Desvio padrão & $\begin{array}{c}\text { Número de } \\
\text { indivíduos }\end{array}$ \\
\hline Projeto & 5,00 & 1,73 & 3 \\
\hline Teste & 6,00 & 1,00 & 3 \\
\hline Uso & 4,33 & 1,53 & 3 \\
\hline Média & $\mathbf{5 , 1 1}$ & - & - \\
\hline
\end{tabular}

Tabela 5.27 - Média de defeitos encontrados por cada indivíduo.

\begin{tabular}{|l|c|c|}
\hline Perspectiva & $\begin{array}{c}\text { Percentual médio de } \\
\text { defeitos encontrados } \\
\text { (do total possível) }\end{array}$ & $\begin{array}{c}\text { Taxa de observação } \\
\text { de defeitos } \\
\text { (horas) }\end{array}$ \\
\hline Projeto & $15,63 \%$ & 4,95 \\
\hline Teste & $18,75 \%$ & 4,70 \\
\hline Uso & $13,54 \%$ & 3,11 \\
\hline Média & $\mathbf{1 5 , 9 7 \%}$ & $\mathbf{4 , 2 5}$ \\
\hline
\end{tabular}

Tabela 5.28 - Percentual médio de defeitos encontrados (do total possível) e taxa de observação de defeitos.

Conforme mostra a Tabela 5.27 e a Tabela 5.28, o indivíduo da perspectiva do TESTE, por exemplo, observou na média 6,00 defeitos a uma taxa de observação de 4,70 defeitos por hora. O percentual médio de defeitos observados (do total possível) foi de 18,75\%. A média de defeitos observados pelos indivíduos foi calculada por meio da divisão entre a somatória das quantidades de defeitos observados por cada indivíduo com cada perspectiva e a quantidade de indivíduos. O percentual médio de defeitos observados foi calculado por meio da divisão entre a somatória dos percentuais individuais de observação de defeitos ${ }^{11}$ em cada perspectiva e a quantidade de indivíduos. A taxa de observação de defeitos foi calculada por meio da divisão entre a somatória das taxas individuais de observação de defeitos ${ }^{12}$ obtidas em cada perspectiva e a quantidade de indivíduos.

Em resumo se observou que dos 32 defeitos existentes no documento PG os indivíduos em grupo conseguiram, combinado os resultados de cada perspectiva, observar 16 defeitos. Isto significa uma efetividade de 50,00\% do total possível.

\footnotetext{
${ }^{11}$ Os percentuais foram calculados a partir da seguinte expressão: $\left(x^{\star} 100\right) / y$. Onde $x$ é a quantidade de defeitos observados pelo indivíduo e y é a quantidade de defeitos existente no documento.

12 As taxas foram calculadas a partir da seguinte expressão: $\mathrm{x} /(\mathrm{y} / 60)$. Onde $\mathrm{x}$ é a quantidade de defeitos observados pelo indivíduo e y é a quantidade de tempo gasto na observação.
} 


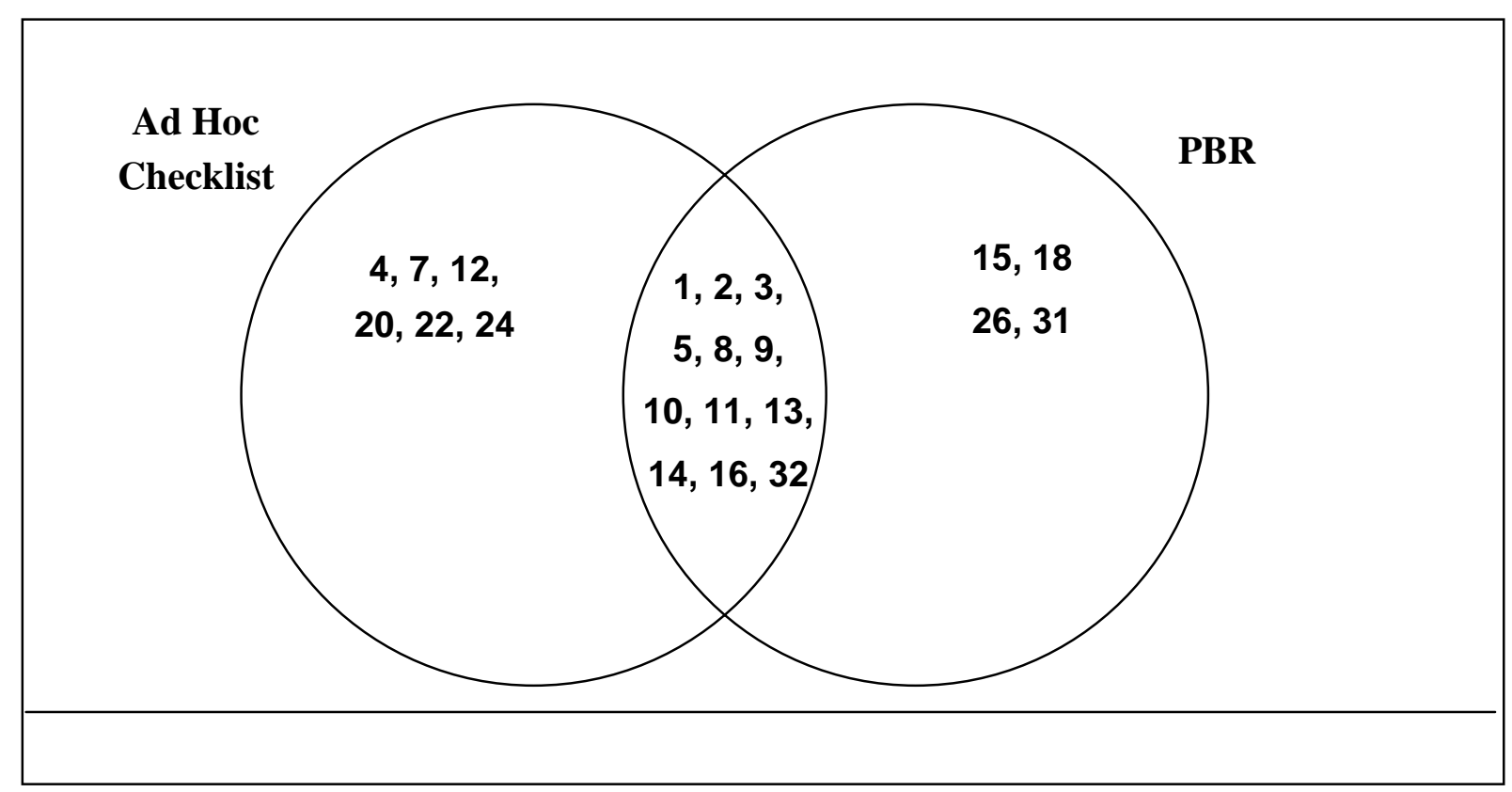

Figura 5.12 - Resumo dos resultados com o documento PG.

A Figura 5.12 apresenta um resumo dos defeitos observados pela técnica Ad Hoc/Checklist e pela técnica PBR quando aplicadas no documento PG. A técnica Ad Hoc/Checklist observou 6 defeitos que a técnica PBR não observou. Em contrapartida a técnica PBR observou 4 defeitos que a técnica Ad Hoc/Checklist não observou. Em comum as técnicas observaram 12 defeitos.

\section{ATM - Automatic Teller Machine e PG - Parking Garage Control System}

A Figura 5.13, a Figura 5.14, a Figura 5.15 e a Figura 5.16 apresentam os percentuais médios de defeitos observados por cada indivíduo em cada documento. No documento ATM os indivíduos 02 e 12 obtiveram os melhores percentuais médios com a técnica Ad Hoc/Checklist (Figura 5.13) enquanto que os indivíduos 01 e 13 obtiveram os melhores percentuais médios com a técnica PBR (Figura 5.14). Os indivíduos 02, 12 e 13 não têm experiência significativa quando comparados com outros indivíduos do grupo. Em contrapartida, o indivíduo 01 é o mais experiente do grupo que aplicou PBR no documento ATM. No documento PG o indivíduo 01 obteve o melhor percentual médio com a técnica Ad Hoc/Checklist enquanto que o indivíduo 07 obteve o melhor percentual médio com a técnica PBR. O indivíduo 01 é o mais experiente do grupo que aplicou Ad Hoc/Checklist e o indivíduo 07 não tem experiência significativa quando comparado com outros indivíduos que aplicaram a técnica PBR no documento PG. 


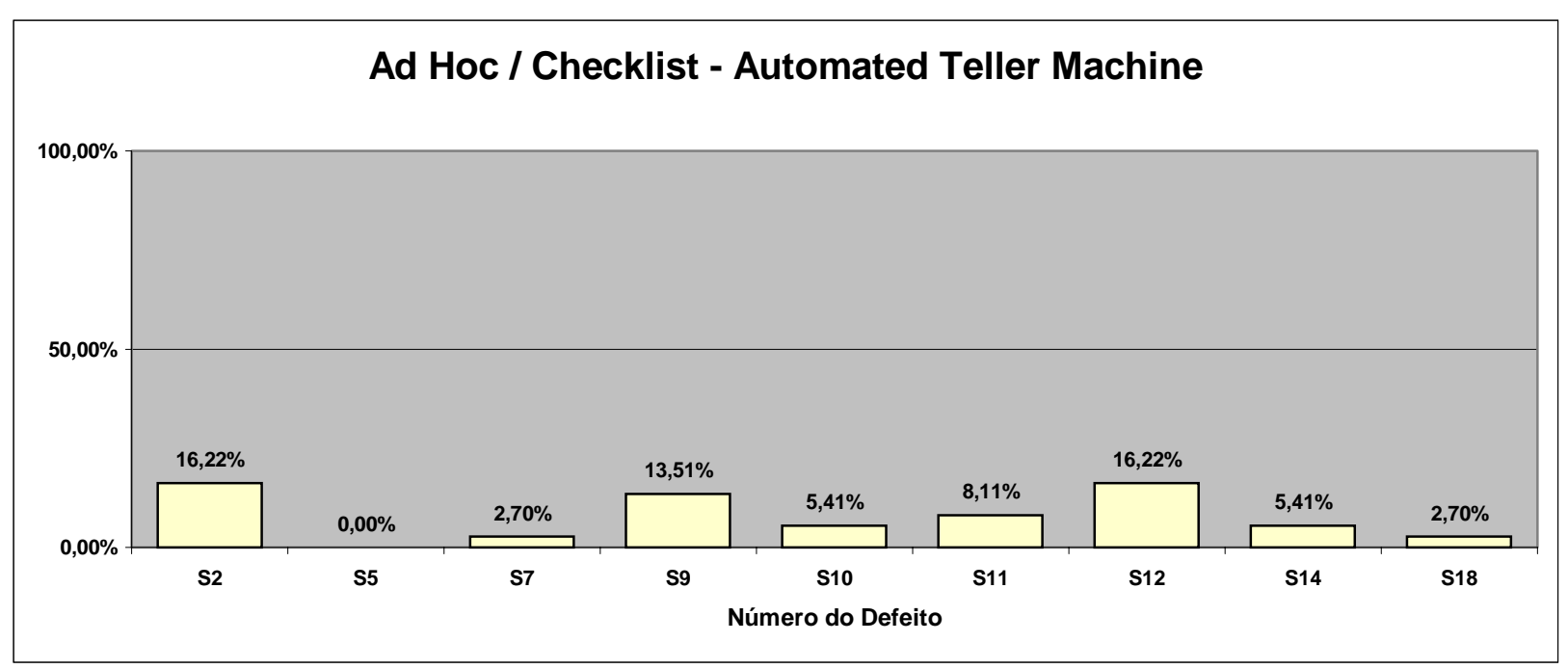

Figura 5.13 - Percentual (do total possível) de defeitos observados pelos indivíduos com Ad Hoc / Checklist no documento ATM.

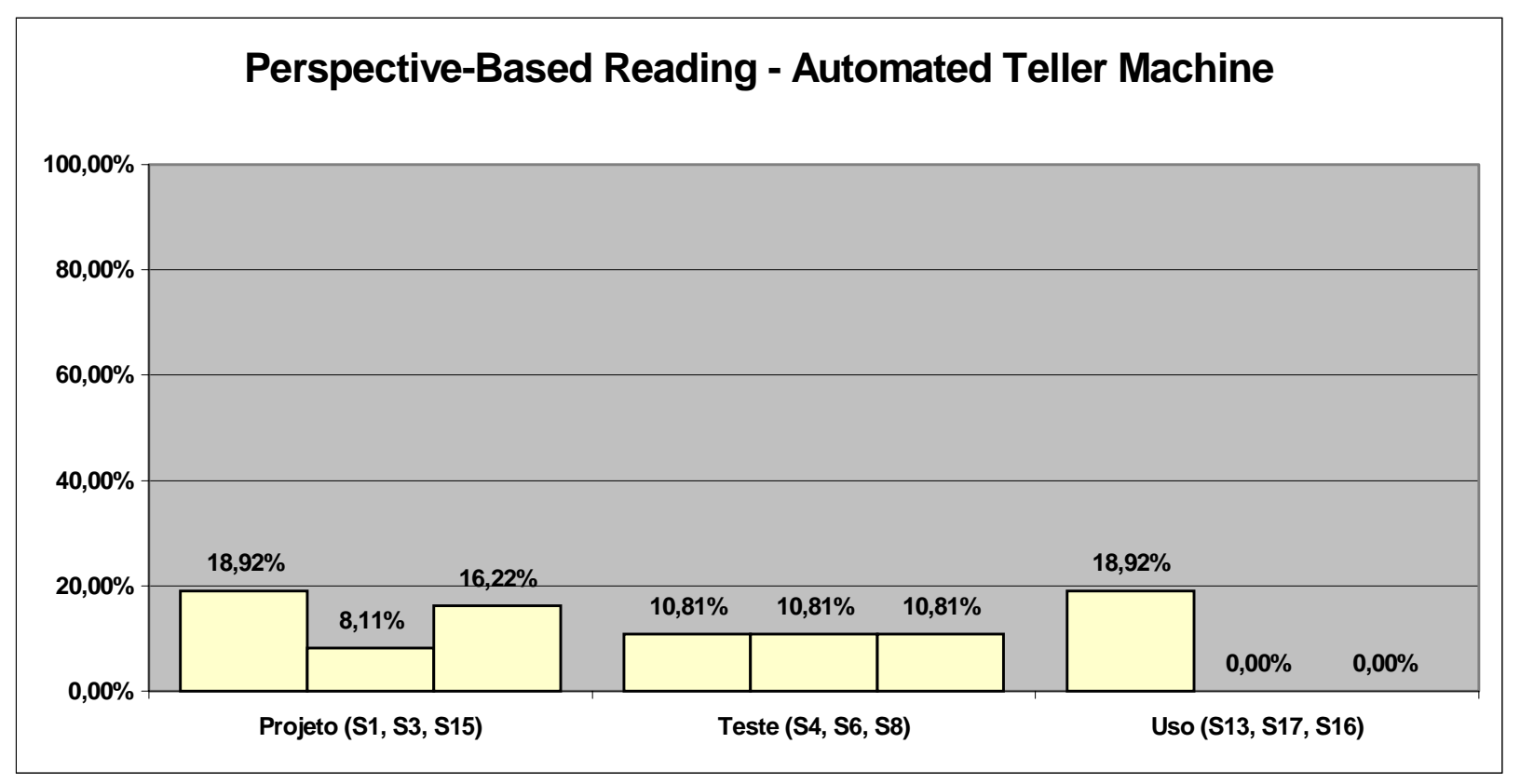

Figura 5.14 - Percentual (do total possível) de defeitos observados pelos indivíduos com PBR no documento ATM. 


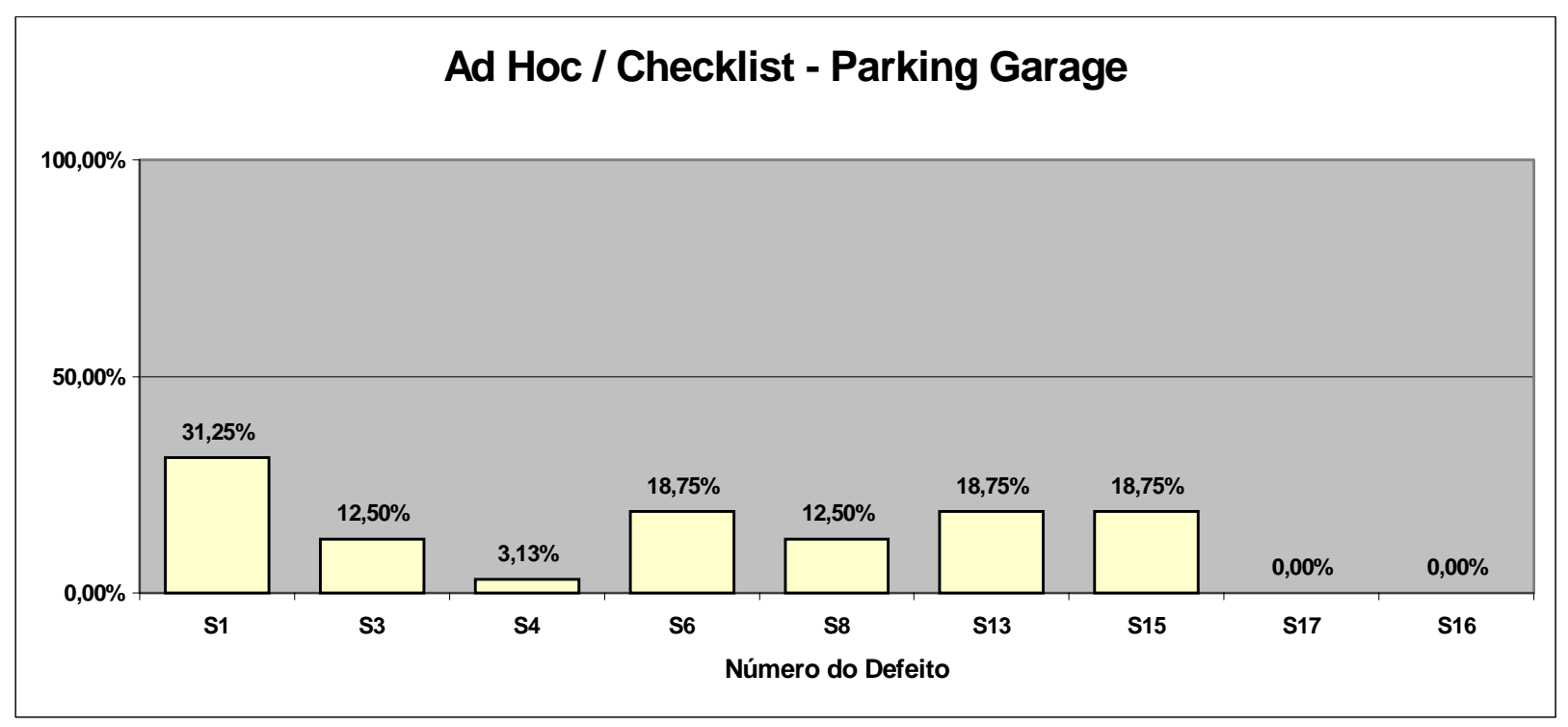

Figura 5.15 - Percentual (do total possível) de defeitos observados pelos indivíduos com Ad Hoc / Checklist no documento PG.

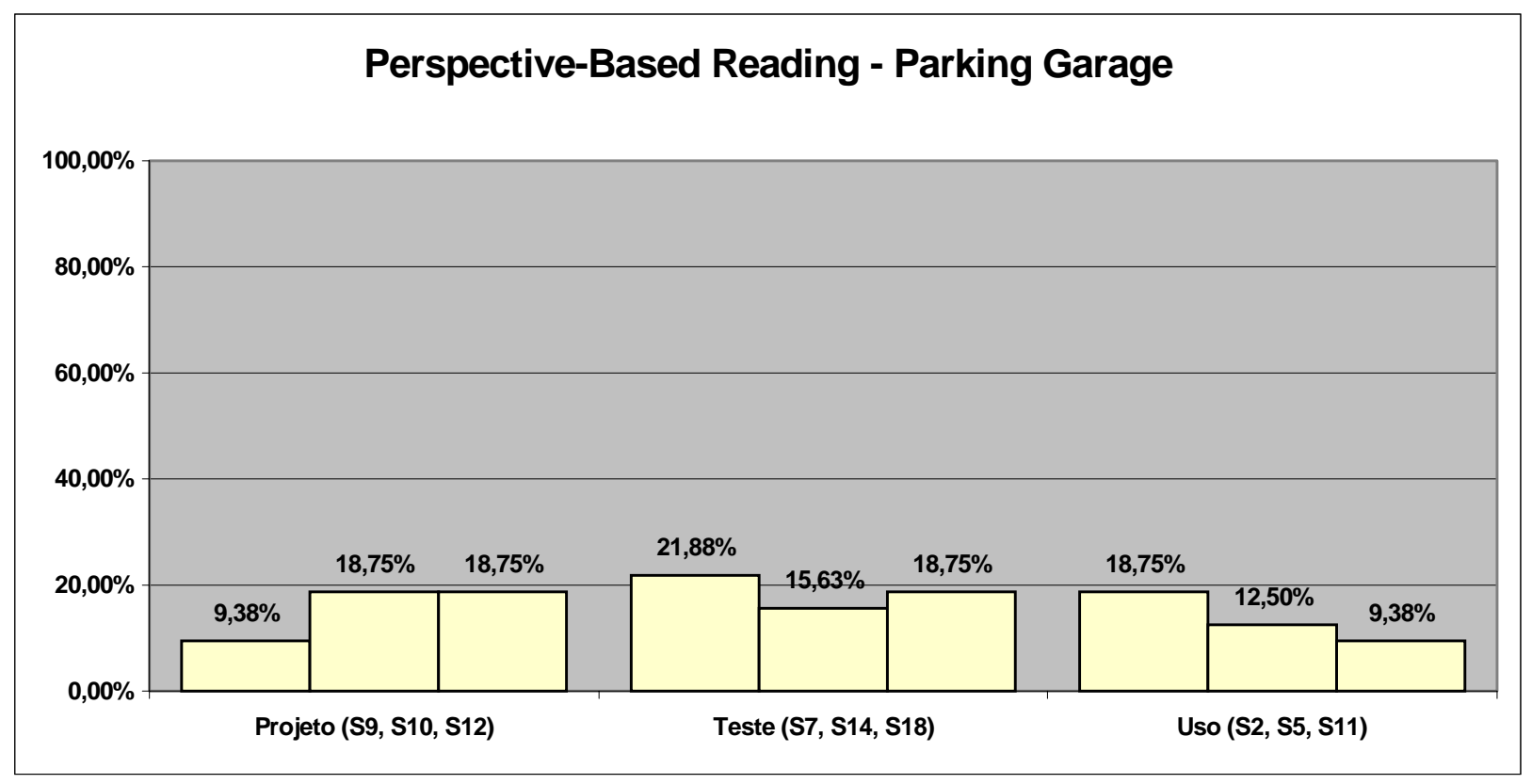

Figura 5.16 - Percentual (do total possível) de defeitos observados pelos indivíduos com PBR no documento PG. 


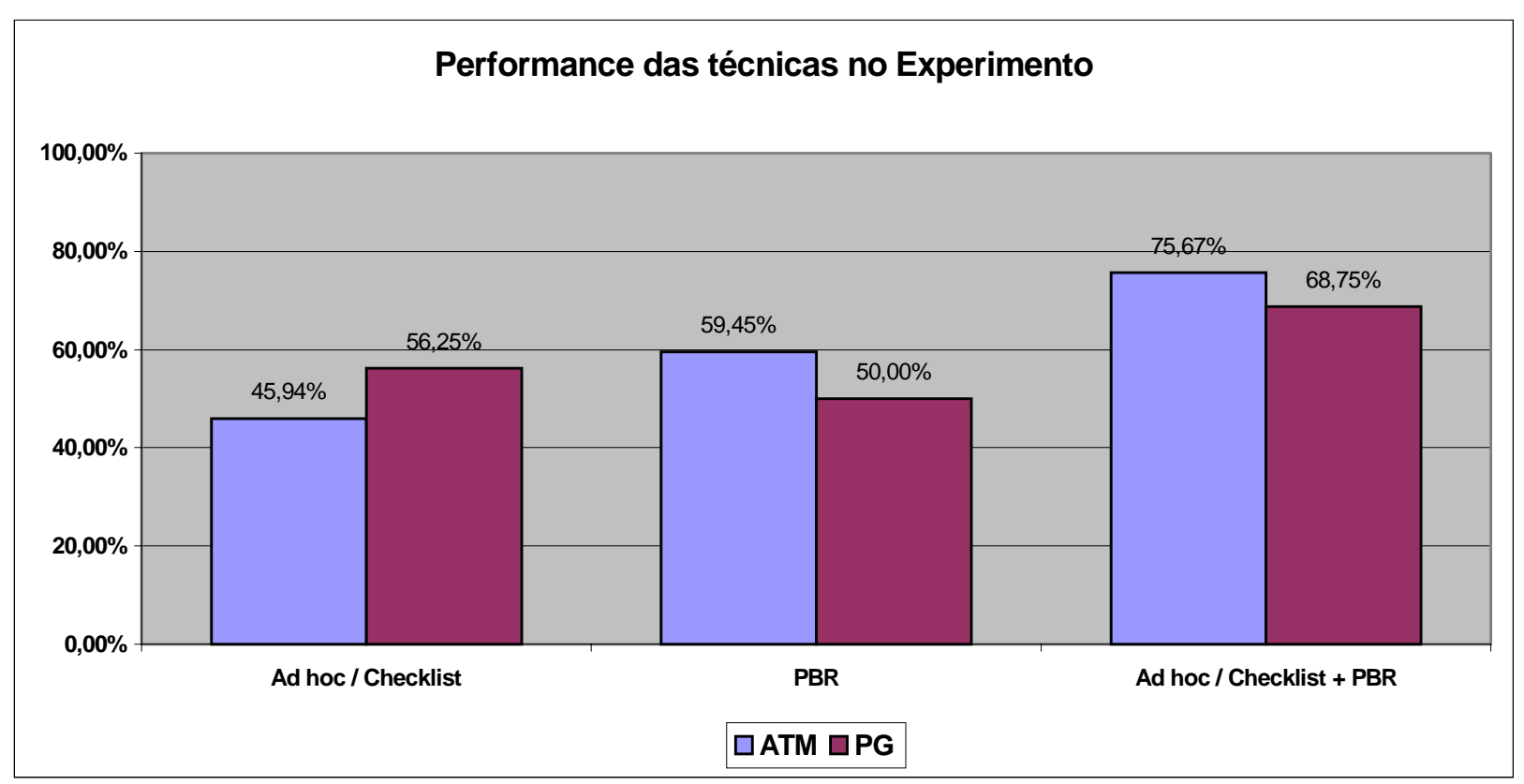

Figura 5.17 - Performance obtida por cada Técnica e pelos pares combinados de Técnicas.

\begin{tabular}{|l|c|c|}
\cline { 2 - 3 } \multicolumn{1}{c|}{} & ATM & PG \\
\hline Ad Hoc / Checklist & $45,94 \%$ & $56,25 \%$ \\
\hline PBR & $59,45 \%$ & $50,00 \%$ \\
\hline Ad Hoc / Checklist + PBR & $75,67 \%$ & $68,75 \%$ \\
\hline
\end{tabular}

Tabela 5.29 - Performance obtida por cada Técnica e pelos pares combinados de Técnicas.

A Figura 5.17 Tabela 5.29 apresentam a performance geral de cada técnica em cada fase do experimento, ou seja, para cada documento. No caso do documento ATM, por exemplo, a técnica PBR obteve melhor performance que a técnica Ad Hoc/Checklist. De um total de 37 defeitos 22 foram observados. Com o objetivo de explorar os aspectos complementares das técnicas foi realizada uma combinação, por meio de simulação, dos resultados obtidos por ambas as técnicas. O resultado combinado foi $16,22 \%$ maior que o melhor resultado alcançado individualmente pela técnica PBR. Este percentual significa 6 defeitos a mais do 22 defeitos observado pela técnica PBR.

\subsection{Comparando os Resultados}

Esta seção tem como principal objetivo comparar os resultados obtidos nesta replicação do experimento com os resultados obtidos por Basili et. al. [BAS96a], que investigaram os efeitos da técnica Perspectiva Based Reading (PBR) em grupos de inspeção e indivíduos 
isoladamente, bem como, o desempenho de cada perspectiva. Comparando os resultados observou-se que:

- As taxas médias de detecção de defeitos alcançadas por cada técnica pelos grupos de inspeção são similares. Com PBR foi obtida uma taxa de 54.72\% (do total possível) e com as técnicas convencionais (Ad hoc e Checklist) uma taxa de $51.09 \%$ (do total possível);

- Indivíduos que aplicaram a técnica PBR tiveram um desempenho melhor que os indivíduos que aplicaram as técnicas convencionais. A taxa média de detecção de defeitos (do total possível) obtida pelos indivíduos aplicando a técnica PBR foi de 13,24\% contra 10,32\% dos indivíduos aplicando Ad Hoc e Checklist;

- Cada perspectiva descobriu um conjunto de defeitos que outras perspectivas não descobriram. Em média foram detectados 18 defeitos considerando ambos os documentos, sendo $34,21 \%$ detectados somente pela perspectiva do projeto, por exemplo.

\subsection{Considerações Finais}

Neste capítulo foi apresentada a replicação do experimento baseado em documentos de especificação de requisitos, bem como, as técnicas utilizadas, programas utilizados, procedimentos de treinamento e execução.

$\mathrm{Na}$ sequiência foram apresentados os resultados obtidos durante a replicação do experimento organizados em duas subseções: análise dos defeitos para o documento ATM e análise dos defeitos para o documento PG. Posteriormente foram apresentadas as análises gerais contemplando os dois documentos. Finalmente, um comparativo entre os resultados obtidos nesta replicação e os resultados obtidos no experimento de Basili et. al. [BAS96a] foi apresentado.

Pode-se observar que a técnica Perspective Based Reading (PBR) foi mais efetiva na detecção de defeitos tanto em relação aos grupos de inspeção como em relação aos indivíduos. A diferença entre a técnica PBR e as técnicas convencionais ao nível de grupo não foram tão grandes, em torno de 3,6\%. A diferença entre as técnicas com relação aos indivíduos foi de quase de $3 \%$.

No próximo capítulo apresentam-se as principais conclusões deste trabalho, bem como, as principais contribuições e trabalhos futuros. 


\section{CAPítulo 6}

\section{Conclusão}

O objetivo deste trabalho foi realizar um estudo comparativo, por meio da replicação de dois experimentos, entre Técnicas de Teste e Técnicas de Revisão no que se refere à detecção de erros em produtos de software (código fonte e documento de especificação de requisitos). Para realizar esses estudos foram utilizados critérios de teste das técnicas funcional (particionamento em classes de equivalência e análise do valor limite), estrutural (todos-nós, todos-arcos, todosusos, todos-potenciais-usos), baseada em erros (análise de mutantes), bem como, técnicas de leitura (stepwise abstraction e perspective based reading) e técnicas de inspeção (ad hoc e checklist).

O experimento baseado em código fonte é uma replicação dos experimentos de Basili \& Selby [BAS87] e Kamsties \& Lott [KAM95]. As principais conclusões obtidas durante a replicação do experimento são sintetizadas a seguir:

- Com relação às falhas, pode-se observar que em uma análise preliminar a técnica Leitura de Código foi mais efetiva na observação de falhas do que as demais técnicas, mas em uma análise mais detalhada, ou seja, uma análise estatística observou-se que não existem diferenças significativas entre as técnicas;

- A técnica Teste Funcional foi mais eficiente que as demais técnicas na observação de falhas, mas não foram diferenças significativas;

- Ao final desta replicação constatou-se que os indivíduos observaram um percentual de apenas $26.96 \%$ das falhas possíveis de serem descobertas; 
- Com relação aos defeitos, pode-se observar que a técnica Leitura de Código foi mais efetiva no isolamento de defeitos que as outras técnicas, mas em uma análise mais detalhada, ou seja, uma análise estatística, observou-se que não existem diferenças significativas entre as técnicas;

- Não foram observadas correlações significativas entre a experiência dos indivíduos e os resultados obtidos;

- Os resultados mostram que o percentual de falhas observadas e defeitos isolados pelos indivíduos poderia ter sido maior se as técnicas tivessem sido aplicadas em conjunto, ou seja, explorando os aspectos complementares de cada técnica. Os piores resultados obtidos por qualquer combinação de técnicas foi melhor que os piores resultados obtidos individualmente por uma determinada técnica.

O experimento baseado em documentos de especificação de requisitos é uma replicação do experimento de Basili et. al. [BAS96a]. As principais conclusões obtidas durante a replicação do experimento são sintetizadas a seguir:

- As taxas médias de detecção de defeitos alcançadas por cada técnica pelos grupos de inspeção são similares;

- Indivíduos que aplicaram a técnica PBR tiveram um desempenho melhor que os indivíduos que aplicaram as técnicas convencionais;

- Cada perspectiva descobriu um conjunto de defeitos que outras perspectivas não descobriram.

As contribuições deste trabalho focalizam, principalmente, a atualização e evolução dos pacotes de replicação. Com relação ao experimento baseado em códigos fontes, a principal contribuição está relacionada à inclusão de uma nova Técnica de Teste, denominada Teste Incremental, que pretende explorar os aspectos complementares das diferentes técnicas de teste.

O Teste Incremental não apresentou, na circunstância do experimento, resultados relevantes, mas deve ser reavaliado em momento oportuno, uma vez que, ficou evidente a dificuldade na aplicação dos critérios baseados em fluxo de dados e análise de mutantes.

Após a realização dos experimentos foram realizadas entrevistas com os participantes objetivando avaliar os pacotes de replicação. Essas informações são de grande importância e 
deverão ser tratadas no futuro para realizar a atualização e evolução dos pacotes. A seguir apresentam-se algumas considerações feitas pelos participantes sobre os experimentos:

a) Experimento baseado em códigos fontes:

- Pouco tempo para o treinamento e para aplicação da técnica Teste Incremental;

- Dificuldade relevante de entendimento das instruções pelo fato de estarem redigidas em Inglês;

- Existem diferenças de complexidade entre os programas utilizados na fase de treinamento e na fase de execução;

- Dificuldade no entendimento dos programas e que a técnica Leitura de Código auxilia esse entendimento em função da sua própria natureza;

- Houve por parte de alguns participantes falta de conhecimento na linguagem de programação;

- As técnicas poderiam ser aplicadas assim que o treinamento fosse dado.

b) Experimento baseado em documentos de especificação de requisitos:

- A técnica Perspective Based Reading foi mais fácil de ser aplicada pelo fato de ser mais específica e direcionada;

- Os tempos destinados ao treinamento e a execução foram satisfatórios;

- Houve uma pequena dificuldade de entendimento das instruções pelo fato de estarem redigidas em Inglês;

- O documento ATM foi mais fácil de se entender, apesar de apresentar requisitos mais complexos, por fazer parte de um domínio de aplicação conhecido pela maioria dos participantes;

- O documento PG tinha requisitos mais claros, mas não faz parte do domínio de aplicação conhecido pela maioria dos participantes;

Algumas propostas de trabalhos futuros são pertinentes no contexto do Projeto NSFCNPq Readers. A primeira replicação do experimento baseado em códigos fontes foi executada com estudantes da pós-graduação. Uma nova replicação deverá ser executada com alunos da graduação. 
Da mesma forma, a primeira replicação do experimento baseado em documentos de especificação de requisitos foi executada com estudantes da graduação. Uma série de novas replicações deverá ser executada: 2 replicações com estudantes de graduação; 2 replicações com estudantes da pós-graduação; e 1 replicação deverá ser executada no contexto da industria.

Faz-se necessário ainda combinar todos os resultados obtidos nestas replicações com os resultados obtidos em outros experimentos já realizados no contexto do Projeto NSF-CNPq Readers. 


\section{Referências Bibliográficas}

[ACR79] Acree, A.T. et al.; Relatório Técnico GIT-ICS-79/08, Georgia Institute of Technology, Atlanta, Ga., Setembro, 1979.

[ADR82] Adrion, W. R.; Branstad, M. A.; Cherniavsky, J. C. Validation, Verification, and Testing of Computer Software. Computing Surveys. n. 2, vol. 14 (1982), 159-192.

[BAR98a] Barbosa, E.; Vincenti, A.; Maldonado, J. C. Uma Contribuição para Determinação de um Conjunto Essencial de Operadores de Mutação no Teste de Programas C, Simpósio Brasileiro de Engenharia de Software - SBES '98, Maringá, PR, Outubro 1998.

[BAR98b] Barbosa, E. F. Uma contribuição para determinação de um conjunto essencial de operadores de mutação no teste de programas C. Dissertação de Mestrado. ICMC / USP, São Carlos, SP, 1998.

[BAS81] Basili, V.; Reiter, R. Jr. A Controlled Experiment Quantitatively Comparing Software Development Approaches. IEEE Transactions on Software Engineering. n. 5, vol. 7 (1981), 299-320.

[BAS86] Basili, V.; Selby, Richard W.; Hutchens, David H. Experimentation in Software Engineering. IEEE Transactions on Software Engineering. n. 7, vol. SE-12 (1986), 733-743.

[BAS 87] Basili, V.; Selby, Richard W. Comparing the Effectiveness of Software Testing Strategies. IEEE Transactions on Software Engineering. n. 12, vol. SE-13 (1987), 1278-1296.

[BAS96a] Basili, V.; Green, S.; Laitenberger, 0.; Lanubile, F.; Shull, F.; Sorumgard, S.; Zelkowitz, M. The Empirical Investigation of Perspective-Based Reading. Empirical Software Engineering: An International Journal. n. 2, vol. 1 (1996), 133164.

[BAS 96b] Basili, V.; Caldiera, G.; Lanubile, F.; Shull, F. lnvestigating, focused techniques for understanding frameworks. Proc. of the 1st International Workshop on Empirical Studies of Software Maintenance (WESS '96), Monterey, Califórnia, USA, 1996, 49-53. 
[BAS96c] Basili, V.; Caldiera, G.; Lanubile, F.; Shull, F. Studies on reading techniques. Proc. of the Twenty-First Ánnual Software Engineering Workshop, SEL-96-002, Goddard Space Flight Center, Greenbelt, Maryland, Dezembro (1996), 59-65.

[BAS98] Basili, V.; Green, S.; Laitenberger, O.; Lanubile, F.; Shull, F.; Sørumgård, S.; Zelkowitz, M.; Lab Package for the Empirical Investigation of Perspective-Based Reading. <http://www.cs.umd.edu/projects/SoftEng/ESEG/manual/pbr_package/manual.html>, 1998.

[BEI84] Beizer, B.; Software System Testing and Quality Assurance. Ed. Van Nostrand Reinhold Company Inc. New York, 1984.

[BOC94] Bochmann, G.; Petrenko, A. Protocol Testing: Review of Methods and Relevance for Software Testing. Proc. of the ISSTA '1994 - International Symposium on Software Testing and Analysis, ACM - Software Engineering Notes, 1994, 109-124.

[BUD80] Budd, T.A. et al.; "Theoretical and Empirical Studies on Using Prog Mutation to Test the Functional Correctness of Prog.", 7th ACM Symposium on Principles of Programming Languages, Janeiro, 1980.

[CHA91] Chaim, M.L.; POKE-TOOL - Uma Ferramenta para Suporte ao Teste Estrutural de Programas Baseados em Análise de Fluxo de Dados, Tese de Mestrado, DCA/FEE/UNICAMP, Campinas, SP, Abril, 1991.

[COW88 Coward, P. A Review of Software. Testing, Information and Software Technology, n. 3, v. 30 (1988), 189-198.

[DEL93] Delamaro, M. E. Proteum - Um Ambiente de Teste Baseado na Análise de Mutantes. Dissertação de Mestrado. ICMC / USP, São Carlos, SP, Outubro 1993.

[DEM78] DeMillo, R.A.; Software Testing and Evaluation, The Benjamim/Commings Publishing Company, Inc, 1978.

[FRE93] Fredman, D. P.; Weinberg, G. M. Manual de Walkthroughs. São Paulo, Makron Books, 1993. 
[FUS97] Fusaro, P.; Lanubile, F.; Visaggio, G. A replicated experiment to assess requirements inspections techniques,. Empirical Software Engineering: An International Journal, n. 1, vol. 2 (1997), 39-57.

[GOM85] Gomes, Frederico Pimentel. Curso de Estatística Experimental. Editora Nobel, São Paulo, 1985.

[HET72] Hetzel, W. Experimental Analysis of Program Verification Problem Solving Capability as They Relate to Programmer Efficiency. Computer Personnel, vol. 3 (1972), IO-I5.

[HET 76] Hetzel, William C. An Experimental Analysis of Program Verification Methods. $\mathrm{PhD}$ thesis, University of North Carolina at Chapel Hill, 1976.

[KAM95] Kamsties, Erik. e Lott, Christopher M. An Empirical Evaluation of Three DefectDetection Techniques. Technical Report ISERN 95-02. Department of Computer Science, University of Kaiserslautern, 67653, Kaiserslautern, Germany, Maio 1995.

[LIN79] Linger, R. C.; Mills, H. D. e Witt, B. I. Structured Programming: Theory and Practice, Addison-Wesley, 1979.

[MAL91a] Maldonado, J. C. Critérios Potenciais Usos: Uma Contribuição ao Teste Estrutural de Software. Tese de Doutorado. DCA/FEE/UNICAMP, Campinas, SP, Julho 1991.

[MAL97] Maldonado, J. C. Critérios de Teste de Software: Aspectos Teóricos, Empíricos e de Automação. Tese de Livre Docência. ICMC / USP, São Carlos, SP, Janeiro 1997.

[MAL98 ] Maldonado, J. C.; Vincenzi, A. M. R; Barbosa, E. F.; Souza, S. R. S.; Delamaro, M. E. Aspectos Teóricos e Empíricos de Teste de Cobertura de Software. Notas do ICMC, 31. Instituto de Ciências Matemáticas e de Computação, Universidade de São Paulo, Junho 1998.

[MYE78] Myers, G. J. A Controlled Experiment in Program Testing and Code Walkthough Inspections. Communications of the ACM, 1978, 760-768. 
[MYE79] Myers, G. J. The Art of Software Testing, Wiley. John Wiley \& Sons. New York, 1979.

[POR95] Porter, Adam A.; Votta, Lawrence G.; Basili, V. Comparing Detection Methods for Software Requirements Inspections: A Replicated Experiment. IEEE Transactions on Software Engineering. n. 6, vol. 21 (1995), 563-575.

[PRE00] Pressman, R. S. Software Engineering - A Practitioner's Approach. 5 Edição, McGraw Hill, 2000.

[RAP 82] Rapps, S. \& Weyuker, E.J.; "Data Flow Analysis Techniques for Test Data Selection", Proceedings International Conference on Software Engineering, Tókio - Japão, Setembro, 1982, pp. 272-278.

[RAP 85] Rapps, S.; Weyuker, E. Selecting Software Test Data Using Data Flow Information. IEEE Transactions Software Engineering,SE- I I(4), Abril 1985.

[SEL87] Selby, R.; Basili, V.; Baker, T. Cleanroom Software Development: An Empirical Evaluation. IEEE Transactions on Software Engineering,n. 9, vol. 13 (1987), 10271037.

[SOU96] Souza, S. R. S. Avaliação do Custo e Eficácia do Critério Análise de Mutantes na Atividade de Teste de Programas. Dissertação de Mestrado. ICMC / USP, São Carlos, SP, Junho 1996.

[SOV96] Sova, Donald W.; Smidts, C. Increasing Testing Productivity and Software Quality: A Comparison of Software Testing Methodologies Within NASA. Empirical Software Engineering: An International Journal. n. 2, vol. 1 (1996), 165-188.

[VIN98] Vincenzi, A. M. R. Subsídios para o Estabelecimento de Estratégias de Teste Baseadas na Técnica de Mutação. Dissertação de Mestrado. ICMC / USP, São Carlos, SP, 1998.

[WIN71] Winer. B. J. Statistical Principles in Experiment Design. McGraw-Hill, $2^{\text {nd }}$. edition. 1971. 
[w0097] Wood, Murray; Roper, Marc; Brooks, Andrew; Miller, James. Comparing and Combining Software Defect Detection Techniques: A Replicated Empirical Study. $6^{\text {th }}$ European Software Engineering Conference $/ 5^{\text {th }}$ ACM SIESOFT Symposium on the Foundations of Software Engineering, LNCS, v. 1301, p. 262-277, 1997

[ZEL97] Zelkowitz, M; Wallace, D. Experimental Validation in Software Engineering. International Conference on Empirical Assessment and Evaluation in SE, Março 1997, Keele University, UK. 